Universidad | Campus Politécnica de Excelencia de Cartagena Internacional

\title{
ANÁLISIS DE IMPACTO Y SOLIDIFICACIÓN DE UNA GOTA DE MATERIAL CERÁMICO EN UN PROCESO DE PROYECCIÓN TÉRMICA POR PLASMA MEDIANTE EL MÉTODO DE REDES
}

Doctorado en Tecnologías Industriales

Autor: Noelia González Morales

Cartagena (2020) 
Universidad | Campus Politécnica de Excelencia de Cartagena Internacional

\section{ANÁLISIS DE IMPACTO Y SOLIDIFICACIÓN DE UNA GOTA DE MATERIAL CERÁMICO EN UN PROCESO DE PROYECCIÓN TÉRMICA POR PLASMA MEDIANTE EL MÉTODO DE REDES}

Doctorado en Tecnologías Industriales

Autor: $\quad$ Noelia González Morales

Director/es: Dr. José Andrés Moreno Nicolás Dr. Juan Francisco Sánchez Pérez

Cartagena (2020) 


\section{CONFORMIDAD DE SOLICITUD DEAUTORIZACIÓN DE DEPÓSITO DE}

\section{TESIS DOCTORAL POR EL DIRECTOR DE LA TESIS}

D. JOSÉ ANDRÉS MORENO NICOLÁS, y D. JUAN FRANCISCO SÁNCHEZ PÉREZ, Director y Codirector de la Tesis doctoral ANÁLISIS DE IMPACTO Y SOLIDIFICACIÓN DE UNA GOTA DE MATERIAL CERÁMICO EN UN PROCESO DE PROYECCIÓN TÉRMICA POR PLASMA MEDIANTE DEL MÉTODO DE REDES,

\section{INFORMA:}

Que la referida Tesis Doctoral, ha sido realizada por $\mathrm{D}^{\mathrm{a}}$. NOELIA GONZALEZ MORALES, dentro del Programa de Doctorado TECNOLOGÍAS INDUSTRIALES (3480), dando mi conformidad para que sea presentada ante el Comité de Dirección de la Escuela Internacional de Doctorado para ser autorizado su depósito.

- Informe positivo sobre el plan de investigación y documento de actividades del doctorando/a emitido por el Director/ Tutor (RAPI).

La rama de conocimiento en la que esta tesis ha sido desarrollada es:

$\square$ Ciencias

$\square \quad$ Ciencias Sociales y Jurídicas

- Ingeniería y Arquitectura

En Cartagena, a 14 de septiembre de 2020

EL DIRECTOR Y CODIRECTOR DE LA TESIS

JOSE ANDRES|

MORENO|

NICOLAS

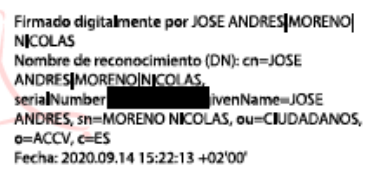

Fecha: 2020.09.14 15:22:13+02'00

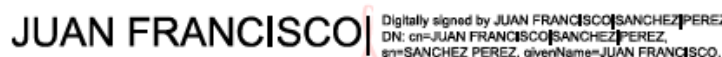
SANCHEZIPEREZ

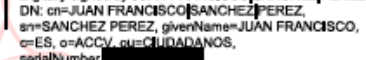

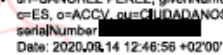

Fdo.: JOSÉ ANDRÉS MORENO NICOLÁS Fdo.: JUAN FRANCISCO SÁNCHEZ PÉREZ 


\section{CONFORMIDAD DE DEPÓSITO DE TESIS DOCTORAL POR LA COMISIÓN ACADÉMICA DEL PROGRAMA}

D JUAN SUARDIAZ MURO, Presidente de la Comisión Académica del Programa DOCTORADO EN TECNOLOGÍAS INDUSTRIALES.

\section{INFORMA:}

Que la Tesis Doctoral titulada, "ANÁLISIS DE IMPACTO Y SOLIDIFICACIÓN DE UNA GOTA DE MATERIAL CERÁMICO EN UN PROCESO DE PROYECCIÓN TÉRMICA POR PLASMA MEDIANTE DEL MÉTODO DE REDES”, ha sido realizada, dentro del mencionado Programa de Doctorado, por $D^{a}$. NOELIA GONZÁLEZ MORALES, bajo la dirección y supervisión del Dr. JOSÉ ANDRÉS MORENO NICOLÁS y codirección del Dr. JUAN FRANCISCO SÁNCHEZ PÉREZ

En reunión de la Comisión Académica, visto que en la misma se acreditan los indicios de calidad correspondientes y la autorización del Director de la misma, se acordó dar la conformidad, con la finalidad de que sea autorizado su depósito por el Comité de Dirección de la Escuela Internacional de Doctorado.

- Evaluación positiva del plan de investigación y documento de actividades por el Presidente de la Comisión Académica del programa (RAPI).

La Rama de conocimiento por la que esta tesis ha sido desarrollada es:

Ciencias

Ciencias Sociales y Jurídicas

- Ingeniería y Arquitectura

En Cartagena, a 08 de septiembre de 2020

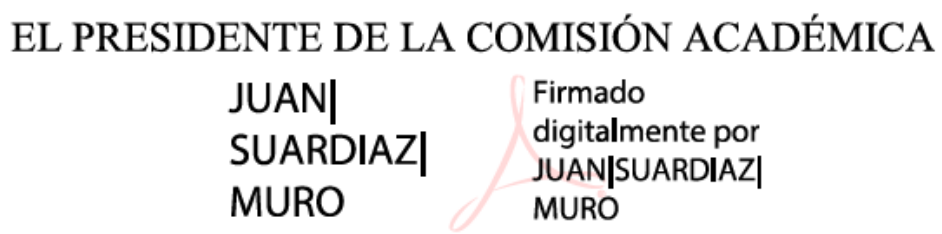

Fdo: JUAN SUARDIAZ MURO 


\section{Agradecimientos}

En primer lugar, quiero agradecer al Dr. José Andrés Moreno y al Dr. Juan Francisco Sánchez Pérez la dedicación y esfuerzo puesto en esta tesis. Sin su guía me hubiera sido imposible acabar esta memoria.

En segundo lugar, al Institute for Manufacturing Technologies of Ceramic Components (IMTCCC), por su colaboración.

En tercer lugar, agradecer a $\mathrm{M}^{\mathrm{a}}$ José Roca Hernández y a $\mathrm{M}^{\mathrm{a}}$ Inmaculada García García por su asesoramiento en la adquisición de imágenes SEM y FIB respectivamente, y a Juan Zapata por su supervisión.

Y por último y no menos importante, a mi familia. A mis padres por su apoyo y ayuda, a Juan Miguel porque sin su ánimo y comprensión no hubiera sido posible. A mis niñas, Aitana e Iria, que han tenido una paciencia infinita. En la última fase de esta tesis han sido las más valientes por haber pasado el estado de alarma con una sonrisa, quedándose en casa.

A todos, muchas gracias. 
A Aitana e Iria

A Juan Miguel

A mis padres 
Nomenclatura

Lista de figuras

Lista de tablas

Resumen

Abstract

1 Introducción

1.1 Introducción

1.2 Objetivos 3

1.3 Desarrollos futuros 4

2 Fundamentos teóricos $\quad 7$

$\begin{array}{ll}2.1 \text { Introducción } & 7\end{array}$

2.2 Proceso térmico de proyección por plasma atmosférico 7

$\begin{array}{ll}\text { 2.2.1 Tecnología de superficies } & 7\end{array}$

2.2.2 Parámetros del proceso APS 13

$\begin{array}{ll}2.3 \text { Salpicadura } & 15\end{array}$

2.3.1 Fases de la alúmina y morfología de grano 16

2.3.2. Morfología de las salpicaduras $\quad 24$

2.3.3 Aplanamiento 31

2.3.4 Velocidad de enfriamiento $\quad 35$

2.3.5 Temperatura de transición de forma de salpicadura 39

2.3.6 Adhesión 49

2.3.7 Grietas y poros $\quad 54$

2.4 Impacto isotérmico de gota

2.4.1 Tensión superficial y mojabilidad $\quad 57$

2.4.2 Método VOF: Algoritmos SOLA-VOF 63

$\begin{array}{ll}2.5 \text { Proceso de solidificación de una gota de material fundido } & 67\end{array}$

$\begin{array}{ll}\text { 2.5.1 El problema de la solidificación } & 67\end{array}$ 
2.5.2 Problema de Stefan $\quad 71$

2.6 Modelos de impacto y solidificación de una gota fundida 80

2.6.1 Ecuaciones de balance, condiciones iniciales y de contorno del impacto isotérmico de una gota 80

2.6.2 Ecuaciones de balance, condiciones iniciales y de contorno del proceso de solidificación $\quad 82$

2.7 Método de simulación por redes (MESIR) 83

2.7.1 El MESIR como método numérico $\quad 84$

$\begin{array}{ll}3 \text { Materiales, equipos y procedimiento experimental } & \mathbf{8 7}\end{array}$

$\begin{array}{ll}\text { 3.1 Materiales utilizados en la experimentación } & 87\end{array}$

3.1.1 Revestimiento de alúmina sobre sustrato de acero 87

3.1.2 Preparación de las muestras $\quad 88$

$\begin{array}{ll}3.2 \text { Equipos utilizados en la experimentación } & 90\end{array}$

3.3 Procedimiento experimental 92

$\begin{array}{ll}3.4 \text { Procesamiento de imagen } & 94\end{array}$

3.4.1 Procesamiento de imagen: Análisis de vista superior 97

4 Modelos en red $\quad 101$

4.1 Modelización del impacto isotérmico de una gota 101

4.1.1 Método de volúmenes finitos 101

4.2 Modelos en red para simulación del proceso de solidificación 107

5 Análisis de impacto de gota fundida y su solidificación $\quad \mathbf{1 1 5}$

5.1 Simulación del impacto isotérmico de una gota de agua mediante el método de Volúmenes Finitos $\quad 115$

5.2 Simulación del proceso de solidificación de una salpicadura de alúmina mediante el método de redes 119

5.2.1 Análisis de la solidificación y enfriamiento de una salpicadura de estaño

5.2.2 Análisis de la solidificación y enfriamiento de una salpicadura de alúmina sin calentamiento del sustrato $\quad 121$

5.2.3 Análisis del efecto del calentamiento del sustrato 128

5.3 Procesamiento de imagen de salpicaduras sobre sustrato 131

$\begin{array}{ll}5.4 \text { Análisis de la vista superior de las salpicaduras } & 131\end{array}$ 
5.5 Análisis de la sección de las salpicaduras

Contribuciones y conclusiones

Bibliografía 
NOMENCLATURA

A Área

a y b Constantes

$\mathrm{a}_{\mathrm{a}}$

Espaciamiento interatómico

$\mathrm{a}_{\mathrm{tv}}$

Parámetro función de la temperatura y velocidad de impacto

B

Longitud del dominio rectangular

$\mathrm{b}_{\mathrm{s}} \quad$ Espesor de la salpicadura

C Capacidad del condensador

$\mathrm{CF}$

Flujo que podría entrar considerando los vacíos de las celdas de estudio y donante

Cou Número de Courant

$\mathrm{C}_{\mathrm{p}, \mathrm{s}} \quad$ Capacidad calorífica de la fase sólida

$\mathrm{C}_{\mathrm{p}, \mathrm{l}} \quad$ Capacidad calorífica de la fase líquida

$\mathrm{C}_{\mathrm{Tk}} \quad$ Capacidad del condensador en el modelo en red de temperatura Velocidad adiabática del sonido

$\mathrm{c}_{\mathrm{e}} \quad$ Calor específico

$\mathrm{c}_{\mathrm{e}, 1} \quad$ Calor específico del líquido

$\mathrm{c}_{\mathrm{e}, \mathrm{s}} \quad$ Calor específico del sólido

ce,sal Calor específico de la salpicadura

$\mathrm{c}_{1} \quad$ Velocidad del sonido en la fase líquida

$\mathrm{c}_{\mathrm{p}} \quad$ Calor específico a presión constante

D Diámetro de la salpicadura

$D_{\text {gap }} \quad$ Difusividad térmica equivalente del contacto en una interfase

$\mathrm{D}_{1} \quad$ Difusividad del líquido

$\mathrm{D}_{\mathrm{s}} \quad$ Difusividad del sólido

d

Ancho de la sección transversal columnar

$\mathrm{d}_{\mathrm{e}} \quad$ Diámetro equivalente

$\mathrm{d}_{\mathrm{ep}} \quad$ Diámetro equivalente calculado en píxel

$\mathrm{d}_{\mathrm{p}} \quad$ Diámetro de la gota que impacta

$\mathrm{dx}_{\mathrm{D}} \quad$ Diferencial de desplazamiento de la frontera de la celda donadora

Erf Funciones de error

Erfc Funciones complementaria de error 
$\mathrm{e}_{\mathrm{p}} \quad$ Efusividad de las partículas

F $\quad$ Fracción de volumen de fluido

$\mathrm{F}_{\mathrm{A}} \quad$ Fracción de volumen de fluido en celda aceptora

$\mathrm{F}_{\mathrm{AD}} \quad$ Fracción de volumen de fluido de la celda aceptora o donadora

$\mathrm{F}_{\mathrm{D}} \quad$ Fracción de volumen de fluido en celda donadora

$\mathrm{F}_{\mathrm{i}} \quad$ Fuentes de corriente, siendo $\mathrm{i}=\mathrm{Re}, \mathrm{V}$ o $\mathrm{I}$, representa un operador funcional

G Gradiente de temperatura

g Aceleración de la gravedad

$\mathrm{g}(\vec{r}, \mathrm{t}) \quad$ Densidad de potencia

$\mathrm{H}(\mathrm{T}) \quad$ Entalpía

Constante de Planck

$\mathrm{h}_{\mathrm{c}}$

Coeficiente de transferencia de calor en condiciones de contacto perfecto

$\mathrm{h}_{\mathrm{i}} \quad$ Coeficiente del calor de transferencia en la interfase

$\mathrm{h}_{\mathrm{r}} \quad$ Coeficiente de transferencia de calor equivalente a la linealización de la radiación

Intensidad

$\mathrm{I}_{\mathrm{Bk}}$

Intensidad generada en la fuente de corriente de la celda $\mathrm{k}$ en el modelo en red de temperatura

$\mathrm{I}_{\mathrm{RiTk}} \quad$ Intensidad que circula por la resistencia $\mathrm{R}_{\mathrm{iTk}}$

$i_{R} \quad$ Intensidad en una resistencia

J Velocidad de nucleación

$\overrightarrow{\mathrm{j}} \quad$ Densidad de flujo calorífico

jint Densidad de corriente

$\mathrm{j}_{\text {conv }}$

Intercambio de energía por convección con un fluido exterior

jfuente

Flujo entrante a través de dA

jmedioi_dSup

Flujo del medio i (siendo i=1 o 2) a través de la superficie de separación de las fases $S_{\text {up }}$

jad $\quad$ Intercambio de calor por radiación hacia el medio exterior

K Conductividad térmica

$\mathrm{K}_{\mathrm{f}} \quad$ Parámetro de aplanamiento

$\mathrm{K}_{\mathrm{f}}^{\mathrm{c}} \quad$ Parámetro de aplanamiento crítico

$\mathrm{K}_{\mathrm{gap}} \quad$ Conductividad térmica equivalente del contacto en una interfase

$\mathrm{K}_{1} \quad$ Conductividad térmica del líquido 


\begin{tabular}{|c|c|}
\hline $\mathrm{K}_{\mathrm{p}}$ & Conductividad térmica de la partícula \\
\hline $\mathrm{K}_{\mathrm{s}}$ & Conductividad térmica del sólido \\
\hline $\mathrm{k}_{\mathrm{B}}$ & Constante de Boltzmann \\
\hline $\mathrm{L}$ & Inductancia \\
\hline $\mathrm{L}^{\prime}$ & Ancho en milímetros \\
\hline $\mathrm{L}_{\mathrm{f}}$ & Calor latente de fusión \\
\hline $\mathrm{L}_{\mathrm{p}}$ & Ancho en pixeles \\
\hline $\mathrm{L}_{\mathrm{r}}$ & Ancho en $\mu \mathrm{m}$ \\
\hline $\mathrm{L}_{\mathrm{s}}$ & Calor latente de solidificación \\
\hline Мa & Número de Mach \\
\hline$\dot{\mathrm{m}}$ & Flujo másico \\
\hline $\mathrm{n}$ & Densidad de nucleación \\
\hline $\mathrm{P}$ & Presión del fluido \\
\hline $\mathrm{p}$ & Perímetro de la salpicadura \\
\hline $\mathrm{p}_{\mathrm{t}}$ & Presión crítica en la cámara \\
\hline Q & Energía de activación \\
\hline$\dot{\mathrm{Q}}$ & Flujo de calor \\
\hline $\mathrm{q}$ & Carga \\
\hline $\mathrm{R}$ & Resistencia \\
\hline $\mathrm{R}_{\mathrm{a}}$ & Rugosidad media aritmética \\
\hline $\operatorname{Re}$ & Número de Reynolds \\
\hline $\mathrm{R}_{\mathrm{i}}$ & Radio de curvatura en el plano i \\
\hline $\mathrm{R}_{\mathrm{t}}$ & Profundidad total de la rugosidad \\
\hline $\mathrm{R}_{\mathrm{Inf}}$ & Resistencia infinita \\
\hline $\mathrm{R}_{\mathrm{iTk}}$ & $\begin{array}{l}\text { Resistencia asociada a la segunda derivada en el modelo en red de } \\
\text { temperatura, donde } i=1,2,3,4 \text { según dirección de la segunda derivada }\end{array}$ \\
\hline $\mathrm{R}_{\text {res }}$ & Resistencia \\
\hline $\mathrm{R}_{\mathrm{th}}$ & Resistencia térmica de contacto \\
\hline $\mathrm{r}, \mathrm{z}$ & Coordenadas cilíndricas \\
\hline $\overrightarrow{\mathrm{r}}$ & Posición \\
\hline$r_{c}$ & Radio de contacto \\
\hline S & Superficie de la interfase líquido-sólido \\
\hline $\mathrm{S}_{\mathrm{r}}$ & Longitud de la barra de escala en $\mu \mathrm{m}$ \\
\hline$S^{\prime}$ & Longitud de la barra de escala en $\mathrm{mm}$ \\
\hline
\end{tabular}


$\mathrm{S}_{\mathrm{E}} \quad$ Parámetro de esparcimiento

$\mathrm{SF}$

$\mathrm{S}_{\mathrm{m}}$

$\mathrm{S}_{\mathrm{sal}}$

Ste

Ste $_{1}$

Ste $_{\mathrm{s}}$

$\mathrm{S}_{\text {up }}$

$\operatorname{sf}(\mathrm{t})$

Sf-s

Tamb

$\mathrm{T}_{\mathrm{c}}$

$\mathrm{T}_{1}$

$\mathrm{T}_{\mathrm{f}}$

$\operatorname{Tf}(\mathrm{K})$

$\mathrm{T}_{\mathrm{k}}$

$\mathrm{T}_{\mathrm{m}}$

$\mathrm{T}_{\mathrm{o}}$

$\mathrm{T}_{\mathrm{p}}$

$\mathrm{T}_{\text {pared }}$

$\mathrm{T}_{\mathrm{ps}}$

$\operatorname{Tr}$

$\mathrm{T}_{\text {sust }}$

$\mathrm{T}_{\mathrm{s}}$

Tsal

$\mathrm{T}_{\mathrm{s} \text {, pared }}$

Tsup

$\mathrm{T}_{\mathrm{t}}$

$\mathrm{T}_{\infty}$

t

$t_{c}$

$t_{\mathrm{ps}}$
Factor de forma

Masa añadida a la fase continua a partir de la segunda fase dispersa y cualquier fuente definida por el usuario

Superficie de la salpicadura

Número de Stephan

Número de Stephan para la fase líquida

Número de Stephan para la fase sólida

Superficie de separación de las fases de sustancias puras o compuestos de tipo eutéctico

Posición de la frontera

Posición de la frontera con respecto a la pared

Temperatura ambiente

Temperatura de la salpicadura caliente

Temperatura en un punto de la fase líquida

Temperatura de fusión

Temperatura de fusión característica

Temperatura en la celda $\mathrm{k}$

Temperatura del metal fundido

Temperatura inicial en el líquido

Temperatura de la partícula

Temperatura de la pared

Temperatura de precalentamiento

Temperatura de referencia del medio exterior para la radiación

Temperatura del sustrato

Temperatura en un punto de la fase sólida

Temperatura de la salpicadura en la interfase

Temperatura en un punto de la fase sólida en la superficie de la pared

Temperatura del contorno superior

Temperatura de transición

Temperatura del fluido exterior lejos de la superficie

Tiempo

Tiempo crítico de impacto

Tiempo de precalentamiento 


\begin{tabular}{ll} 
Uf & Flujo saliente \\
$\mathrm{u}_{\mathrm{n}}$ & Dirección normal de la frontera \\
$\mathrm{u}_{\mathrm{r}}$ & Velocidad según coordenada $\mathrm{r}$ \\
$\mathrm{u}_{\mathrm{z}}$ & Velocidad según coordenada $\mathrm{z}$ \\
$\mathrm{V}$ & Volumen \\
$\mathrm{V}_{\mathrm{CTk}}$ & Voltaje a través de cada condensador \\
$\mathrm{V}_{\mathrm{l}}(\mathrm{t})$ & Velocidad convectiva del líquido \\
$\mathrm{Vr}_{\mathrm{r}}$ & Velocidad de enfriamiento \\
$\mathrm{V}_{\mathrm{Res}}$ & Voltaje entre terminales de una resistencia \\
$\mathrm{Vs}_{\mathrm{s}}$ & Velocidad de solidificación \\
$\mathrm{V}_{\mathrm{s}}(\mathrm{t})$ & Velocidad de la frontera sólido-líquido \\
$\mathrm{V}_{\mathrm{x}}$ & Flujo en volumen que atraviesa la cara de la celda por unidad de área \\
$\mathrm{V}_{\mathrm{ap}}$ & Velocidad máxima de aplanamiento \\
$\mathrm{V}_{\mathrm{d}}$ & Velocidad de la gota \\
$\mathrm{V}_{\mathrm{f}}$ & Flujo de líquido \\
$\mathrm{V}_{\mathrm{fluid}}$ & Velocidad del fluido \\
$\mathrm{V}_{\mathrm{z}}$ & Velocidad del remolino \\
$\mathrm{We}$ & Número de Weber \\
$\mathrm{x}_{\mathrm{l}}$ & Posición para un punto de la fase líquida \\
$\mathrm{x}_{\mathrm{s}}$ & Posición para un punto de la fase sólida \\
$\mathrm{Z}$ & Altura del dominio rectangular \\
\hline
\end{tabular}

\section{Letras griegas}

$\begin{array}{ll}\alpha, \beta \text { y } \theta & \begin{array}{l}\text { Ángulos de contacto } \\ \gamma\end{array} \\ \Delta \mathrm{Gv}_{\mathrm{V}} & \text { Tensión superficial } \\ \Delta \mathrm{P} & \text { Fuerza motriz para la solidificación } \\ \Delta \mathrm{T} & \text { Incremento de presión entre superficies } \\ \Delta \mathrm{Tr} & \text { Reducción del subenfriamiento } \\ \Delta \mathrm{r}, \Delta \mathrm{x}, \Delta \mathrm{z} & \text { Discretización en las direcciones r, } \mathrm{x} \text { y } \mathrm{z}, \text { respectivamente } \\ \Delta \mathrm{t}_{\mathrm{f}} & \text { Incremento temporal basado en el flujo } \\ \Delta \mathrm{t}_{v} & \text { Incremento temporal basado en la velocidad } \\ \Delta \mathrm{x} & \text { Tamaño de la celda }\end{array}$




\begin{tabular}{ll}
$\delta$ & Solución de la ecuación transcendente \\
$\varepsilon$ & Emisividad de la superficie \\
$\eta$ & Parámetro de Sommerfeld \\
$\theta_{\mathrm{D}}$ & Temperatura de Debye \\
$\mathrm{K}$ & Curvatura \\
$\lambda$ & Relación de densidades líquido sólido \\
$\mu$ & Viscosidad dinámica \\
$\xi$ & Grado de aplanamiento \\
$\rho$ & Densidad \\
$\rho_{\mathrm{l}}$ & Densidad del líquido \\
$\rho_{\mathrm{imp}}$ & Densidad del fluido impactando \\
$\rho_{\mathrm{p}}$ & Densidad a presión constante \\
$\rho_{\mathrm{s}}$ & Densidad del sólido \\
$\sigma$ & Constante de Stefan-Boltzmann \\
$\sigma_{\mathrm{s}}$ & Energía superficial en la interfase sólido-líquido \\
$\gamma_{\mathrm{C}}$ & Tensión superficial crítica \\
$\gamma_{\mathrm{ij}}$ & Tensión superficial entre las dos fases indicadas \\
$\Omega_{\mathrm{celda}}$ & Volumen de la celda \\
$\omega$ & Frecuencia de vibración atómica \\
\hline & \\
\hline &
\end{tabular}




\section{LISTA DE FIGURAS}

2.1 Relación entre la velocidad y la temperatura de los diferentes procesos (Oksa et al., 2011) ...................................................... 10

2.2 Proceso de proyección por llama (IMTCCC; Acedo Fornell, 2005) ............. 10

2.3 Imagen esquemática del proceso HVOF (IMTCCC; Acedo Fornell, 2005) .... 11

2.4 Imagen esquemática del proceso de proyección de plasma atmosférico, APS (IMTCCC; Acedo Fornell, 2005)

2.5 Tipos de partículas de polvo empleadas en procesos de proyección térmica (Acedo Fornell, 2005)

2.6 Imagen de microscopía de salpicaduras en la superficie del revestimiento (Zimmer, 2010)

2.7 Imagen de microscopía de salpicaduras proyectadas en agua (Zimmer, 2010) 18

2.8 Patrones de difracción de rayos x: revestimiento (superior), partículas en agua (medio) y polvo (inferior) (Zimmer, 2010)

2.9 Dos tipos de salpicaduras de alúmina a $20^{\circ} \mathrm{C}$ sobre sustratos de cristal (izquierda) y acero inoxidable (derecha) (Mostaghini et al., 2002) ....

2.10 Relación entre el tipo de grano, el gradiente de temperatura $(G)$ y la velocidad de solidificación (Pantelis, 1993; Kou, 2003)

2.11 Sección transversal de una salpicadura formada sobre un sustrato precalentado a $200^{\circ} \mathrm{C}$ (Christoulis et al., 2008)

2.12. Detalle del área A de la figura 2.11 (Christoulis et al., 2008)

2.13 Sección de la salpicadura formada sobre un sustrato precalentado a $250^{\circ} \mathrm{C}$ (Christoulis et al., 2008)

2.14 Sección de la salpicadura formada sobre un sustrato precalentado a $300^{\circ} \mathrm{C}$ (Christoulis et al., 2008)

2.15 Morfología de las salpicaduras de alúmina basada en su velocidad y temperatura inicial de impacto en una proyección por plasma (Mohamed et al., 2015)

2.16 Formas de impacto: tortita (izquierda) y flor (derecha) (Pasandideh-Fard et al., 2002) 
2.17 Mapa tridimensional de transición del comportamiento en un proceso de pulverización (Fukumoto et al., 2007) ....

2.18 Salpicaduras de zirconia sobre un sustrato de acero inoxidable (Bianchi et al., 1997b)

2.19 Estructura columnar dentro de un área pequeña $\left(5 \times 5 \mu \mathrm{m}^{2}\right)$ de una salpicadura representada en la figura 2.17 (Bianchi et al., 1977)

2.20 Representación esquemática del aplastamiento de una salpicadura de $\mathrm{NiCr}$ sobre sustrato de acero (Brossard, 2010)

2.21 Representación esquemática de una salpicadura de $\mathrm{NiCr}$ sobre sustrato de acero (Brossard, 2010)

2.22 Sección transversal de una salpicadura de NiCr sobre sustrato de acero con forma de tortita con hueco central (Brossard, 2010)

2.23 Sección transversal de una salpicadura de $\mathrm{NiCr}$ sobre sustrato de acero con forma floreada (Brossard, 2010)

2.24 Sección transversal de una salpicadura de $\mathrm{NiCr}$ sobre sustrato de acero con forma floreada. (a) Periferia, (b) Hueco central (Brossard, 2010)

2.25 Esquema de propagación en el impacto con resultado de salpicadura (Cedelle et al., 2004)

2.26 Ángulos de mojado (Fauchais et al., 1997) .

2.27 Impacto de una gota de estaño sobre una lámina de acero inoxidable con diferentes rugosidades superficiales (Shakeri y Chandra, 2002) .................

2.28 Morfología del contorno de una salpicadura de alúmina entre el revestimiento de oro y el sustrato de acero inoxidable: (a) forma de tortita, flor y (b) corona (Tanaka y Fukumoto, 2001)

2.29 Relación entre la mojabilidad y el patrón de salpicadura (Tanaka y Fukumoto, 2001)

2.30 Variación de la temperatura de transición con la conductividad térmica de la partícula que impacta (Tanaka y Fukumoto, 2001)

2.31 Microestructuras transversales de salpicaduras de níquel en un sustrato de acero inoxidable 304L con temperaturas de sustrato: $300 \mathrm{~K}$ (izda.) y $600 \mathrm{~K}$ (dcha.) (Fukumoto et al, 2000) 
2.32 Tamaño del grano de una salpicadura de Ni con distintas condiciones de proyección: curva de ajuste (a) obtenida a presión atmosférica, curva (b) obtenida a baja presión, $10 \mathrm{~Pa}$ sobre un sustrato pulido, punto (c) obtenido a presión atmosférica y punto (d) obtenido en bajo vacío (Fukumoto et al, 2002) .............

2.33 Relación entre el parámetro a y la temperatura del substrato para gotas de Ni de $2 \mathrm{~mm}$ de diámetro y vp de 4,2 m/s $(\operatorname{Re}=12103$ y We=157) (Fukumoto et al., 2001)

2.34 Variación de la resistencia adhesiva del revestimiento con la temperatura del sustrato (Fukumoto et al 1995a) (material pulverizado de Ni con una distribución de tamaños de 10 a $44 \mu \mathrm{m}$, sustrato de acero inoxidable AISI304) .............. 53

2.35 Medida de la rugosidad (Dagnall, 2003) ............................ 54

2.36 Sección transversal esquematizada de una partícula aplanada con grietas verticales: interfase unida (línea discontinua) e interfase no unida (línea continua) (Ohmori y Li, 1993) .

2.37 Formación de tensiones cuando Tc > Ts (izquierda) y cuando ambas temperaturas se igualan (derecha) (David, 2004)

2.38 Esquema del mecanismo de formación de una microgrieta vertical en una partícula aplanada (Mifune y Harada, 2004)

2.39 Efecto de la contracción del revestimiento (David, 2004)

2.40 Esquema de la estructura de una partícula fundida (David, 2004)

2.41 Sección transversal de un revestimiento proyectado térmicamente con defectos microestructurales (Pawlowski, 2008)

2.42 Curvatura asociada a la dirección z cuando la superficie libre es casi horizontal (Pasandideh-Fard, 1998)

2.43 Curvatura asociada a la dirección r cuando la superficie libre es casi vertical (Pasandideh-Fard, 1998)

2.44 Representación gráfica de los ángulos de contacto de retroceso, $\theta$ r y avance, $\theta \mathrm{a},(\mathrm{Good}, 1992)$

2.45 Fases fluidas y ángulos de contacto (Rowlinson y Widom, 1982) ........... 60

2.46 Triángulo de Neumann (Rowlinson y Widom, 1982) ....

2.47 Ángulo de contacto de una gota sobre un plano sólido (De Gennes, 1994) ... 
2.48 Mojabilidad dinámica: (a) Estado Wenzel; (b) Estado Cassie (Whyman et al., 2008) ............................................................. 62

2.49 Problema de Stefan. Geometría y sistema de coordenadas (Alhama, 1998) .. 74

3.1 Alúmina en polvo empleada en las muestras (Institute for Manufacturing Technologies of Ceramic Components and Composites (IMTCCC)) ........... 87

3.2 Detalle de sujeción del sustrato ....................................... 88

3.3 Placa con taladros para generar las salpicaduras aisladas .................... 89

3.4 Bastidor con la placa que actúa como máscara $\ldots \ldots \ldots \ldots \ldots \ldots \ldots \ldots \ldots \ldots \ldots . . \ldots 9$

3.5 Imagen de una probeta con tres círculos donde se agrupan las salpicaduras ... 90

3.6 Microscopio electrónico de barrido S-3500N de Hitachi (UPCT) ............ 90

3.7 Microscopio SEM-FIB, Scios dualbeam (Universidad de Murcia) ........... 92

3.8 Imagen de una salpicadura sobre acero. Recubrimiento realizado en el IMTCCC

3.9 Imagen de una salpicadura de estaño sobre una placa de acero (Shakeri y Chandra, 2002)

3.10 Estructura en columnas de una sección transversal de la salpicadura sobre sustrato de aluminio (Mulero, 2014)

3.11 Sección de una salpicadura

3.12 Salpicadura de alúmina con burbuja sobre sustrato de aluminio. Recubrimiento realizado en el IMTCCC (Mulero, 2014) ...................... 95

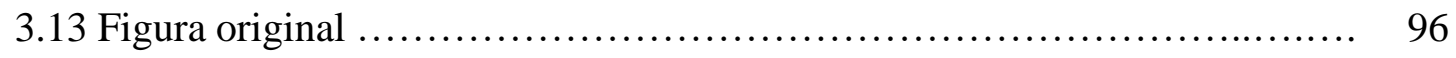

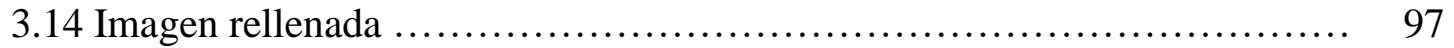

3.15 Selección de los contornos de la salpicadura ........................... 97

3.16 Flujo de trabajo (Mulero et al, 2015) .............................. 98

4.1. Dominio a discretizar .............................................. 103

4.2 Porción de sustrato (gris oscuro) con sección de salpicadura (gris claro) (González Morales et al., 2020)

4.3 a) Sección de gota con solidificación rápida, en $\mu \mathrm{m}$ y b) Sección de gota con solidificación lenta, en $\mu \mathrm{m}$ (González Morales et al., 2020) 
4.4 Elemento de volumen utilizado en los cálculos de solidificación (González Morales et al., 2020) .................................................. 109

4.5 Modelo de red para temperatura, T (González Morales et al., 2020) .......... 110

4.6 Modelo de red para el circuito de solidificación (González Morales et al., 2020)

5.1 Salpicadura a $0,338 \mathrm{~ms}$

5.2 Salpicadura a $0,938 \mathrm{~ms}$

5.3 Salpicadura a $1,707 \mathrm{~ms}$

5.4 Salpicadura a $1,338 \mathrm{~ms}$

5.5 Salpicadura a $2,315 \mathrm{~ms}$

5.6 Fotografía de una gota de agua de $2 \mathrm{~mm}$ de diámetro impactando sobre una superficie de acero inoxidable con una velocidad de $1 \mathrm{~m} / \mathrm{s}$ (Pasandideh-Fard et al., 1996)

5.7 Evolución de temperaturas en la celda 12211 del sustrato sin y con Rth $10^{-6}$ $\mathrm{m} 2 \cdot \mathrm{K} / \mathrm{W}$ (González Morales et al., 2020)

5.8 Evolución de temperaturas en el sustrato en el centro de la gota de estaño (Pasandideh-Fard, 1998)

5.9 Evolución de temperaturas en la celda 12322 del estaño sin y con Rth $10^{-6}$ $\mathrm{m}^{2} \cdot \mathrm{K} / \mathrm{W}$ (González Morales et al., 2020)

5.10 Evolución de temperaturas la celda 12655 de la salpicadura con y sin radiación térmica (González Morales et al., 2020)

5.11 Distribución de temperaturas en la salpicadura considerando radiación térmica en $9,84 \mu \mathrm{s}$

5.12 Distribución de temperaturas en el sustrato considerando radiación térmica en $9,84 \mu \mathrm{s}$

5.13 Distribución de temperaturas en la salpicadura considerando radiación térmica en $21,06 \mu \mathrm{s}$

5.14 Distribución de temperaturas en el sustrato considerando radiación térmica en $21,06 \mu \mathrm{s}$ 
5.15 Evolución de temperatura en las celdas 12322, 12340 y 12322 de la salpicadura considerando radiación térmica en 1 ms (González Morales et al., 2020)

516. Evolución de temperatura en las celdas 12655, 12673, 12691 de la salpicadura considerando radiación térmica en 1 ms (González Morales et al., 2020)

5.17 Evolución de temperatura en la celda 12507, 12525 y 12543 de la salpicadura considerando radiación térmica en 1 ms (González Morales et al., 2020)

5.18 Evolución de temperaturas en las celdas 12211, 12229, 12247 y 12321 del sustrato (González Morales et al., 2020)

5.19 Evolución de temperaturas las celdas 5551 y 1 del sustrato (González Morales et al., 2020)

5.20 Evolución de la velocidad de enfriamiento en la celda 12340, 12322 y 12655 alúmina a 1 ms (González Morales et al., 2020)

5.21 Evolución de la temperatura en la celda 12322, 12340 y 12358 de la alúmina para temperatura del sustrato $150^{\circ} \mathrm{C}$ en $1 \mathrm{~ms}$ (González Morales et al., 2020) .... 128 5.22 Evolución de la temperatura en la celda 12655, 12673 y 12691 de la alúmina para temperatura del sustrato $150^{\circ} \mathrm{C}$ en $1 \mathrm{~ms}$ (González Morales et al., 2020) .... 5.23 Distribución de temperaturas en la salpicadura considerando radiación térmica en $9,84 \mu \mathrm{s}$ y precalentamiento

5.24 Distribución de temperaturas en el sustrato considerando radiación térmica en $9,84 \mu$ s y precalentamiento

5.25 Distribución de temperaturas en la salpicadura considerando radiación térmica en $21,06 \mu \mathrm{s}$ y precalentamiento

5.26 Distribución de temperaturas en el sustrato considerando radiación térmica en $21,06 \mu$ s y precalentamiento

5.27 Salpicaduras segmentadas y caracterizadas en procesamiento de imagen ...

5.28 Diámetro equivalente de las salpicaduras en forma de tortita respecto a diferentes tamaños de polvo para dos conjuntos de intensidades y caudal másico de hidrógeno 
5.29 Diámetro equivalente de las salpicaduras en forma de corona circular respecto a diferentes tamaños de polvo para dos conjuntos de intensidades y caudal másico de hidrógeno

5.30 Diámetro exterior equivalente de las salpicaduras en forma de tortita y corona circular respecto a diferentes velocidades angulares del suministrador de polvo 


\section{LISTA DE TABLAS}

Tabla 2.1 Parámetros de proyección (Christoulis et al., 2008)

20

Tabla 2.2 Ancho de las columnas de la salpicadura (d) y su subenfriamiento $(\Delta \mathrm{T})$ en función de la temperatura inicial de un sustrato pulido de espejo (Christoulis et al., 2008)

Tabla 2.3 Ancho de las columnas de la salpicadura (d) y su subenfriamiento $(\Delta \mathrm{T})$ en función de la temperatura inicial del sustrato con una rugosidad ( Ra) de 0,02 $\mu \mathrm{m}$ (Christoulis et al., 2008)

Tabla 2.4 Ancho de las columnas de la salpicadura (d) y su subenfriamiento $(\Delta \mathrm{T})$ en función de la temperatura inicial del sustrato con una rugosidad ( $\mathrm{Ra}$ ) de 1,33 $\mu \mathrm{m}$. (Christoulis et al., 2008)

Tabla 2.5 Efecto del tiempo de precalentamiento del sustrato a $500 \mathrm{~K}$ sobre revestimientos de alúmina (distribución del tamaño de las partículas de 22 a 45 $\mu \mathrm{m}$; fundidas y trituradas) depositados sobre sustratos de fundición de acero con Ra de 6 mm (Fauchais et al., 1996; Pech et al., 1997; Pech et al., 1999a) ............

Tabla 2.6 Efecto de la temperatura y tiempo de precalentamiento sobre revestimientos de zirconia (distribución del tamaño de las partículas de 22 a 45 $\mu \mathrm{m}$; Fundidas y trituradas) depositados sobre sustratos de acero inoxidable con Ra de $12 \mu \mathrm{m}$ (Fauchais et al., 1996; Pech et al., 1997; Pech et al., 1999a) ........... Tabla 2.7 Características de las salpicaduras de alúmina sobre diferentes sustratos de alúmina (Denoirjean et al., 1998) ..................................... 52

Tabla 3.1 Caudal de gas portador y corriente de alimentación .................. 88

Tabla 5.1 Datos experimentales para la temperatura del acero en el centro de la gota de estaño (Pasandideh- Fard, 2008)

Tabla 5.2 Dimensiones de las salpicaduras en forma de corona circular para la muestra S1

Tabla 5.3 Ancho de la imagen calculado a partir de la escala SEM en $\mu \mathrm{m}$ para la muestra $\mathrm{S} 1$

Tabla 5.4. Dimensiones de las salpicaduras en forma de corona circular para la muestra S1

Tabla 5.5. Dimensiones de las salpicaduras en forma de tortita para la muestra S1 


\section{RESUMEN}

En esta tesis se implementan métodos de análisis experimental y modelos de simulación numérica dentro del ámbito de los procesos de térmicos de proyección por plasma atmosférico, en concreto para los problemas de impacto y solidificación de las salpicaduras. La aplicación del método de volúmenes finitos, más eficiente en problemas que implican mecánica de fluidos, al análisis del impacto junto con el empleo del método de simulación por redes en la solidificación han aportado modelos precisos y eficientes, permitiendo la representación de soluciones de simulaciones numéricas y resultados experimentales. Así, sin aplicar hipótesis que simplifiquen las ecuaciones de gobierno, se obtienen tiempos de computación reducidos.

El método de volúmenes finitos se aplica más eficazmente al análisis de impacto al afectar a problemas de mecánica de fluidos, y la aplicación de métodos de simulación de redes en la solidificación proporciona un modelo eficaz y preciso que puede replicar la simulación numérica y la solución. Los resultados experimentales tienen suficiente tiempo de cálculo sin necesidad de simplificar los supuestos en la ecuación del gobierno.

Para el problema de impacto, se formulan las ecuaciones de balance en el software de elementos de volúmenes finitos utilizado, Fluent, mediante ecuaciones más generales, completándose con las condiciones de contorno e iniciales, no pudiéndose aplicar el método de simulación por redes debido a obstáculos insalvables tales como cambios de geometría y forma característica de la salpicadura. En el caso del problema de solidificación, a partir del modelo matemático y las condiciones de contorno e iniciales, se diseña el modelo en red de la celda elemental. La simulación numérica de este último se lleva a cabo mediante el software Ngspice, programa informático de software abierto.

Respecto al análisis experimental, se ha diseñado un método para la consecución de gotas aisladas en condiciones normales de operación. Se trata de un procedimiento rápido, económico e integrable en procesos automatizados de optimización de revestimientos. También se ha automatizado el análisis de la morfología de la salpicadura utilizando las técnicas más modernas de procesamiento de imagen, proporcionando una clasificación eficiente de las morfologías para su posterior asignación de correspondencias entre estas y los parámetros de fabricación asociados al revestimiento. 


\section{ABSTRACT}

In this Ph.D. experimental analysis methods and numerical simulation models are implemented within the scope of atmospheric plasma projection thermal processes, specifically for the impact and solidification problems of splashes. The application of the finite volume method, more efficient in problems involving fluid mechanics, to impact analysis together with the use of the network simulation method in solidification have provided accurate and efficient models, allowing the representation of solutions reproducing numerical simulation solutions and experimental results. Thus, even without applying hypotheses that simplify the government equations, they present reduced computation times.

The finite volume method is most effectively applied to impact analysis by affecting fluid mechanics problems, and the application of network simulation methods in solidification provides an efficient and accurate model that can replicate the numerical simulation and solution. The experimental results have sufficient computation time without the need to simplify the assumptions in the government equation.

For the impact problem, the balance equations are formulated in the finite volume element software used, Fluent, by means of more general equations, completing with the boundary and initial conditions, and the network simulation method cannot be applied due to obstacles insurmountable such as changes in geometry and characteristic shape of the splash. In the case of the solidification problem, based on the mathematical model and the boundary and initial conditions, the network model of the elementary cell is designed. The numerical simulation of the latter is carried out using the Ngspice, open software computer program.

Regarding the experimental analysis, a method has been designed to obtain isolated drops under normal operating conditions. It is a fast, economical and integrable procedure in automated coating optimization processes. The analysis of the morphology of the splat has also been automated using the most modern image processing techniques, providing an efficient classification of the morphologies for their subsequent mapping between these and the manufacturing parameters associated with the coating. 


\section{CAPÍTULO 1}

\section{INTRODUCCIÓN}

\subsection{INTRODUCCIÓN}

La primera toma de contacto del grupo de investigación del Método de Simulación por Redes con la idea de relacionar la morfología de las salpicaduras y la adherencia de los revestimientos se planteó en el verano de 2008, durante una estancia de uno de los componentes del grupo en el Instituto de Recubrimientos Cerámicos (IMTCCC). Ésta fue acogida con escepticismo. A pesar de no obtener resultados suficientemente claros para realizar una publicación, dada las dificultades de análisis de fenómenos en una escala microscópica, se pudo verificar, a partir de la bibliografía disponible, el interés por estudiar una salpicadura aislada. Esta fase se estableció como el punto de partida para implementar métodos propios de análisis experimental, en base a la tecnología disponible en la Región de Murcia, y desarrollos de modelos de simulación numérica, también basados en software desarrollado por dicho grupo de investigación.

La propuesta para realizar este trabajo dentro del grupo de investigación ha cumplido más de una década. Mi experiencia desde mi incorporación en esta tarea a través de la tesis doctoral, debo decir, ha supuesto un reto en todos los sentidos.

En relación al campo de la simulación numérica, el método de redes (MESIR), se ha aplicado de forma efectiva en campos tales como, reacciones electroquímicas (Horno et al., 1993, Moya, 2011), transporte iónico (Horno et al., 1995), magneto-hidrodinámica (Bég et al., 2009) transferencia de calor (Alhama F. et al., 1997; González-Fernández et al., 1998a 1998b; Alarcón et al., 2002; Del Cerro et al., 2008; Luna Abad, 2010), transporte a través de membranas (Horno et al., 1990), problemas inversos (Zueco et al., 2005, 2006; Alhama et al., 2007), problemas acoplados de flujo y transporte (Soto, 2007, Soto et al., 2007; Alhama et al., 2011a, et al., 2011b, 2012), mecánica de sólidos deformables (Morales et al., 2012a, 2012b), fricción (Marín et al., 2012, 2016) y otros (Alcaraz et al., 2005; Moreno Nicolás et al., 2007; Benavent-Climent et al., 2012). El 
planteamiento consistió en ampliar el método a otro ámbito, el del impacto isotérmico y solidificación de gotas.

La primera fase, aún con los objetivos no completamente concretados, fue la de realizar una investigación sobre el estado del arte en esta disciplina. Los intentos iniciales se concentraron en analizar los modelos tradicionales de análisis de impacto y solidificación. Así, el modelo de simulación numérica de impacto isotérmico, con sus cambios profundos en la naturaleza de cada celda y la dificultad intrínseca de las ecuaciones de NavierStokes, se ha resistido durante varios años al empleo del método de redes. Por tanto, se ha optado por un software comercial cuya licencia está disponible en la Universidad, basado en el método de volúmenes finitos, para su resolución; dejando la aplicación del método de redes, cuyos intentos de aplicación continúan, fuera del marco de esta tesis. Tanto los modelos desarrollados por el método de redes, que no han proporcionado soluciones satisfactorias, como el análisis de los resultados y el manejo del software de volúmenes finitos, que no había sido usado anteriormente en el grupo de investigación, exigió una comprensión adecuada de la mecánica de fluidos computacional, lo que demoró perceptiblemente el desarrollo de esta memoria.

El segundo modelo, solidificación, sí que se adapta perfectamente a la esencia del método de redes. La dificultad ahora provenía del cambio de fase asociado a la solidificación, que implica la resolución de un problema de frontera móvil.

A partir de este punto, fue posible desarrollar los modelos incluidos en la memoria, que abarcan los aspectos más importantes relacionados con la formación de la salpicadura.

Si la parte de simulación, que sin ser la más fácil, parecía más asequible por la experiencia del grupo de investigación en el que se ha desarrollado esta tesis, presentó las dificultadas mencionadas en el apartado anterior; no resulto menos problemática la parte experimental. Tanto la reducida información técnica de la bibliografía disponible como la falta de experiencia en este campo concreto en esta universidad y en la de Murcia, supuso que la especialista en microscopia electrónica y corte con haz de iones fuera la primera sorprendida cuando logramos realizar un corte preciso de una gota de material cerámico de unas pocas micras sobre un sustrato de acero y en un tiempo muy reducido. Este resultado es bastante esperanzador para la programación de análisis de procesos de proyección térmica cuando se disponga de una instalación de estas características en esta 
comunidad autónoma.

La elaboración de esta tesis ha supuesto un trabajo que ha sido al mismo tiempo extenso y extenuante. Sin embargo, las metas parciales, que han tenido que ser reajustadas en función del progreso de este trabajo, nos han facilitado conseguir uno a uno los objetivos planteados y los supuestos tras el alcance de varias de estas metas. Se han intentado publicar, gradualmente, los resultados de este trabajo. Al final, como resultados parciales de éste hemos presentado una ponencia en las I Jornadas de Tecnologías de Fabricación organizadas por la ETSII de la UPCT, con la participación de investigadores del IMTCCC, y elaborado dos artículos, uno de ellos publicado en una revista especializada. Los modelos planteados se han comprobado con los resultados de otras publicaciones y con ensayos experimentales.

Esta memoria está estructurada en 6 capítulos. En el capítulo 1, tras la introducción, se enuncian los objetivos planteados. En el capítulo 2 se exponen los fundamentos teóricos del impacto isotérmico y solidificación de gotas, y del método de simulación por redes, origen del diseño de los modelos de solidificación. En el capítulo 3 se describen los procedimientos experimentales aplicados. Los modelos diseñados para analizar el impacto isotérmico por el método de volúmenes finitos y la solidificación por el método de redes se analizan en el capítulo 4. El capítulo 5, principal de esta memoria, presenta aplicaciones del método de volúmenes finitos para la resolución de los problemas de impacto isotérmico, y del método de simulación por redes para la resolución de los problemas de solidificación. Por último, las contribuciones y conclusiones se detallan en el capítulo final de la memoria.

\subsection{OBJETIVOS}

El objetivo primordial del trabajo es verificar la capacidad del Método de Redes para operar con los modelos de impacto y solidificación de gotas, procediendo al análisis progresivo de los siguientes problemas: modelo de proceso de solidificación en dos dimensiones (2D) (Dutil et al., 2011; Rangel y Bian, 1996; Ahmed y Meshrif, 2009; Pasandideh-Fard, 1998) y modelo de impacto isotérmico de gota (Anderson et al., 2009).

Los objetivos de carácter particular pueden clasificarse en: 
- En primer lugar, el desarrollo de los modelos en red para la solidificación.

- En segundo lugar, el análisis de la representación de los resultados cuando estos son complejos de visualizar.

- En tercer lugar, la comprensión de los procesos de impacto y solidificación de una gota y su verificación mediante técnicas experimentales (Brossard, 2010).

- Finalmente, la aplicación industrial de los procesos de impacto y solidificación estudiados, que permiten analizar el efecto de los parámetros de proyección térmica sobre el impacto y la solidificación de una gota de material cerámico.

\subsection{DESARROLLOS FUTUROS}

En primer lugar, se propone la implementación de un sistema automatizado de optimización de los parámetros de operación del equipo de revestimiento a partir de la información proporcionada por la inspección automatizada de salpicaduras aisladas, unido a la información recolectada a partir de la monitorización del haz de proyección. En segundo lugar, elaboración de un paquete integrado de programas para la concepción y simulación de modelos de salpicadura, cuyos módulos de cálculo y post-procesado son el objetivo de esta tesis, quedando pendiente el desarrollo de la interfaz con el usuario. El programa deberá crear el modelo mediante una interacción sencilla y eficaz con el usuario, que suministrará las características del material seleccionado para el polvo y el sustrato, así como el rango de valores permitido para los parámetros de operación.

Vinculada con la anterior proposición, es conveniente mencionar la utilidad de plantear la simulación de otros procesos de proyección térmica, como el High-Velocity-OxygenFuel (HVOF).

Como líneas de actuación alternativas podemos distinguir: i) aplicación de los modelos desarrollados a otros materiales, ii) ampliación de los modelos a tres dimensiones, iii) propuestas de problemas inversos desde sus distintos puntos de vista para este proceso teniendo en cuenta la experiencia del método en otros ámbitos, iv) estudios de modelización de la superficie del sustrato: rugosidad, geometrías distintas a una superficie plana, presencia de óxidos y otros contaminantes y v) desarrollo de modelos en red de 
versiones simplificadas de Navier-Stokes que permitan avanzar hacia un modelo en red completo del impacto isotérmico de una gota. 


\section{CAPÍTULO 2}

\section{FUNDAMENTOS TEÓRICOS}

\subsection{INTRODUCCIÓN}

La base teórica de esta investigación se recoge en un capitulo inicial, como es frecuente en las memorias de tesis, de forma que en cualquier parte del texto se puede hacer referencia a éste. En dicho capítulo, se exponen las ecuaciones que definen el modelo matemático del proceso de impacto y solidificación de gotas, siendo uno de los objetivos primordiales de esta memoria su solución numérica mediante el método de simulación por redes.

Para el desarrollo de los modelos matemáticos anteriormente mencionados, primero, analizamos el proceso de impacto y solidificación de la gota y segundo, revisamos las ecuaciones básicas que conforman el origen del diseño de los modelos.

\subsection{PROCESO TÉRMICO DE PROYECCIÓN POR PLASMA ATMOSFÉRICO}

\subsubsection{TECNOLOGÍA DE SUPERFICIES}

Las nuevas exigencias del mercado han incrementado las cargas mecánicas, térmicas y químicas soportadas por las máquinas. Así, los materiales empleados tradicionalmente y con un coste asumible, como aceros, metales ligeros y polímeros, no pueden cumplir con estas exigencias; mientras que los nuevos que sí pueden, cerámicas, metales de alta dureza, cermets, o metales puros con calidad superior, no están disponibles en las cantidades requeridas, tienen un alto coste o son difíciles de mecanizar.

Ante esta dificultad, los procesos de tecnología superficial proporcionan una mejora en la funcionalidad de los elementos que componen la maquinaria, creando una superficie adaptada a la carga, por ejemplo, tribológica, térmica o corrosiva, sobre un sustrato que satisface las condiciones de estabilidad geométrica y mecánica. Estos procesos, termo- 
mecánicos o termoquímicos, modifican las redes cristalinas aumentando la resistencia superficial y la dureza.

En el caso de procesos térmicos en aleaciones $\mathrm{Fe}-\mathrm{C}$, se busca un endurecimiento mediante enfriamiento rápido a partir de temperaturas entre 1000 y $1200^{\circ} \mathrm{C}$, que origina una estructura martensítica donde se disuelven los átomos de carbono en la red cristalina. El origen de la fuente de calor permite clasificarlos por el uso de: llama, inmersión, inducción, conducción y alta energía, como láser o haz de electrones (ASM, 1993).

En caso de procesos termoquímicos, elementos no metálicos, como $\mathrm{C}$ y $\mathrm{N}$, o metálicos, como $\mathrm{Cr}, \mathrm{Al}$ y $\mathrm{Si}$, se difunden en el substrato ayudados de una alta temperatura. El elemento añadido permite clasificarlos en: aluminizado, borado, cromado, nitrocarburación, nitruración y siliconado.

Sobre estos procesos termoquímicos se puede aplicar otro adicional, que puede ser: carburación, borado, nitrocarburación y cromado.

Frente a estos procedimientos, los procesos de deposición de materiales constituyen una alternativa económica. Para estos, la funcionalidad del conjunto depende de un buen enlace entre el substrato y la capa depositada.

Entre estos procesos, los de revestimiento se han usado desde principios del siglo XX, cuando Schoop los introdujo utilizando una llama. Esta tecnología posiciona materiales metálicos y no metálicos en un estado fundido o semifundido sobre una superficie de substrato activado. Su activación, es decir, la eliminación de impurezas y las capas de reacción química, así como el aumento de la superficie específica, incrementa la resistencia de los enlaces de la capa compuesta; siendo el granallado la técnica más empleada. Así se pueden obtener espesores que van normalmente desde 50 a $250 \mu \mathrm{m}$, aunque en aplicaciones especiales pueden llegar hasta varios milímetros (Pawlowski, 1995).

La gran variedad de procesos de deposición hace difícil su enumeración, por lo que resulta más conveniente mencionar grupos más reducidos clasificados según: el estado físico del material durante la deposición y la fuente de energía.

Así, en cuanto al estado físico del material durante la deposición estos pueden clasificarse en: estado líquido, como en el lacado, estado sólido, como en revestimientos 
electrostáticos o procesos de proyección térmica, estado gaseoso, como en procesos de deposición física o química de vapor, y estado iónico, como en galvanoplastia y procesos galvánicos.

Entre los beneficios de la aplicación de estos procesos están el bajo coste de los equipamientos y operación, el mecanismo simple de operación y el bajo impacto medioambiental.

En cuanto a la fuente de energía, pueden clasificarse en: los que emplean combustión, eléctricos, los fríos y los que usan láser.

Los procesos que emplean combustión como fuente de energía se pueden clasificar a su vez en:

- $\quad$ proyección por llama (Flame Spray, FS), usando polvo o alambre,

- $\quad$ proyección térmica por detonación (D-Gun),

- $\quad$ proyección térmica (High Velocity Oxygen Fuel, HVOF), usando gas combustible (HVOF-G) o líquido combustible (HVOF-K).

Los procesos que emplean como fuente de calor energía eléctrica se pueden clasificar en:

- $\quad$ por plasma, en atmósfera específica (Inductive Plasma Spray, IPS, Vacuum Plasma Spray, VPS, y Suspension Plasma Spraying, SPS), atmosférico (Air Plasma Spraying, APS) y especiales (High Pressure Plasma Spraying, HPPS, Water Stabilized Plasma Spraying, WSPS, Radio Frecuency Spraying, RPS, y Underwater Plasma Spray, UPS)

- $\quad$ los de proyección de hilo por arco eléctrico (Wire Arc Spray, WAS),

Otros procesos emplean la energía cinética de un gas precalentado, proyección fría (CGS), o la energía térmica generada por la incidencia de un láser (Villa et al., 2012).

Tras la clasificación de los procesos es conveniente analizar sus características generales para estar en condición de valorarlos. La temperatura y la velocidad de las partículas es un criterio interesante para valorar los procedimientos mencionados, figura 2.1. 


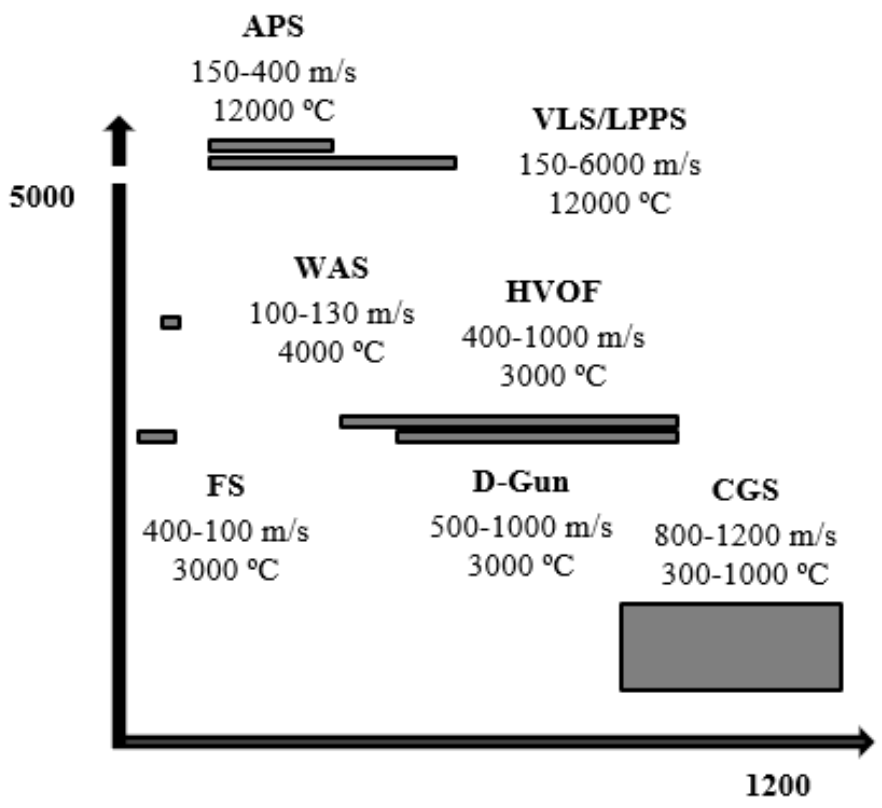

Figura 2.1 Relación entre la temperatura y la velocidad de los diferentes procesos (Oksa et al, 2011).

Los procesos de proyección por llama son los primeros empleados dentro de la clasificación de proyección térmica, utilizan una llama externa generada mediante la combustión de una combinación de gases, normalmente acetileno, y oxígeno. El polvo o hilo se funden en la llama y son proyectados sobre el substrato, pudiendo ser acelerado mediante el uso de aire comprimido. En la figura 2.2. se presenta una imagen esquemática de dicho proceso.
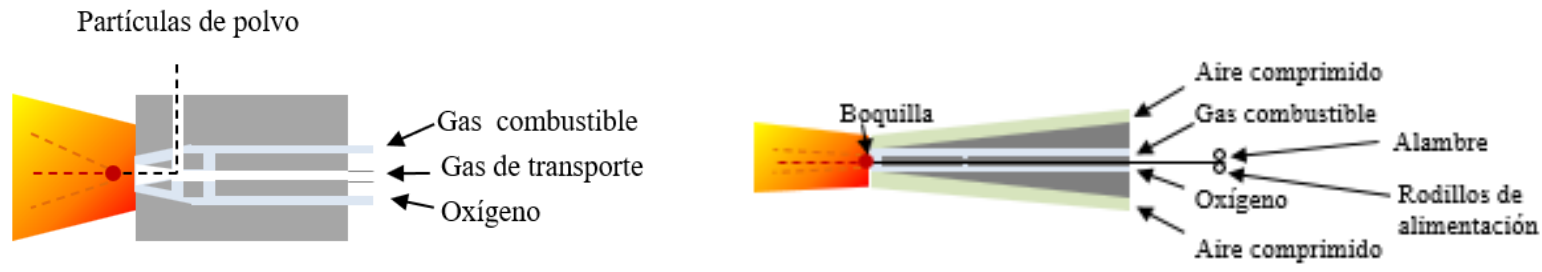

Figura 2.2 Proceso de proyección por llama (IMTCCC; Acedo Fornell, 2005).

Una alternativa más eficiente al uso del polvo consiste en el uso de un material de aportación almacenado en un revestimiento metálico, además de la mayor sencillez de manejo, almacenamiento y operación.

A diferencia de los procesos de proyección por llama, en los procesos HVOF la combustión es interna, y las velocidades de flujo y presiones de gas son mucho más elevadas. Por tanto, las velocidades de las partículas son extremamente altas. La 
combinación de altos caudales de gas y la elevada presión de combustión conduce a la generación de un chorro de gas supersónico.

La figura 2.3 muestra un proceso HVOF-G y HVOF-K de forma esquemática.

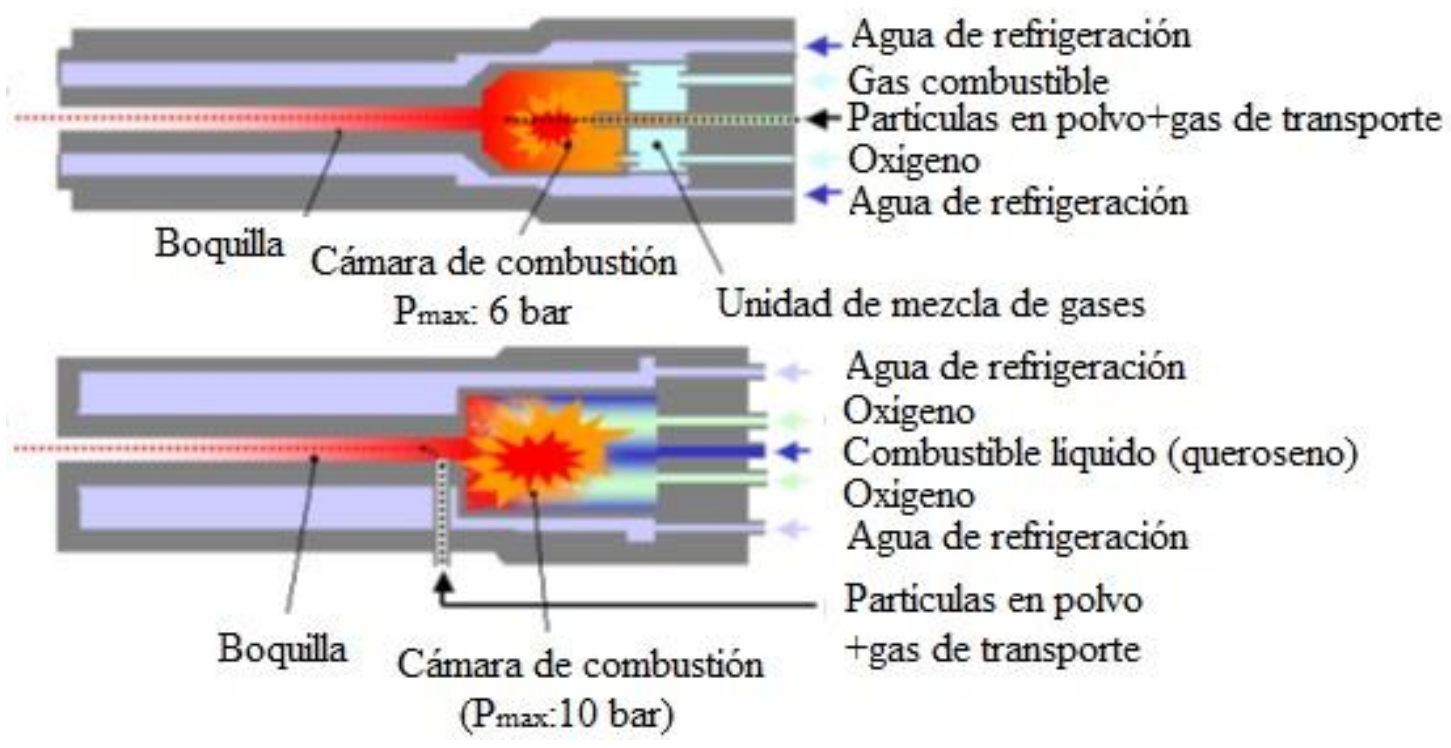

Figura 2.3 Imagen esquemática del proceso HVOF (IMTCCC; Acedo Fornell, 2005).

En los inicios de esta técnica, se empleaba una gran variedad de combustibles gaseosos, como hidrocarburos mezclados con oxígeno, etano, acetileno, propano o propileno. En la actualidad, los procesos de proyección HVOF utilizan combustible líquido, lo que producen temperaturas de combustión más bajas, pero debido al incremento del flujo de oxígeno, la velocidad de impacto aumenta considerablemente.

La fuente de calor para originar la fusión del material de aportación no tiene que proceder de la combustión, una alternativa interesante es un arco eléctrico. Así, los procesos de proyección por plasma utilizan un arco eléctrico de corriente continua (DC) o radiofrecuencia $(\mathrm{RF})$ para generar una corriente de plasma ionizado a partir de un flujo continuo de gases inertes. El arco eléctrico salta entre un cátodo de tungsteno y un ánodo de cobre, produciendo desgaste en una o más zonas, llamadas "raíces".

La elección de los gases está sujeta a su capacidad para fundir las partículas proyectadas. Así, los gases moleculares, especialmente el hidrógeno, tienen mayor capacidad para fundir debido a su alta conductividad térmica. En cambio, los gases monoatómicos generan mayores flujos. La mezcla de gases monoatómicos y moleculares asegura una correcta fusión de las partículas junto a una alta velocidad de proyección. El helio se usa 
como aditivo del argón debido a su alta conductividad térmica, pero también porque causa un cono de proyección estrecho.

Los gases habitualmente empleados en este proceso son: argón, mezclas de hidrógeno y argón, mezclas de argón y helio, mezclas de argón y nitrógeno, nitrógeno, mezclas de nitrógeno e hidrógeno. El flujo normal es aproximadamente de 40-50 Nl/min, aunque en algunos casos puede superar los $80 \mathrm{Nl} / \mathrm{min}$.

La forma más simple de alimentar el sistema con material para el revestimiento es usar polvo, que es transportado por el chorro de plasma donde es fundido y propulsado hacia el sustrato, siendo posible trabajar con materiales de alto punto de fusión debido a la alta energía térmica del chorro de plasma. Un esquema del proceso de plasma atmosférico se presenta en la figura 2.4.

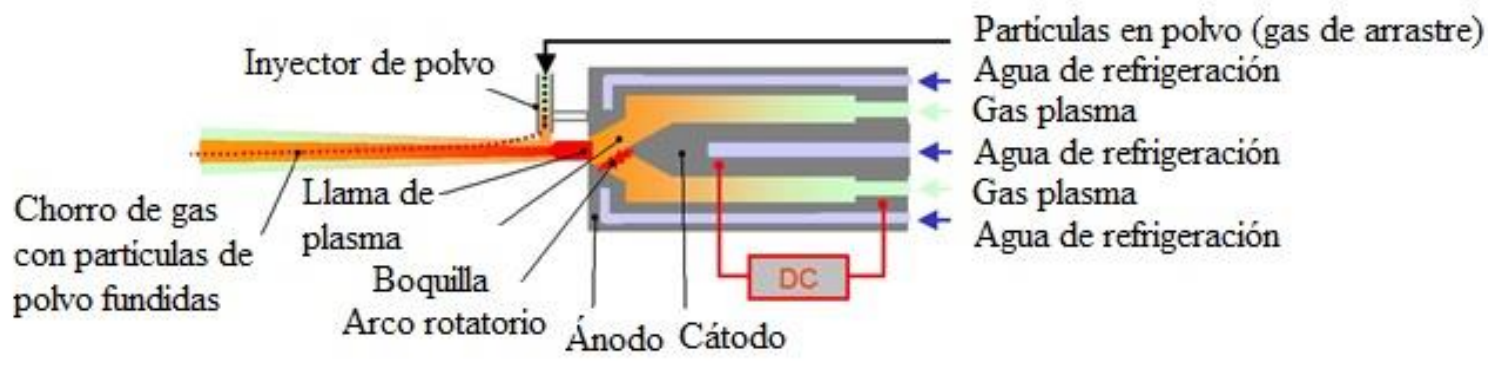

Figura 2.4 Imagen esquemática del proceso de proyección de plasma atmosférico, APS. (IMTCCC;

Acedo Fornell, 2005).

También es posible utilizar hilo como material de alimentación, que ofrece las ventajas de una tasa alta de deposición y la simplicidad de los equipos, que no requieren refrigeración por agua y fuentes de alimentación de baja tensión. Los materiales de revestimiento del hilo más comunes son zinc, aluminio, acero y sus aleaciones.

Una vez conocidas las características de los diferentes procesos, es viable la selección de revestimiento para un problema específico, que frecuentemente sigue la siguiente secuencia: análisis del problema, especificación de las propiedades del revestimiento, propuesta de la solución, incluida la selección de materiales a ser proyectados, equipamientos y técnicas, aplicación del revestimiento, y análisis de resultados en términos de viabilidad térmica y económica. 


\subsubsection{PARÁMETROS DE OPERACIÓN DEL PROCESO APS}

Abordar todos los procesos de proyección térmica significaría generar una cantidad de software de simulación que excedería en mucho lo abarcable en un trabajo doctoral, ya que cada proceso tiene sus particularidades. Es por ello que se ha decidido concentrar los esfuerzos en uno de los procesos de proyección, APS, siendo posible en posteriores trabajos extender el software desarrollado a otros procedimientos de proyección térmica.

La primera tarea que es necesaria realizar para entender este proceso es identificar los parámetros de operación y los aspectos del diseño de componentes de la instalación de proyección térmica, así como la selección de materiales proyectados y sustrato. Estos últimos, determinan tanto el funcionamiento de la instalación como los parámetros de operación, pero deben ser prefijados correctamente antes de dicha operación. Ambos determinan la calidad del producto obtenido, es decir, el revestimiento.

Para enumerarlos es necesario distinguir claramente los componentes que participan en el proceso: antorcha, material proyectado, substrato y accionador, que posiciona la antorcha respecto al sustrato. Así podemos asociar a la antorcha los parámetros de operación energía eléctrica disponible y flujo de gas, siendo la geometría de los electrodos y la boquilla aspectos de diseño que hay que preseleccionar antes de la operación. Al material de revestimiento podemos asociar los parámetros de operación que determinen su caudal másico, siendo su geometría y propiedades físicas, así como la forma de suministro parte de los aspectos de diseño. El sustrato viene definido por las características de su superficie y su temperatura. Finalmente, es necesario colocar la antorcha a una distancia de la superficie y orientarla respecto a la normal a dicha superficie, parámetros de operación asociados al accionador. A continuación, se indica la información más relevante sobre estos parámetros de operación, así como información sobre el resto de aspectos que condicionan el efecto de los parámetros de operación seleccionados.

En referencia a la antorcha, la potencia corrientemente alcanza los $60 \mathrm{~kW}$, pero puede llegar a más de $100 \mathrm{~kW}$. Respecto a los electrodos, el cátodo usado en estas antorchas debe corresponder con el gas de trabajo seleccionado, mientras que el ánodo determinará la distribución radial de velocidades del plasma. La estabilización del plasma se consigue mediante el chorro de gas, y en algunos casos, el arco se reduce mediante un remolino de 
aire (Pawlowski, 2008). A la salida de la antorcha, la boquilla, caracterizada por su longitud y diámetro de abertura, condiciona la velocidad del chorro proyectado, que arrastra las partículas fundidas, total o parcialmente, del material proyectado.

El segundo elemento mencionado, el material proyectado térmicamente, tiene una gran influencia en la calidad del revestimiento. En el caso de usar polvo como material de aportación, este viene definido por: composición química, composición de fase, proceso de fabricación, tamaño de grano y distribución, morfología, y propiedades térmicas y físicas.

La morfología, la composición y el coste de la materia prima pueden variar según su fabricación, figura 2.5, encontrándose el tamaño de las partículas normalmente en el rango de 5 a $200 \mu \mathrm{m}$. Un tamaño de grano grande proporciona una mayor rugosidad superficial y por consiguiente una mayor porosidad.
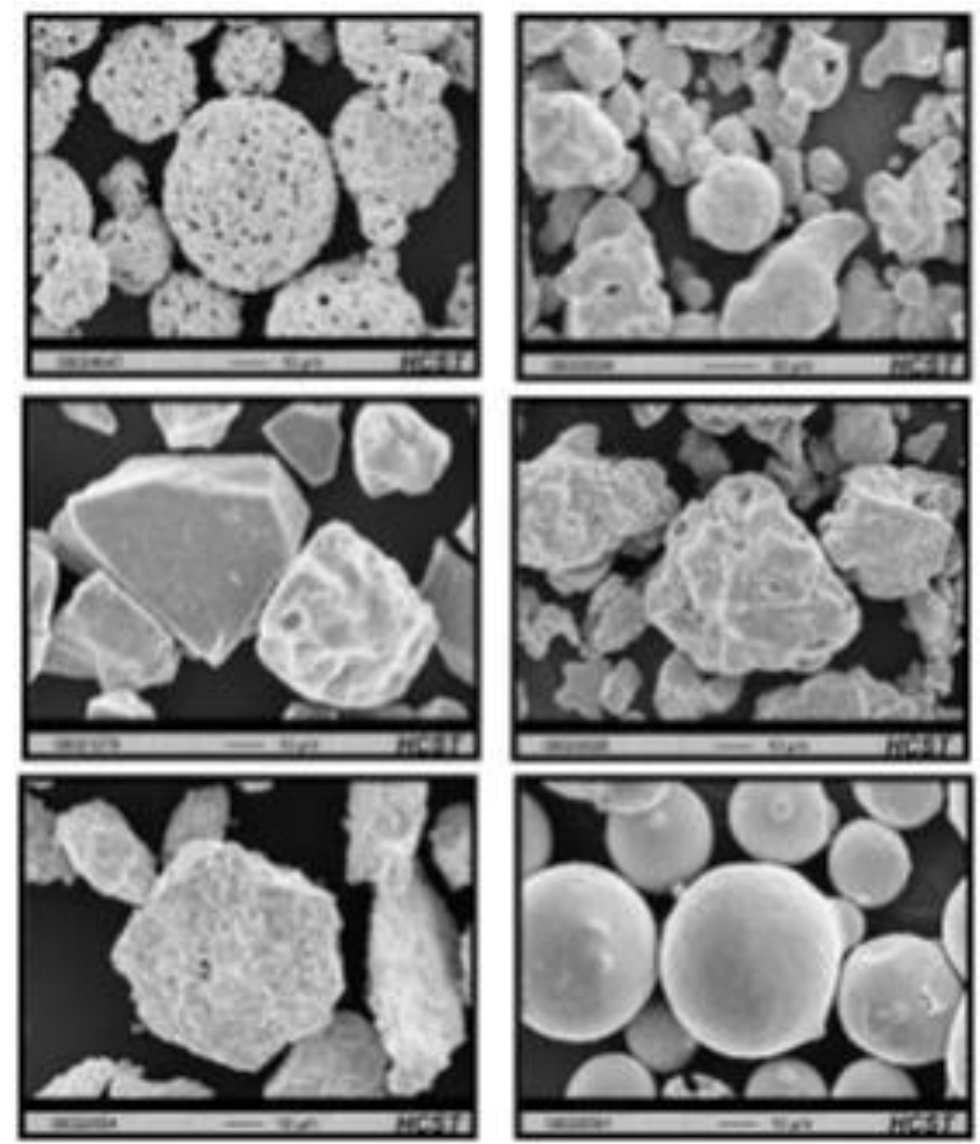

Figura 2.5 Tipos de partículas de polvo empleadas en procesos de proyección térmica (Acedo Fornell, 2005). 
Las propiedades físicas consideradas son la dureza, el coeficiente de dilatación térmica, el calor específico, el módulo de Young, la conductividad, el límite de fluencia, la ductilidad y las tensiones residuales.

Y, como se ha mencionado anteriormente, asociado al material de aportación, se puede considerar su suministro. En el caso de polvo, el suministro puede realizarse: por gravedad, lecho fluidizado, ruedas giratorias y por vibración. El caudal normal es de 50 a $100 \mathrm{~g} / \mathrm{min}$, pero puede alcanzar $200 \mathrm{~g} / \mathrm{min}$, que es facilitado por un flujo de gas, cuyo valor puede ir de 3 a $10 \mathrm{Nl} / \mathrm{min}$. Si el material de aportación es refractario se inyecta dentro de la boquilla con un ángulo de $90^{\circ}$, aunque a veces es de $60^{\circ}$. Si el material no es refractario se inyecta en la llama.

El último elemento en la trayectoria del material proyectado es el sustrato, para el que hay que considerar los siguientes aspectos: composición química, tratamiento superficial, existencia de una capa adicional de material y temperatura.

Para terminar con esta relación de componentes, hay que mencionar el actuador, generalmente un robot, que posiciona la antorcha. El borde de esta, el final de la boquilla, se suele situar entre 60 y $130 \mathrm{~mm}$ del sustrato, y forma un ángulo de $90^{\circ}$; aunque puede cambiar según la geometría de la pieza a recubrir (Pawlowski, 2008).

En resumen, podemos enumerar los siguientes parámetros de operación. Para la antorcha: potencia eléctrica disponible, caudal de gas en la antorcha y caudales de gas asociados al suministro de material de revestimiento. Para el accionador, la velocidad de avance, distancia y ángulo respecto al sustrato.

\subsection{SALPICADURA}

El análisis de salpicaduras de alúmina, objetivo de esta tesis, incluye tanto el estudio de las fases y granos desarrollados dentro de estas, como el de su forma, fenómeno asociado al aplanamiento.

Una adecuada comprensión de este fenómeno permite enlazar los parámetros de fabricación con la adhesión del revestimiento, así como las tensiones residuales desarrolladas en este. 


\subsubsection{FASES DE LA ALÚMINA Y MORFOLOGÍA DE GRANO}

La temperatura y composición con la que llega una partícula fundida, o semifundida, al sustrato, la temperatura y características de este, y la forma que adquiere la partícula tras el aplanamiento, la salpicadura, determinan como se enfría esta. Las consecuencias de esta solidificación determinan las características de la salpicadura, entre las que se encuentran la fase sólida y la morfología de grano, que pueden usarse a posteriori para confirmar la información obtenida a partir de simulaciones numéricas.

Si nos centramos en la alúmina, ésta existe en muchas formas metaestables, además de la alfa alúmina, el corindón, que es termodinámicamente estable (Levin y Brandon, 1998). Esta fase es la más densa, con un valor de esta propiedad de 3,66 a 3,99 g/ $\mathrm{cm}^{3}$ cuando está sólida y $2,8 \mathrm{~g} / \mathrm{cm}^{3}$ cuando todavía está líquida (Glorieux et al., 1999).

Las estructuras metaestables pueden clasificarse en dos grandes categorías: la cúbica centrada en las caras (FCC) y la hexagonal compacta (HCP). Las estructuras basadas en el empaquetamiento FCC de oxígeno incluyen las formas $\gamma$ y $\eta$ (cúbicas), $\theta$ (monoclínica), y $\delta$ (tanto tetragonal como ortorrómbica); mientras que las estructuras basadas en un empaquetamiento HCP presentan fases $\alpha$ (trigonal), $\kappa$ (ortorrómbica), y $\chi$ (hexagonal). Aparte de las fases mencionadas, Zimmer ha identificado otras (Zimmer, 2010).

En general, las fases metaestables basadas en el empaquetamiento FCC se obtienen a través de los siguientes procesos:

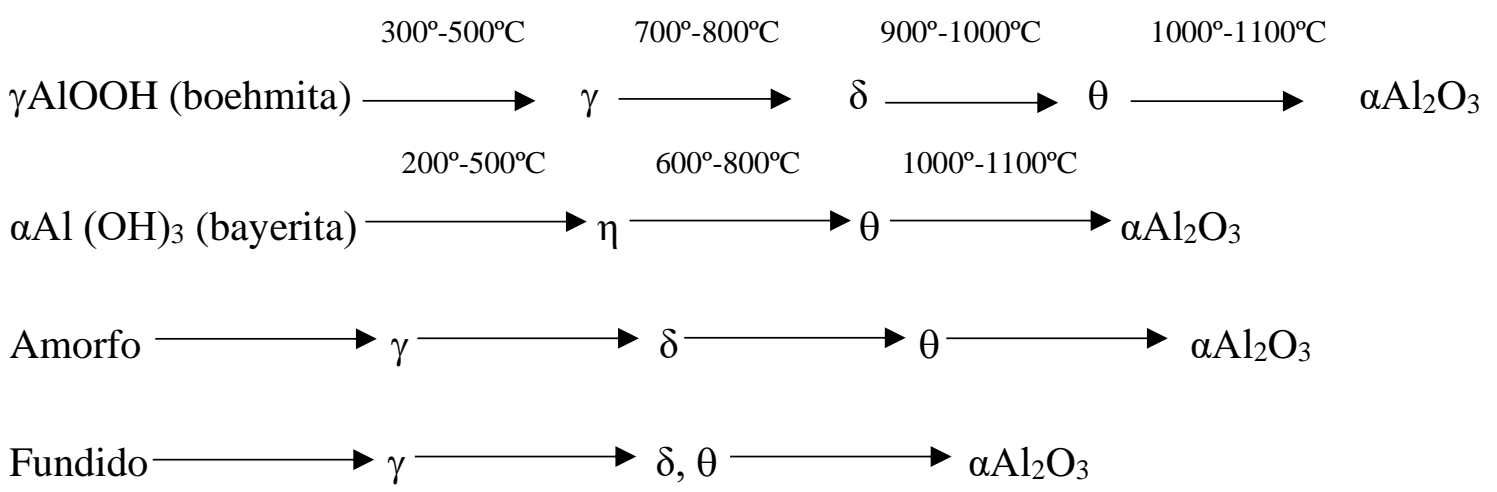

Y las basadas en el empaquetamiento HCP mediante los siguientes procesos:

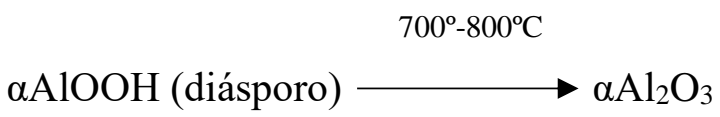




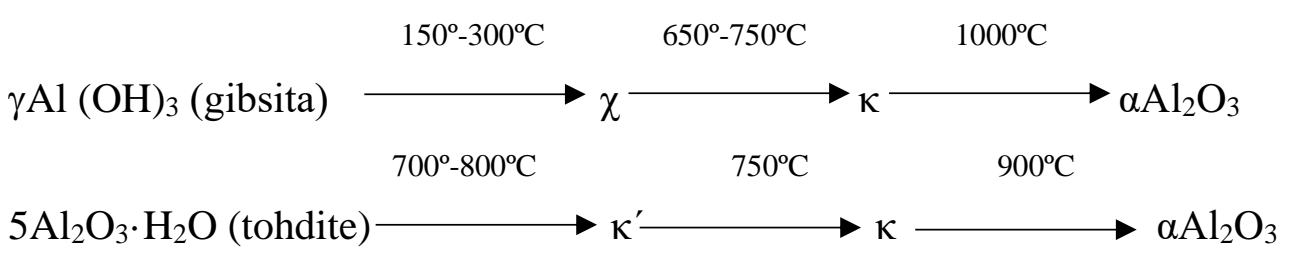

Vapor $(\mathrm{CDV}) \longrightarrow \kappa \longrightarrow \alpha \mathrm{Al}_{2} \mathrm{O}_{3}$

Si la solidificación es rápida, la fase predominante es la gamma, dado que la alúmina líquida presenta una coordinación similar (Landron et al., 2001).

Como se ha comentado anteriormente, la velocidad de enfriamiento determina la fase durante la solidificación. Esta hipótesis, lógica por otra parte, ha sido confirmada por los modelos de Levi et al., que obtuvieron los siguientes resultados: fase amorfa con un enfriamiento de aproximadamente $10^{5} \mathrm{~K} / \mathrm{s}$, fase gamma con velocidades de enfriamiento más bajas y fase alfa con un enfriamiento en el intervalo de 1 a $100 \mathrm{~K} / \mathrm{s}$ (Levi et al., 1988).

Zimmer et al. han estudiado distintas muestras de alúmina obtenidas a distintas velocidades de enfriamiento para confirmar estas relaciones. La figura 2.6 muestra este material sobre revestimiento, mientras que la figura 2.7 muestra el mismo en partículas depositadas en agua. En estas condiciones, la gota fundida está en contacto con el líquido y el agua hirviendo, siendo menor el coeficiente de transferencia de calor. El análisis de difracción por rayos $\mathrm{X}(\mathrm{XRD})$ de la figura 2.8 confirma estas diferencias. Así, el revestimiento presenta predominantemente fase gamma y alúmina amorfa, mientras que las partículas capturadas en agua contienen prácticamente todas fases alfa. Estos resultados son análogos a los de Gualtieri et al., que encontraron en un revestimiento de alúmina por plasma aproximadamente un $84 \%$ en peso de fase gamma, $12 \%$ en peso de fase amorfa y un 3,7\% de fase alfa (Gualtieri et al., 2006).

En un revestimiento, las primeras salpicaduras están en contacto con el sustrato y experimentan velocidades mayores de enfriamiento, lo que determina una mayor probabilidad de fase amorfa, figura 2.9 (Mostaghini et al., 2002). Posteriormente, las salpicaduras que caen sobre otras depositadas recientemente, tienen velocidades de enfriamiento algo menores, lo que explica la presencia de fase gamma.

El material del sustrato también influye en la formación de la fase. El estudio de Ashenford et al. muestra que la fase alfa puede crecer sobre un sustrato de zafiro de un solo plano r, con la misma estructura que el corindón, pero no sobre sustratos de acero 
(Ashenford et al., 1999).

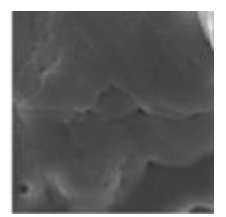

Figura 2.6 Imagen de microscopía de salpicaduras en la superficie del revestimiento (Zimmer, 2010).

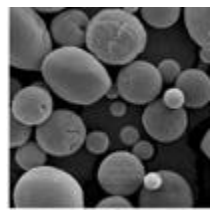

Figura 2.7 Imagen de microscopía de salpicaduras proyectadas en agua (Zimmer, 2010).

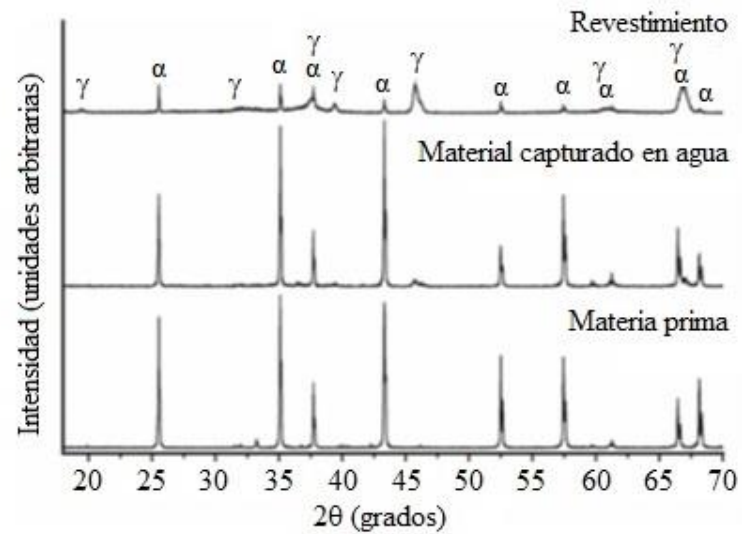

Figura 2.8 Patrones de difracción de rayos x: revestimiento (superior), partículas en agua (medio) y polvo (inferior) (Zimmer, 2010). 


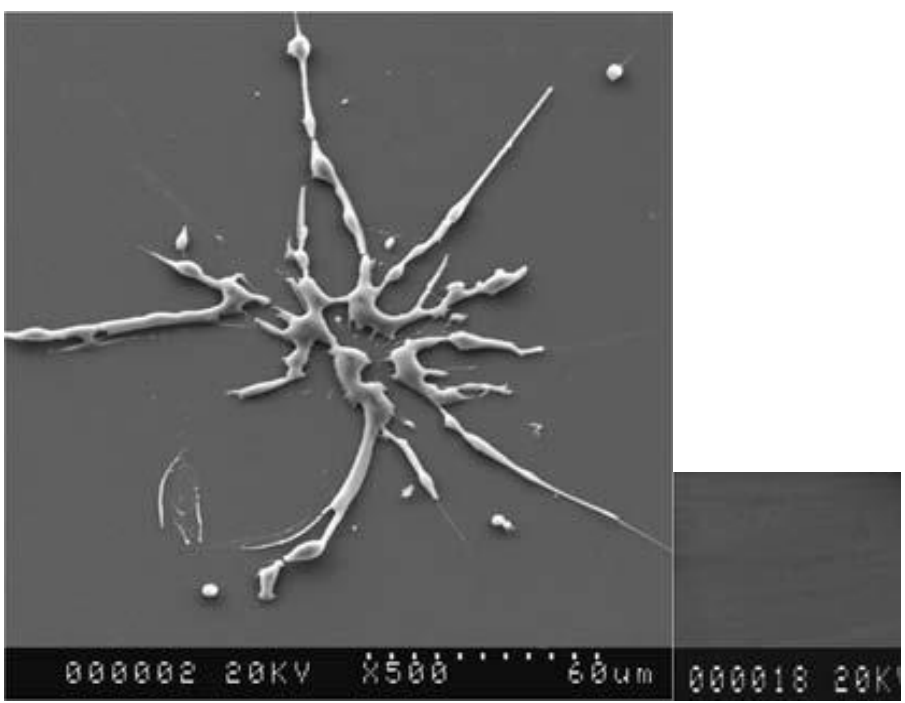

Figura 2.9 Dos tipos de salpicaduras de alúmina a $20^{\circ} \mathrm{C}$ sobre sustratos de cristal (izquierda) y acero inoxidable (derecha) (Mostaghimi et al., 2002).

La velocidad de enfriamiento determina también el tamaño de grano, produciéndose tamaños menores cuando mayor es la velocidad de enfriamiento. En relación a esta cuestión, Chraska y King confirmaron tamaños menores de grano en la interfase del revestimiento con el sustrato, donde la velocidad de enfriamiento es menor, en una salpicadura de zirconio pulverizada con plasma (Chraska y King, 1999). La figura 2.10 relaciona el tipo de grano, relacionado con su tamaño, con el gradiente de temperatura (G) y la velocidad de solidificación (Vs), dependiente de la velocidad de enfriamiento (Vr) y la temperatura del sustrato.

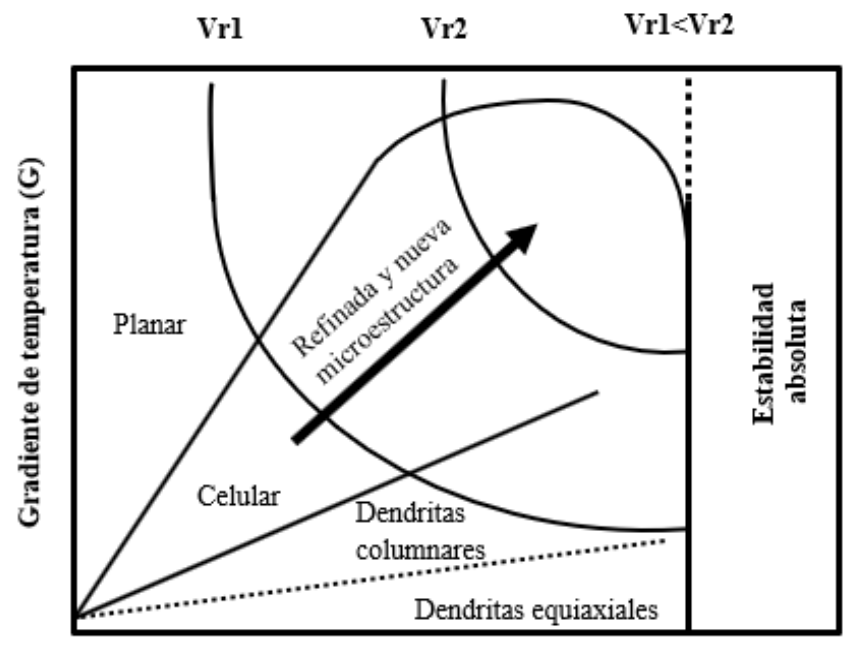

Velocidad de solidificación (Vs)

Figura 2.10. Relación entre el tipo de grano, el gradiente de temperatura (G) y la velocidad de solidificación (Pantelis, 1993; Kou, 2003). 
Otra cuestión a considerar en los procesos de enfriamiento de la salpicadura, es que en los procesos de proyección, el sustrato no suele estar a temperatura ambiente, sino que se suele utilizar un precalentamiento. Por tanto, resulta interesante saber que tamaños y tipos de grano aparecen en una zona de la salpicadura, por ejemplo, su zona central de una salpicadura, figura 2.11, para unos parámetros de proyección, como los mostrados en la tabla 2.1, y distintas temperaturas iniciales del sustrato, figuras 2.12 a 2.14.

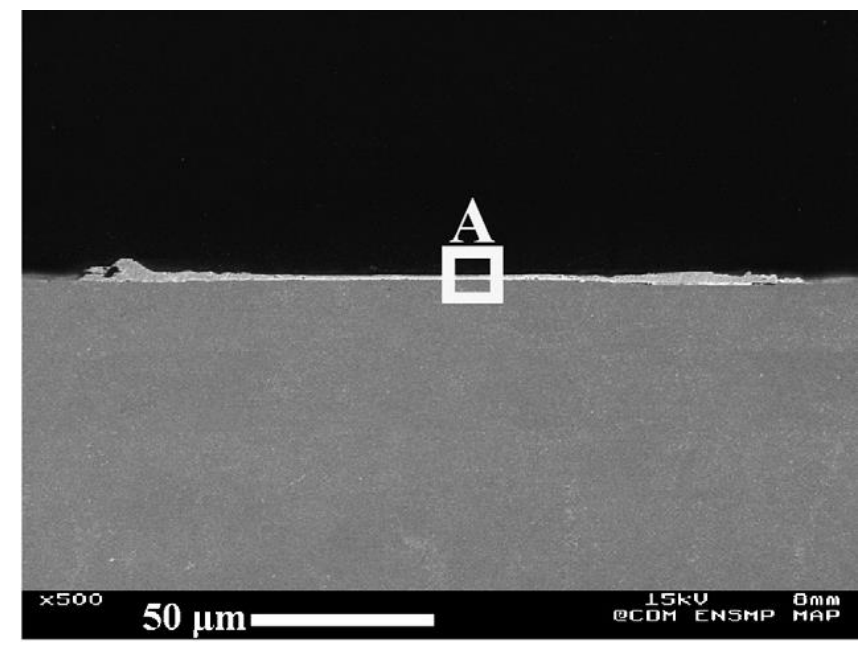

Figura 2.11 Sección transversal de una salpicadura formada sobre un sustrato precalentado a $200^{\circ} \mathrm{C}$

(Christoulis et al., 2008)

Tabla 2.1 Parámetros de proyección (Christoulis et al., 2008)

Antorcha de plasma

F4-VB

Diámetro de la boquilla de la antorcha $(\mathrm{mm})$

6

Gas plasma (I/min)

$80(\mathrm{Ar}), 10\left(\mathrm{H}_{2}\right)$

Intensidad del arco (I)

600

Voltaje (V)

66

Distancia de proyección (mm)

140

Caudal másico del gas de arrastre

Flujo de alimentación de polvo (g/min)

30 


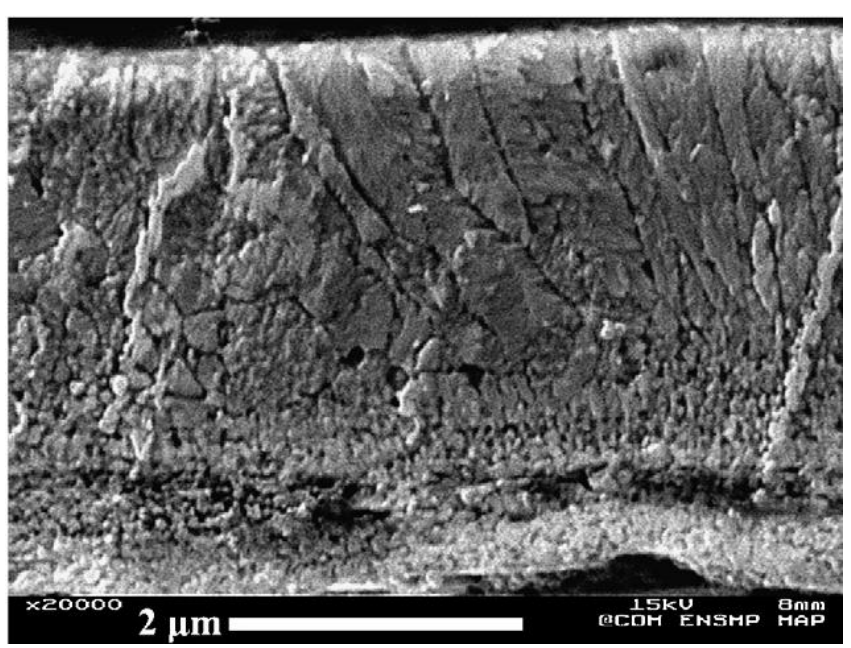

Figura 2.12. Detalle del área A de la figura 2.11 (Christoulis et al., 2008).

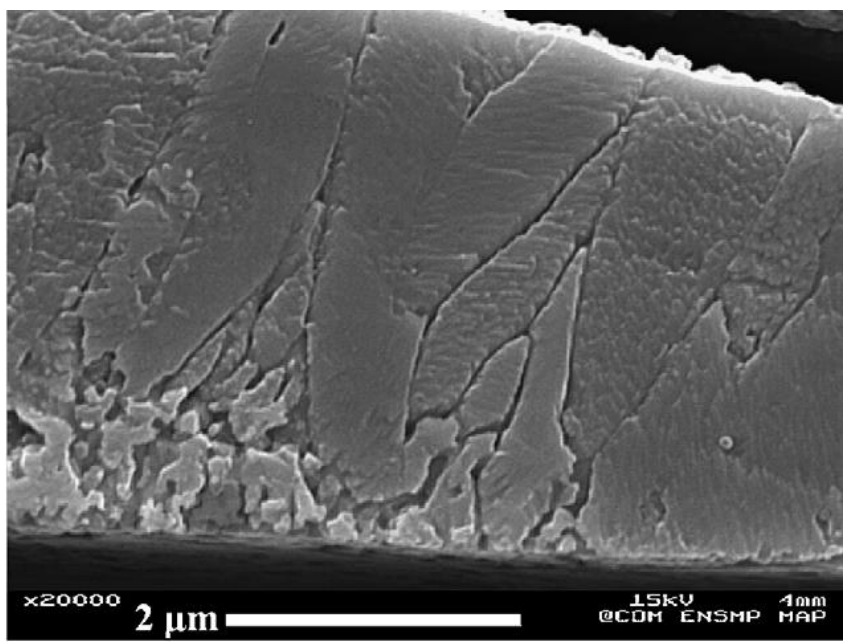

Figura 2.13 Sección de la salpicadura formada sobre un sustrato precalentado a $250^{\circ} \mathrm{C}$ (Christoulis et al., 2008).

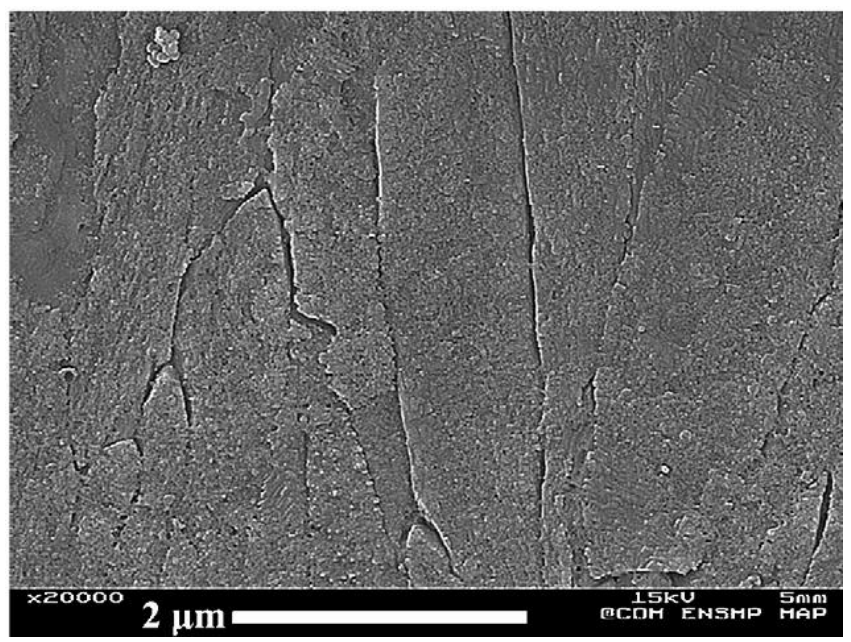

Figura 2.14 Sección de la salpicadura formada sobre un sustrato precalentado a $300^{\circ} \mathrm{C}$ (Christoulis et al., 2008).

Aparte de las relaciones cualitativas que se puedan deducir a partir de las imágenes 
mencionadas, se han ensayado algunas expresiones cuantitativas que permiten relacionar estos parámetros geométricos con la velocidad de enfriamiento. Así, Chraska y King han relacionado el ancho de las columnas con el subenfriamiento $(\Delta \mathrm{T})$. En concreto, el ancho de la sección transversal columnar (d) se determina mediante (Chraska y King, 2001):

$$
d=\sqrt[3]{\frac{8 V s}{\pi J}}
$$

donde Vs es la velocidad de solidificación y J es la velocidad de nucleación.

La velocidad de solidificación puede ser estimada mediante:

$$
\mathrm{Vs}=\mathrm{a}_{\mathrm{a}} \omega \cdot \exp \left(-\frac{\mathrm{Q}}{\mathrm{k}_{\mathrm{B}} \mathrm{T}}\right)\left[1-\exp \left(-\frac{\Delta \mathrm{G}_{\mathrm{V}}}{\mathrm{k}_{\mathrm{B}} \mathrm{T}}\right)\right]
$$

donde $\mathrm{a}_{\mathrm{a}}$ es el espaciamiento interatómico, $\omega$ la frecuencia de vibración atómica, $\mathrm{Q}$ la energía de activación para transferir un átomo a través de la interfase sólido-líquido, $\mathrm{k}_{\mathrm{B}}$ la constante de Boltzmann y $\Delta \mathrm{G}_{\mathrm{V}}$ la fuerza motriz para la solidificación.

La frecuencia de vibración atómica puede ser estimada mediante:

$$
\omega=\left(k_{B} T_{m}\right) / h
$$

donde h es la constante de Planck.

La fuerza motriz para la solidificación se ha aproximado como

$$
\Delta \mathrm{G}_{\mathrm{V}} \approx \mathrm{L}_{\mathrm{f}} \cdot \Delta \mathrm{T}_{\mathrm{r}}
$$

donde $\mathrm{L}_{\mathrm{f}}$ es calor latente de fusión, $\Delta \mathrm{T}_{\mathrm{r}}=\mathrm{T}_{\mathrm{m}}-\mathrm{T} / \mathrm{T}_{\mathrm{m}}$ la reducción del subenfriamiento y $\mathrm{T}_{\mathrm{m}}$ la temperatura del metal fundido (Christoulis et al., 2008).

La velocidad de nucleación puede ser estimada mediante:

$$
J=n \omega \cdot \exp \left(-\frac{Q}{k_{B} T}\right)\left[\exp \left(-\frac{16 \pi \sigma_{S}^{3} f(\theta)}{3 \Delta G_{V}^{2} k_{B} T}\right)\right]
$$

donde $\mathrm{n}$ es la densidad de nucleación, $\sigma_{\mathrm{s}}$ es la energía superficial en la interfase sólidolíquido y $\mathrm{f}(\theta)$ es una función del ángulo de contacto, $\theta$, para un núcleo sólido en la superficie del sustrato. 
La función $\mathrm{f}(\theta)$ puede estimarse mediante:

$$
f(\theta)=\left(2-3 \cos \theta+\cos ^{3} \theta\right) / 4
$$

Finalmente, el valor de d puede escribirse como:

$$
\mathrm{d}=\sqrt[3]{\frac{8 \mathrm{a}_{\mathrm{a}}\left[1-\exp \left(-\left(\Delta \mathrm{G}_{\mathrm{v}}\right) /\left(\mathrm{k}_{\mathrm{B}} \mathrm{T}\right)\right]\right.}{\pi \mathrm{n} \cdot \exp \left(-\frac{16 \pi \sigma_{\mathrm{S}}^{2} \mathrm{f}(\theta)}{\mathrm{k}_{\mathrm{B}} \mathrm{T}}\right)}}
$$

El valor de d para cada columna de una salpicadura se determinó a partir de su análisis de imagen y el subenfriamiento, ecuación 2.4, se calculó a partir de la temperatura del sustrato usada para conseguir dicha salpicadura. Con varios anchos de columna para distintas temperaturas de sustrato, se pudo ajustar la ecuación 2.7. En dichos cálculos se supuso un valor de $\mathrm{a}_{\mathrm{a}}$ de $5 \cdot 10^{-10} \mathrm{~m}$ para metales (ASM, 1993) y $10^{42} \mathrm{~m}^{-3} \mathrm{~s}^{-1}$ para el producto $n \cdot \omega$ (Kurz y Fisher, 1989).

En la tabla 2.2 se muestran los resultados que confirman que la velocidad de enfriamiento de la salpicadura disminuye con la diferencia positiva entre la temperatura del sustrato y la temperatura de transición $\left(\mathrm{T}_{\mathrm{t}}\right)$ entre formas de salpicadura, que será tratada en el apartado 2.3.3 (Christoulis et al., 2008). Las tablas 2.3 y 2.4 muestran el valor de d y $\Delta \mathrm{T}$ para dos valores de rugosidad del sustrato.

Tabla 2.2 Ancho de las columnas de la salpicadura (d) y su subenfriamiento $(\Delta \mathrm{T})$ en función de la temperatura inicial de un sustrato pulido de espejo (Christoulis et al., 2008).

\begin{tabular}{cccc}
\hline Temperatura & Ancho & Ancho & Subenfriamiento \\
$\mathbf{T}_{\text {sust }}(\mathbf{\circ}$ C) & valor medio $(\mu \mathrm{m})$ & S.D. $(\mu \mathrm{m})$ & $\Delta \mathbf{T}(\mathbf{0}$ ) \\
\hline 200 & 0,82 & $\pm 0,08$ & 792 \\
250 & 0,95 & $\pm 0,07$ & 375 \\
300 & 1,15 & $\pm 0,07$ & 249 \\
\hline
\end{tabular}


Tabla 2.3 Ancho de las columnas de la salpicadura (d) y su subenfriamiento $(\Delta T)$ en función de la temperatura inicial del sustrato con una rugosidad $\left(\mathrm{R}_{\mathrm{a}}\right)$ de $0,02 \mu \mathrm{m}$ (Christoulis et al., 2008).

\begin{tabular}{cccc}
\hline Temperatura & Ancho & Ancho & Subenfriamiento \\
$\mathbf{T}_{\text {sust }}(\mathbf{0} \mathrm{C})$ & valor medio d $(\mu \mathrm{m})$ & S.D. $(\mu \mathrm{m})$ & $\Delta \mathbf{T}(\mathbf{0} \mathrm{C})$ \\
\hline 200 & 0,82 & $\pm 0,08$ & 792 \\
250 & 0,95 & $\pm 0,07$ & 375 \\
\hline
\end{tabular}

Tabla 2.4 Ancho de las columnas de la salpicadura (d) y su subenfriamiento $(\Delta T)$ en función de la temperatura inicial del sustrato con una rugosidad $\left(\mathrm{R}_{\mathrm{a}}\right)$ de $1,33 \mu \mathrm{m}$. (Christoulis et al., 2008).

\begin{tabular}{cccc}
\hline Temperatura & Ancho & Ancho & Subenfriamiento \\
$\mathbf{T}_{\text {sust }}(\mathbf{\circ}$ C) & valor medio $(\mu \mathrm{m})$ & S.D. $(\mu \mathrm{m})$ & $\Delta \mathbf{T}(\mathbf{\circ}$ C) \\
\hline 300 & 1,15 & $\pm 0,07$ & 249 \\
200 & 1,08 & $\pm 0,07$ & 276 \\
300 & 1,44 & $\pm 0,07$ & 192 \\
\hline
\end{tabular}

\subsubsection{MORFOLOGÍA DE LAS SALPICADURAS}

El análisis del proceso de aplanamiento y formación de la salpicadura (splat) resulta más sencillo si se considera dividido en dos fases: compresión y expansión. La primera fase comienza cuando las partículas esféricas toman contacto con el sustrato, y finaliza con la formación de la salpicadura, con el líquido comprimido cerca de la zona de contacto de la superficie del sustrato.

Durante la segunda fase, el líquido se expande radialmente adoptando una forma similar a una de las mostradas en la figura 2.15 (Mohamed et al., 2015); siendo las más representativas las de forma de tortita o disco, tipo 12, y las de forma de flor, tipo 4. La figura 2.16 muestra casos claros de ambos tipos. 


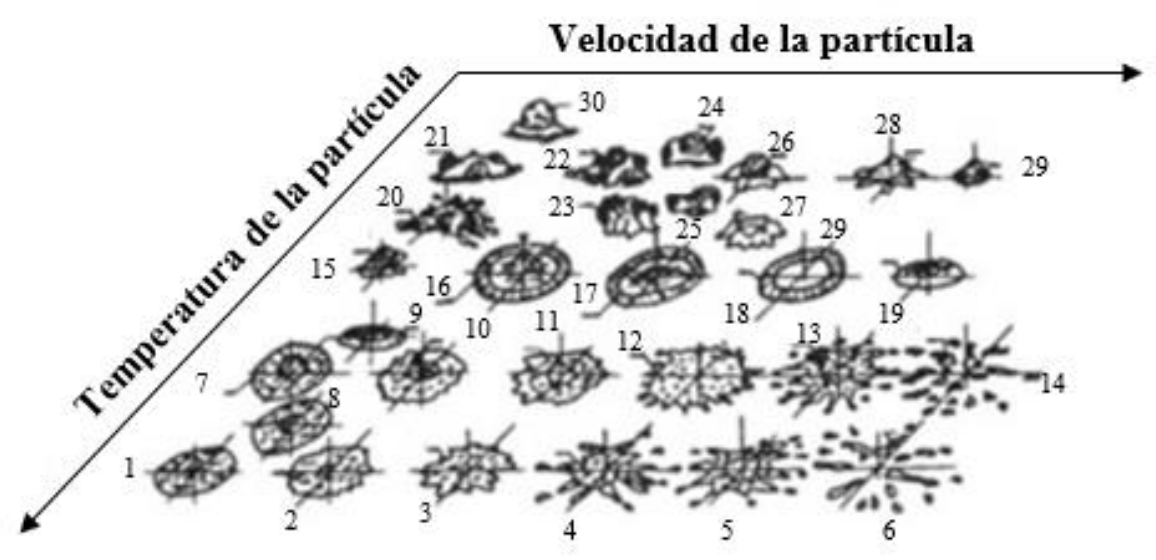

Figura 2.15 Morfología de las salpicaduras de alúmina basada en su velocidad y temperatura inicial de impacto en una proyección por plasma (Mohamed et al., 2015).

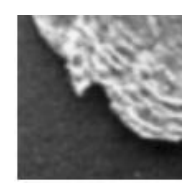

Figura 2.16 Formas de impacto: tortita (izquierda) y flor (derecha) (Pasandideh-Fard et al., 2002)

Una vez establecida una clasificación de morfologías, se puede definir una expresión para evaluarlas. La propuesta más aceptada es el factor de forma (SF):

$$
\mathrm{SF}=\left(4 \pi \mathrm{S}_{\mathrm{sal}}\right) / \mathrm{p}^{2}
$$

donde $\mathrm{p}$ es el perímetro de la salpicadura y $\mathrm{S}_{\mathrm{sal}}$ es la superficie.

Esta expresión asigna un valor unidad a una forma de tortita, y valores menores conforme aumenta la irregularidad de la salpicadura.

Tras establecer la clasificación es conveniente mencionar que estas geometrías están determinadas por las condiciones del sustrato antes del proceso de revestimiento, aunque estas cuestiones serán analizadas en el apartado 2.3.5. Para ilustrar esto, se puede adelantar algo de dicho apartado. Así, antes de que se deposite la partícula fundida, una 
temperatura de sustrato alta a presiones reducidas favorece la desorción; mientras que si la presión es la atmosférica se favorece la oxidación. Tanto la desorción como la oxidación aumentan la rugosidad y determinan el tipo de salpicadura, figura 2.17.

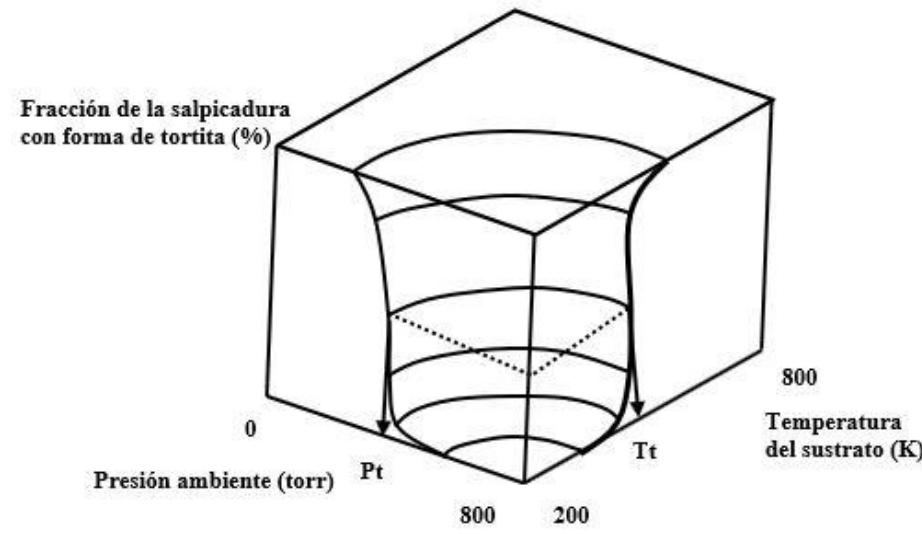

Figura 2.17. Mapa tridimensional de transición del comportamiento en un proceso de pulverización

(Fukumoto et al., 2007).

Una vez analizada la forma de la salpicadura se puede comenzar con el análisis de la textura de su superficie y la sección de esta. Estos análisis proporcionan información útil sobre el proceso de solidificación, que se tratará en el apartado 2.3.5.

Así, como adelanto a dicho apartado, para una salpicadura de zirconia tipo tortita sobre un sustrato de acero inoxidable, figura 2.18 , con una rugosidad media $\left(\mathrm{R}_{\mathrm{a}}\right)$ menor que $0,02 \mu \mathrm{m}$ y una temperatura del sustrato ( $\mathrm{T}_{\text {sust }}$ ) de alrededor de $300{ }^{\circ} \mathrm{C}$, el microscopio de fricción atómica (AFM) permite observar detalles de tamaño de $0,1 \mu \mathrm{m}$ o menos. Con este instrumento se pueden distinguir la estructura en columnas de la salpicadura o los detalles de una grieta o borde, figura 2.19 .

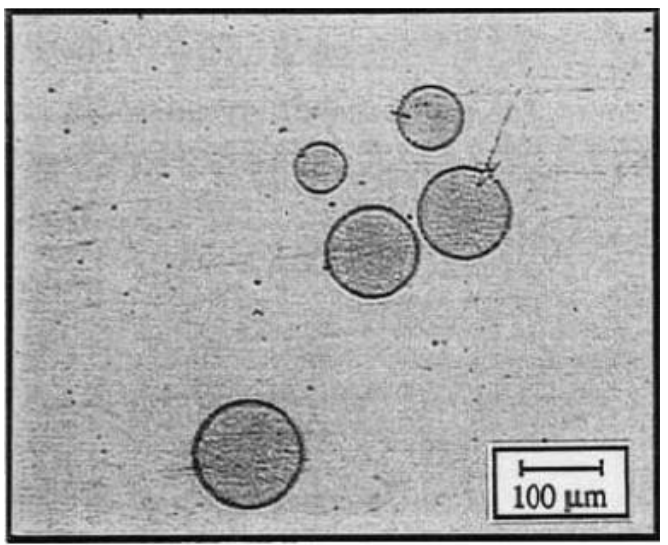

Figura 2.18. Salpicaduras de zirconia sobre un sustrato de acero inoxidable (Bianchi et al., 1997b). 


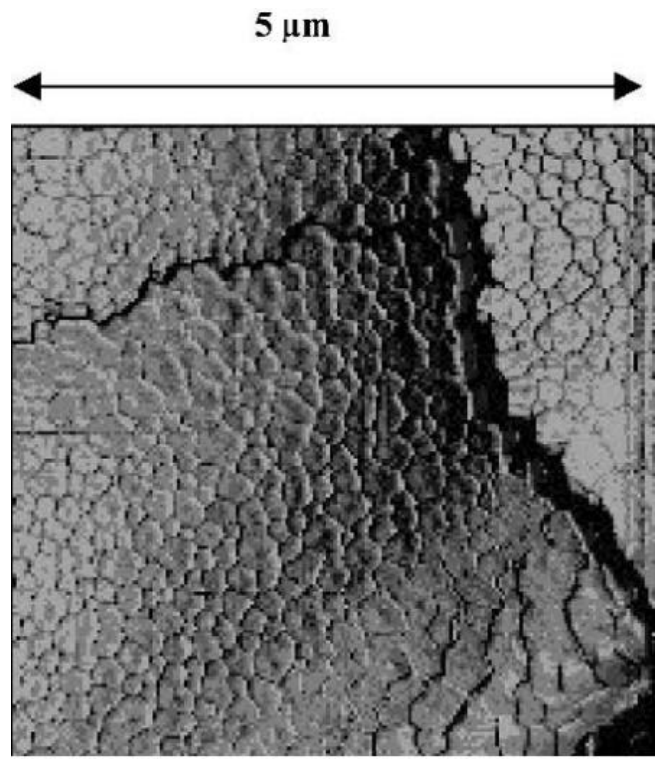

Figura 2.19. Estructura columnar dentro de un área pequeña $\left(5 \times 5 \mu \mathrm{m}^{2}\right)$ de una salpicadura representada en la figura 2.17 (Bianchi et al., 1997b).

En cuanto al análisis de las secciones de las salpicaduras, este indica la distribución de poros y la presencia de diferentes compuestos, que son identificados mediante procedimientos de análisis visual. Así, en la figura 2.20 se puede apreciar un esquema de esta distribución en una salpicadura de $\mathrm{NiCr}$ sobre sustrato de acero.

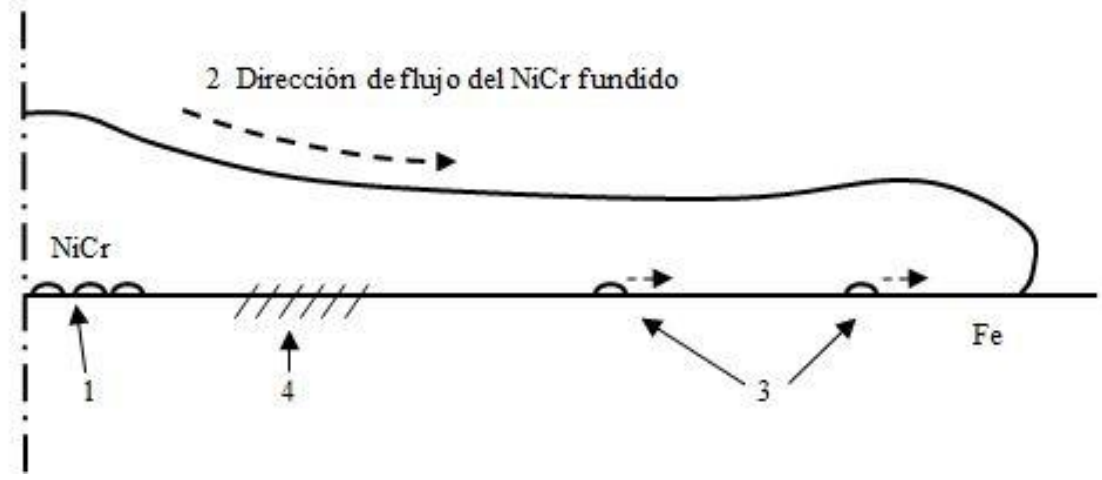

Figura 2.20. Representación esquemática del aplastamiento de una salpicadura de $\mathrm{NiCr}$ sobre sustrato de acero (Brossard, 2010)

Si se analiza más detalladamente esta sección, se puede apreciar en el centro de la salpicadura, marca 1, la formación de varios huecos, relacionados con las ondas de presión originadas durante el impacto (Brossard, 2010), que reducen la superficie de interfase entre salpicadura y sustrato, dificultando el enfriamiento de la salpicadura.

Si el hueco alcanza un tamaño crítico, se vuelve inestable y se convierte en una burbuja. 
Además, el oxígeno, o gases con alto contenido de vapor de agua, presentes en su interior oxidan el Ni, formando un óxido menos estable que el de cromo (Stringer et al., 1972).

La sucesión de acontecimientos puede resumirse de la siguiente manera. Mientras las partículas fundidas de $\mathrm{NiCr}$ se aplastan sobre la superficie, las sustancias liberadas por el sustrato debido al aumento de temperatura quedan atrapadas por la salpicadura en el proceso de aplastamiento, y son impulsadas hacia la periferia, marca 3 en la figura 2.20. En las zonas donde hay un buen contacto el calor transferido por la salpicadura es suficiente para fundir localmente el sustrato y arrastrarlo durante el aplanamiento, marca 4, pudiendo producirse también difusión entre ambas zonas. Este fenómeno puede ocurrir dada la similitud de estructuras cristalográficas entre la austenita y el $\mathrm{NiCr}$, y se ve más favorecido por la baja velocidad de los procesos de enfriamiento y solidificación que por la formación de alguna fase intermetálica.

Un caso más complejo es representado esquemáticamente en la figura 2.21. Esta vez, el óxido de níquel aparece tanto en la periferia, marca 7, como en el hueco central de la salpicadura, marca 8. La marca 4 muestra un mayor desplazamiento del sustrato, tras la fusión local, que en la figura 2.20. En la capa exterior de la salpicadura se pueden encontrar óxidos de cromo, marca 5; mientras que, en la interior, justo donde la salpicadura empieza a enrollarse hacia abajo en el borde, se puede encontrar óxido de hierro, marca 6. En esta última localización, el óxido se forma probablemente por la oxidación de los gases liberados por el impacto y la extensión de la gota, quedando restos del material original (NiCr), marca 9 (Brossard, 2010).

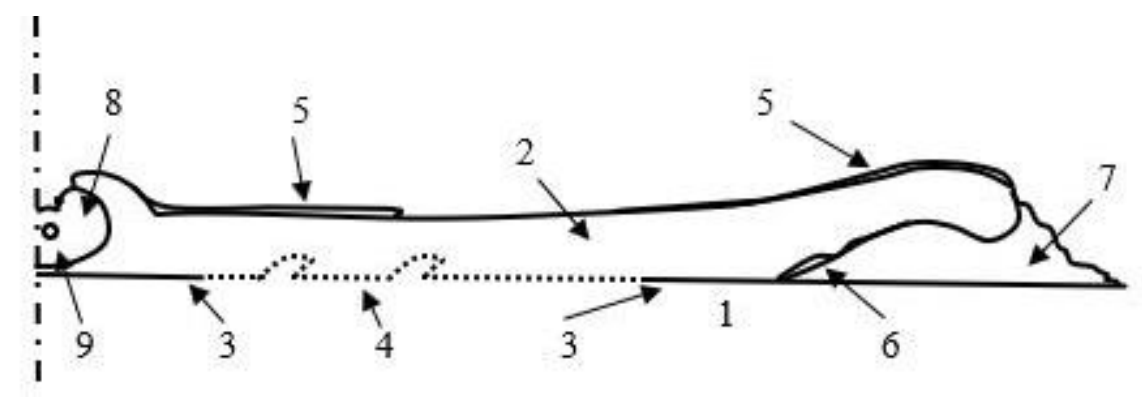

Figura 2.21 Representación esquemática de una salpicadura de $\mathrm{NiCr}$ sobre sustrato de acero

(Brossard, 2010).

En cuanto a las estructuras que se pueden formar en el interior de la salpicadura, en la figura 2.22, que presenta una sección transversal de una salpicadura de $\mathrm{NiCr}$ con forma 
de tortita con hueco central, se pueden apreciar granos con forma de columna, marca 1, y diámetro inferior a $1 \mu \mathrm{m}$. Existen regiones donde no es posible distinguir la interfase entre la salpicadura y el sustrato, marca 2, aparentemente debido a una fusión local. Se pueden observar algunos huecos en la interfase cerca del hueco central, marca 3, y también en el borde de la salpicadura, marca 4. Estos últimos están relacionados con el enrollamiento del borde debido a una adhesión insuficiente y la contracción asociada a la solidificación. En la región asociada al hueco central, marca 5, hay una zona en la que no puede distinguirse la estructura de grano.

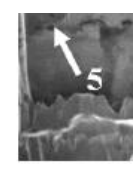

Figura 2.22 Sección transversal de una salpicadura de NiCr sobre sustrato de acero con forma de tortita con hueco central (Brossard, 2010). La imagen cuadrada en la esquina superior derecha muestra una vista cenital de la salpicadura en escala más reducida.

Tras analizar salpicaduras en forma de tortita, es conveniente contrastar el procedimiento de análisis con otro tipo de forma. Así, la figura 2.23 muestra una sección transversal de una salpicadura de $\mathrm{NiCr}$ con forma floreada. En la periferia se puede observar la separación de la salpicadura, marca 1, y huecos en la interfase, marca 2. La estructura de grano del sustrato es más fina cerca de la interfase debido al tratamiento superficial o a una fusión asociada con el impacto y aplastamiento de la gota, seguida de una rápida solidificación. Finalmente, el espesor de la salpicadura se estrecha cerca del centro, marca 3.

Otro ejemplo de este tipo de salpicadura aparece en la figura 2.24, que muestra dos secciones de una salpicadura floreada: una en la periferia y otra en el centro.

En la de la periferia los granos tienen un tamaño de 2 a $4 \mu \mathrm{m}$, y una dirección normal al sustrato, marca 1, que indica la dirección de solidificación. La región de óxido adyacente (probablemente $\mathrm{NiO}$ ), marca 2, con una estructura no identificable a la escala de observación, contiene algunas partículas de $\mathrm{NiCr}$, marca 3. Finalmente, se observan algunos huecos en la interfase entre la salpicadura y el sustrato, marca 4. 


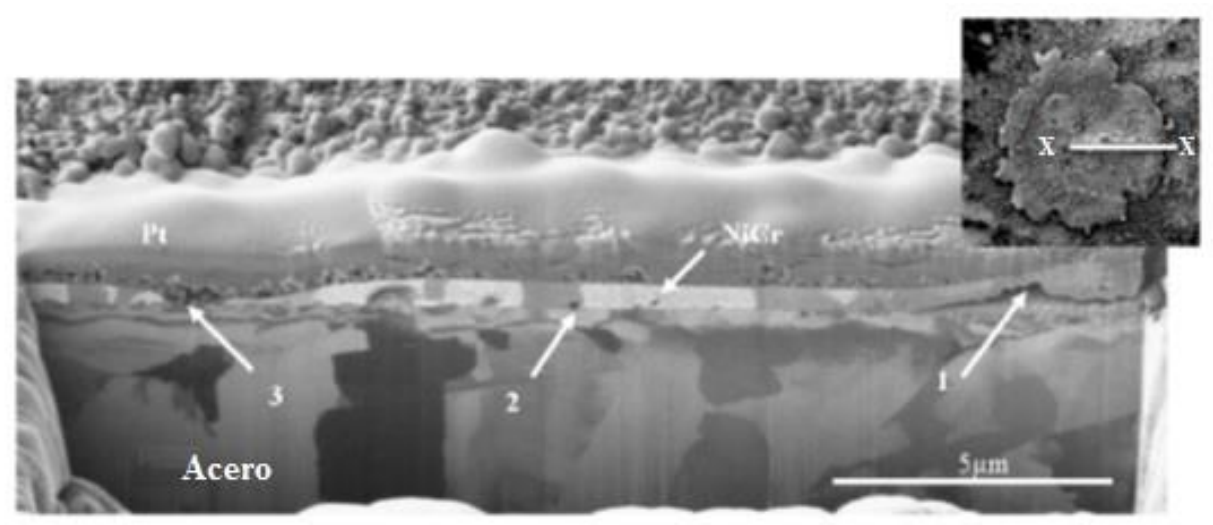

Figura 2.23 Sección transversal de una salpicadura de NiCr sobre sustrato de acero con forma floreada (Brossard, 2010). La imagen cuadrada en la esquina superior derecha muestra una vista cenital de la salpicadura en escala más reducida.
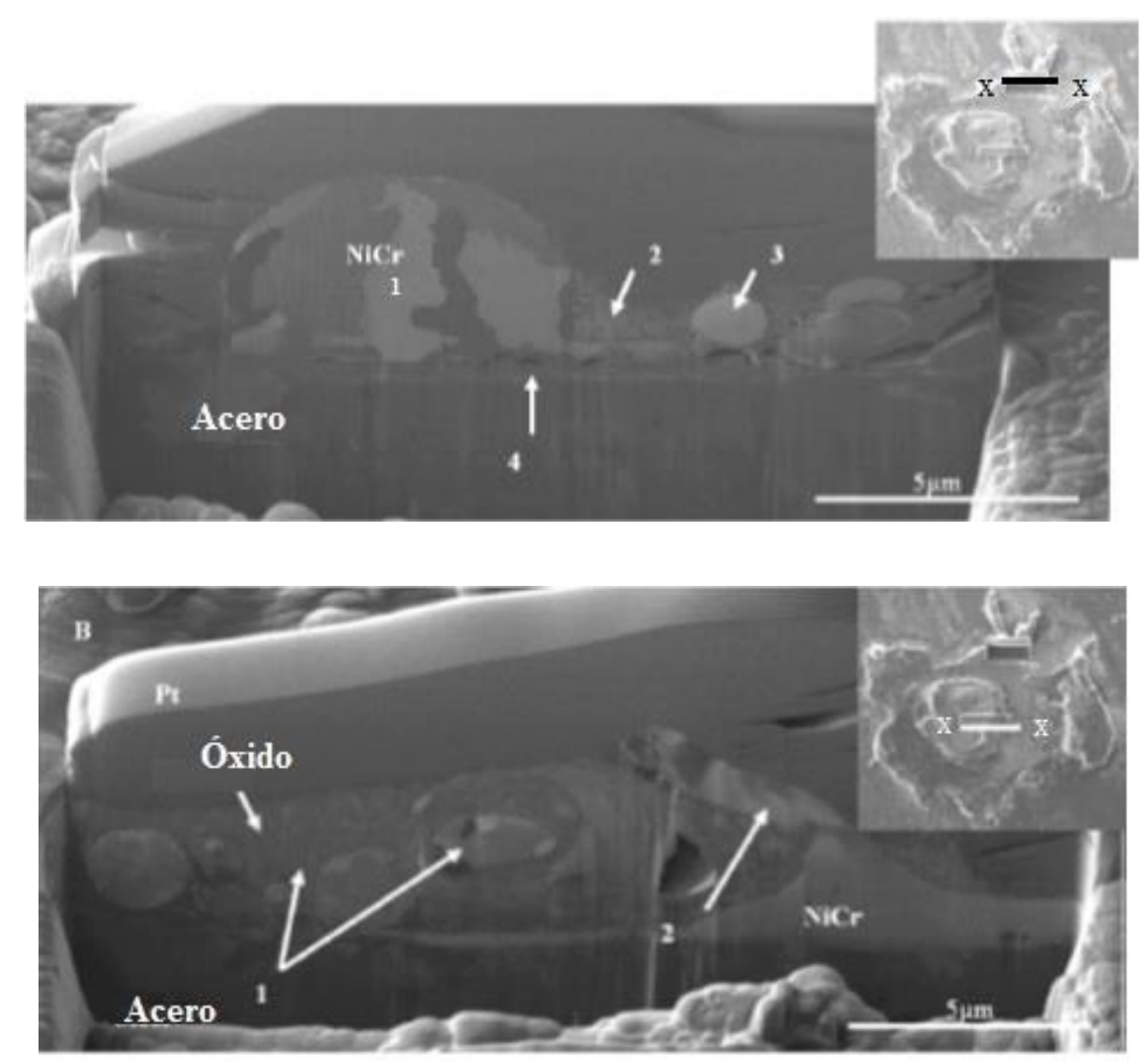

Figura 2.24 Sección transversal de una salpicadura de $\mathrm{NiCr}$ sobre sustrato de acero con forma floreada.

(a) Periferia, (b) Hueco central (Brossard, 2010). Las imágenes cuadradas en las esquinas superiores derechas muestran las vistas cenitales de la salpicadura y posiciones de los cortes en escala más reducida.

En la sección central se observa una mezcla de óxido y partículas de $\mathrm{NiCr}$, marca 1. La forma de la salpicadura de $\mathrm{NiCr}$, marca 2 , sugiere que el metal fundido ha sido empujado hacia arriba, lejos del sustrato. Este efecto podría estar asociado con el gas liberado por el sustrato, que se calienta por la salpicadura fundida, o atrapado durante el impacto, 
ocasionando una burbuja inestable. El óxido puede surgir de la oxidación del sustrato o la salpicadura debido a la presencia tanto de calor como de oxígeno. Las partículas incrustadas de $\mathrm{NiCr}$ son debidas a la inestabilidad de la evolución del gas desde la superficie el cual actúa para dispersar la salpicadura fundida.

Además de los factores mencionados, el ángulo de la pistola de proyección determina mediante la velocidad de impacto la forma de la salpicadura. Conforme disminuye este ángulo, las salpicaduras comienzan a ser cada vez más alargadas. La presión con la que la gota actúa sobre el sustrato disminuye con un factor del coseno de este ángulo. Esto ocasiona uniones mecánicas más débiles, con una peor transmisión de calor, y, consecuentemente, peor adherencia (Montavon et al., 1997).

\subsubsection{APLANAMIENTO}

El aplanamiento y el tamaño de grano o columna de la salpicadura resultante ha sido estudiado sistemáticamente para muchas combinaciones de material partícula/sustrato (Houben, 1984; Nogi et al., 1992; Montavon et al., 1995; Vardelle et al., 1997; Fukumoto y Huang, 1999; Fauchais et al., 2004). En algunos de los artículos se presentan modelos analíticos de formación de salpicaduras (Dykhuizen, 1994; Fauchais et al., 1997; Sobolev y Guilemany, 1999a; Vardelle et al., 2000; Armster et al., 2002).

La forma habitual de definir este aplanamiento es mediante el factor de alargamiento (grado de aplanamiento), definido como:

$$
\xi=\mathrm{D} / \mathrm{d}_{\mathrm{p}}
$$

donde $\mathrm{D}$ es el diámetro de la salpicadura, suponiéndola cilíndrica, $\mathrm{d}_{\mathrm{p}}$ es el diámetro de la gota que impacta.

Usando esta expresión, los estudios de Li muestran que las salpicaduras de alúmina por proyección por plasma usando polvo con un diámetro de partícula de $20 \mu \mathrm{m}$ tenían un espesor de $1,75 \mu \mathrm{m}(\mathrm{Li}, 1989)$. Este resultado corresponde a un grado de aplanamiento de 2,76 .

Si se consideran condiciones típicas de proyección térmica y suponiendo que la solidificación comienza cuando se completa el aplanamiento, la energía superficial es insignificante en comparación con la energía cinética, y $\xi$ se convierte en una función del 
número de Reynolds, Re, que cuantifica la disipación viscosa de las fuerzas de inercia:

$$
\xi=\mathrm{a} \cdot \operatorname{Re}^{\mathrm{b}}
$$

donde a y b son constantes, y Re es definido por $\rho v_{d} d_{p} / \mu$, donde $\rho$ es la densidad, $\nu_{d}$ es la velocidad de la gota y $\mu$ la viscosidad dinámica.

Los valores corrientes para esas constantes están en el rango de 0,5 a 1,294 para a y de 0,125 a 0,25 para b (Kang y Ng, 2006). Por ejemplo, Madejski usa 1,29 para a y 0,2 para b (Madejski, 1976). En otras referencias a varía entre 0,8, para una salpicadura floreada, y 1,294, para una salpicadura en forma de tortita, mientras que b puede ser $0,2,0,125 \mathrm{o}$ 0,167 (Fauchais al., 1997).

Al margen de esta expresión de $\xi$ considerando condiciones ideales, se han propuesto otras, que aparecen en los artículos de Kang y Ng (Kang y Ng, 2006), Vardelle et al. (Vardelle et al., 1995), Amada et al. (Amada, Tomoyasu et al., 1997; Amada, Haruyama et al., 2001) y Li et al. (Li et al., 2005).

Una de estas considera que si la salpicadura solidifica a medida que se extiende, se puede reducir su diámetro. El efecto de la solidificación en la restricción de elongación de la salpicadura se modela asumiendo que toda la energía cinética almacenada en la capa solidificada se pierde.

Otra expresión considera el máximo valor del factor de dispersión, definido en función de un nuevo parámetro, $\mathrm{s}^{*}$, calculado por $\mathrm{b}_{\mathrm{s}} / \mathrm{d}_{\mathrm{p}}$ y el número de Weber, We, es (Pasandideh-Fard, 1998):

$$
\xi=\sqrt{\frac{\mathrm{We}+12}{\frac{3}{8} \mathrm{We} \cdot \mathrm{s}^{*}+3(1-\cos \theta)+4 \frac{\mathrm{We}}{\sqrt{\mathrm{Re}}}}}
$$

donde $b_{s}$ es el espesor de la salpicadura cuando esta ha alcanzado su máxima extensión, y We es definido por $\rho v_{\mathrm{d}}{ }^{2} \mathrm{~d}_{\mathrm{p}} / \gamma$, que expresa la conversión de la energía cinética en energía superficial, donde $\gamma$ es la tensión superficial.

Hay modelos que incluyen la posibilidad de que la gota pueda rebotar, depositarse o fraccionarse, al menos parcialmente. Estos modelos son denominados incompresibles. 
Este fraccionamiento corresponde a la expulsión de gotas muy pequeñas principalmente en la dirección del impacto, en adelante "fraccionamiento de impacto" (impact splashing), figura 2.25 (Cedelle et al., 2004). Estos fenómenos han sido observados al menos para una gota de agua o etanol, (Armster et al., 2002; Mundo et al., 1995; Stow y Hadfiel, 1981; Escure et al., 2003) con valores críticos del parámetro de Sommerfeld, $\eta$, definido como:

$$
\eta=\mathrm{We}^{1 / 2} \cdot \mathrm{Re}^{1 / 4}
$$

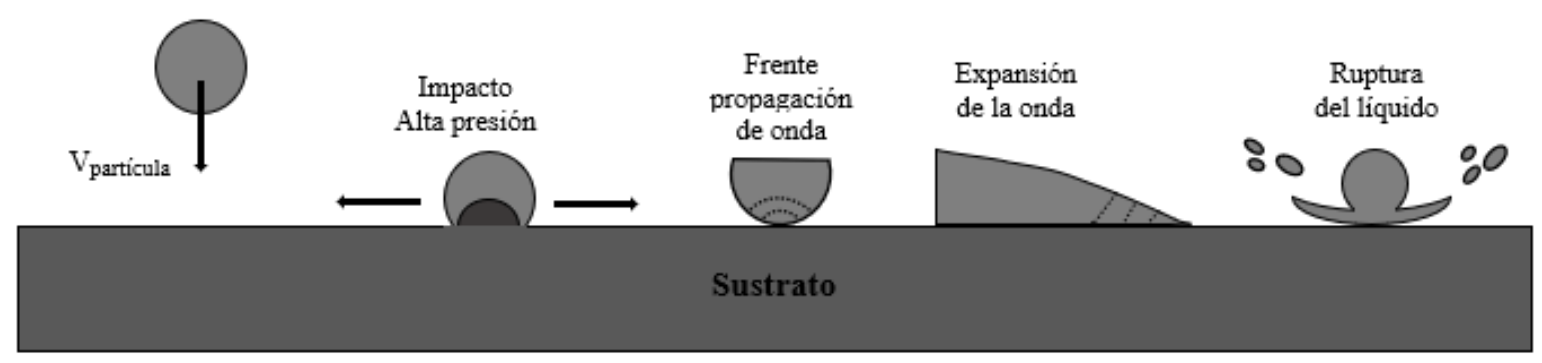

Figura 2.25 Esquema de propagación en el impacto con resultado de salpicadura (Cedelle et al, 2004).

Así, para $\eta$ menor a 3 la gota del líquido mencionado rebota, cuando es mayor que 58 se fracciona y para valores intermedios se deposita. Para una gota que no experimenta solidificación antes de finalizar el aplanamiento, el parámetro $\eta$ de Sommerfeld caracteriza los fenómenos en el impacto.

Siguiendo este modelo, Escure et al. investigaron las condiciones de deposición y fraccionamiento para valores de $\eta$ comprendidos entre 4 y 1800 y salpicaduras de alúmina sobre sustratos de acero inoxidable o alúmina, utilizando proyección por plasma en vacío (Escure C., 2000; Escure et al., 2001; Escure et al., 2003). La temperatura del sustrato de acero inoxidable varió entre 600 y $1100 \mathrm{~K}$ y la del sustrato de alúmina entre 600 y 2300 K. A $600 \mathrm{~K}$, los sustratos de acero inoxidable y alúmina están por encima de la temperatura de transición entre la forma de flor y la de tortita, que será tratada en el apartado 2.3.5, y sobre ellos se generan salpicaduras que no presentan aplanamiento (forma de tortita). A $2300 \mathrm{~K}$, el aplanamiento se produce sin solidificación si el sustrato es de alúmina.

En estos ensayos, la cantidad de gotas rebotadas, en el rango de $1 \mu \mathrm{m}$, aumenta con $\eta$ (Escure et al., 2003). Para partículas que impactan con un diámetro medio de aproximadamente $30 \mu \mathrm{m}$, las gotas rebotadas, con diámetros en el rango de algunos 
micrómetros, alcanzan distancias respecto del sustrato de aproximadamente $3 \mathrm{~mm}$. Además, estas distancias superan el espesor de la capa límite dinámica y, por lo que las partículas desprendidas son dispersadas por el flujo de plasma.

Contrariamente a lo que se observó con gotas de etanol, la transición entre la deposición $\mathrm{y}$ fraccionamiento no corresponde exactamente a $\eta=57,7$ (Mundo et al., 1995). Con estos sustratos, cualquiera que sea su temperatura, la deposición se produce para $\eta$ entre 4 y 70 , mientras que el fraccionamiento se observa a partir de $\eta=10$ y es común para $\eta>70$. Esta dispersión puede deberse al hecho de que la superficie lisa se vuelve rugosa después del impacto de 5 a 10 partículas y a la baja precisión en la estimación de $\eta$, del orden del $30 \%$.

En las condiciones habituales de procesos de proyección por plasma, los límites entre deposición y rebote no son precisos, pero la tendencia es la misma (Escure et al., 2003). Así, las partículas de alúmina proyectadas por un chorro de plasma DC, tienen valores de $\eta$ entre 50 y 1800, siendo más común la fragmentación que la deposición (Escure et al., 2003).

Al margen de estas expresiones que usan parámetros simples, se ha especulado sobre los aspectos a tener en cuenta durante el aplanamiento y se han desarrollado modelos más complejos. Así, Allen ha sugerido que las salpicaduras pueden ser resultado de las inestabilidades de Rayleigh-Taylor que ocurren cuando un fluido se acelera dentro de uno de menor densidad (Allen, 1975).

Un nuevo avance en estos modelos consistió en la incorporación de la tensión superficial del material líquido a través de la introducción de la inversa del número de Weber. Al comienzo del aplanamiento, cuando la velocidad $\mathrm{v}_{\mathrm{d}}$ es alta, como sucede en la proyección de plasma DC y la proyección supersónica de plasma RF, este valor no puede despreciarse. Algunas teorías también introducen el ángulo de contacto entre el sólido y el líquido que tiene un efecto apreciable al final del proceso de aplanamiento.

Los modelos que incluyen la compresión, debido a su complejidad, sólo se han utilizado para estudiar el inicio del impacto (Dykhuizen, 1994; Armster et al., 2002). Estos cálculos han demostrado que la presión de impacto de una gota esférica es mayor que la presión del clásico martillo de agua, $\rho_{\mathrm{imp}} \cdot \mathrm{c}_{\mathrm{l}} \cdot \mathrm{v}_{\mathrm{d}}$, donde $\mathrm{c}_{\mathrm{l}}$ es la velocidad del sonido en la fase líquida y $\rho_{\text {imp }}$ la densidad del líquido impactando. 
Según Armster et al. la compresibilidad gobierna el aplanamiento en el primer momento, cuando la gota golpea la superficie (Armster et al., 2002). La compresibilidad se caracteriza en el impacto por el número de Mach, $\mathrm{v}_{\mathrm{d}} / \mathrm{c}_{1}$. En ese momento, la velocidad del líquido cambia rápidamente y la onda propagada en el interior de la gota provoca que el líquido se comprima, figura 2.25. Así, para una gota de metal líquido impactando a 300 $\mathrm{m} / \mathrm{s}$, con una $\rho_{\mathrm{imp}}$ de aproximadamente $8000 \mathrm{~kg} / \mathrm{m}^{3}$, y c 1 de $3000 \mathrm{~m} / \mathrm{s}(\mathrm{Ma}=0,1)$; la presión de impacto es aproximadamente $7 \cdot 10^{9} \mathrm{~Pa}$ (70.000 atm) (Armster et al., 2002). Esta presión comienza a liberarse después de cierto tiempo

$$
\mathrm{t}_{\mathrm{c}} \sim \mathrm{d}_{\mathrm{p}} \cdot \mathrm{v}_{\mathrm{d}} /\left(4\left(\mathrm{c}_{\mathrm{l}}\right)^{2}\right)
$$

Así, con un radio de la gota de $20 \mu \mathrm{m}$, $\mathrm{t}_{\mathrm{c}}$ es aproximadamente $3 \cdot 10^{-10} \mathrm{~s}$, valor muy pequeño comparado con el tiempo de aplanamiento, alrededor de $10^{-6} \mathrm{~s}$. En ese momento, el radio de contacto es igual

$$
\mathrm{r}_{\mathrm{c}}=\mathrm{d}_{\mathrm{p}} \cdot \mathrm{v}_{\mathrm{d}} /\left(2 \mathrm{c}_{\mathrm{l}}\right)=\mathrm{d}_{\mathrm{p}} \cdot \mathrm{Ma} / 2
$$

siendo este radio de $2 \mu \mathrm{m}$ para los datos mencionados.

Si además el modelo incluye la posibilidad de solidificación durante el aplanamiento, este modelo debe considerar los siguientes factores: velocidad de enfriamiento, $\mathrm{Vr}$, proceso de solidificación y fraccionamiento de la salpicadura durante el proceso de aplanamiento. Por ello algunas expresiones sobre el aplanamiento serán tratadas al final del siguiente apartado.

\subsubsection{VELOCIDAD DE ENFRIAMIENTO}

Los modelos analíticos unidimensionales de transferencia de calor ofrecen aproximaciones del valor de $\mathrm{Vr}$, que dependen de los siguientes factores (Allen, 1975; Vardelle et al., 1995; Wang et al., 1998b; Sun et al., 2000; Fauchais et al., 1995): La calidad del contacto entre la salpicadura y el sustrato, el calor latente de fusión, la relación entre las difusividades térmicas de la salpicadura y el sustrato, especialmente para un contacto perfecto, y el valor inverso del espesor de la salpicadura.

En referencia al primer factor, uno de los modelos más simples que lo considera (Sobolev y Guilemany, 1999a, 1999b) proporciona una aproximación a la velocidad de 
enfriamiento, a través de la velocidad de solidificación en determinadas condiciones, mediante la siguiente expresión:

$$
\mathrm{V}_{\mathrm{s}}=\mathrm{h}_{\mathrm{i}} \cdot \mathrm{T}_{\mathrm{p}} /\left(\mathrm{L}_{\mathrm{s}} \cdot \rho\right)
$$

Donde $h_{i}$ el coeficiente del calor de transferencia en la interfase, $T_{p}$ la temperatura de la partícula, $L_{s}$ es el calor latente de solidificación y $\rho$ la densidad del material.

En esta expresión $h_{i}$ tiene un efecto radical sobre la velocidad de solidificación en la interfase, que comienza generalmente al final del proceso de aplanamiento, cuando la energía superficial llega a ser elevada (Sobolev y Guilemany, 1999a, 1999b; Vardelle et al., 1995; Dykhuizen, 1994; Fauchais et al., 1997).

Si el contacto es uniforme, $h_{i}$ puede expresarse en función del ángulo de contacto o mojado, figura 2.26, a través de la expresión

$$
\mathrm{h}_{\mathrm{i}}=0,5 \cdot \mathrm{h}_{\mathrm{c}} \cdot(1+\cos \theta)
$$

donde $h_{c}$ es el coeficiente de transferencia de calor en condiciones de contacto perfecto $(\theta=0)$. Este ángulo será tratado con más detalle en el apartado 2.4.1.

Aunque la definición de h más clásica relaciona esta propiedad con el flujo de calor, en la práctica, se suele sustituir por la inversa de su valor, dando lugar a la resistencia térmica de contacto, $\mathrm{R}_{\mathrm{th}}$. Este parámetro permite cuantificar la calidad del contacto entre la salpicadura y la capa subyacente. Así, se considera que un contacto perfecto corresponde a $\mathrm{R}_{\mathrm{th}} \sim 10^{-8} \mathrm{~m}^{2} \mathrm{~K} / \mathrm{W}$ mientras que un contacto pobre presenta un valor de alrededor de $10^{-6} \mathrm{~m}^{2} \mathrm{~K} / \mathrm{W}$.

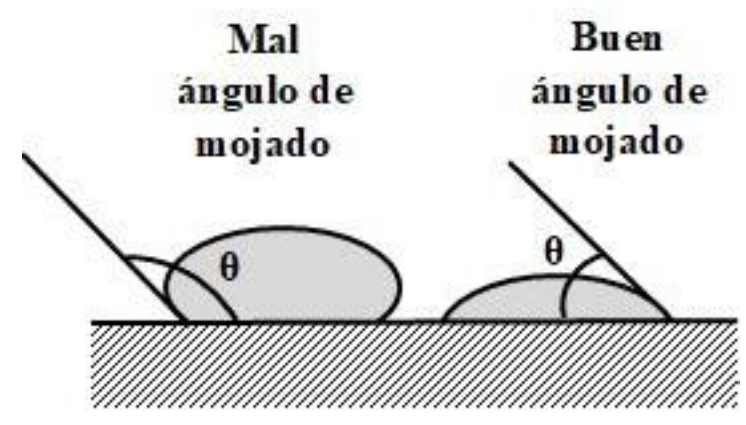

Figura 2.26 Ángulos de mojado (Fauchais et al., 1997).

Una vez definido el coeficiente de transferencia de calor en la interfase, es necesario 
mencionar que los experimentos de caída libre similares a los de Fukumoto, Liu (Liu et al., 1995), Hofmeister (Hofmeister y Bayuzick, 1998) y Bennett (Bennett y Poulikakos, 1994) permiten una buena aproximación de este parámetro (Fauchais, 2004).

Siguiendo el orden elegido en la enumeración al principio de este apartado, se va a analizar la influencia del calor latente de fusión. Para ello resulta interesante utilizar el número de Stephan, que es una medida del tiempo de solidificación:

$$
\text { Ste }_{\mathrm{s}}=\mathrm{C}_{\mathrm{p}, \mathrm{s}} \cdot\left(\mathrm{T}_{\mathrm{m}}-\mathrm{T}_{\text {sust }}\right) / \mathrm{L}_{\mathrm{s}}
$$

donde $\mathrm{C}_{\mathrm{p}, \mathrm{s}}$ es la capacidad calorífica de la fase sólida y $\mathrm{T}_{\mathrm{m}}$ la temperatura del metal fundido.

A veces también se define para la fase líquida como

$$
\mathrm{Ste}_{\mathrm{l}}=\mathrm{C}_{\mathrm{p}, 1} \cdot\left(\mathrm{T}_{\mathrm{p}}-\mathrm{T}_{\mathrm{m}}\right) / \mathrm{L}_{\mathrm{f}}
$$

donde $\mathrm{C}_{\mathrm{p}, 1}$ es la capacidad calorífica de la fase líquida, y $\mathrm{T}_{\mathrm{p}}$ la temperatura de la gota en el comienzo del impacto.

Si nos centramos en otro de los factores enumerados, el espesor de la salpicadura, es interesante comentar la relación de este factor con el procedimiento de proyección térmica utilizado. Por tanto, Vr será mucho menor con una proyección subsónica de plasma RF, con menor espesor de salpicadura, que con una de plasma DC, con mayor espesor. Además, Vr debería ser más alta en la periferia de la gota aplanada, siempre que el contacto sea perfecto. Precisamente esto no sucede en el borde, donde la presión de contacto es muy baja y la tensión superficial es máxima. Con estas condiciones, se produce un rizado en la salpicadura, que se despega del sustrato, induciendo así un enfriamiento más lento por no estar en contacto con el sustrato.

En cambio, en el interior de la salpicadura, el contacto con el sustrato es bueno y el grosor de esta es menor, por lo que podría pensarse que la solidificación podría empezar allí. Sin embargo, esta área podría estar definida por un radio mayor que el doble del de la gota que impacta, no siendo suficiente la presión que ejerce la salpicadura sobre el sustrato para superar la presión de condensados o adsorbatos del sustrato evaporados. Además, las asperezas del sustrato dificultan el proceso de expansión, produciendo una alta resistencia térmica en el contacto. Por tanto, la solidificación comenzará en un área donde 
el espesor es menor pero la presión de impacto es mayor.

Una vez considerados los factores que influyen en $\mathrm{Vr}$, se van a estudiar las características de la salpicadura ya solidificadas y enfriadas que permitan estimar este valor. En este sentido, el tamaño de las columnas dentro de las salpicaduras, permite establecer rangos para Vr. Así, los valores altos de este parámetro en la proyección por plasma, hasta $10^{9}$ $\mathrm{K} / \mathrm{s}$, suelen generar una nucleación heterogénea que comienza en contacto con el material subyacente; siendo posible establecer correlaciones mediante la teoría clásica de la nucleación en régimen estacionario (Fauchais et al., 1995; Pasandideh-Fard et al., 1998, 2002; Robert, 1998). En estas ecuaciones, el cambio crítico de energía libre necesario para alcanzar un tamaño crítico del germen está relacionado con el ángulo de contacto.

En este sentido, también resulta de interés el trabajo de varios investigadores que analizaron el proceso de aplanamiento y solidificación conjuntamente, incluyendo la velocidad de enfriamiento en sus consideraciones. De esta forma, Gougeon y Moreau estimaron que el material líquido se extendía hasta que la energía cinética se disipaba completamente, en ese momento la tensión superficial contraía la gota. Esta hipótesis ha sido corroborada a partir del análisis de la evolución del área de una salpicadura de molibdeno sobre vidrio, medida mediante un método de atenuación láser (Gougeon y Moreau, 2001). El área de aplanamiento tiende a aumentar hasta que se produce una disminución rápida en una relación de entre 2 y 4 . Al final del proceso de aplanamiento, comienza la solidificación, especialmente en las proximidades de la periferia de la salpicadura, donde el espesor es menor. Este cambio de estado físico puede impedir el flujo del líquido y generar una división en varios flujos, aunque este continuará casi paralelo a la superficie del sustrato y dará como resultado salpicaduras con prolongaciones tentaculares.

Un fenómeno similar ocurrirá cuando el flujo del líquido encuentre asperezas superficiales. El efecto de la rugosidad del sustrato se observa en la figura 2.27, que representa varias gotas de estaño de 2,2 $\mathrm{mm}$ de diámetro después de impactar sobre el sustrato. La evolución temporal se observa en la dirección vertical descendente y el efecto de la rugosidad superficial, $\mathrm{R}_{\mathrm{a}}$, en la dirección horizontal.

Se puede comprobar que una menor rugosidad superficial permite que la salpicadura tenga más libertad en el proceso de contracción, como ocurre al final de la primera 
columna. Por el contrario, en la última columna, con mayor rugosidad superficial, la salpicadura tiene más dificultades para contraerse. Finalmente, la última imagen de la segunda columna muestra que el proceso de contracción es más inestable y la gota parece dividirse en dos núcleos unidos por una hebra estrecha.

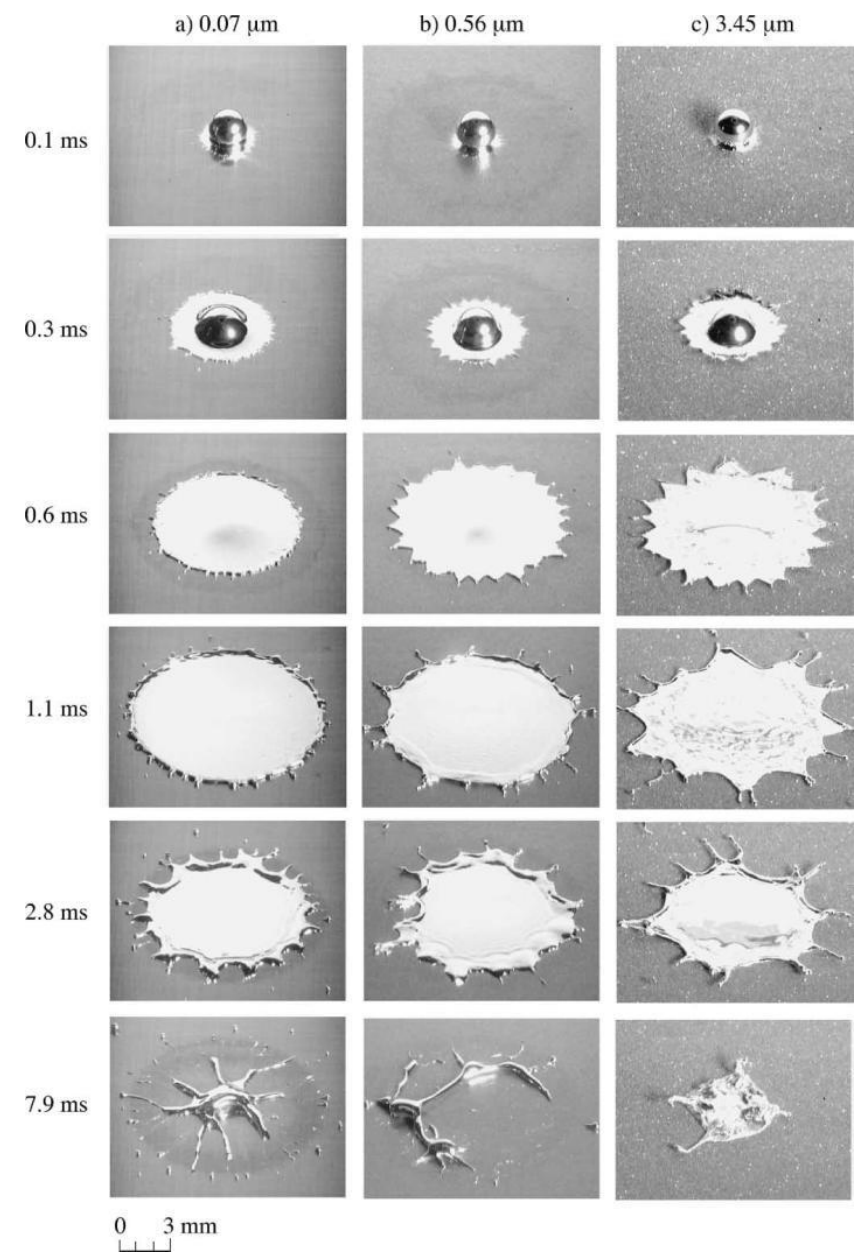

Figura 2.27 Impacto de una gota de estaño sobre una lámina de acero inoxidable con diferentes rugosidades superficiales (Shakeri y Chandra, 2002).

\subsubsection{TEMPERATURA DE TRANSICIÓN DE FORMA DE SALPICADURA}

Una vez planteadas las definiciones y consideraciones básicas, conviene centrarse en dos parámetros fundamentales: características superficiales y temperatura inicial del sustrato, generalmente precalentado. Estos parámetros modifican la velocidad de enfriamiento y generan tipos distintos de salpicaduras.

Si se consideran únicamente sustratos lisos, $\mathrm{R}_{\mathrm{a}}$ inferior a $0,5 \mu \mathrm{m}$, y la temperatura inicial del sustrato es inferior a una temperatura determinada, que depende del material del sustrato y del polvo de proyección, las salpicaduras comienzan a adoptar forma de flor. 
En caso contrario la forma predominante es de tortita, llamándose sus ramificaciones radiales "prolongación radial de aplanamiento" (flattening splashing), que es conveniente diferenciar del "fraccionamiento de impacto" definido anteriormente. Fukumoto et al. definieron este valor como temperatura de transición, $T_{t}$ (Fukumoto et al., 1995b). El cambio de forma de la salpicadura con la temperatura del sustrato también ha sido reconocido por Houben (Houben, 1984).

Para buscar la causa de este cambio de forma con la temperatura, y la existencia de esta temperatura umbral, es necesario establecer la relación entre este parámetro y la presencia de contaminantes en la superficie a revestir. Así, en sustratos con temperatura inicial baja, la base de las salpicaduras muestra numerosos poros y estructuras que han solidificado rápidamente, lo que implica que la solidificación comienza en puntos distribuidos de manera irregular en la base, que a su vez alteran el flujo del resto de material aún líquido (Safai y Herman, 1977; Sampath y Herman, 1996; Inada y Yang, 1994).

A temperaturas del substrato mayores que $T_{t}$, casi no se observan poros. En estos casos la parte sólida parece bastante plana y densa en más del 50-60\% de su base, por lo que es más probable que la solidificación se haya producido tras el aplanamiento. Algunas simulaciones numéricas de Mostaghimi apoyan esta hipótesis (Mostaghimi et al., 2002). Además, el precalentamiento del sustrato a una temperatura mayor que $\mathrm{T}_{\mathrm{t}}$ puede dar lugar a la generación de una capa superficial de óxido en el sustrato, generando, en contra de lo esperado, perfiles con tentáculos (Bianchi, Leger et al., 1997).

La temperatura de transición, independientemente de la temperatura del sustrato, está condicionada por la desorción de adsorbatos y condensados en la superficie del sustrato, la mojabilidad del sustrato por el material líquido y los efectos de solidificación. (Fauchais et al., 2004; Houben, 1984; Fukumoto et al., 1995a, 1998, 1999, 2000, 2001, 2002; Bianchi, 1995; Sakakibara et al., 2000; Pershin et al., 2001b; Safai y Herman, 1977; Sampath y Herman, 1996; Inada y Yang, 1994; Mostaghimi et al., 2002; Mehdizadeh et al., 2002; Huang et al., 1996; Fukumoto y Huang, 1999; Tanaka y Fukumoto, 1999, 2001; Nishioka et al., 2001).

La mojabilidad también determina la presencia de óxidos, dada la relación entre la energía libre estándar de formación de la capa de óxido sobre el sustrato y el valor estático de esta propiedad del metal fundido (Suganuma, 1990). Se supone también que esta relación es 
aplicable a la mojabilidad dinámica, que será analizada en el apartado 2.4.1 con mayor detalle.

Para conocer el efecto de la mojabilidad sobre la temperatura de transición, resulta conveniente recurrir a los análisis de la morfología de salpicaduras de alúmina proyectada con plasma DC sobre un sustrato de acero inoxidable recubierto parcialmente con oro. La temperatura del sustrato estaba por debajo de la temperatura de transición del oro y próxima a la del acero inoxidable. En estos ensayos se observó media salpicadura en forma de flor sobre el sustrato recubierto de oro y la otra media con forma de tortita sobre el sustrato desnudo, figura 2.28 (a). Además, en la superficie desnuda, probablemente se formó el reborde de la tortita sin ninguna solidificación inicial, figura 2.28 (b). Así, la segunda figura muestra que la dicha solidificación, iniciada en forma de flor sobre el sustrato de oro, tal y como determina la temperatura de transición en este sustrato, cambia de forma al llegar a una porción reducida del sustrato de acero, cumpliendo con la condición de la temperatura de transición en este otro sustrato. Esto no parece poder explicarse mediante una temperatura de transición, que determina el comienzo de la solidificación, sino más bien por la mojabilidad. Expresado de otro modo, dado que el sustrato revestido de oro presenta la peor mojabilidad para esa temperatura del sustrato, tiene, por tanto, la temperatura de transición más alta.

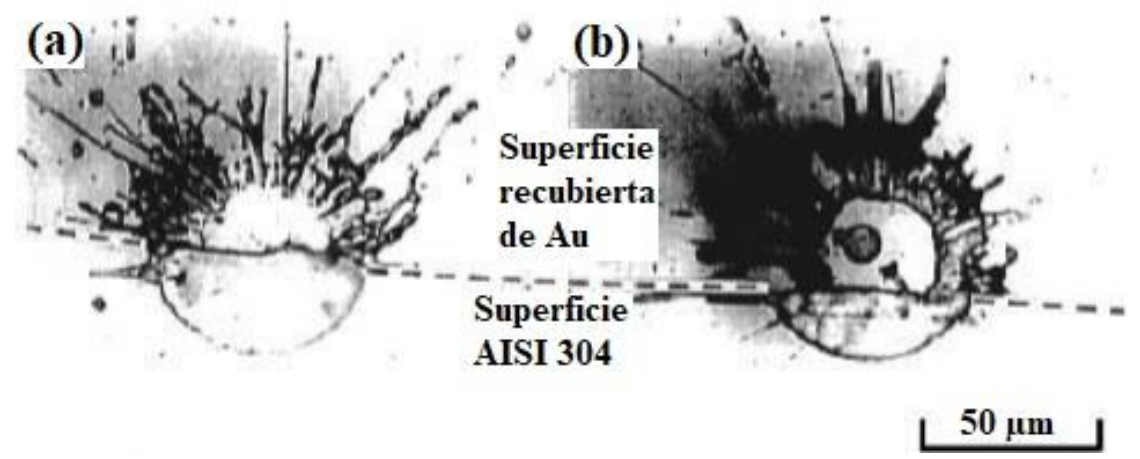

Figura 2.28 Morfología del contorno de una salpicadura de alúmina entre el revestimiento de oro y el sustrato de acero inoxidable: (a) forma de tortita, flor y (b) corona (Tanaka y Fukumoto, 2001).

La figura 2.29, que representa la relación entre la mojabilidad de las salpicaduras y la temperatura del sustrato, merece un comentario detallado. Incluye tres curvas que se elevan hacia la derecha y su margen derecho muestra el tipo de salpicadura obtenida. Las dos bandas horizontales sombreadas corresponden a distintos tipos de salpicadura en forma de flor: la inferior corresponde a una solidificación inicial rápida, y la superior 
corresponde a salpicaduras en forma de corona. En el caso de que el sustrato esté a temperatura ambiente, punto a en las curvas B y C (banda sombreada inferior), se forma una trazado tentacular aunque no se produce solidificación en la fase inicial del aplanamiento. Si la condición de mojabilidad sobrepasa el valor máximo de la banda inferior, punto c (temperatura ambiente) en la curva $\mathrm{A}, \mathrm{ob}$ (por encima de la temperatura ambiente) en las curvas B y C, se obtendrá una salpicadura con forma de corona. Por encima de estas bandas sombreadas se generan discos (tortitas). Las temperaturas de transición aumentan con la temperatura del sustrato, que mejoran la mojabilidad del material.

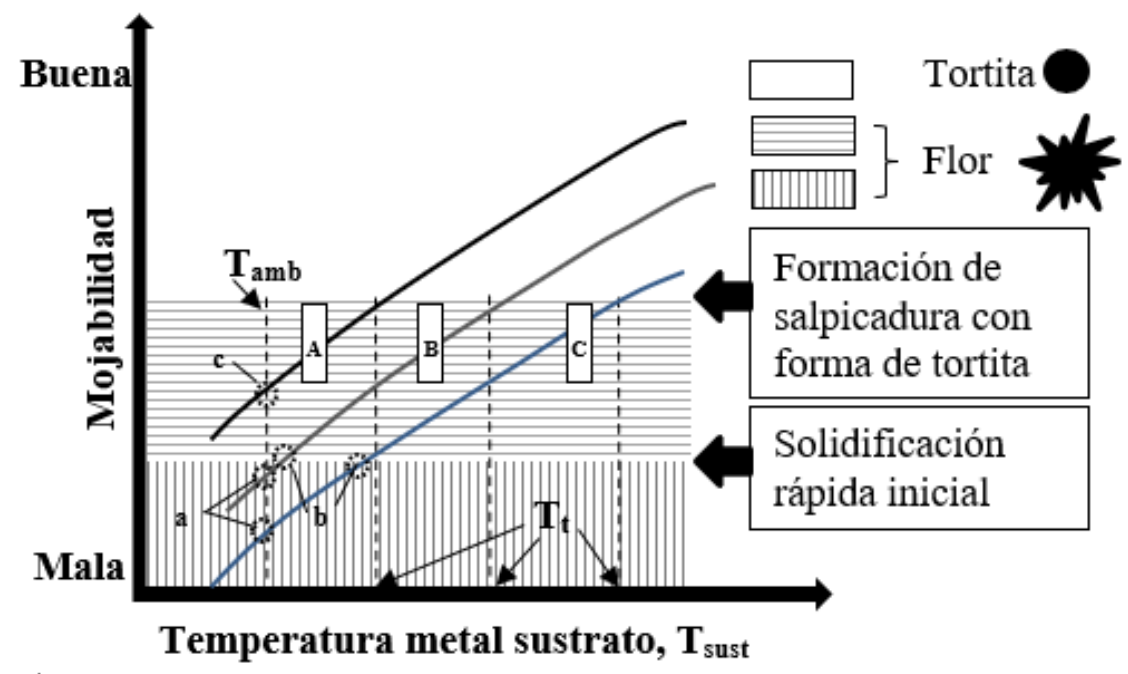

Figura 2.29 Relación entre la mojabilidad y el patrón de salpicadura (Tanaka y Fukumoto, 2001).

A pesar de que la mojabilidad de la interfase, la temperatura y la viscosidad de las partículas eran diferentes en las combinaciones de materiales usadas, se pudo observar una relación lineal entre $\mathrm{T}_{\mathrm{t}} \mathrm{y}$ la conductividad térmica de las partículas para cada material, figura 2.30. Esta relación indica que el aplanamiento de las partículas podría estar unido a su conductividad térmica.

Se puede concluir que el mojado en la interfase salpicadura-sustrato parece ser el factor dominante con respecto al aplanamiento, aunque la solidificación en la interfase altera la transmisión de calor e influye en el aplanamiento. Así, la observación SEM de una salpicadura de Ni de tamaño milimétrico sobre un sustrato revestido de oro muestra que la película de oro se rompió en el lugar donde la gota de Ni chocó, mientras permaneció intacta en la región entre el disco central y las proyecciones radiales. De este resultado se 
deduce que la propagación del líquido no se debe al flujo de material líquido sobre la superficie del sustrato desde el punto de impacto hasta la periferia, sino a un chorro paralelo al sustrato proveniente de la parte superior del material fundido (Tanaka y Fukumoto, 2001).

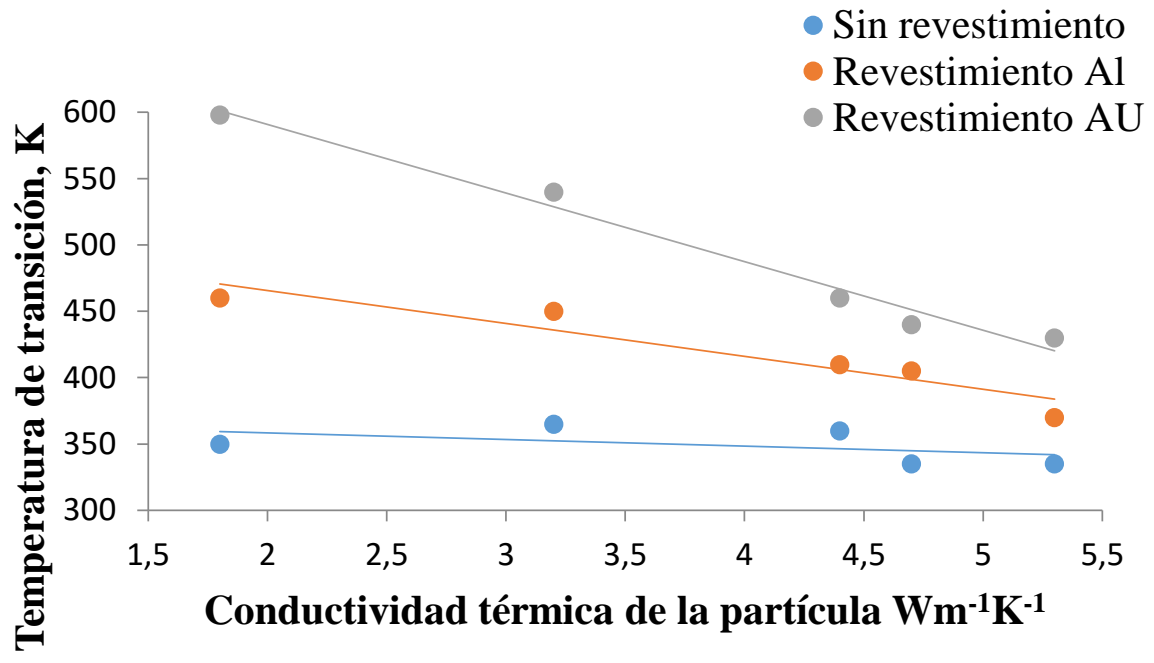

Figura 2.30 Variación de la temperatura de transición con la conductividad térmica de la partícula que impacta (Tanaka y Fukumoto, 2001).

En línea con lo anterior, los cambios de mojabilidad pueden explicar comportamientos sorprendentes en la solidificación de salpicaduras. Así, la velocidad de solidificación de estas sobre un sustrato mantenido a temperatura ambiente es considerablemente más baja que sobre un sustrato a alta temperatura, tal y como muestra la figura 2.31 (izda.). En ella aparece la sección transversal de una salpicadura de Ni sobre acero inoxidable, obtenida mediante impacto por caída libre a temperatura ambiente (Fukumoto et al., 2000; Fukumoto et al., 2002), con una estructura de grano grueso isotrópico típica en enfriamientos lentos. Sin embargo, la solidificada en un sustrato con una alta temperatura inicial, figura 2.31 (dcha.), tiene una estructura columnar fina. Resultados similares se obtuvieron con salpicaduras de alúmina o zirconia depositadas sobre sustratos de acero inoxidable (Pasandideh-Fard et al., 1998).

Tras mencionar los aspectos más importantes del efecto de la mojabilidad sobre la temperatura de transición, se va a tratar ahora la desorción de adsorbatos y condensados en la superficie del sustrato. Para estudiar su efecto, Li et al. depositaron sustancias evaporables (xileno, glicol y glicerol) con diferentes puntos de ebullición (417, 471 y 563 $\mathrm{K}$, respectivamente) sobre un sustrato de acero inoxidable pulido, $\mathrm{Ra}<0,05 \mu \mathrm{m}$, 
utilizando el precalentamiento para controlar su presencia (Li, Li y Wang, 1998; Li et al., 1999). Los materiales esparcidos con plasma fueron $\mathrm{Al}, \mathrm{Ni}, \mathrm{Cu}, \mathrm{Al}_{2} \mathrm{O}_{3}$ y $\mathrm{Mo}$. Los resultados muestran que, con excepción del Mo, la presencia de una sustancia evaporable en la superficie afecta significativamente al proceso de aplanamiento. Tan pronto como el sustrato es precalentado $50 \mathrm{~K}$ sobre la temperatura de ebullición de la película orgánica, que también corresponde para los sistemas estudiados a una temperatura del sustrato mayor que la de transición, se obtienen salpicaduras en forma de tortita. Las salpicaduras presentan grandes tentáculos cuando el sustrato está por debajo de la temperatura de evaporación.

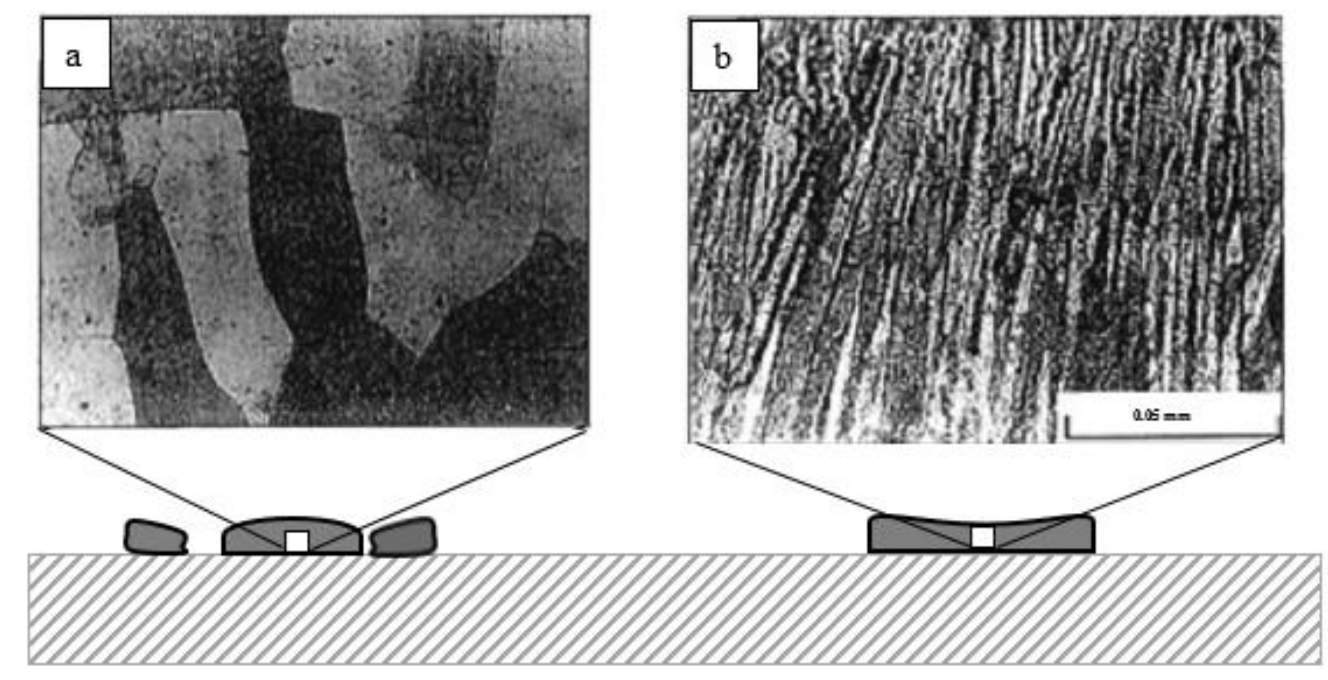

Figura 2.31. Microestructuras transversales de salpicaduras de níquel en un sustrato de acero inoxidable 304L con temperaturas de sustrato: 300K (izda.) y $600 \mathrm{~K}$ (dcha.) (Fukumoto et al., 2000).

Como se ha mencionado en el párrafo anterior, para el molibdeno, el precalentamiento del sustrato casi no tiene efecto, y nunca se obtienen salpicaduras en forma de tortita. Probablemente la evaporación de la capa orgánica tras el impacto de la gota fundida induce el fraccionamiento, cambiando las direcciones de flujo en la periferia de la salpicadura (Li, Li y Wang, 1998; Li et al., 1999).

La temperatura de transición también se observó en experimentos a baja presión (Fukumoto et al., 2000; Sakakibara et al., 2000; Jiang et al., 2001). De esta forma, Fukumoto et al. han demostrado que con gotas de $\mathrm{Cu}$ (Fukumoto et al., 2000) o Ni, (Sakakibara et al., 2000) de $2 \mathrm{~mm}$ de diámetro que impactan sobre un sustrato de acero inoxidable 304L, la temperatura de transición depende también de una presión crítica en la cámara, $\mathrm{p}_{\mathrm{t}}$. Por debajo de $\mathrm{p}_{\mathrm{t}}$, la transición ya no depende de la temperatura del sustrato 
como se ilustra en la figura 2.32. A presión atmosférica, curva a de la figura 2.32, y temperaturas superiores a $500 \mathrm{~K}$ tiene lugar la transición a forma de tortita y, a más de $600 \mathrm{~K}$, los tamaños de las columnas son bastante pequeños.

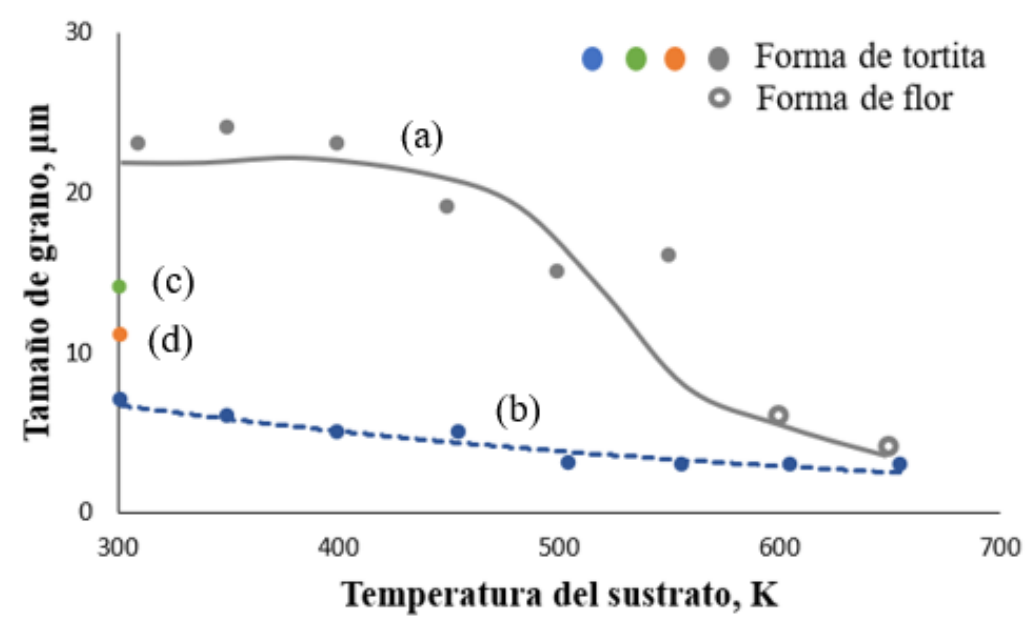

Figura 2.32. Tamaño del grano de una salpicadura de Ni con distintas condiciones de proyección: curva de ajuste (a) obtenida a presión atmosférica, curva (b) obtenida a baja presión, 10 Pa sobre un sustrato pulido, punto (c) obtenido a presión atmosférica y punto (d) obtenido en bajo vacío (Fukumoto et al., 2002).

Una vez que el sustrato ha sido precalentado ya sea en aire o vacío suave, los tamaños de columna son bastante pequeños (puntos c y d en la figura 2.32). Cuando el sustrato se deja a temperatura ambiente a una presión de $10 \mathrm{~Pa}$, el tamaño de la columna es pequeño incluso a $300 \mathrm{~K}$ y disminuye un poco cuando la temperatura del sustrato aumenta. Así, se puede suponer que la desorción de adsorbatos y condensados promueve la aparición de salpicaduras en forma de tortita (Fukumoto et al., 2000; Sakakibara et al., 2000; Jiang et al., 2001, Li, Li y Wang, 1998). Esta hipótesis también fue usada por Pershin et al. al considerar el impacto de partículas de alúmina proyectadas por plasma sobre acero inoxidable y vidrio, donde las temperaturas variaron en el rango de $20-500{ }^{\circ} \mathrm{C}$ (Pershin et al., 2001a).

Además de los adsorbatos y condensados se han estudiado el efecto de los óxidos sobre el sustrato, ya que la composición, rugosidad y grosor de esta capa juegan también un papel muy relevante en la formación de la salpicadura y su Vr (Maître et al., 2002; Valette et al., 2003; Pech et al., 1999a, 1999b; Valette et al., 2004; Haure, 2003; Espié et al., 1999; Trapaga et al., 2003). Estas características varían para el mismo metal o aleación con la temperatura de precalentamiento, la cinética de precalentamiento y el tiempo 
durante el cual se precalienta el sustrato.

Aparte de los efectos mencionados producidos por la temperatura de precalentamiento, esta tiene gran peso en el crecimiento de la capa de óxido, que sigue una ley cinética de tipo Arrhenius.

El tiempo de precalentamiento está relacionado con el espesor de la capa de óxido, pero no cambia su composición (American Welding Society, 1999). Cuando la capa de óxido es delgada, aproximadamente $10 \mathrm{~nm}$, como con las aleaciones de titanio o los aceros inoxidables, puede fundirse y formar un óxido intermedio que refuerza la adherencia de la lámina. Este es el caso de sustratos de titanio, donde la capa de $\mathrm{TiO}_{2}$ se funde por el impacto de partículas de alúmina líquida formando $\mathrm{TiAl}_{2} \mathrm{O}_{5}$, que permite lograr una adhesión muy buena (superior a $50 \mathrm{MPa}$ ) sobre sustrato liso, $\mathrm{R}_{\mathrm{a}}<0,05$ (Pech et al., 1999a). Por el contrario, con acero inoxidable, la capa de espinela en la superficie, incluso cuando se funde, no puede reaccionar con alúmina líquida y la adherencia es bastante baja.

Cuando la capa de óxido es gruesa, como sucede con el acero de bajo contenido en carbono, donde la capa de hematita puede alcanzar unos pocos micrómetros, no puede producirse fusión y la adhesión es puramente mecánica.

Dada la influencia de la fusión del sustrato durante el impacto, se puede comprender fácilmente la necesidad de encontrar un parámetro que represente dicha fusión. Ese parámetro es la efusividad de las partículas, que se define por:

$$
\mathrm{e}_{\mathrm{p}}=\sqrt{\rho_{\mathrm{p}} \cdot \mathrm{c}_{\mathrm{p}} \cdot \mathrm{K}_{\mathrm{p}}}
$$

donde $c_{p}, \rho_{p}$ y $K_{p}$ representan el calor específico a presión constante, la densidad y la conductividad térmica de la partícula, respectivamente.

Así, el molibdeno, con una efusividad, $\mathrm{e}_{\mathrm{Mo}}$, superior a la del acero inoxidable, $\mathrm{e}_{\mathrm{ss}}$, puede provocar la fusión del sustrato en el impacto. La fusión se observa efectivamente en el cráter formado por debajo del impacto de las partículas (Jiang et al., 2000). Este cráter condiciona la forma de la salpicadura (Armster et al., 2002). Sin embargo, con el aumento de la temperatura del sustrato, la salpicadura cambia de floreada a tortita. Esto subraya, una vez más, la importancia de la temperatura de transición. Resultados similares fueron 
obtenidos por Li et al. (Li, Li, Wang et al., 1998).

Para acabar este apartado, y considerando que se ha definido ya la temperatura de transición, $T_{t}$, se presenta una expresión que permite calcular la velocidad de aplanamiento considerando la temperatura del sustrato.

Este parámetro determina la forma de la salpicadura independientemente de la velocidad de impacto de las partículas. Así, para velocidades entre 30 y 300 m/s las salpicaduras tienen forma de tortita tan pronto como la temperatura del sustrato está por encima de la temperatura de transición. Por tanto, la fase final del aplanamiento de salpicaduras, cuando $\mathrm{T}_{\text {sust }}<\mathrm{T}_{\mathrm{t}}$ depende del flujo de líquido, $\mathrm{v}_{\mathrm{f}}$. Esta velocidad depende de la velocidad inicial de la partícula, $\mathrm{v}_{\mathrm{d}}$, pero también del espesor del líquido que determina el $\mathrm{Vr}$ de la salpicadura, con relaciones de $\mathrm{v}_{\mathrm{d}} / \mathrm{v}_{\mathrm{f}}$ de hasta 10 para la misma temperatura de impacto, $\mathrm{T}_{\mathrm{p}}$.

En la literatura especializada se utiliza otro parámetro para estudiar el aplanamiento, que utiliza la velocidad máxima de aplanamiento, $v_{a p}$, y el espesor de la salpicadura, $b_{s}$. Este parámetro, $\mathrm{K}_{\mathrm{f}}$, se define como

$$
\mathrm{K}_{\mathrm{f}}=\mathrm{We}_{\mathrm{f}}^{0,5} \cdot \operatorname{Re}_{\mathrm{f}}^{0,25}=\rho^{0,75} \mathrm{~b}_{\mathrm{s}}^{0,75} \mathrm{v}_{\mathrm{ap}}^{1,25} / \gamma^{0,5} \mu^{0,25}
$$

donde $\gamma$ es el coeficiente de tensión superficial y $\mu$ la viscosidad dinámica de la gota.

La máxima velocidad de aplanamiento cambia con la temperatura del sustrato. Esta está relacionada con $\mathrm{v}_{\mathrm{d}}$ mediante

$$
\mathrm{v}_{\mathrm{ap}}=\mathrm{a}_{\mathrm{tv}} \cdot \mathrm{v}_{\mathrm{d}}
$$

El parámetro atv es una función tanto de la temperatura del sustrato como de la velocidad de impacto. La forma esférica original se convierte en una cilíndrica justo después del impacto y $b_{s}$ se puede obtener de la ecuación de conservación de la masa:

$$
b_{\mathrm{s}}=2 \mathrm{~d}_{\mathrm{p}}^{3} / 3 \mathrm{D}^{2}
$$

donde $\mathrm{D}$ es el diámetro de la salpicadura.

Esta expresión utiliza la relación de aplanamiento de Madejski: 


$$
b_{s}=0,4 \cdot d_{p} \cdot R e^{-0,4}
$$

Y K $\mathrm{K}_{\mathrm{f}}$, basado en el parámetro de aplanamiento, viene dado por

$$
\mathrm{K}_{\mathrm{f}}=0,5 \cdot \mathrm{a}_{\mathrm{tv}}^{1,25} \operatorname{Re}^{-0.3} \cdot \eta
$$

Para evaluar $\mathrm{K}_{\mathrm{f}}$ y la morfología de la salpicadura se requiere un valor concreto de $\mathrm{a}_{\mathrm{tv}}$. Sin embargo, la velocidad de aplanamiento no puede medirse debido a que éste es demasiado rápido (aproximadamente $1 \mu$ s en proyección de plasma DC). Por lo tanto, se usó un experimento con gotas en caída libre bajo números de Reynolds y Peclet equivalentes a los experimentados en la proyección térmica. Los resultados experimentales, en el caso de gotas de Ni que impactan sobre un sustrato de acero inoxidable, se representan en la figura 2.33 .

A partir de estos ensayos, se obtuvo un valor de a decreciente con $\mathrm{T}_{\text {sust, }}$, con un salto cuando la temperatura del sustrato alcanza el valor $\mathrm{T}_{\mathrm{t}}$. Es decir, cuando la salpicadura adopta la forma de tortita, la velocidad de aplanamiento disminuye súbitamente. Por lo tanto, el aplanamiento se debe al rápido flujo de líquido durante este proceso. De ello se deduce que a medida que $T_{\text {sust }}$ aumenta, $K_{f}$ disminuye gradualmente con una discontinuidad para una temperatura del sustrato de $\mathrm{T}_{\mathrm{t}}$. Cuando $\mathrm{T}_{\text {sust }}$ es igual a $\mathrm{T}_{\mathrm{t}}$, el valor crítico de $\mathrm{K}_{\mathrm{f}}, \mathrm{K}_{\mathrm{f}}^{\mathrm{c}}$, es aproximadamente 7 . Por tanto, si $\mathrm{K}_{\mathrm{f}}$ es menor que 7, la salpicadura tiene forma de tortita; mientras que si es mayor tendrá forma de flor.

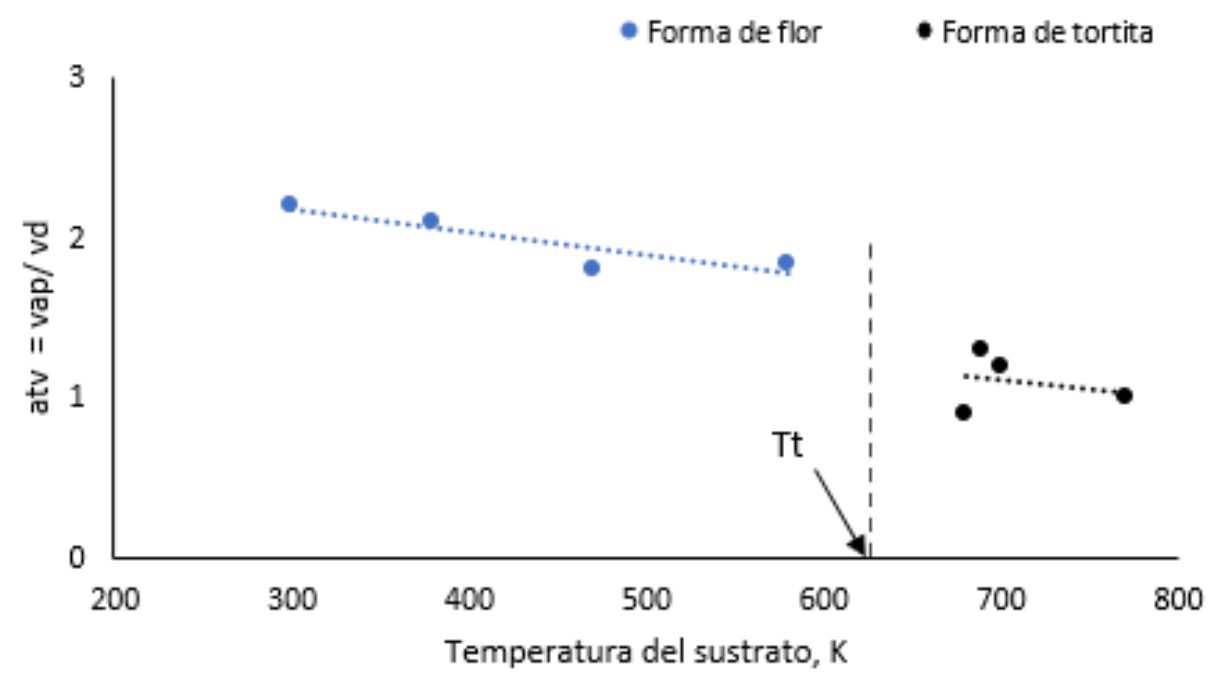

Figura 2.33 Relación entre el parámetro a y la temperatura del substrato para gotas de Ni de 2mm de diámetro y $\mathrm{V}_{\mathrm{d}}$ de 4,2 m/s $(\mathrm{Re}=12103$ y We=157) (Fukumoto et al, 2001). 


\subsubsection{ADHESIÓN}

La adhesión depende de varios mecanismos, incluyendo reacción química, difusión y enclavamiento mecánico (American Welding Society, 1999; Pawlowski, 1995).

La reacción química se produce sólo si la partícula que hace impacto funde localmente el sustrato, formándose un nuevo compuesto si ambos líquidos se difunden. En sustratos a temperatura ambiente, la reacción química sólo puede producirse si la efusividad de las partículas es mayor que la del sustrato. Para revestimientos de alto punto de fusión, el precalentamiento es necesario, $\mathrm{y}$, como se ha mencionado en el apartado anterior, se puede generar una capa de óxido, cuyo espesor aumenta con la temperatura de precalentamiento. Su composición también cambiará drásticamente. Estas afirmaciones pueden verificarse mediante el análisis con microscopía electrónica de transmisión (Transmission Electron Microscopy, TEM) de salpicaduras de $\mathrm{Al}_{2} \mathrm{O}_{3}$ sobre sustrato de Ti-6Al-4V, que mostró que la interfase salpicadura-óxido estaba compuesta de elementos de ambos materiales (Haure et al., 2001).

Las características de la capa de óxido están ligadas al material del sustrato, al tipo de precalentamiento y a la atmósfera circundante durante este (Bianchi et al., 1997a; Bianchi et al., 1997b; Leger et al., 1995; Haddadi et al., 1995; Maître et al., 2002; Valette, et al., 2003, 2004; Pech et al., 1997; Haure, 2003; Espié et al., 1999; Valette, 2004; Zanchetta et al., 1995). A su vez el precalentamiento viene definido por la llama, chorro de plasma $\mathrm{u}$ horno, cinética de calentamiento, temperatura de precalentamiento, $\mathrm{T}_{\mathrm{ps}}, \mathrm{y}$ tiempo de precalentamiento, $\mathrm{t}_{\mathrm{ps}}$. Por ejemplo, en sustratos de acero inoxidable 304L se observan dos tipos de capas de óxido a $573 \mathrm{~K}$ : una espinela $\mathrm{Fe}_{3-\mathrm{x}} \mathrm{Cr}_{\mathrm{x}} \mathrm{O}_{4}$ y una hematita pura, de 30-50 $\mathrm{nm}$ de espesor dependiendo del tiempo de precalentamiento (Bianchi, Denoirjean et al., 1997; Bianchi et al., 1997b; Valette, 2004). A 773 K, se desarrollan capas dobles de óxido, con sesquióxido $\mathrm{Fe}_{2-\mathrm{x}} \mathrm{Cr}_{\mathrm{x}} \mathrm{O}_{3}(\mathrm{x} \sim 0.1)$ y una espinela de cromita de $\mathrm{Ni}$, de $50 \div 100 \mathrm{~nm}$ de espesor. En sustratos de acero de bajo contenido de carbono, acero 1040, el espesor relativo de ambas capas de óxido formadas (hematita en la parte superior y magnetita en la parte inferior) varía dependiendo de los parámetros de precalentamiento, tales como la cinética del calentamiento, $\mathrm{T}_{\mathrm{ps}} \mathrm{y} \mathrm{t}_{\mathrm{ps}}$ (Pech et al., 1999a).

Así, en la bibliografía se pueden observar algunas relaciones entre adhesión y la presencia de óxido. La adhesión del revestimiento de alúmina sobre un sustrato rugoso con alto 
contenido de hematita alcanza $34 \pm 4 \mathrm{MPa}$ y $40 \pm 8$ cuando su contenido es bajo (Pech et al., 1999a). De hecho, la capa de hematita sobre sustratos lisos es muy frágil y se producen defectos de adhesión en su interior tan pronto como el espesor es superior a $150 \mathrm{~nm}$ (Pech et al., 1999a).

La importancia de la temperatura y el tiempo de precalentamiento se ilustra en las Tablas 2.5 y 2.6, donde se observa que la fundición de hierro es más sensible al tiempo de precalentamiento que el acero inoxidable. Así, la adhesión/cohesión se reduce en algo menos de un tercio si el tiempo de precalentamiento se triplica, mientras que para el acero inoxidable solo se reduce esta propiedad en un $30 \%$ cuando el tiempo de precalentamiento se quintuplica. En este caso, la mayor rugosidad, al reducir la superficie real de contacto entre salpicadura y sustrato, puede promover la fusión del sustrato o capa de óxido. Para los valores recogidos en la tabla 2.6 el tamaño de la columna se encuentra en el rango de 125 a $250 \mathrm{~nm}$.

Tabla 2.5. Efecto del tiempo de precalentamiento del sustrato a $500 \mathrm{~K}$ sobre revestimientos de alúmina (distribución del tamaño de las partículas de 22 a $45 \mu \mathrm{m}$; fundidas y trituradas) depositados sobre sustratos de fundición de acero con Ra de 6 m (Fauchais et al., 1995; Pech et al., 1997; Pech et al., 1999a)

\begin{tabular}{cccc}
\hline $\begin{array}{c}\text { Tiempo de } \\
\text { calentamiento }(\mathbf{s})\end{array}$ & $\begin{array}{c}\text { Adhesión/ } \\
\text { cohesión }(\mathrm{MPa})^{*}\end{array}$ & $\begin{array}{c}\text { Forma de la salpicadura } \\
\text { sobre sustrato liso }\end{array}$ & $\begin{array}{c}\text { Tamaño de la } \\
\text { columna }(\mathbf{n m})\end{array}$ \\
\hline 90 & $60 \pm 5$ & Tortita & $100-150$ \\
300 & $22 \pm 4$ & Flor & Irregular \\
\hline
\end{tabular}

\footnotetext{
* El promedio se ha calculado con diez datos.
}

Otros ensayos aportan más información sobre el efecto de distintos tipos de calentamiento. Así, Denoirjean et al. proyectaron partículas de alúmina sobre revestimientos pulidos realizados con proyección por plasma, con una $R_{a}$ de aproximadamente 0,4 $\mu \mathrm{m}$, para obtener fase gamma (Denoirjean et al., 1998). Para obtener fase alfa con estructura de grano columnar se realizó un recocido de muestras revestidas consistente en un calentamiento lento, a $5 \mathrm{~K} / \mathrm{min}$, hasta $1373 \mathrm{~K}$, mantenida durante $6 \mathrm{~h}$, seguido de un enfriamiento a la misma velocidad. Otras muestras se 
recocieron mediante un calentamiento a la misma velocidad del proceso anterior hasta una temperatura de $1873 \mathrm{~K}$, mantenida durante $3 \mathrm{~h}$, seguido de un enfriamiento a la misma velocidad, dando como resultado fase alfa con estructura granular con un tamaño entre 3 y $5 \mu \mathrm{m}$. También se depositó un revestimiento de deposición química de vapor asistida por plasma (Plasma-Enhanced Chemical Vapor Deposition, PECVD) de aproximadamente $3 \mu \mathrm{m}$ de espesor sobre un sustrato de acero inoxidable 304L a $573 \mathrm{~K}$. El revestimiento presentaba una estructura en columnas con diámetros entre 100 y 150 $\mathrm{nm}$, y un $\mathrm{R}_{\mathrm{a}}$ de $6 \mathrm{~nm}$. Los resultados obtenidos con las salpicaduras y los revestimientos asociados se recopilan en la Tabla 2.7 .

Tabla 2.6. Efecto de la temperatura y tiempo de precalentamiento sobre revestimientos de zirconia (distribución del tamaño de las partículas de 22 a $45 \mu \mathrm{m}$; Fundidas y trituradas) depositados sobre sustratos de acero inoxidable con $\mathrm{R}_{\mathrm{a}}$ de $12 \mu \mathrm{m}$ (Fauchais et al., 1995; Pech et al., 1997; Pech et al., 1999a)

\begin{tabular}{cccc}
\hline $\begin{array}{c}\text { Tiempo de } \\
\text { calentamiento (s) }\end{array}$ & $\begin{array}{c}\text { Temperatura de } \\
\text { calentamiento (K) }\end{array}$ & $\begin{array}{c}\text { Adhesión/ } \\
\text { cohesión (MPa) }\end{array}$ & $\begin{array}{c}\text { Forma de la salpicadura } \\
\text { sobre sustrato liso }\end{array}$ \\
\hline 60 & 573 & $50 \pm 2$ & Tortita \\
120 & 773 & $65 \pm 4$ & Tortita \\
600 & 773 & $45 \pm 2$ & Tortita con poros \\
\hline
\end{tabular}

* Diez puntos de datos para cada valor.

Tales resultados han sido confirmados recientemente por Valette et al. (Valette et al., 2003, 2004; Valette, 2004).

En cuanto al gas que compone la atmósfera que rodea el sustrato durante el precalentamiento, se puede afirmar que puede determinar la naturaleza del óxido formado sobre el sustrato. Así, cuando se precalienta un sustrato de acero bajo en carbono en una atmósfera de $\mathrm{CO}_{2}$, se desarrolla $\mathrm{Fe}_{1-\mathrm{x}} \mathrm{O}$ en su superficie. Después del precalentamiento por plasma de la superficie del sustrato sobre la temperatura de transición, la capa $\mathrm{Fe}_{1-\mathrm{x}} \mathrm{O}$ se transforma en $\mathrm{Fe}_{3} \mathrm{O}_{4}$. La superficie oxidada resultante está compuesta de granos planos de $1 \div 2 \mu \mathrm{m}$ de espesor y $3 \div 7 \mu \mathrm{m}$ de ancho. La adhesión del revestimiento de alúmina en esta superficie alcanza $60 \mathrm{MPa}$ y parece principalmente debido a una buena estructura 
progresiva de estructuras cristalinas con cinco zonas de interfase: una zona de transición entre el acero 1040 y el acero empobrecido en $\mathrm{C}$ resultante del tratamiento de preoxidación, una zona de transición entre el acero, muy pobre en carbono y hierro puro en la parte superior del área de difusión del C, una interfase entre el hierro puro y el monóxido de hierro (wustita), unidas por una relación epitaxial bien conocida, que posiblemente desempeña el papel de una zona flexible ya que se considera que el óxido de hierro es más plástico, una zona de transición entre $\mathrm{Fe}_{1-\mathrm{x}} \mathrm{O}$ y $\mathrm{Fe}_{3} \mathrm{O}_{4}$ manteniendo estructura inicial de monóxido de hierro (agrupaciones observadas en imágenes TEM), y una interfase entre $\mathrm{Fe}_{3} \mathrm{O}_{4}$ y alúmina gamma con posible relación cristalográfica.

Tabla 2.7. Características de las salpicaduras de alúmina sobre diferentes sustratos de alúmina (Denoirjean et al., 1998).

\begin{tabular}{|c|c|c|c|c|}
\hline $\begin{array}{l}\text { Proceso de } \\
\text { fabricación }\end{array}$ & $\begin{array}{l}\text { Fase del } \\
\text { sustrato }\end{array}$ & $\mathrm{R}_{\mathrm{a}}(\mathrm{nm})$ & $\begin{array}{c}\text { Morfología } \\
\text { de la salpicadura }\end{array}$ & $\begin{array}{l}\text { Adhesión/ } \\
\text { cohesión } \\
\text { (MPa)* }\end{array}$ \\
\hline $\begin{array}{l}\text { Proyección } \\
\text { por plasma }\end{array}$ & $\gamma$-alúmina ${ }^{* *}$ & 400 & $\begin{array}{l}\text { Columnar: regular } \\
\text { 100-150nm }\end{array}$ & $35 \pm 3$ \\
\hline \multirow[t]{3}{*}{ PECVD } & $\alpha$-columnar ${ }^{* *}$ & 400 & $\begin{array}{l}\text { Columnar: regular } \\
\sim 150-300 \mathrm{~nm}\end{array}$ & $3 \pm 1$ \\
\hline & $\alpha$-columnar & 400 & $\begin{array}{l}\text { Columnar: muy irregular } \\
\qquad 100-400 \mathrm{~nm}\end{array}$ & Despegado \\
\hline & $\alpha$-columnar ${ }^{* * *}$ & 6 & $\begin{array}{c}\text { Tortita con poros } \\
\text { o corona }\end{array}$ & $60 \pm 5$ \\
\hline
\end{tabular}

\footnotetext{
* El promediado se ha realizado con diez datos.

** Para los sustratos revestidos por plasma y pulidos, las columnas del sustrato están orientadas en casi todas las direcciones.

*** Para el sustrato PECVD, las columnas son todas paralelas a la dimensión del impacto de la partícula.
}

Estas interfases corresponden a una zona en la que las propiedades físicas evolucionan 
gradualmente sin ningún salto, lo que constituye una condición esencial para una buena resistencia a tensiones mecánicas o térmicas (Zanchetta et al., 1995).

En cuanto al efecto de la rugosidad del sustrato en esta propiedad, el análisis de alúmina sobre un sustrato con $\mathrm{R}_{\mathrm{a}}$ de aproximadamente $10 \mathrm{~nm}$ muestra un valor de $36 \pm 5 \mathrm{MPa}$, mientras que para $\mathrm{R}_{\mathrm{a}}$ de aproximadamente $50 \mathrm{~nm}$ se obtiene $18 \pm 5 \mathrm{MPa}$. Otro resultado disponible en la bibliografía, utilizó PECVD (proceso mencionado en este apartado), que eliminó la capa de óxido de $20 \mathrm{~nm}$ de espesor en una superficie de acero 316L y formó una capa de alúmina de $3 \mu \mathrm{m}$ de espesor con Ra de aproximadamente $6 \mathrm{~nm}$. La adhesión medida es de $66 \pm 5 \mathrm{MPa}$. En el caso de $\mathrm{TiO}_{2}$ como material de revestimiento, su buena adherencia sobre el Ti-6Al-4V pulido es probablemente debida a la fusión de la capa de $\mathrm{TiO}_{2}$ y la formación de $\mathrm{Al}_{2} \mathrm{TiO}_{5}$, mientras no puede formarse óxido $\mathrm{Fe}_{\mathrm{x}} \mathrm{Al}_{\mathrm{y}} \mathrm{Cr}_{\mathrm{z}} \mathrm{O}_{\mathrm{w}}$ con la espinela existente sobre la superficie de acero 316L (Zanchetta et al, 1995).

Muchos autores han demostrado que, cuando se obtienen salpicaduras en forma de tortita en un sustrato liso, $\mathrm{R}_{\mathrm{a}}$ alrededor de $50 \mathrm{~nm}$, precalentado a $\mathrm{T}_{\text {sust }}$ mayor que $\mathrm{T}_{\mathrm{t}}$, la adhesión del revestimiento del mismo material proyectado sobre el sustrato precalentado a $\mathrm{T}_{\mathrm{s}}$ es de 2 a 5 veces mayor que sobre un sustratro precalentado a $T_{\text {sust }}<T_{t}$ (Fukumoto, Hayashi et al., 1995; Bianchi et al., 1995; Sakakibara et al., 2000; Pershin et al., 2001b). Así, la figura 2.34 muestra el efecto de la temperatura del sustrato sobre la adhesión del revestimiento. Su dependencia de la temperatura del substrato se corresponde bastante bien con la forma de la salpicadura sobre un sustrato liso. Por tanto, el estudio del mecanismo de aplanamiento de las partículas proyectadas es significativo para la aplicación práctica de la proyección térmica (Fauchais et al., 2004).

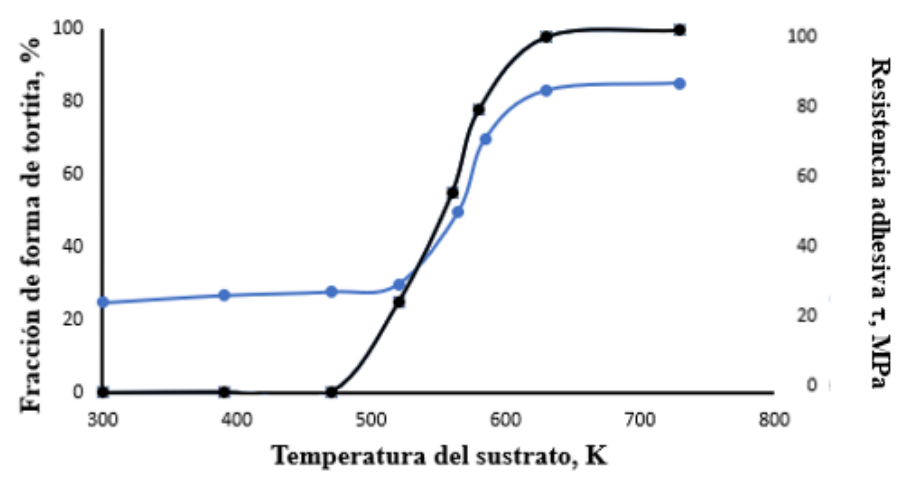

Figura 2.34 Variación de la resistencia adhesiva del revestimiento con la temperatura del sustrato (Fukumoto et al., 1995a) (material pulverizado de Ni con una disposición de tamaños de 10 a $44 \mu \mathrm{m}$, sustrato de acero inoxidable AISI304). 
Otro de los mecanismos de adhesión, la difusión, sólo es efectiva en metales y aleaciones si las temperaturas del sustrato son superiores a 1100-1200K, la proyección se realiza a bajo vacío y la capa de óxido en la superficie del sustrato se retira previamente. Esto sucede cuando se utiliza un arco de polaridad inversa entre el sustrato y la antorcha de plasma, controlando la corriente, de decenas de amperios, mediante la separación de la antorcha respecto del sustrato.

El enclavamiento mecánico, el último de los mecanismos de adherencia mencionado, es distancia entre el punto más elevado y el más bajo del sustrato, figura 2.35 , medida mediante $\mathrm{R}_{\mathrm{t}}$, debe adaptarse al diámetro de la salpicadura, que debería estar entre el doble y el triple de este valor de rugosidad (Dagnall, 2003).

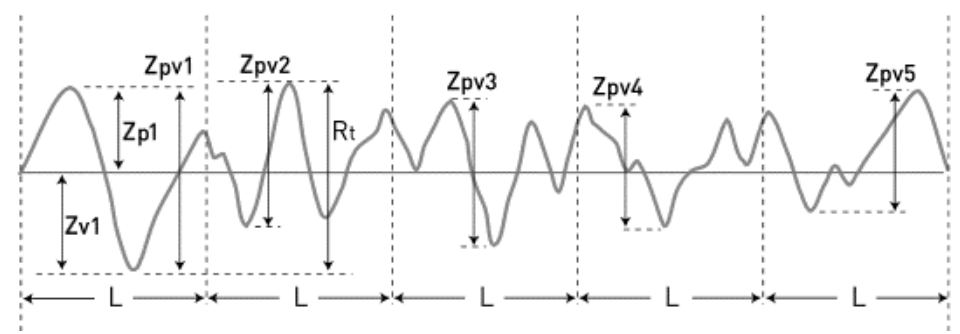

Figura 2.35. Medida de la rugosidad (Dagnall, 2003).

\subsubsection{GRIETAS Y POROS}

Otra característica importante del revestimiento es la existencia de grietas y poros en la superficie. La figura 2.36 muestra diferentes tipos de grietas (Ohmori y Li, 1993).

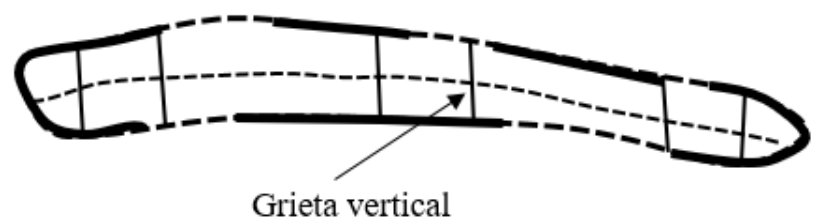

Figura 2.36. Sección transversal esquematizada de una partícula aplanada con grietas verticales: interfase unida (línea discontinua) e interfase no unida (línea continua) (Ohmori y Li, 1993).

Las tensiones generadas durante el proceso de enfriamiento de la salpicadura son la fuente corriente de estas grietas. Así, durante el enfriamiento se pueden distinguir dos fases: en la primera la salpicadura está más caliente que la zona del sustrato en contacto con ella, después las temperaturas se igualan. Mientras la salpicadura está más caliente, el sustrato 
se dilata y esta se contrae, experimentando una tracción ejercida por el sustrato; pero a partir del momento en que se igualan las temperaturas, el sustrato con un coeficiente de dilatación térmico mayor, se contrae más rápido e induce una compresión en ella, figura 2.37 (Wenzelburger et al., 2004). Como resultado de una rápida solidificación, pueden generarse microfisuras perpendiculares a la superficie si las tensiones de tracción superan a la resistencia a la rotura del material, figura 2.38 (Kulkarni et al., 2004). Si tras alcanzar la misma temperatura la salpicadura y el sustrato el enfriamiento es muy rápido, se producen tensiones de cizallamiento interfaciales que pueden deformar el sustrato o debilitar su unión con el revestimiento, figura 2.39.

\section{Deposición y contracción de la salpicadura}

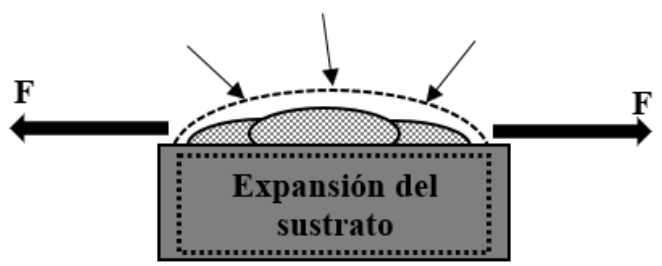

Tc $<\mathbf{T}_{\text {sust }}$

\section{Contracción del revestimiento}

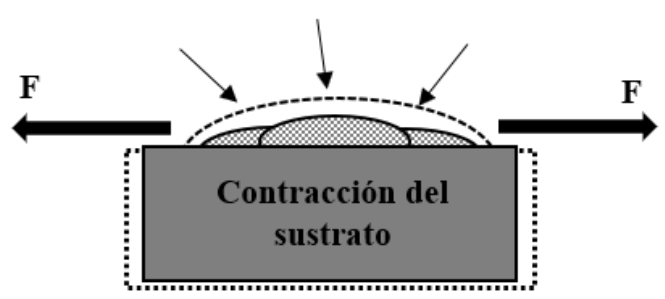

$\mathbf{T c} \approx \mathbf{T}_{\text {sust }}$

Figura 2.37 Formación de tensiones cuando $\mathrm{T}_{\mathrm{c}}>\mathrm{T}_{\text {sust }}$ (izquierda) y cuando ambas temperaturas se igualan (derecha) (David, 2004).

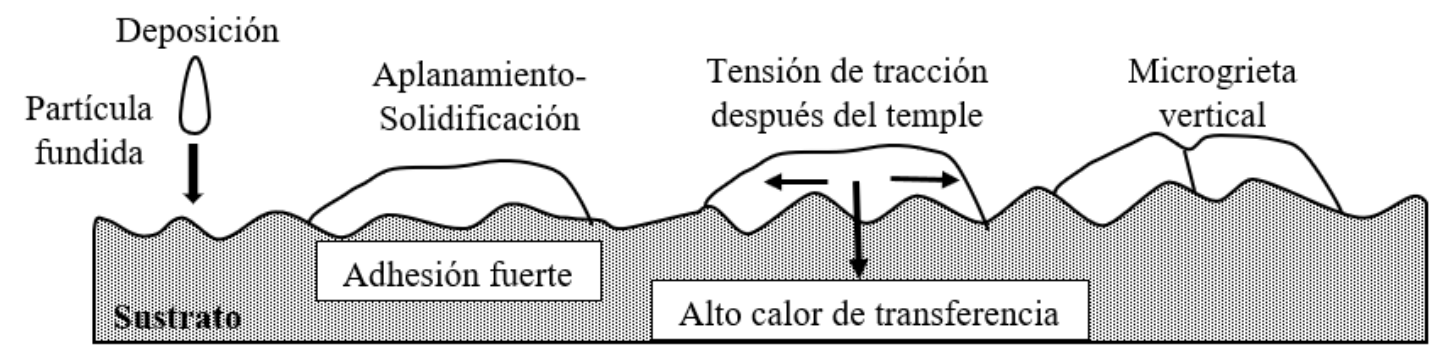

Figura 2.38 Esquema del mecanismo de formación de una microgrieta vertical en una partícula aplanada (Mifune y Harada, 2004).

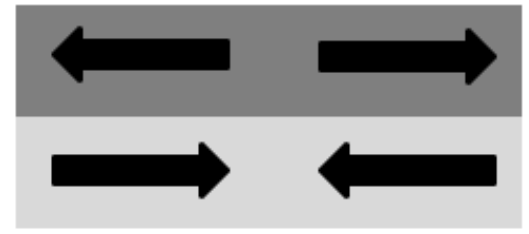

Antes de la proyección

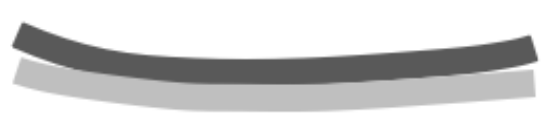

Después de la proyección

Figura 2.39 Efecto de la contracción del revestimiento (David, 2004). 
El examen de fracturas en revestimiento tras ensayos mecánicos sugiere que éstas se producen en el área de interfase entre las salpicaduras, la parte más débil del revestimiento. Por otro lado, las fracturas perpendiculares a la superficie del sustrato ocurren en la transición entre la interfase unida al sustrato y la no unida, excepto en la zona próxima al final de la salpicadura.

Otro aspecto importante, es el área de la interfase que está en contacto real con el sustrato (Ohmori y Li, 1993). Así, las mediciones en un revestimiento de alúmina comúnmente utilizado y proyectado en condiciones óptimas muestran que la fracción de superficie de la interfase solo llega al $32 \%$ de la posible.

La figura 2.40 representa esquemáticamente la estructura de una salpicadura originada a partir de una partícula fundida adecuadamente. En esta figura se pueden ver poros en el centro de la base. Otra característica importante es la fractura en la periferia de la salpicadura.

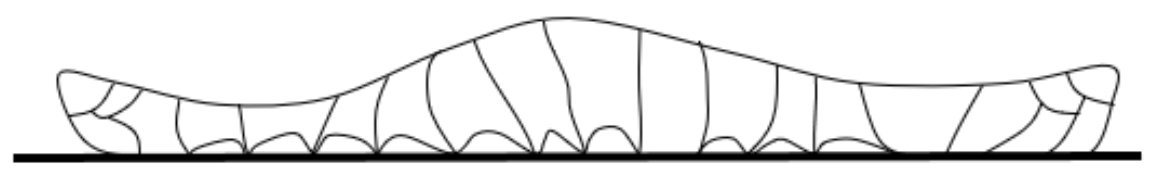

Figura 2.40 Esquema de la estructura de una partícula fundida (David, 2004).

En cuanto a los poros, estos pueden ser interlaminares o globulares. El origen de los poros interlaminares procede de contactos incompletos; mientras que los globulares proceden de partículas sin fundir, núcleos que faltan y gas atrapado (Kulkarni et al., 2004). Los poros interlaminares pueden explicarse por una transferencia de calor deficiente. Así, la figura 2.41 muestra los defectos microestructurales comunes en un revestimiento. La marca con el número 1 indica el sustrato, la 2 el contacto débil con el sustrato, la 3 la grieta resultante de las tensiones de paso de la antorcha, la 5 las laminillas solidificadas con cristales columnares, la 6 la grieta resultante de la relajación de tensiones en el plano, la 7 el poro de algunos micrómetros, las 8 laminillas deformadas, la 9 las partículas de polvo sólidas tras la vaporización y la 10 un poro de tamaño pequeño. 


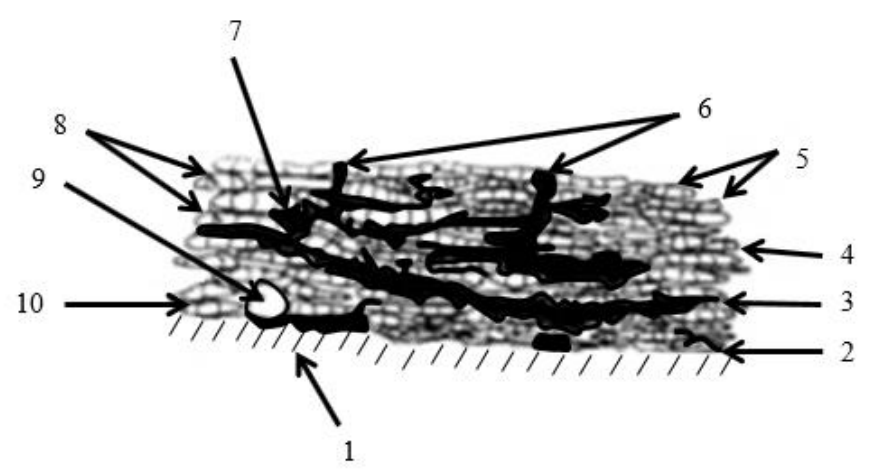

Figura 2.41 Sección transversal de un revestimiento proyectado térmicamente con defectos microestructurales (Pawlowski, 2008).

\subsection{IMPACTO ISOTÉRMICO DE GOTA}

Tras una descripción de la salpicadura se van a presentar las ecuaciones que van a modelar su impacto y solidificación.

\subsubsection{TENSIÓN SUPERFICIAL Y MOJABILIDAD}

La tensión superficial es proporcional a la curvatura, como recoge la ley de YoungLaplace (Rowlinson y Widom, 1982):

$$
\Delta \mathrm{P}=\gamma\left(\frac{1}{\mathrm{R}_{1}}+\frac{1}{\mathrm{R}_{2}}\right)
$$

donde $\Delta \mathrm{P}$ es el incremento de presión entre superficies, $\gamma$ es la tensión superficial y $\mathrm{R}_{\mathrm{i}}$ es el radio de curvatura en el plano i, plano rz para el subíndice 1 y el perpendicular para el 2, o plano azimutal.

A su vez, recurriendo a consideraciones geométricas, la curvatura puede ser calculada mediante la siguiente expresión (Krivoshapko y Ivanov, 2015)

$$
\kappa=\frac{1}{\mathrm{R}_{1}}+\frac{1}{\mathrm{R}_{2}}=\frac{\mathrm{d}}{\mathrm{dr}}\left[\frac{\mathrm{dZ} / \mathrm{dr}}{\sqrt{1+(\mathrm{dZ} / \mathrm{dr})^{2}}}\right]+\frac{\operatorname{sen} \beta}{\mathrm{r}_{\mathrm{i}}}
$$

donde $\mathrm{Z}$ es la coordenada vertical de la superficie del líquido, y $\beta$ es el ángulo de la recta tangente a la superficie del líquido respecto del horizontal considerando un plano azimutal.

Si la interfase es casi horizontal, figura $2.42, \beta$ es menor que $45^{\circ}$, y resulta ventajoso 
definir este ángulo mediante

$$
\operatorname{sen} \beta=\frac{\operatorname{tg} \beta}{\sqrt{1+\operatorname{tg}^{2} \beta}}=\frac{|\mathrm{dZ} / \mathrm{dr}|}{\sqrt{1+(\mathrm{dZ} / \mathrm{dr})^{2}}}
$$

Si la interfase es casi vertical, figura $2.43, \beta$ es mayor que $45^{\circ}$, y ahora resulta ventajoso definir el ángulo $\alpha=(\pi / 2)-\beta \mathrm{y}$

$$
\kappa_{\mathrm{cyl}}=\frac{\cos \alpha}{\mathrm{r}_{\mathrm{i}}}
$$

donde el coseno viene definido por:

$$
\cos \alpha=\frac{1}{\sqrt{1+\operatorname{tg}^{2} \alpha}}=\frac{1}{\sqrt{1+(\mathrm{dR} / \mathrm{dz})^{2}}}
$$

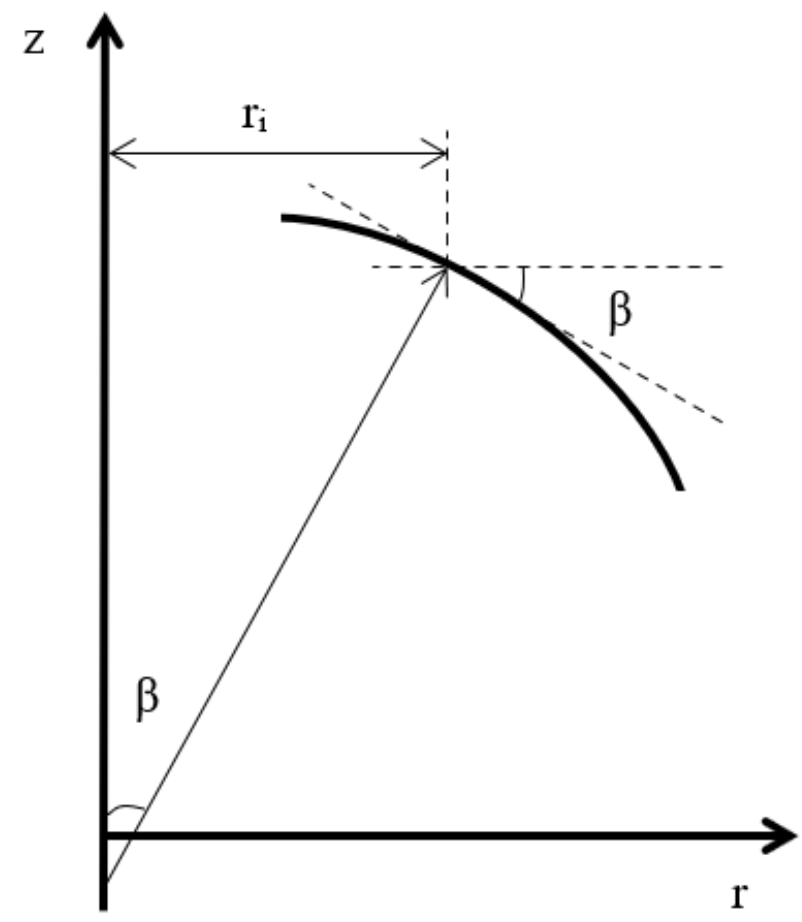

Figura 2.42 Curvatura asociada a la dirección z cuando la superficie libre es casi horizontal (PasandidehFard, 1998). 


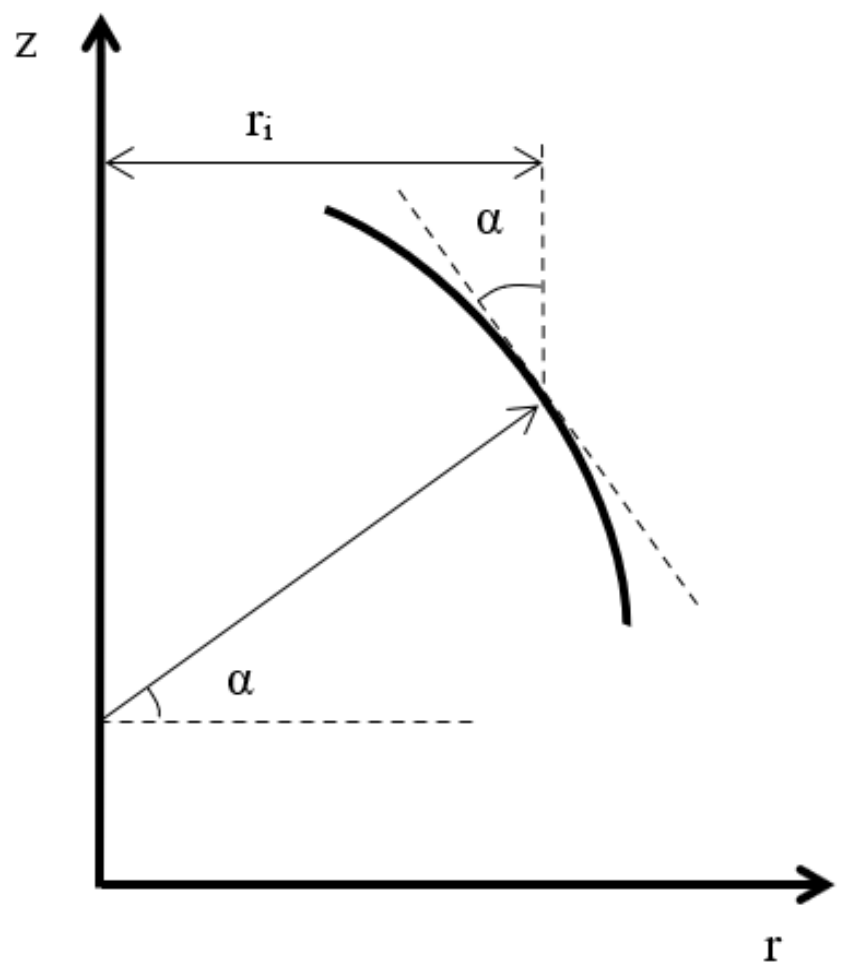

Figura 2.43 Curvatura asociada a la dirección r cuando la superficie libre es casi vertical (PasandidehFard, 1998).

La tensión superficial no es la única fuerza que condiciona la superficie de la salpicadura. El ángulo de contacto, $\theta$ en la figura 2.44, está definido por la resultante de las fuerzas adhesivas y cohesivas y es el que conforma el líquido respecto a la superficie de contacto con el sólido.

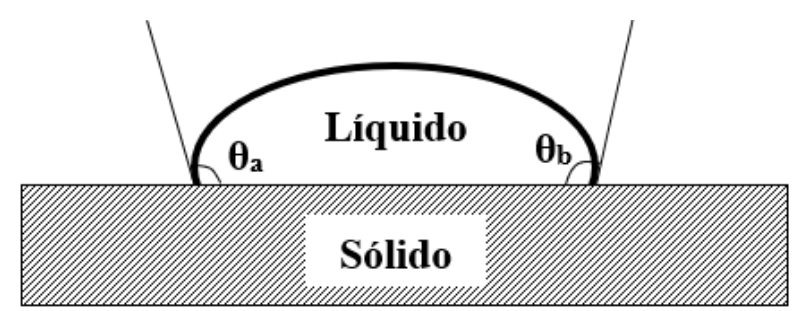

Figura 2.44 Representación gráfica de los ángulos de contacto de retroceso, $\theta_{\mathrm{r}}$ y de avance, $\theta_{\mathrm{a}}$. (Good, 1992).

Su valor es una estimación de la inversa de la mojabilidad, dado que una gota tiende a extenderse en una superficie plana conforme disminuye este ángulo (Sharfrin, 1960). Así, una superficie sólida se considera ideal cuando es químicamente homogénea, rígida, plana, perfectamente lisa, y no posee histéresis del ángulo de contacto, figura $2.44\left(\theta_{\mathrm{a}}=\right.$ $\left.\theta_{r}\right)$. En una superficie de esta clase, cualquier gota recobrará su forma original al 
producirse una perturbación (Johnson, 1993; Eustathopoulos et al., 1999).

Zisman proporcionó una relación más precisa entre ángulo de contacto y tensión superficial, concretamente, el $\cos \theta$ es inversamente proporcional a la tensión superficial (Johnson, 1993; Zhu et al., 2010). Aprovechando esta relación, la tensión superficial crítica, $\gamma_{\mathrm{C}}$, se define como la tensión superficial correspondiente a un coseno unidad, o mojabilidad nula. Este parámetro depende solamente de las características del sólido, por lo que a partir de su valor es posible predecir la mojabilidad de la superficie (Sharfrin, 1960).

Tras describir el sistema, se puede proceder a estudiarlo físicamente. En equilibrio termodinámico, la fuerza neta por unidad de longitud en la frontera de las tres fases (salpicadura, sustrato y atmósfera) debe ser nula. En la dirección de cada una de las interfases, las componentes de la fuerza neta son:

$$
\begin{aligned}
& \gamma_{\alpha \theta}+\gamma_{\theta \beta} \cos \theta+\gamma_{\alpha \beta} \cos \alpha=0 \\
& \gamma_{\alpha \theta} \cos \theta+\gamma_{\theta \beta}+\gamma_{\alpha \beta} \cos \beta=0 \\
& \gamma_{\alpha \theta} \cos \alpha+\gamma_{\theta \beta} \cos \beta+\gamma_{\alpha \beta}=0
\end{aligned}
$$

donde $\alpha, \beta$ y $\theta$ son los ángulos de contacto, figura 2.45 , y $\gamma_{\mathrm{ij}}$ es la energía superficial entre las fases anteriormente mencionadas.

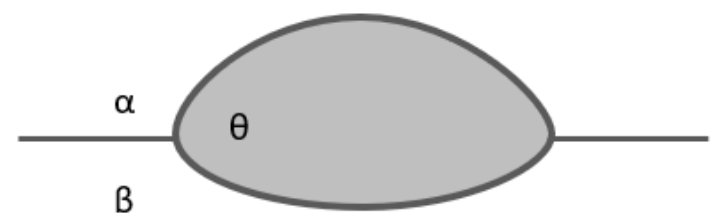

Figura 2.45 Fases fluidas y ángulos de contacto (Rowlinson y Widom, 1982).

El designado como triángulo de Neumann, figura 2.46, muestra las relaciones al aplicar la ley del coseno y la ley del seno (Rowlinson y Widom, 1982). En este triángulo, los lados simbolizan las energías superficiales, y por tanto se deben cumplir las desigualdades triangulares $\gamma_{\mathrm{ij}}<\gamma_{\mathrm{jk}}+\gamma_{\mathrm{ik}}$.

Si la fase en la zona inferior se sustituye por una superficie sólida rígida, figura 2.47 , entonces se cumple $\beta=\pi$, y la segunda ecuación de la fuerza neta se simplifica a la 
ecuación de Young-Dupre (Young, 1805; Chow, 1998)

$$
\gamma_{\mathrm{SV}}=\gamma_{\mathrm{SL}}+\gamma_{\mathrm{LV}} \cos \theta
$$

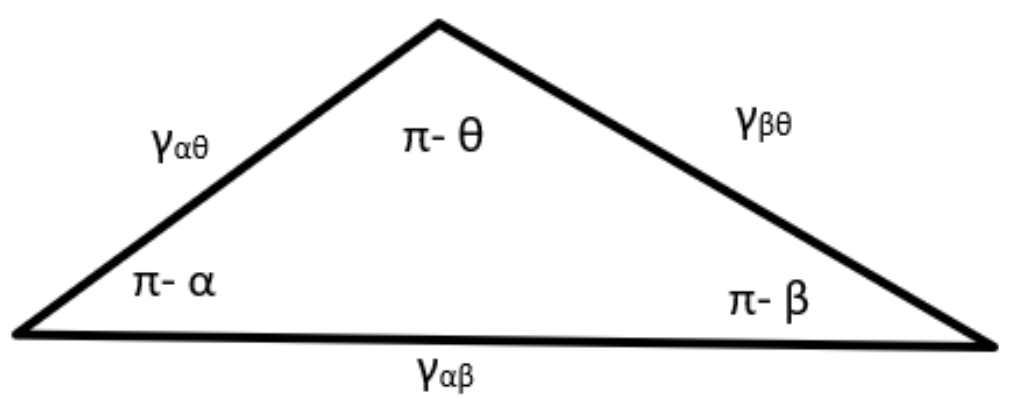

Figura 2.46 Triángulo de Neumann (Rowlinson y Widom, 1982).

La ecuación anteriormente mencionada relaciona las tensiones superficiales entre las fases (sólido, líquido y vapor) y permite estimar el ángulo de contacto de una gota de líquido en una superficie sólida.

Por otro lado, la ecuación de Young indica que ni $\gamma_{S V}$ ni $\gamma_{S L}$ puede ser mayor que la suma de las otras dos energías superficiales. Una consecuencia de esta restricción es la mojabilidad nula cuando $\gamma_{\mathrm{SL}}=\gamma_{\mathrm{SV}}+\gamma_{\mathrm{LV}}$ y completa cuando $\gamma_{\mathrm{SV}}=\gamma_{\mathrm{SL}}+\gamma_{\mathrm{LV}}$.

A partir de las deducciones anteriores, se puede establecer que el parámetro más práctico para medir esta propiedad es el denominado «parámetro de esparcimiento» $\mathrm{S}_{\mathrm{E}}$ :

$$
\mathrm{S}_{\mathrm{E}}=\gamma_{\mathrm{SV}}-\left(\gamma_{\mathrm{SL}}+\gamma_{\mathrm{LV}}\right)
$$

con valores negativos para mojabilidad parcial y positivos para completa.

Si se combina el parámetro definido con la relación de Young, se consigue la ecuación de Young-Dupre:

$$
\mathrm{S}_{\mathrm{E}}=\gamma_{\mathrm{LV}}(\cos \theta-1)
$$

la cual solamente presenta soluciones válidas para $\theta$ cuando $S_{E}<0$.

Uno de los parámetros mencionados, la histéresis del ángulo de contacto, $\theta_{\mathrm{a}}-\theta_{\mathrm{r}}$, figura 2.47, es básicamente el desplazamiento de una línea de contacto. Este fenómeno está asociado a sólidos reales, con distintos ángulos de contactos termodinámicamente 
estables: el ángulo estable más elevado es el ángulo de contacto de avance, mientras que el más pequeño es el de retroceso. Estos estados son termodinámicamente metaestables (Johnson, 1993).

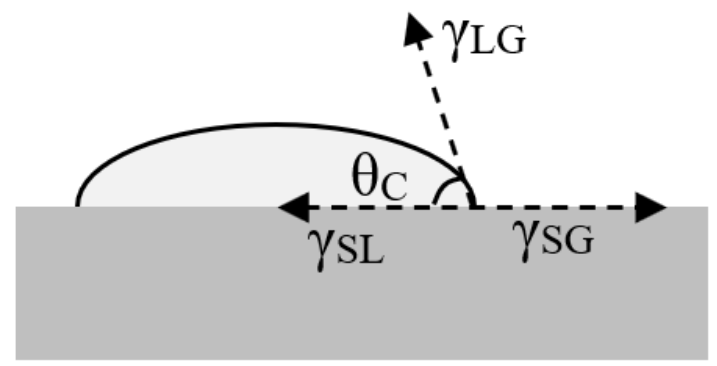

Figura 2.47 Ángulo de contacto de una gota sobre un plano sólido (De Gennes, 1994).

La capacidad de movimiento del límite de una de las fases se denomina mojabilidad dinámica. Cuando una línea de contacto progresa, de forma que ocupa más superficie con el líquido, el ángulo de contacto aumenta, normalmente de forma creciente con la velocidad de la línea de contacto (De Gennes, 1994).

En caso de superficies rugosas, el régimen es homogéneo cuando el líquido cubre los surcos de la superficie y heterogéneo en caso contrario, como en superficies compuestas por aire y sólido. Los modelos de Cassie-Baxter y de Wenzel analizan la mojabilidad de las superficies texturadas, figura 2.48. No obstante, su formulación solo es aplicable cuando el tamaño de la gota supera en cierta magnitud a la rugosidad superficial (Marmur, 2003).
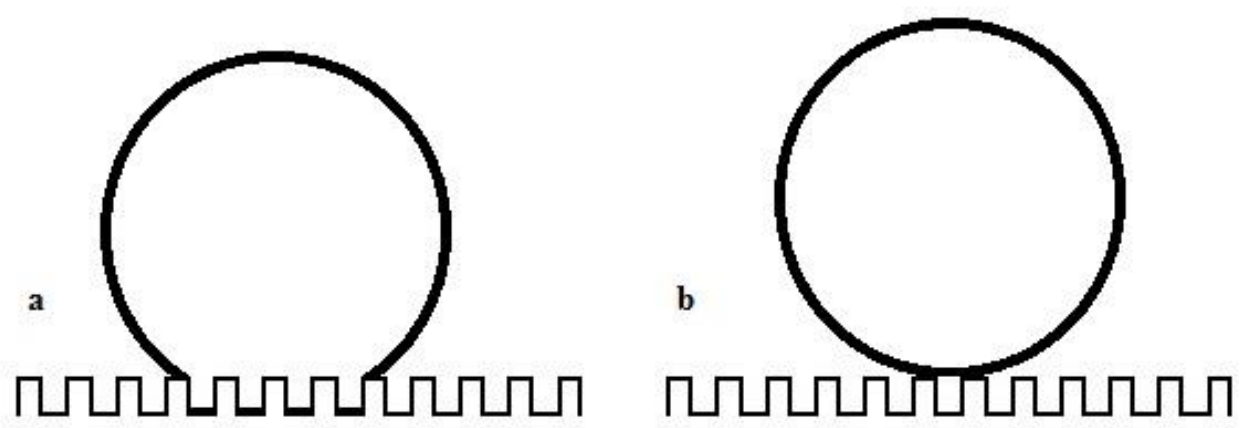

Figura 2.48 Mojabilidad dinámica: (a) Estado Wenzel; (b) Estado Cassie (Whyman et al., 2008)

Tras estudiar estos efectos, se han desarrollado expresiones aproximadas de la evolución del espesor y el ancho de la salpicadura tomando como argumento la rugosidad superficial 
(Sobolev et al., 1996). Se supone que la rugosidad aumenta el esfuerzo cortante debido a la fricción entre la gota y la superficie rugosa. Así, Fukanuma desarrolló un modelo matemático con diferentes asperezas geométricas (Fukanuma, 1996), que fue después mejorado (Fukanuma et al., 2002). Estos modelos muestran que la rugosidad favorece el fraccionamiento durante el aplanamiento y distorsiona bastante las salpicaduras, haciéndolas más gruesas (hasta 3 veces) y disminuyendo su Vr.

\subsubsection{EL MÉTODO VOF: ALGORITMOS SOLA-VOF}

En dinámica estructural, es habitual emplear coordenadas lagrangianas en algoritmos de solución numérica. En dinámica de fluidos, sin embargo, tanto las coordenadas lagrangianas como las eulerianas han tenido un éxito considerable.

En las representaciones discretas lagrangianas para fluidos cada zona de la malla que divide el fluido en elementos permanece inalterable. Las fuerzas de superficie y volumen se definen con facilidad, por lo que el cálculo de la respuesta dinámica de dichos elementos es directo. Por otro lado, en la representación euleriana, la malla permanece fija y los elementos individuales del fluido no se mantienen, aunque es corriente considerar el fluido en una celda de esta malla como un elemento de fluido en el que las fuerzas de superficie y volumen pueden ser calculadas de forma completamente análoga a la de la representación lagrangiana.

Básicamente, los dos métodos se diferencian en cómo los elementos fluidos se mueven a nuevas posiciones tras calcular las nuevas velocidades. En la representación lagrangiana la malla se mueve con la velocidad calculada del elemento, mientras que en la euleriana es necesario calcular el flujo de fluido en la malla. Este flujo, o cálculo de flujo convectivo, requiere un promediado de las propiedades del flujo de todos los elementos que se encuentran en una celda dada durante un tiempo determinado, siendo este el mayor inconveniente de los métodos eulerianos.

En problemas de dinámica de fluidos que incorporan frontera móvil, como es el caso del impacto de gotas, se elige la formulación euleriana ya que la frontera experimenta grandes deformaciones que la representación lagrangiana no puede gestionar (Nichols et al., 1980). Esta frontera móvil es considerada como una superficie libre o interfase del material, que plantea los siguientes problemas en su modelización: la representación discreta, la evolución temporal y la manera de imponer las condiciones de contorno. 
En representación euleriana, el promediado convectivo suaviza las variaciones de flujo, y en particular asegura una reducción de las discontinuidades de superficie. La única manera de superar esta pérdida de resolución del contorno es añadir algún tratamiento especial que reconozca discontinuidades y evite el promediado en ellas. Aunque existen varias técnicas todas tienen limitaciones (Harlow y Welch, 1965; Chan y Street, 1970; Nichols y Hirt, 1971). El análisis de sus ventajas y desventajas condujo a una técnica nueva simple y efectiva: el método de fracción de volumen de fluido (Fractional Volumen of Fluid, VOF) (Hirt y Nichols, 1980).

El algoritmo SOLA-VOF ha sido diseñado para una variedad de aplicaciones: fluido único con superficie libre, o dos fluidos inmiscibles con superficies libres. También incluye compresibilidad limitada, tensión superficial y fuerzas de adhesión de pared. Su fundamento es el esquema VOF para seguimiento de frontera móvil, técnica que define una función F (r, z, t) cuyo valor es unidad en una celda llena de fluido, nulo si la celda está vacía y un valor intermedio en las celdas en la frontera móvil.

En una malla euleriana, debe calcularse el flujo de F moviéndose con el fluido a través de la celda, pero como se ha comentado anteriormente las aproximaciones habituales en diferencias finitas suelen conducir a una suavización de $\mathrm{F}$ y a una pérdida de definición en la interfase. Afortunadamente, el hecho de que F sea una función escalón con valores entre cero y uno permite el uso de aproximaciones de flujo que conservan su naturaleza discontinua. Esta aproximación, denominada en la literatura método donante-receptor, se va a describir posteriormente en este apartado.

Así, las técnicas VOF proporcionan un medio de seguimiento de las zonas con fluido a través de la malla euleriana de celdas estacionarias. El método almacena una cantidad de información mínima, y debido a que sigue zonas más que contornos, evita problemas lógicos asociados con superficies que interseccionan. El método VOF puede extenderse al cálculo tridimensional, donde su economía de almacenamiento de información resulta ventajosa.

En principio, este método puede usarse para seguir una frontera entre propiedades de un material, como velocidad tangencial o cualquier otro parámetro. El caso considerado en este trabajo determina las condiciones de contorno específicas que deben aplicarse en la localización del contorno. Para situaciones en las que la frontera no permanezca fija en el 
fluido, sino que tiene un movimiento relativo, la ecuación de conservación de la cantidad de movimiento debe ser modificada. Esto ocurre en caso de ondas de choque, frentes de reacciones químicas y contornos de separación entre zonas de flujo monofásico y bifásico.

Corresponde ahora, por tanto, describir el desarrollo de los métodos de diferencias finitas eulerianos, cuyo uso en dinámica de fluidos incompresibles está muy asentado. El primer método usado con éxito, denominado método Marcador y Celda (Marker-and-Cell method, MAC), incorporaba movimientos complejos de frontera libre. Este método constituyó la primera técnica que usó presión y velocidad como variables dependientes primarias. MAC utilizó una distribución de partículas marcadoras para definir las zonas de fluido y fijó de forma sencilla las presiones de la frontera móvil en el centro de las celdas pertenecientes a dicha frontera. No se aplicaron condiciones de contorno de presión en la celda de la frontera móvil. Posteriormente se incorporó una aproximación basta, y las partículas marcadoras se sustituyeron por cadenas de partículas en la frontera móvil (Harlow y Welch, 1965).

Existe una versión simplificada del algoritmo básico de solución (Solution Algorithm, SOLA) usada en el MAC. Aunque SOLA no trata fronteras móviles, existe una versión extendida, SOLA-SURF, que usa el método de la función de altura de la superficie.

A continuación, se revisarán los detalles del algoritmo de solución SOLA-VOF, deteniéndose en las consideraciones especiales necesarias en aproximaciones de diferencias finitas en mallas no uniformes y para localización de interfaces.

SOLA-VOF usa una malla euleriana de celdas rectangulares. Aunque no es tan flexible como una malla compuesta por cuadriláteros arbitrarios, su capacidad para usar una malla variable supone una ventaja considerable en comparación con métodos que usan rectángulos de igual tamaño, ya que permite aumentar la resolución en la zona deseada.

La función $\mathrm{F}$ identifica la celda que contiene fluido. Desarrollando más esta idea, se define una celda de la frontera móvil o interfase como una celda que contiene valores no nulos de F y que tiene al menos una celda vecina con un valor nulo de F. Las celdas con F igual cero están vacías. Las celdas con F no nulo y con celdas adyacentes no vacías son tratadas como celdas llenas de fluido.

La idea esencial del método Donante-Aceptor, mencionado anteriormente, es usar tanto 
la información de F corriente abajo como corriente arriba del contorno del fluido para establecer la frontera, y a partir de esta calcular el flujo. Varios investigadores han usado variantes de este concepto (Johnson, 1970; Kershner y Nader, 1972; Noh y Woodward, 1976).

El método básico desarrollado para la técnica VOF puede explicarse considerando la cantidad de F que fluye a través de la cara derecha de la celda en cada instante supuesto un flujo en dicha dirección. El flujo en volumen que atraviesa la cara de la celda por unidad de área es $\mathrm{V}_{\mathrm{x}}=\mathrm{u}_{\mathrm{r}} \cdot \mathrm{dt}$. El signo de $\mathrm{u}_{\mathrm{r}}$ identifica a la celda como donante o aceptora. La cantidad de F fluyendo a través de la cara de la celda durante un instante es

$$
\mathrm{dF}=\min \left\{\mathrm{F}_{\mathrm{AD}} \cdot\left|\mathrm{V}_{\mathrm{x}}\right|+\mathrm{CF}, \mathrm{F}_{\mathrm{D}} \cdot \mathrm{dx}_{\mathrm{D}}\right\}
$$

donde $\mathrm{CF}=\max \left\{\left(1-\mathrm{F}_{\mathrm{AD}}\right) \cdot\left|\mathrm{V}_{\mathrm{x}}\right|-\left(1-\mathrm{F}_{\mathrm{D}}\right) \cdot \mathrm{dx}_{\mathrm{D}}, 0\right\}$, los subíndices $\mathrm{A}, \mathrm{D}$ y AD denotan aceptor, donante y aceptor o donante según la orientación de la interfase en función de la dirección del flujo, respectivamente.

Los componentes de la expresión anterior indican:

- $\quad \mathrm{F}_{\mathrm{D}} \cdot \mathrm{dx} \mathrm{x}_{\mathrm{D}}$ es el máximo volumen por unidad de tiempo (flujo) posible desde la celda donante.

- $\quad \mathrm{F}_{\mathrm{AD}} \cdot\left|\mathrm{V}_{\mathrm{x}}\right|+\mathrm{CF}$ es el máximo flujo posible que puede entrar en la celda de estudio.

En cuanto al máximo flujo posible que puede entrar en la celda de estudio, este debe considerar:

- $\quad \mathrm{F}_{\mathrm{AD}} \cdot\left|\mathrm{V}_{\mathrm{x}}\right|$ es el flujo saliente desde la celda de estudio.

- CF es el flujo que podría entrar considerando los vacíos de las celdas de estudio y donante.

Respecto al último componente mencionado, éste se puede desglosar en:

- $\quad\left(1-\mathrm{F}_{\mathrm{AD}}\right) \cdot\left|\mathrm{V}_{\mathrm{x}}\right|$ es el flujo que podría entrar en la celda estudiada

- $\quad\left(1-F_{D}\right) \cdot d x_{D}$ es el flujo que no podría salir desde la celda donante 


\subsection{PROCESO DE SOLIDIFICACIÓN DE UNA GOTA DE MATERIAL FUNDIDO}

\subsubsection{EL PROBLEMA DE LA SOLIDIFICACIÓN}

Se han publicado numerosos estudios (Alhama, 1998) sobre problemas de cambio de fase, inicialmente se emplearon métodos numéricos para soluciones aproximadas, no siendo adecuados para todos ellos (Bankoff, 1964; Goodman, 1964; Carslaw y Jaeger, 1959; Crank, 1984).

Acerca del problema de la solidificación, tanto Lame y Clapeyron (Rubinstein, 1971) como Newman (Bankoff, 1964; Carslaw y Jaeger, 1959; Muelhbauer y Sunderland, 1965) realizaron propuestas sobre problemas unidimensionales, los primeros a cuya frontera se aplica una temperatura constante por debajo de la de fusión y el segundo con condiciones de frontera isoterma. El caso estudiado por Newman demanda la determinación de tres ecuaciones en derivadas parciales, una de balance energético y dos de difusión y su resolución y su solución indica que la posición de la frontera móvil es proporcional a la raíz cuadrada del tiempo.

Posteriormente, Stefan publicó una relación de artículos acerca del problema de una fase con frontera móvil y de dos fases para medios infinitos y semiinfinitos (Rubinstein, 1971; Carslaw y Jaeger, 1959; Muelhbauer y Sunderland, 1965; Stefan, 1981). Estos problemas son conocidos como "Problemas de Stefan".

Se han publicado otros trabajos de referencia (Alhama, 1998), como los problemas de frontera móvil (Landau, 1950; Evans et al., 1950), de solidificación con radiación (Ruan et al., 1955), de cambio de fase (Kreith y Romie, 1955), introducción de parámetros al problema de la solidificación (Goodman y Shea, 1960), de cambio de fase con hipótesis polinómica de temperaturas, (Imber y Huang, 1973), solidificación sin conducción en la fase sólida (Solomon, 1979), condiciones de contorno convectivas en el problema de Stefan (Lozano y Reemsten, 1981), aproximaciones de Frederick y Greif a los problemas con condiciones de contorno de primera clase (Frederick y Greif, 1985), soluciones aproximadas en placas finitas (Gutman, 1986), determinación de procesos de congelación (Cleland et al., 1987) y otros problemas (Oliver y Sunderland, 1987; Cho y Sunderland, 1974; Cerrato et al., 1989a, 1989b; Tao, 1981, 1989; Koichi y Kozo, 1990; Dursunkaya 
y Nair, 1990; Venkateshan y Kothari, 1987; Venkateshan y Solaiappan, 1990; Lecomte y Batsale, 1991; Zhong et al., 1991; Zhang et al., 1993b; Goodman y Shea, 1960; Zhang et al., 1993a; Nyros y Hsieh, 1994; Zubair y Chaudry, 1994; Hwang et al., 1994; Blackwell y Hogan, 1994; Ji y Bu-xuan, 1995; Loulou y Delaunay, 1997; Kahranan, 1998; Abhat, 1983 Eyres et al., 1946; Kumar y Raikar, 1988;Runnels y Carey, 1991; Hunter y Kuttler, 1989, 1991; Ramos et al.,1991, 1994a, 1994b; 1995; Shastri, 1998).

Si nos centramos exclusivamente en procesos de solidificación de salpicaduras, la mayoría de investigadores en los años sesenta y setenta estudiaron los aspectos metalúrgicos de la proyección (Kumar, 2014) e ignoraron los efectos asociados a la mecánica de fluidos. Como se ha mencionado en el apartado relativo a los algoritmos SOLA-VOF, en 1980 Nichols et al. desarrollaron un algoritmo alternativo para resolver la ecuación de Navier-Stokes en flujos transitorios con superficie libre múltiple (Nichols et al.,1980).

Trapaga et al. usaron un código comercial para estudiar la transferencia de calor y la solidificación de una salpicadura suponiendo un sustrato isotérmico, y despreciando la resistencia de contacto térmico entre la salpicadura y el sustrato (Trapaga et al., 1992).

Liu et al. desarrollaron un modelo de solidificación unidimensional junto con una técnica de flujo continuo bifásico para seguir la frontera líquido-sólido, aunque sin incluir la convección en el líquido y la conducción con el sustrato (Liu et al., 1993).

Bennet y Poulikakos estudiaron la deposición de una gota suponiendo que la solidificación comienza solo después del aplanamiento y considerando una salpicadura en forma de disco (Bennett y Poulikakos, 1994). Sus ensayos y cálculos mostraron que la conductividad térmica del sustrato afecta significativamente a la Vr de la salpicadura. Sus análisis no consideraron la convección.

Zhao et al. desarrollaron modelos y experimentos para estudiar la dinámica de fluidos y la transferencia de calor durante la formación de las salpicaduras (Zhao et al., 1996a, 1996b). Ampliaron el modelo de Fukai et al. para incorporar los fenómenos de conducción y convección térmica antes de la solidificación.

Wang y Matthys investigaron los efectos de la resistencia de contacto numérica y experimentalmente con gotas de cobre (Wang y Matthys, 1996). 
Chung y Rangel analizaron numéricamente la resistencia de contacto entre el sustrato y la salpicadura y el efecto de subenfriamiento en el contacto salpicadura-sustrato (Chung y Rangel, 2000).

Xu y Lavernia (Xu y Lavernia, 2001) desarrollaron un modelo numérico de la nucleación durante la proyección térmica. Sus resultados confirmaron que durante el estado inicial, una nucleación secundaria podía ocurrir en la porción líquida restante de la salpicadura. Las dos nucleaciones generaron granos grandes y pequeños entremezclados al final de la solidificación.

Wang et al. implementaron un modelo integrado de interacción entre flujo fundido y solidificación de no-equilibrio en procesos de proyección térmica (Wang et al., 2002; Yang et al., 2013)

Pasandideh-Fard et al. desarrollaron un modelo tridimensional de flujo con superficie libre que incluía transferencia de calor y solidificación de partículas de níquel (Pasandideh-Fard et al., 2002).

En este modelo, la transferencia de calor dentro de la gota se modeló resolviendo la ecuación de conservación de energía, despreciando la disipación viscosa y considerando que las densidades del líquido y del sólido eran constantes e iguales. Dado que la ecuación de energía tiene dos variables dependientes, la temperatura y la entalpía, se optó por un modelo de transformación de entalpía (Cao et al., 1989), que permite expresar energía sólo en función de la entalpía. La principal ventaja de este método consiste en permitir resolver ambas fases simultáneamente. Se consideraron condiciones adiabáticas en la superficie de la gota. El proceso de transmisión de calor más importante es la conducción a través del sustrato en el momento del impacto, mientras que después predomina la conducción y la convección dentro de la gota. El calor perdido por convección desde la superficie de la gota a la atmósfera es tres órdenes de magnitud menor que al sustrato. Por tanto, la condición adiabática está plenamente justificada. La resistencia de contacto entre la gota y el sustrato fue considerada como un valor conocido y constante. El modelo utilizó una versión modificada del método de velocidad fija.

Zhang et al. realizaron simulaciones numéricas de solidificación de salpicaduras de Mo sobre acero inoxidable o vidrio con espesores de 2 y $1 \mu \mathrm{m}$ y diámetros de 100 y $120 \mu \mathrm{m}$ respectivamente (Zhang et al., 2004). Se basaron en la teoría clásica de nucleación y 
consideraron una cinética de nucleación y generación de cristal heterogénea para obtener la temperatura de nucleación y la distribución de tamaño de grano.

Kamnis y Gu probaron mediante gotas de estaño y sustrato de acero que la resistencia térmica de contacto es un parámetro clave en la caracterización de la rugosidad del sustrato en procesos de modelización de impactos de gotas (Kamnis y Gu, 2005). Esta rugosidad determina el aplanamiento y solidificación de la salpicadura y la presencia de aire atrapado.

Dhiman et al. proponen un procedimiento de predicción de la morfología de la salpicadura basado en un parámetro definido por la correlación entre el espesor de la capa sólida en la base de la salpicadura durante el aplanamiento y el espesor tras la solidificación completa (Dhiman et al., 2007). Estos valores se calculan mediante un modelo analítico de solidificación que considera un sustrato semiinfinito, isotrópico y con propiedades térmicas constantes.

Wang et al. realizaron la simulación numérica unidimensional de la solidificación y fusión repetida en una serie de salpicaduras depositadas sucesivamente (Wang et al., 2008). Investigaron el efecto de la resistencia térmica de contacto, el sobrecalentamiento de la salpicadura, la temperatura del sustrato, el espesor de la salpicadura y la frecuencia de deposición de salpicaduras sobre la fusión repetida de las capas ya depositadas.

Para describir los fenómenos de no-equilibrio, sólo se usan modelos de transferencia de calor unidimensionales que incluyan líquido subenfriado, nucleación y cinética de crecimiento de cristales. Estos modelos (Lahmar-Mebdoua et al., 2010) consideran una nucleación donde la energía crítica depende fuertemente del ángulo de contacto entre la superficie del sustrato y el núcleo. La temperatura de la interfase está correlacionada con la velocidad de la frontera mediante una ecuación cinética lineal (Wang et al., 1998a). Las predicciones realizadas con estos modelos muestran que el material líquido podría alcanzar grados de subenfriamiento significativos. Lahmar et al. desarrollaron un modelo unidimensional de transferencia de calor entre salpicaduras de alúmina y sustratos lisos de acero y alúmina. Este modelo incluyó subenfriamiento, nucleación heterogénea en la interfase salpicadura-sustrato y crecimiento de cristal. Igualmente, consideró la existencia de una capa de óxido y precalentamiento del sustrato.

Kumar desarrolló un modelo mediante un software comercial para analizar el impacto y 
solidificación de gotas de aleación Al-33Cu sobre acero inoxidable 304 (Kumar, 2014). Este trabajo validó el resultado mediante la teoría de Jackson y Hunt (Jackson y Hunt, 1966), que relaciona el espaciado interlaminar en aleaciones eutécticas solidificadas con la velocidad del frente de solidificación.

Shukla et al. implementaron un modelo axisimétrico bidimensional para analizar el impacto, aplanamiento y solidificación rápida de una gota de metal sobre sustrato considerando una cinética de solidificación rápida de no equilibrio en la interfase (Shukla et al., 2018).

\subsubsection{PROBLEMA DE STEFAN}

Los elementos simples y los compuestos de tipo eutéctico, tienen una temperatura de fusión característica, $\mathrm{T}_{\mathrm{f}}(\mathrm{K})$. El resto de las sustancias, aleaciones y mezclas, materiales impuros, sustancias orgánicas, compuestos heterogéneos, etc., muestran un comportamiento diferente; aparece un intervalo de temperaturas dentro del cual coexisten ambas fases.

La geometría, las condiciones iniciales, las de contorno y el tipo de material o materiales que cambian de fase dan lugar a una gran variedad de combinaciones que se constituyen en problemas específicos, en el ámbito de la conducción con cambio de fase, también llamados problemas de frontera móvil. La mayor parte de ellos requieren el concurso de métodos numéricos para su solución.

El problema general de cambio de fase requiere resolver, por separado, la ecuación de conducción en cada una de las fases, despreciando el movimiento de convección en la fase líquida. La solución está definida por las condiciones iniciales y de contorno, más una condición añadida en la frontera móvil de cambio de fase que se traduce en una ecuación diferencial no lineal consecuencia de la aplicación del balance energético a la superficie de separación de las fases. Cualquier análisis de este problema implica conocer la evolución de la frontera móvil, lo que requiere, a su vez, la determinación del campo térmico transitorio en cada uno de los medios.

Para sustancias puras o compuestos del tipo eutéctico las fases quedan separadas por una superficie $S_{u p}$; el balance energético a través de un elemento de esta superficie $d S_{\text {up }}$ impone 


$$
\mathrm{j}_{\text {medio1_dS }}+\mathrm{j}_{\text {medio2_dS }}=\frac{\dot{\mathrm{Q}}}{\mathrm{A}}
$$

La traducción de esta condición en una expresión matemática, en el caso de que las densidades de las fases sean diferentes, debe tener en cuenta los efectos de contracción o dilatación de la fase naciente, líquida o sólida según se trate de procesos de fusión o solidificación, respectivamente. En general los cuerpos se contraen al solidificarse y la fase líquida tiene, en consecuencia, un movimiento convectivo que desplaza el líquido para ocupar el volumen contraído en la solidificación.

En el proceso de solidificación de un líquido semiinfinito, en geometría 1-D, para el que $\rho_{\mathrm{s}}>\rho_{\mathrm{l}}$; si $\mathrm{V}_{\mathrm{s}}(\mathrm{t})$ es la velocidad de la frontera sólido-líquido, $\mathrm{V}_{\mathrm{l}}(\mathrm{t})$ es la velocidad convectiva del líquido que compensa la contracción asociada al cambio de densidad y la superficie de frontera es la unidad, la conservación de la masa en la frontera exige que:

$$
\dot{\mathrm{m}}_{\text {fase_sólida }}=\dot{\mathrm{m}}_{\text {fase_líquida }}+\dot{\mathrm{m}}_{\text {líquido_por_convección }}
$$

o bien

$$
\rho_{\mathrm{s}} \mathrm{V}_{\mathrm{s}}=\rho_{\mathrm{l}}\left(\mathrm{V}_{\mathrm{s}}-\mathrm{V}_{\mathrm{l}}\right)
$$

Esta condición, llevada al balance energético resulta en la ecuación no lineal:

$$
\mathrm{K}_{\mathrm{s}}\left(\frac{\partial \mathrm{T}_{\mathrm{s}}}{\partial \mathrm{n}}\right)-\mathrm{K}_{\mathrm{l}}\left(\frac{\partial \mathrm{T}_{\mathrm{l}}}{\partial \mathrm{n}}\right)=\rho_{\mathrm{s}} \mathrm{L}_{\mathrm{f}}\left(\frac{\partial \mathrm{s}_{\mathrm{f}}}{\partial \mathrm{t}}\right)
$$

donde $\mathrm{s}_{\mathrm{f}}(\mathrm{t})$ es la posición de la frontera, $\mathrm{V}_{\mathrm{s}}=\mathrm{ds}_{\mathrm{f}} / \mathrm{dt}$, y $\mathrm{L}_{\mathrm{f}}$ el calor latente de fusión. Los subíndices s, 1 y f hacen referencia a las fases sólida y líquida, y a la frontera de fase, respectivamente.

En definitiva, para un proceso de solidificación de sustancias puras o compuestos de tipo eutéctico, con $\rho_{\mathrm{s}}>\rho_{\mathrm{l}}$, la formulación del problema viene dada por el conjunto de ecuaciones:

$$
\begin{array}{ll}
\text { Fase sólida: } & \nabla\left[\mathrm{K}_{\mathrm{s}} \nabla \mathrm{T}_{\mathrm{s}}(\overrightarrow{\mathrm{r}}, \mathrm{t})\right]=\rho_{\mathrm{s}} \mathrm{c}_{\mathrm{e}, \mathrm{s}}\left(\frac{\partial \mathrm{T}_{\mathrm{s}}}{\partial \mathrm{t}}\right) \\
\text { Fase líquida: } & \nabla\left[\mathrm{K}_{\mathrm{l}} \nabla \mathrm{T}_{\mathrm{l}}(\overrightarrow{\mathrm{r}}, \mathrm{t})\right]=\rho_{\mathrm{l}} \mathrm{c}_{\mathrm{e}, \mathrm{l}}\left(\frac{\partial \mathrm{T}_{\mathrm{l}}}{\partial \mathrm{t}}\right)
\end{array}
$$




$$
\text { Interfase sólido-líquido: } \quad \mathrm{K}_{\mathrm{S}}\left(\frac{\partial \mathrm{T}_{\mathrm{s}}}{\partial \mathrm{n}}\right)-\mathrm{K}_{\mathrm{l}}\left(\frac{\partial \mathrm{T}_{\mathrm{l}}}{\partial \mathrm{n}}\right)=\rho_{S} \mathrm{~L}_{\mathrm{f}}\left(\frac{\partial \mathrm{s}_{\mathrm{f}}}{\partial \mathrm{t}}\right)
$$

Las ecuaciones que rigen procesos de solidificación con $\rho_{\mathrm{s}}<\rho_{\mathrm{l}}$, se obtienen partiendo de los mismos principios de conservación masa y energía, en la frontera, y son de naturaleza similar.

Como se ha mencionado son muchos los compuestos en los que el cambio de fase se inicia, paulatinamente, dentro de un cierto intervalo de temperaturas; en las aleaciones de composición no eutéctica, por ejemplo, uno o los dos extremos del intervalo son función de la composición del compuesto, representándose esta información en diagramas de solidificación. En el proceso aparece una región difusa en la que coexisten ambas fases, con dos fronteras que las separan de las regiones unifásicas. Para estas sustancias, el problema de conducción puede formularse a partir de la entalpía, H(T), mediante una única ecuación que rige en todo el medio.

$$
\nabla[\mathrm{K} \nabla \mathrm{T}(\overrightarrow{\mathrm{r}}, \mathrm{t})]=\rho \frac{\partial \mathrm{H}}{\partial \mathrm{t}}
$$

y cuya solución implica disponer de la relación de la entalpía con la temperatura, que suele ser una función continua. Mediante esta formulación del problema, llamada método o modelo entálpico, propuesta inicialmente por Eyres (Eyres et al., 1946) y posteriormente desarrollada por Baxter (Baxter, 1962), se evita la discontinuidad que presenta la frontera de fase aún en los problemas que tratan con sustancias puras, a las que también es aplicable el método (Shamsundar y Sparrow, 1975). Sin embargo, las técnicas basadas en diferencias finitas dan problemas a la hora de asegurar la conservación de la energía en la frontera (Kurz y Fisher, 1992).

Por tanto, en los procesos de conducción en los que la no linealidad más importante se debe a un proceso progresivo de cambio de fase que tiene lugar en el medio, encuadrados dentro de los llamados problemas de frontera móvil. La aplicación de métodos numéricos clásicos requiere de ciertos refinamientos para evitar problemas de convergencia en la simulación.

A un medio homogéneo, unidimensional y semiinfinito, con una temperatura fija para el cambio de fase sólido-líquido, con una temperatura superior a la de fusión se le aplica una condición de contorno de temperatura constante por debajo de la de fusión, en la 
frontera. El calor extraído por la pared enfría el líquido, lo que resulta en un efecto de solidificación gradual.

Si la densidad de cada etapa es distinta, se producirá una expansión o contracción continua en la nueva etapa, lo que dificulta la distribución de coordenadas. Se puede emplear el sistema de coordenadas formulado por Grigull y Sandner, en el que la pared en el instante inicial es la referencia para especificar la posición de la frontera (Grigull y Sadner, 1984). El conjunto de coordenadas espaciales, se define de acuerdo con la fig. 2.49. En esta figura se definen las siguientes abscisas medidas respecto a la posición inicial de la pared: $\mathrm{x}_{1}$ para un punto de la fase líquida $\mathrm{y} \mathrm{s}_{\mathrm{f}-1}$ para la frontera. $\mathrm{Y}$ otras medidas respecto a la posición actual de la pared: $x_{\mathrm{s}}$ para un punto de la fase sólida y Sf-s para la frontera.

Así mismo, en un instante t se definen las temperaturas: $T_{\mathrm{s}}$ para el valor en un punto de la fase sólida con una coordenada $\mathrm{x}_{\mathrm{s}}, \mathrm{y} \mathrm{T}_{1}$ para el valor en un punto de la fase líquida de coordenada $\mathrm{x}_{1}$. La temperatura de fusión del medio se designa mediante $\mathrm{T}_{\mathrm{f}}$, la condición de contorno, temperatura en la pared, por $\mathrm{T}_{\text {pared }} \mathrm{y}$ el valor inicial, temperatura en el líquido, por $\mathrm{T}_{\mathrm{o}}$.

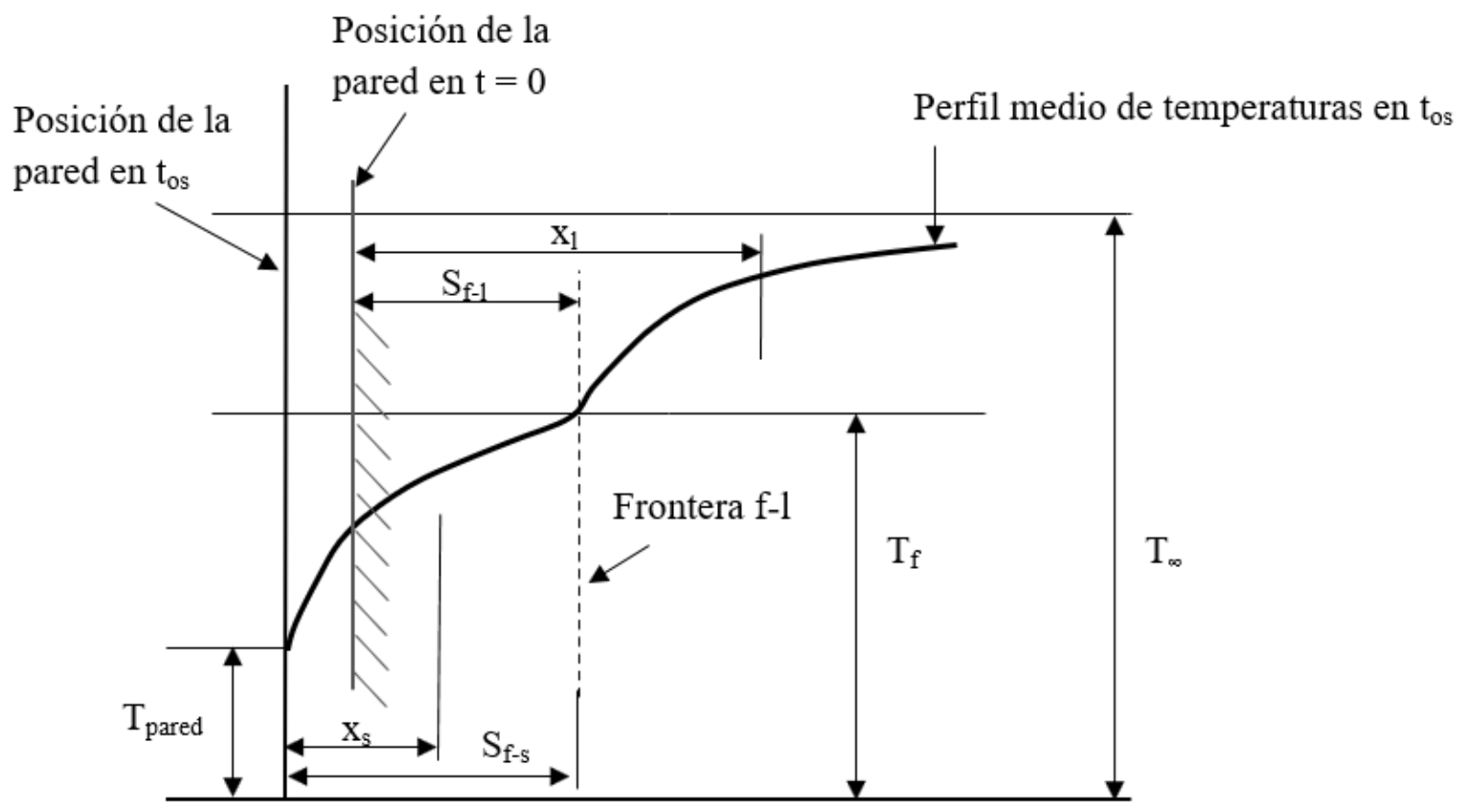

Figura 2.49 Problema de Stefan. Geometría y sistema de coordenadas (Alhama, 1998).

Las propiedades del material son consideradas independientes de la temperatura y designadas mediante: $\rho_{1}$ y $\rho_{\mathrm{s}}$ para las densidades de las fases líquida y sólida, $\mathrm{c}_{\mathrm{e}, 1}$ y $\mathrm{c}_{\mathrm{e}, \mathrm{s}}$ 
para los calores específicos de las fases líquida y sólida, $\mathrm{K}_{1}$ y $\mathrm{K}_{\mathrm{s}}$ para las conductividades térmicas de las fases líquida y sólida, $\mathrm{D}_{1}$ y $\mathrm{D}_{\mathrm{s}}$ para las difusividades de las fases líquida y sólida, siendo $\mathrm{D}_{\mathrm{i}}=\mathrm{K}_{\mathrm{i}} /\left(\rho \cdot c_{\mathrm{e}, \mathrm{i}}\right)$ con $\mathrm{i}=1$ o s, y $\mathrm{L}_{\mathrm{s}}$ para el calor latente de solidificación.

El modelo matemático está formado por las ecuaciones de difusión de las fases líquida y sólida, respectivamente:

$$
\begin{aligned}
& \frac{\partial \mathrm{T}_{1}}{\partial \mathrm{t}}=\mathrm{D}_{\mathrm{l}} \frac{\partial^{2} \mathrm{~T}_{\mathrm{l}}}{\partial \mathrm{x}_{\mathrm{l}}^{2}} \\
& \frac{\partial \mathrm{T}_{\mathrm{s}}}{\partial \mathrm{t}}=\mathrm{D}_{\mathrm{s}} \frac{\partial^{2} \mathrm{~T}_{\mathrm{s}}}{\partial \mathrm{x}_{\mathrm{s}}^{2}}
\end{aligned}
$$

Las condiciones iniciales vienen definidas por:

$$
\begin{gathered}
\mathrm{T}_{\mathrm{l},(\mathrm{t}=0)}=\mathrm{T}_{0} \\
\mathrm{~s}_{\mathrm{f}-\mathrm{l},(\mathrm{t}=0)}=\mathrm{s}_{\mathrm{f}-\mathrm{s},(\mathrm{t}=0)}=0
\end{gathered}
$$

Las condiciones de contorno son:

$$
\begin{gathered}
\mathrm{T}_{\mathrm{s}, \operatorname{pared}(\mathrm{t} \geq 0)}=\mathrm{T}_{\text {pared }} \\
\mathrm{T}_{\mathrm{l}(\mathrm{x} \rightarrow \infty)}=\mathrm{T}_{0}
\end{gathered}
$$

Y las condiciones de frontera en la interfase sólido-líquido son:

$$
\begin{gathered}
\mathrm{T}_{\mathrm{s}}\left(\mathrm{x}_{\mathrm{s}}=\mathrm{s}_{\mathrm{f}-\mathrm{s}}\right)=\mathrm{T}_{\mathrm{l}}\left(\mathrm{x}_{\mathrm{l}}=\mathrm{s}_{\mathrm{f}-\mathrm{l}}\right)=\mathrm{T}_{\mathrm{f}} \\
\mathrm{K}_{\mathrm{s}}\left[\left(\frac{\partial \mathrm{T}_{\mathrm{s}}}{\partial \mathrm{x}_{\mathrm{s}}}\right)\right]_{\mathrm{sf}-\mathrm{s}}-\mathrm{K}_{\mathrm{l}}\left[\left(\frac{\partial \mathrm{T}_{\mathrm{l}}}{\partial \mathrm{x}_{\mathrm{l}}}\right)\right]_{\mathrm{sf}-\mathrm{l}}-\rho_{\mathrm{s}} \mathrm{L}_{\mathrm{s}}\left(\frac{\mathrm{ds}_{\mathrm{f}-\mathrm{s}}}{\mathrm{dt}}\right)=0
\end{gathered}
$$

La última de las cuales se obtiene de aplicar el balance energético a la frontera.

La solución propuesta por Newman al problema de Stefan implica considerar el campo térmico en cada fase, expresado en forma adimensional mediante $\theta_{\mathrm{s}} \mathrm{y} \theta_{\mathrm{l}}$, respectivamente $\left(\mathrm{T}_{\mathrm{s}}-\mathrm{T}_{\mathrm{p}}\right) /\left(\mathrm{T}_{\mathrm{f}}-\mathrm{T}_{\mathrm{p}}\right)$ y $\left(\mathrm{T}_{1}-\mathrm{T}_{\mathrm{f}}\right) /\left(\mathrm{T}_{\mathrm{o}}-\mathrm{T}_{\mathrm{f}}\right)$, según las ecuaciones: 


$$
\begin{gathered}
\theta_{\mathrm{s}}=\frac{\operatorname{Erf}\left(\frac{1}{2 \cdot \sqrt{\mathrm{Fo}_{\mathrm{X}, \mathrm{s}}}}\right)}{\operatorname{Erf}(\delta)} \\
\theta_{\mathrm{l}}=1-\frac{\operatorname{Erf}\left(\frac{1}{2 \sqrt{\mathrm{Fo}_{\mathrm{x}, \mathrm{l}}}}+\delta \cdot \frac{1-\lambda}{\lambda}\right)}{\operatorname{Erfc}\left(\frac{\delta}{\lambda \cdot \sqrt{\mathrm{a}}}\right)}
\end{gathered}
$$

Donde $\mathrm{Fo}_{\mathrm{x}, \mathrm{s}}$ y $\mathrm{Fo}_{\mathrm{x}, 1}$ son respectivamente $\mathrm{D}_{\mathrm{s}} \mathrm{t} / \mathrm{x}_{\mathrm{s}}^{2}$ y $\mathrm{D}_{\mathrm{l}} \mathrm{t} / \mathrm{x}_{1}{ }^{2}$, a es $\mathrm{D}_{1} / \mathrm{D}_{\mathrm{s}}$ y $\lambda$ es $\rho_{1} / \rho_{\mathrm{s}}$.

Erf y Erfc son respectivamente las funciones de error y complementaria de error, y $\delta$ es la solución de la ecuación transcendente:

$$
\delta \cdot \sqrt{\pi} \cdot \text { Ste }=\frac{1}{\exp \left(\delta^{2}\right) \cdot \operatorname{Erf}(\delta)}-\frac{\beta \cdot \theta_{\text {ref }}}{\exp \left(\frac{\delta^{2}}{\mathrm{a} \cdot \lambda^{2}}\right) \cdot \operatorname{Erfc}\left(\frac{\delta}{\lambda \cdot \sqrt{\mathrm{a}}}\right)}
$$

donde $\beta$ es $k_{2} /\left(k_{1} \cdot \sqrt{a}\right)$ y $\theta$ ref es $\left(T_{o}-T_{f}\right) /\left(T_{f}-T_{p}\right)$.

Ste es la forma adoptada para el número de Stefan, indicativo de la relación entre el calor latente y el calor sensible:

$$
\text { Ste }=\frac{\mathrm{c}_{\mathrm{f}}}{\mathrm{c}_{\mathrm{e}, \mathrm{s}} \cdot\left(\mathrm{T}_{\mathrm{f}}-\mathrm{T}_{\mathrm{p}}\right)}
$$

La evolución de la frontera de cambio de fase puede obtenerse a partir de la ecuación 2.52 haciendo $\theta_{\mathrm{s}}$ igual a 1 , o $\mathrm{T}_{\mathrm{s}}$ igual a $\mathrm{T}_{\mathrm{f}}$. La solución es:

$$
\mathrm{s}_{\mathrm{f}-\mathrm{s}}=2 \cdot \delta \cdot \sqrt{\mathrm{t} \cdot \mathrm{D}_{\mathrm{s}}}
$$

Para que el líquido solidifique, el calor debe ser eliminado mediante dos procedimientos: conducción a otras zonas más frías del sólido o mediante flujos de calor a través de las superficies libres del líquido o el sólido.

En la conducción, el intercambio energético tiene lugar en fluidos en reposo, o sólidos, debido a la presencia de un gradiente térmico en el medio (Alhama, 1998). Para un medio homogéneo e isótropo, la relación entre la densidad de flujo calorífico, $\vec{\jmath}$, y el gradiente térmico viene dada por la ley de Fourier 


$$
\vec{j}(\vec{r}, t)=-K \cdot \nabla[T(\vec{r}, t)]
$$

donde $\mathrm{K}$ es la conductividad térmica, $\overrightarrow{\mathrm{r}}$ es la posición y t el tiempo.

En general, el valor de la conductividad depende de la temperatura en mayor o menor grado. Los tipos de dependencias de $\mathrm{K}$ con $\mathrm{T}$ son muy amplios y las aproximaciones sólo son adecuadas para ciertos rangos de temperatura. No obstante, se puede afirmar que las dependencias más comunes incluyen básicamente funciones del tipo polinómico de grado arbitrario, exponenciales de argumento directa o inversamente proporcional a $\mathrm{T}, \mathrm{o}$ combinación de ambas.

La ecuación diferencial de conducción del calor para un medio en reposo, isótropo, homogéneo y que genera o absorbe calor en su interior, es

$$
-(\nabla \cdot \vec{\jmath})+g(\vec{r}, t)=\rho \cdot c_{p} \cdot \frac{\partial T}{\partial t}
$$

donde $\mathrm{g}(\vec{r}, \mathrm{t})$ es la densidad de potencia, $\rho$ es la densidad y $\mathrm{c}_{\mathrm{p}}$ el calor específico a presión constante.

El calor específico de los cuerpos sólidos tiende a cero conforme la temperatura absoluta se acerca a cero; a temperaturas superiores a la de Debye, $\theta_{\mathrm{D}}$, tiene un comportamiento asintótico al aumentar T. Por debajo de $\theta_{\mathrm{D}}$, la dependencia de $c_{\mathrm{e}}$ con $\mathrm{T}$ puede ser aproximada por tramos mediante funciones polinómicas y exponenciales.

Haciendo uso de la expresión de Fourier, (2.57), la ecuación 2.59 puede escribirse

$$
\nabla \cdot[\mathrm{K} \cdot \nabla \mathrm{T}(\overrightarrow{\mathrm{r}}, \mathrm{t})]+\mathrm{g}(\overrightarrow{\mathrm{r}}, \mathrm{t})=\rho \cdot \mathrm{c}_{\mathrm{e}} \cdot \frac{\partial \mathrm{T}}{\partial \mathrm{t}}
$$

y si $\mathrm{K}$ y ce son constantes y no existe generación interna de calor, la ecuación se reescribe como:

$$
\nabla^{2} \mathrm{~T}(\overrightarrow{\mathrm{r}}, \mathrm{t})=\frac{1}{\mathrm{D}_{\mathrm{i}}} \cdot \frac{\partial \mathrm{T}(\overrightarrow{\mathrm{r}}, \mathrm{t})}{\partial \mathrm{t}}
$$

donde $\mathrm{D}_{\mathrm{i}}=\mathrm{K} /\left(\rho \cdot \mathrm{c}_{\mathrm{e}}\right)$ es la llamada difusividad térmica, asociada con la rapidez de propagación del calor en el medio, con i= 1 o s.

En cuanto al flujo calorífico de conducción según la dirección normal a la superficie del 
elemento, para un elemento de superficie de área dA, toma el valor

$$
\mathrm{j}_{\mathrm{n}}(\overrightarrow{\mathrm{r}})=-\left.\mathrm{K} \cdot \frac{\partial \mathrm{T}(\overrightarrow{\mathrm{r}})}{\partial \mathrm{n}}\right|_{\text {pared }}
$$

Los flujos caloríficos a través de superficies se pueden definir como:

- $\quad$ jfuente, flujo entrante a través de dA, procedente de una fuente externa,

- $\quad j_{\text {conv }}$, representa el intercambio de energía por convección con un fluido exterior. Su valor es

$$
\mathrm{j}_{\text {conv }}=\mathrm{h}_{\mathrm{i}} \cdot\left(\mathrm{T}_{\text {pared }}-\mathrm{T}_{\infty}\right)
$$

donde $\mathrm{T}_{\text {pared }}$ es la temperatura en la pared, $\mathrm{T}_{\infty}$ la del fluido exterior lejos de la superficie y $h_{i}$ el llamado coeficiente de transferencia de calor o coeficiente de película; este coeficiente depende del tipo de flujo, de la geometría y aspecto superficial de la pared, de la diferencia de temperaturas $\left(\mathrm{T}_{\mathrm{pared}}-\mathrm{T}_{\infty}\right)$, de las propiedades físicas del fluido, etc.

- $\quad \mathrm{j}_{\mathrm{rad}}$, representa el intercambio de calor por radiación hacia el medio exterior. Su valor viene dado por

$$
\mathrm{j}_{\text {rad }}=\varepsilon \cdot \sigma \cdot\left(\mathrm{T}_{\text {pared }}^{4}-\mathrm{T}_{\mathrm{r}}^{4}\right)
$$

donde $\sigma$ la constante de Stefan-Boltzmann, $\varepsilon$ es la emisividad de la superficie y $\mathrm{T}_{\mathrm{r}}$ la temperatura de referencia del medio exterior para la radiación.

El balance energético a través de $\mathrm{dA}, \mathrm{j}_{\mathrm{n}}\left(\overrightarrow{\mathrm{r}}_{\text {frontera }}\right)=\mathrm{j}_{\text {fuente }}+\mathrm{j}_{\text {conv }}+\mathrm{j}_{\text {rad }}$, usando las ecuaciones 2.63 y 2.64 , puede escribirse,

$$
-\left.\mathrm{K} \frac{\partial \mathrm{T}(\mathrm{r})}{\partial \mathrm{n}}\right|_{\text {pared }}=-\mathrm{j}_{\text {fuente }}+\mathrm{h}_{\mathrm{i}} \cdot\left(\mathrm{T}_{\text {pared }}-\mathrm{T}_{\infty}\right)+\varepsilon \sigma\left[\mathrm{T}_{\text {pared }}^{4}-\mathrm{T}_{\mathrm{r}}^{4}\right]
$$

estando solo en función de una variable, la temperatura en la pared, $\mathrm{T}_{\text {pared. }}$

Estos flujos, están asociados a condiciones de contorno, pueden agruparse en distintas clases. Así, la condición de contorno de primera clase define la temperatura en la frontera como una función habitualmente dependiente del tiempo y la posición, $\mathrm{T}\left(\overrightarrow{\mathrm{r}}_{\text {frontera, }}, \mathrm{t}\right)$. Así, 
se denomina condición de contorno homogénea de primera clase a $\mathrm{T}\left(\overrightarrow{\mathrm{r}}_{\text {frontera }}, \mathrm{t}\right)=0$.

En la condición de contorno de segunda clase el flujo externo en la superficie de la pared es conocido, y generalmente corresponde a un eje de simetría:

$$
-\left.\mathrm{K} \frac{\partial \mathrm{T}(\overrightarrow{\mathrm{r}})}{\partial \mathrm{n}}\right|_{\text {pared }}=0
$$

La condición de contorno de tercera clase corresponde a una condición convectiva. En este caso, el flujo de conducción en la superficie de la pared coincide con el de convección del fluido exterior,

$$
-\left.\mathrm{K} \frac{\partial \mathrm{T}(\mathrm{r})}{\partial \mathrm{n}}\right|_{\text {pared }}=\mathrm{h}_{\mathrm{i}} \cdot\left(\mathrm{T}_{\text {pared }}-\mathrm{T}_{\infty}\right)
$$

Una condición de contorno asimilable a esta clase sucede cuando dos medios de igual o diferente conductividad se someten a un contacto térmico imperfecto. El balance energético en una frontera así requiere que se cumpla una ecuación lineal del tipo

$$
-\left.\mathrm{K}_{1} \frac{\partial \mathrm{T}(\overrightarrow{\mathrm{r}})}{\partial \mathrm{n}}\right|_{\text {pared,1 }}=\mathrm{h}_{\mathrm{i} 1,2} \cdot\left(\mathrm{T}_{\text {pared }, 1}-\mathrm{T}_{\text {pared }, 2}\right)=-\left.\mathrm{K}_{2} \frac{\partial \mathrm{T}(\overrightarrow{\mathrm{r}})}{\partial \mathrm{n}}\right|_{\text {pared,2 }}
$$

donde $\mathrm{h}_{\mathrm{i} 1,2}$ es la llamada conductancia térmica de contacto entre medios, que depende de la rugosidad de las superficies, tipo de material, presión de contacto, material de separación de los medios, etc.

Para un contacto perfecto y conductancia infinita, la ecuación 2.68 se convierte

$$
-\left.\mathrm{K}_{1} \frac{\partial \mathrm{T}(\overrightarrow{\mathrm{r}})}{\partial \mathrm{n}}\right|_{\text {pared }}=-\left.\mathrm{K}_{2} \frac{\partial \mathrm{T}(\overrightarrow{\mathrm{r}})}{\partial \mathrm{n}}\right|_{\text {pared }}
$$

La condición de contorno radiante viene definida por:

$$
-\left.\mathrm{K} \frac{\partial \mathrm{T}(\overrightarrow{\mathrm{r}})}{\partial \mathrm{n}}\right|_{\text {pared }}=\varepsilon \cdot \sigma \cdot\left(\mathrm{T}_{\text {pared }}^{4}-\mathrm{T}_{\mathrm{r}}^{4}\right)
$$

Algunos autores califican esta condición, cuando $\varepsilon$ y $T_{\mathrm{r}}$ son constantes, como cuarta clase (Mills, 1995). En el caso que $\left|\left(\mathrm{T}_{\text {pared }}-\mathrm{T}_{\mathrm{r}}\right) / \mathrm{T}_{\mathrm{r}}\right|<<1$, la ecuación 2.70 puede aproximarse mediante la ecuación lineal: 


$$
-\left.\mathrm{K} \frac{\partial \mathrm{T}\left(\mathrm{r}^{3}\right)}{\partial \mathrm{n}}\right|_{\text {pared }}=\mathrm{h}_{\mathrm{r}} \cdot\left(\mathrm{T}_{\text {pared }}-\mathrm{T}_{\mathrm{r}}\right)
$$

donde $\mathrm{h}_{\mathrm{r}}$ viene definido $4 \cdot \varepsilon \cdot \sigma \cdot \mathrm{T}_{\mathrm{r}}^{3}$.

\subsection{MODELOS DE IMPACTO Y SOLIDIFICACION DE UNA GOTA FUNDIDA}

\subsubsection{ECUACIONES DE BALANCE, CONDICIONES INICIALES Y DE CONTORNO DEL IMPACTO ISOTÉRMICO DE UNA GOTA}

Dada la simetría axial de la gota se van a utilizar coordenadas cilíndricas. Las ecuaciones de conservación de momento, ecuaciones de Navier Stokes, para este tipo de coordenadas son (Versteeg y Malalasekera, 2007):

$$
\begin{gathered}
\rho\left(\frac{\partial \mathrm{u}_{\mathrm{r}}}{\partial \mathrm{t}}+\mathrm{u}_{\mathrm{r}} \cdot \frac{\partial \mathrm{u}_{\mathrm{r}}}{\partial \mathrm{r}}+\mathrm{u}_{\mathrm{z}} \cdot \frac{\partial \mathrm{u}_{\mathrm{r}}}{\partial \mathrm{z}}\right)=-\frac{\partial \mathrm{P}}{\partial \mathrm{r}}+\mu\left[\frac{1}{\mathrm{r}} \frac{\partial}{\partial \mathrm{r}}\left(\mathrm{r} \cdot \frac{\partial \mathrm{u}_{\mathrm{r}}}{\partial \mathrm{r}}\right)-\frac{\mathrm{u}_{\mathrm{r}}}{\mathrm{r}^{2}}+\frac{\partial^{2} \mathrm{u}_{\mathrm{r}}}{\partial \mathrm{z}^{2}}\right] \\
\rho\left(\frac{\partial \mathrm{u}_{\mathrm{z}}}{\partial \mathrm{t}}+\mathrm{u}_{\mathrm{r}} \cdot \frac{\partial \mathrm{u}_{\mathrm{z}}}{\partial \mathrm{r}}+\mathrm{u}_{\mathrm{z}} \cdot \frac{\partial \mathrm{u}_{\mathrm{z}}}{\partial \mathrm{z}}\right)=-\frac{\partial \mathrm{P}}{\partial \mathrm{z}}+\rho \cdot \mathrm{g}+\mu\left[\frac{1}{\mathrm{r}} \frac{\partial}{\partial \mathrm{r}}\left(\mathrm{r} \cdot \frac{\partial \mathrm{u}_{\mathrm{z}}}{\partial \mathrm{r}}\right)+\frac{\partial^{2} \mathrm{u}_{\mathrm{z}}}{\partial \mathrm{z}^{2}}\right]
\end{gathered}
$$

donde $\mu$ es la viscosidad dinámica, y P y g son la presión del fluido y la aceleración de la gravedad respectivamente, $\mathrm{r}$ y $\mathrm{z}$ son las coordenadas cilíndricas, $\mathrm{y} \mathrm{u}_{\mathrm{r}} \mathrm{y} \mathrm{u}_{\mathrm{z}}$ son las velocidades según las coordenadas mencionadas.

Las ecuaciones 2.72 y 2.73 deben ser complementadas con una ecuación de continuidad que considere los efectos de compresibilidad:

$$
\frac{1}{\mathrm{r}} \cdot \frac{\partial\left(\mathrm{r} \cdot \mathrm{u}_{\mathrm{r}}\right)}{\partial \mathrm{r}}+\frac{\partial \mathrm{u}_{\mathrm{z}}}{\partial \mathrm{z}}=\frac{1}{\rho \cdot \mathrm{c}^{2}} \cdot \frac{\partial \mathrm{P}}{\partial \mathrm{t}}
$$

donde c es la velocidad adiabática del sonido en el fluido.

Si se considera la gota en movimiento descendente sobre el eje $\mathrm{z}$ las condiciones iniciales son

$$
\mathrm{u}_{\mathrm{r}}(\mathrm{r}, \mathrm{z})=0
$$

en todo el dominio, $\mathrm{y}$

$$
\mathrm{u}_{\mathrm{z}}(\mathrm{r}, \mathrm{z})=-1 \text {, en celdas dentro de la gota }
$$




$$
\mathrm{u}_{\mathrm{z}}(\mathrm{r}, \mathrm{z})=0 \text {, en celdas fuera de la gota }
$$

La posición inicial del centro de la gota viene dada por $\left(\mathrm{r}_{0}, \mathrm{z}_{0}\right)$ y el valor inicial de la presión es el de la atmosférica. El valor inicial de la fracción de volumen es la unidad en el interior de la gota y cero fuera.

El dominio a estudiar es un rectángulo delimitado en su base por una superficie sólida donde impacta la gota. La condición de contorno en el borde inferior, con coordenada $\mathrm{z}$ $=0$, equivale a un deslizamiento nulo. La condición de contorno en el eje de simetría, por tanto, con una velocidad radial nula, es $\partial \mathrm{u}_{\mathrm{z}} / \partial \mathrm{r}=0$. Este eje se sitúa sobre una línea con coordenada $\mathrm{r}=0$. Los dos lados restantes del dominio rectangular, definidos por $\mathrm{z}=\mathrm{Z} \mathrm{y}$ $\mathrm{r}=\mathrm{B}$, están muy alejados de la gota, por lo que no intervienen en el proceso. Esta condición equivale a una velocidad nula en la dirección perpendicular al borde y un gradiente nulo de la velocidad en la dirección paralela al borde. Estas condiciones de contorno se traducen en las siguientes ecuaciones:

$$
\begin{aligned}
& u_{r}(0, z)=0 \\
& u_{r}(B, z)=0 \\
& u_{r}(Z, 0)=0 \\
& \left.\frac{\partial u_{r}(r, z)}{\partial z}\right|_{z=Z}=0 \\
& \left.\frac{\partial u_{z}(r, z)}{\partial r}\right|_{r=0}=0 \\
& \left.\frac{\partial u_{z}(r, z)}{\partial r}\right|_{r=B}=0 \\
& u_{z}(r, 0)=0 \\
& u_{z}(r, Z)=0
\end{aligned}
$$

Dado que la gota no queda confinada en un lugar del dominio, la fracción de volumen debe ser considerada con las ecuaciones anteriores.

Las condiciones iniciales para la fracción de volumen equivalen a valores nulos en los centros de celda, salvo dentro de la gota, donde la fracción de volumen es la unidad. 
Además, cuando se produce el llenado de una celda concreta, la fracción de volumen en su centro varía entre 0 y 1.

Utilizando F, la ecuación de continuidad puede formularse como:

$$
\frac{\partial \mathrm{F}}{\partial \mathrm{t}}+\frac{1}{r} \frac{\partial\left(\mathrm{r} \cdot \mathrm{u}_{\mathrm{r}} \cdot \mathrm{F}\right)}{\partial \mathrm{r}}+\frac{\partial\left(\mathrm{u}_{\mathrm{z}} \cdot \mathrm{F}\right)}{\partial \mathrm{z}}=0
$$

\subsubsection{ECUACIONES DE BALANCE, CONDICIONES INICIALES Y DE CONTORNO DEL PROCESO DE SOLIDIFICACIÓN}

La ecuación diferencial de conducción del calor para un medio en reposo, isótropo, homogéneo y que genera o absorbe calor en su interior, es (Bejan y Kraus, 2003):

$$
\begin{aligned}
& \mathrm{D}_{\mathrm{l}}\left(\frac{1}{\mathrm{r}} \frac{\partial \mathrm{T}_{\mathrm{l}}}{\partial \mathrm{r}}+\frac{\partial^{2} \mathrm{~T}_{\mathrm{l}}}{\partial \mathrm{r}^{2}}+\frac{\partial^{2} \mathrm{~T}_{\mathrm{l}}}{\partial \mathrm{z}^{2}}\right)=\frac{\partial \mathrm{T}_{\mathrm{l}}}{\partial \mathrm{t}} \\
& \mathrm{D}_{\mathrm{s}}\left(\frac{1}{\mathrm{r}} \frac{\partial \mathrm{T}_{\mathrm{s}}}{\partial \mathrm{r}}+\frac{\partial^{2} \mathrm{~T}_{\mathrm{s}}}{\partial \mathrm{r}^{2}}+\frac{\partial^{2} \mathrm{~T}_{\mathrm{s}}}{\partial \mathrm{z}^{2}}\right)=\frac{\partial \mathrm{T}_{\mathrm{s}}}{\partial \mathrm{t}}
\end{aligned}
$$

donde $\mathrm{D}_{\mathrm{i}}=\mathrm{k} /\left(\rho \cdot \mathrm{c}_{\mathrm{e}}\right)$ es la llamada difusividad térmica, asociada con la rapidez de propagación del calor en el medio, con i= 1 o s.

El modelo matemático de la ecuación de Stefan está formado por:

$$
\mathrm{K}_{\mathrm{s}} \frac{\partial \mathrm{T}}{\partial \mathrm{n}}-\mathrm{K}_{\mathrm{l}} \frac{\partial \mathrm{T}}{\partial \mathrm{n}}=\rho \mathrm{L}_{s} \frac{\partial \mathrm{u}_{\mathrm{n}}}{\partial \mathrm{t}}
$$

donde la conductividad térmica del sólido es $\mathrm{K}_{\mathrm{s}}$, la conductividad térmica del líquido es $\mathrm{K}_{1}$ y el avance en la dirección normal de la frontera es $\mathrm{u}_{\mathrm{n}}$.

Nos encontramos tres fases: cuando el material está fundido, ecuación 2.90, cuando el material está solidificando, con la temperatura igual a la de solidificación y cuando ha solidificado, ecuación 2.88 .

Una formulación alternativa al uso de la ecuación de Stefan es considerar que un volumen infinitesimal de material líquido a la temperatura de solidificación finaliza dicho proceso cuando transfiere el calor latente de solidificación:

$$
-\mathrm{K}_{\mathrm{l}}\left(\frac{\partial \mathrm{T}_{1}}{\partial \mathrm{r}}+\frac{1}{\mathrm{r}} \frac{\partial \mathrm{T}_{1}}{\partial \theta}+\frac{\partial \mathrm{T}_{1}}{\partial \mathrm{z}}\right) \mathrm{dS}=\mathrm{L}_{\mathrm{s}} \rho \frac{\mathrm{d} \Omega}{\mathrm{dt}}
$$


Si el problema es axisimétrico la ecuación 2.90 se transforma en:

$$
-\mathrm{K}_{\mathrm{l}}\left(\frac{\partial \mathrm{T}_{1}}{\partial \mathrm{r}}+\frac{\partial \mathrm{T}_{1}}{\partial \mathrm{z}}\right) \mathrm{dS}=\mathrm{L}_{\mathrm{s}} \rho \frac{\mathrm{d} \Omega}{\mathrm{dt}}
$$

El dominio a estudiar corresponde a la sección de la gota tras el impacto. Una simplificación aplicable consiste en considerar esta sección equivalente a un rectángulo. En el eje de simetría la condición de contorno es adiabática. Al contorno superior y derecho le corresponden condiciones convectivas.

$$
\frac{\mathrm{dQ}}{\mathrm{dt}}=\mathrm{h}_{\mathrm{i}}\left(\mathrm{T}_{\mathrm{sup}}-\mathrm{T}_{\mathrm{amb}}\right) \mathrm{dS}
$$

\subsection{MÉTODO DE SIMULACIÓN POR REDES (MESIR)}

El MESIR, empleado de forma eficaz en determinados ámbitos de la ingeniería, como se ha comentado en el apartado 1.1, ha servido para implementar aplicaciones informáticas autónomas, bien para simulación, diseño y optimización de problemas de flujo de fluidos, transmisión de calor, de elasticidad o corrosión. Ejemplos de ellos son PROCCA-09 (Alhama y del Cerro Velázquez, 2010), PRODASIM (Gómez Lopera et al., 2006), FAHET (Alhama et al., 2010a), FATSIM-A (Alhama et al., 2010b), EPSNET_10 (Morales et al., 2011) y OXIPSIS_12 (Alhama y Sánchez, 2013).

Originariamente, el MESIR es un método en el que mediante modelos matemáticos pueden simularse procesos físicos. Las etapas en que consiste son, en primer lugar, la elaboración de un circuito eléctrico equivalente o modelo en red y en segundo lugar la resolución de dicho modelo mediante un adecuado programa.

La equivalencia entre dicho modelo y el proceso físico se basa en que ambos están gobernados por idénticas ecuaciones diferenciales en diferencias finitas en el espacio, referidas tanto a las condiciones de contorno como a la celda o volumen elemental. En el diseño de este modelo el tiempo se mantiene como variable continua.

El modelo en red se elabora reticulando el espacio en celdas elementales o elementos de volumen y aplicado las ecuaciones diferenciales. De esta forma, se genera una colección de ecuaciones en diferencias finitas que suponen el inicio del modelo en red. Es indispensable el establecimiento de la correspondencia entre variables eléctricas y 
las dependientes del problema, así como la asociación de celdas a la geometría del problema que alcanzará un mayor nivel de precisión a mayor número de dichas celdas.

En los procesos de transporte, en los que se constituye una relación entre variables de tipo potencial y de flujo, se establecen tantos circuitos distintos como ecuaciones incluya el modelo matemático.

\subsubsection{EL MESIR COMO MÉTODO NUMÉRICO}

En el MESIR siempre se parte de una serie de ecuaciones en derivadas parciales (EDP) espacio-temporales que definen el modelo matemático de un determinado proceso. La discretización de la variable espacial, es el pilar para crear el modelo en red, que sirve como esquema de programación para Ngspice (Nenzi y Vogt, 2014), el paquete informático de software abierto utilizado en esta tesis.

Inicialmente la reticulación es espacial y es el propio software el que realiza la temporal.

En la operación de simulación se consigue la solución numérica de la representación matemática del modelo en red, que incluye, las ecuaciones correspondientes a las limitaciones asignadas por las leyes de Kirchhoff, las de las distintas tipologías de monopuertas, y la información específica acerca de la interconexión de los diversos componentes eléctricos de cada modelo.

Los algoritmos de computación incluyen un grupo de actividades que constituyen el proceso de simulación, como el desarrollo de las ecuaciones, integración numérica y solución de ecuaciones lineales y no lineales.

Ngspice, el software empleado en esta tesis, pertenece a un conjunto de programas de simulación de circuitos SPICE2, (Nagel, 1975). De mayor potencia y rapidez que las versiones anteriores, fue implementado en los años setenta por la Universidad de California y emplea algoritmos más complejos con los mis mos patrones de entradasalida. El uso generalizado de este software muestra su potencial para analizar muy diversos problemas en simulación de circuitos.

Los algoritmos utilizados, documentados en la tesis de Nagel y mejorados en posteriores versiones (Nagel, 1977), son resultado de detalladas comparativas de las diferentes 
pruebas realizadas con los métodos numéricos disponibles en el marco particular de la simulación de circuitos.

Finalmente, el programa se organiza como una relación que incluye la totalidad de los componentes eléctricos del circuito, con interruptores, fuentes, condensadores y resistencias, entre otros.

La exigencia de llevar a cabo considerables simulaciones de los modelos, objetivo de esta tesis, nos impuso la elaboración de códigos en MATLAB, (MATrix LABoratory, laboratorio de matrices) (Matlab, 2007) para automatizar la generación de ficheros para uso con programas con otros lenguajes de programación, como $\mathrm{NgSpice,} \mathrm{y} \mathrm{la} \mathrm{representación} \mathrm{de} \mathrm{sus} \mathrm{resultados.} \mathrm{Este} \mathrm{software} \mathrm{es} \mathrm{un} \mathrm{sistema} \mathrm{numérico}$ computacional que aporta un entorno de desarrollo integrado (IDE) con un lenguaje de programación propio (lenguaje M). Así, su eficiente programación basada en el uso de múltiples rutinas incluidas en el software permite generar texto combinado con parámetros y gráficas mediante un número reducido de comandos. 
CAPÍTULO 3

\section{MATERIALES, EQUIPOS Y PROCEDIMIENTO EXPERIMENTAL}

\subsection{MATERIALES UTILIZADOS EN LA EXPERIMENTACIÓN}

\subsubsection{REVESTIMIENTO DE ALÚMINA SOBRE SUSTRATO DE ACERO}

Con el fin de analizar la morfología de las salpicaduras aisladas, se van a proyectar gotas de alúmina sobre una placa de acero inoxidable. El polvo a utilizar tendrá dos tamaños de partícula: $-20+5 \mu \mathrm{m}$ y $-40+10 \mu \mathrm{m}$. El polvo con notación -20+5 $\mu \mathrm{m}$, que será usado en la preparación de las muestras 1 y 2 , tiene un $10 \%$ de partículas con un diámetro equivalente menor a $5 \mu \mathrm{m}$, mientras que el $90 \%$ es menor que $20 \mu \mathrm{m}$. Por otra parte, el polvo con notación $-40+10 \mu \mathrm{m}$, usado en las muestras 4 y 5, tiene un $20 \%$ de partículas con un diámetro equivalente menor a $10 \mu \mathrm{m}$, mientras que el $90 \%$ es menor que $40 \mu \mathrm{m}$. La morfología de dichas partículas se puede apreciar en la figura 3.1, que, aunque no son esféricas, pueden alcanzar esta forma al fundirse.
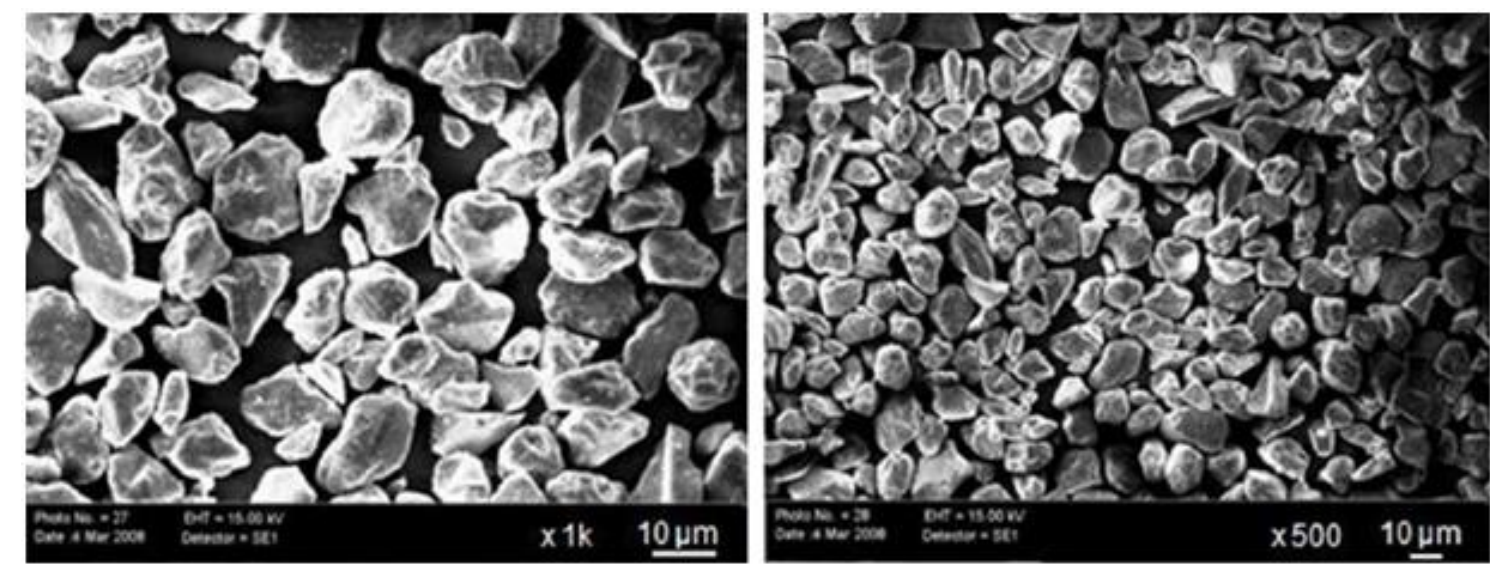

Figura 3.1. Alúmina en polvo empleada en las muestras (Institute for Manufacturing Technologies of Ceramic Components and Composites (IMTCCC))

Se van a utilizar los siguientes parámetros de proyección térmica: una separación de la tobera de la pistola APS respecto al sustrato de $130 \mathrm{~mm}$ y una velocidad de 
desplazamiento de la pistola de 0,5 m/s (GTV Verschleiss-Schutz GmbH).

Como se explicará en el apartado relativo a la elaboración de las muestras, se utilizará una placa con taladros para conseguir que las gotas alcancen el sustrato siguiendo una trayectoria perpendicular. El número de gotas que atraviesan los taladros depende de la velocidad de la pistola de proyección, así a menor velocidad un mayor número de gotas llegará al sustrato. Una velocidad excesivamente baja aumentaría el número de salpicaduras superpuestas.

Se van a preparar cinco muestras utilizando los parámetros de proyección mostrados en la tabla 3.1.

Tabla 3.1. Caudal de gas portador y corriente de alimentación.

\begin{tabular}{ccc}
\hline $\begin{array}{c}\text { Designación } \\
\text { de la muestra }\end{array}$ & $\begin{array}{c}\text { Caudales } \\
\mathrm{Ar} / \mathbf{H}_{2} \\
(\mathbf{N I} / \mathbf{m i n})\end{array}$ & Corriente (A) \\
\hline $\mathbf{S}_{1}$ & $40 / 12$ & 600 \\
\hline $\mathbf{S}_{2}$ & $40 / 8$ & 550 \\
\hline $\mathbf{S}_{3}$ & $40 / 12$ & 600 \\
\hline $\mathbf{S}_{4}$ & $40 / 8$ & 550 \\
\hline $\mathbf{S}_{5 \mathrm{~A}} / \mathbf{S}_{5 \mathrm{~B}}$ & $40 / 12$ & 600 \\
\hline
\end{tabular}

Dado que las partículas que impactan sobre el sustrato sin precalentamiento tienen una morfología de salpicadura más compleja, esta opción será la utilizada.

\subsubsection{PREPARACIÓN DE LAS MUESTRAS}

La figura 3.2 muestra un detalle de la fijación del sustrato al marco soporte mediante unas arandelas.

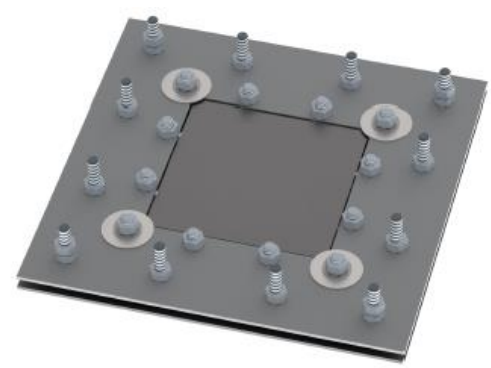

Figura 3.2 Detalle de sujeción del sustrato. 
Para conseguir salpicaduras aisladas el sustrato se cubre con una placa con cuatro grupos de tres taladros de $3 \mathrm{~mm}$ de diámetro, figura 3.3. Las franjas más claras sobre la máscara en dicha figura corresponden a las pasadas de la pistola de proyección.

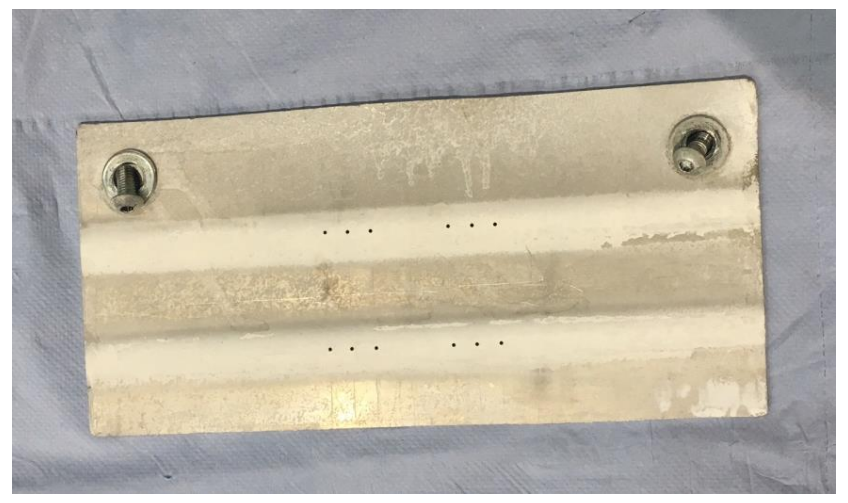

Figura 3.3 Placa con taladros para generar las salpicaduras aisladas.

El conjunto sustrato-máscara es soportado por un bastidor, figura 3.4. Hay un espacio entre la placa que actúa de sustrato y la máscara, que corresponde al espesor del perfil de aluminio usado para construir el bastidor.

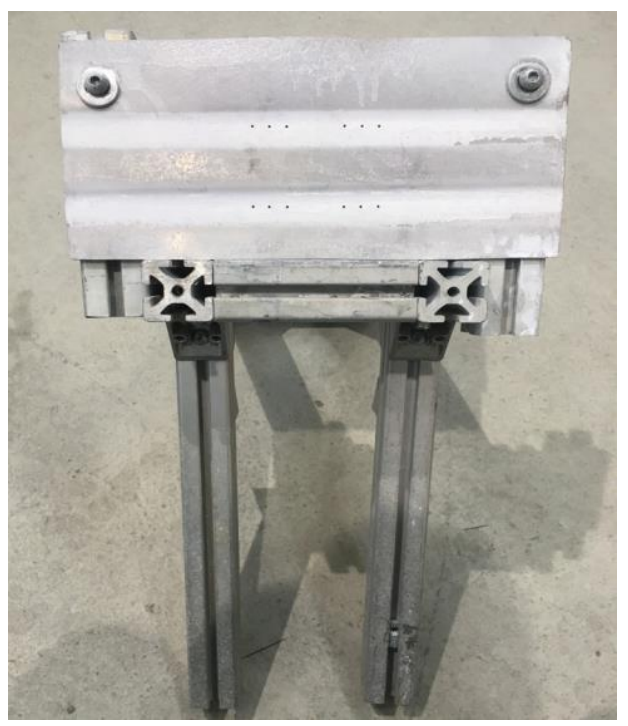

Figura 3.4 Bastidor con la placa que actúa como máscara.

Una vez recubierto el sustrato, la placa es cortada en cuatro trozos con tres círculos donde se agrupan las salpicaduras, figura 3.5.

En cuanto al procedimiento usado para la designación de salpicaduras, el registro S.1.3_10, por ejemplo, indica salpicadura 10 en el círculo 3 y muestra 1. 


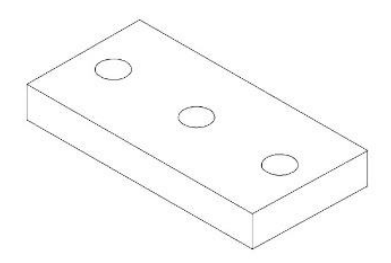

Figura 3.5 Imagen de una probeta con tres círculos donde se agrupan las salpicaduras.

\subsection{EQUIPOS UTILIZADOS EN LA EXPERIMENTACIÓN}

Para la obtención de imágenes, se ha empleado el microscopio electrónico de barrido HITACHI 3500, figura 3.6. Este tipo de microscopio reproduce imágenes a alta resolución empleando un haz de electrones. El SEM se puede configurar tanto en alto vacío como en presión variable. Así mismo, es capaz de obtener buenos resultados a bajo voltaje.

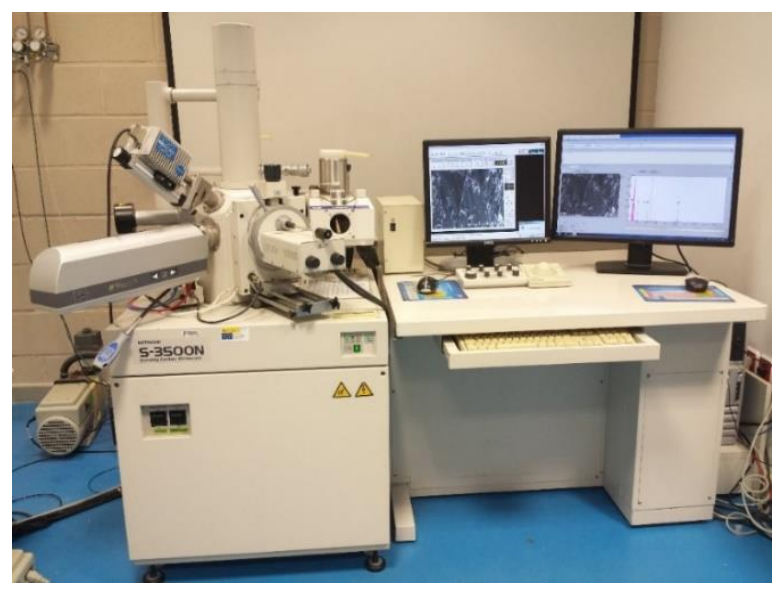

Figura 3.6 Microscopio electrónico de barrido S-3500N de Hitachi (UPCT).

El equipo cuenta con los elementos siguientes:

- Microscopio electrónico de barrido S-3500N de Hitachi, que cuenta con un cañón de electrones con un voltaje acelerador de 0,5 a $30 \mathrm{kV}$, ajustable por pasos, fuente de electrones con filamento de $\mathrm{W}$, polarización automática y alineamiento electrónico del cañón, sistema de lentes con supresión de histéresis, movimientos motorizados en ambos ejes horizontales, resolución de imagen de electrones secundarios de al menos 3,0 nm en modo de alto vacío, y de imagen de electrones retrodispersados de al menos $5,0 \mathrm{~nm}$ en modo de presión variable, rango de magnificación desde $18 \mathrm{X}$ hasta 300.000X, en más de 60 etapas, cámara infrarroja, sistema de vacío con control de 
evacuación, provisto de una bomba difusora y dos bombas rotatorias, enfoque manual y automático con ajuste grueso y fino y rastreo automático del foco.

- Analizador por energías dispersivas de rayos X de Bruker AXS Microanalysis, cuya resolución es de $129 \mathrm{eV}$ en el pico Ka del Mn a la mitad de su altura, área activa de 10 $\mathrm{mm}^{2}$, detecta desde B hasta Am, registra hasta $750.000 \mathrm{cps}$, dispone de trampa de electrones optimizada para un análisis libre de interferencias en el rango bajo de energías y refrigeración termoeléctrica por efecto Peltier. La aplicación informática instalada es Esprit (Quantax), capaz de manejar espectros de energías dispersivas de rayos $\mathrm{X}$, perfiles de distribución de elementos a lo largo de una línea y mapas de distribución de elementos en un área seleccionada.

- Sistema de difracción de electrones retrodispersados de Bruker Nano retráctil y ajustable verticalmente (hasta $\pm 4^{\circ}$ ) para la optimización de la distancia de trabajo y el centrado de patrones de difracción en la pantalla de fósforo, autocalibrable, permite un uso combinado con el detector de energías dispersivas de rayos X y la selección de una zona de interés donde realizar los análisis, dispone de portamuestras preinclinados a $70^{\circ}$ y $45^{\circ}$. La aplicación informática Esprit (CrystAlign) es capaz de llevar a cabo estudios de orientación y distribución de fases cristalinas.

Otro de los equipos empleados es el microscopio dual, electrónico de barrido y de haz de iones focalizados, SEM-FIB, de FEI (ThermoFisher Scientific, 2019) y modelo Scios dualbeam, figura 3.7. Dispone de un haz de electrones para barrido y obtención de la imagen, y un haz de iones Galio para realizar cortes dentro del equipo revelando la estructura debajo de la capa superficial, haciendo secciones transversales, capas de deposición, etc.

Entre los beneficios de este equipo destacan:

- Excelente contraste combinado con altas velocidades de adquisición y alta resolución a bajos $\mathrm{kV}$.

- Esquemas flexibles de detección para la adquisición simultánea de toda la información relevante.

- Productividad instantánea para todos los operadores con una guía de usuario única y automatización avanzada.

- Soluciones de flujo de trabajo para aumentar la productividad: asistente de análisis de Amira, microscopía correlativa (Correlative Light and Electron Microscopy, 
CLEM) para sección transversal (AutoSlice \& View) y crio microscopio de transmisión (CryoTEM).

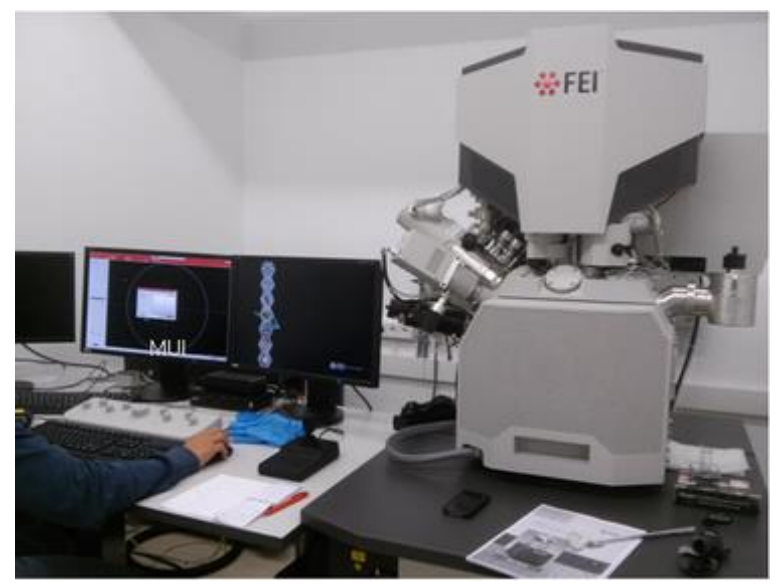

Figura 3.7 Microscopio SEM-FIB, Scios dualbeam (Universidad de Murcia).

\subsection{PROCEDIMIENTO EXPERIMENTAL}

Las salpicaduras se pueden estudiar desde dos enfoques: vista superior y sección transversal. Con las imágenes tomadas desde arriba podemos apreciar la morfología, el grado de aplastamiento, la textura de la superficie, grietas, partículas sin fundir y poros. Así, la figura 3.8, que muestra una salpicadura en forma de tortita cuyo formato ideal podría ser el de la figura 3.9, presenta grietas en la zona central.

Por otro lado, la sección transversal nos da información sobre el proceso de solidificación y el contacto con el sustrato. Las figuras 3.10 y 3.11 ilustran la diferencia entre trabajar con una sección realizada de forma manual y otra realizada mediante FIB (Munroe, 2009).

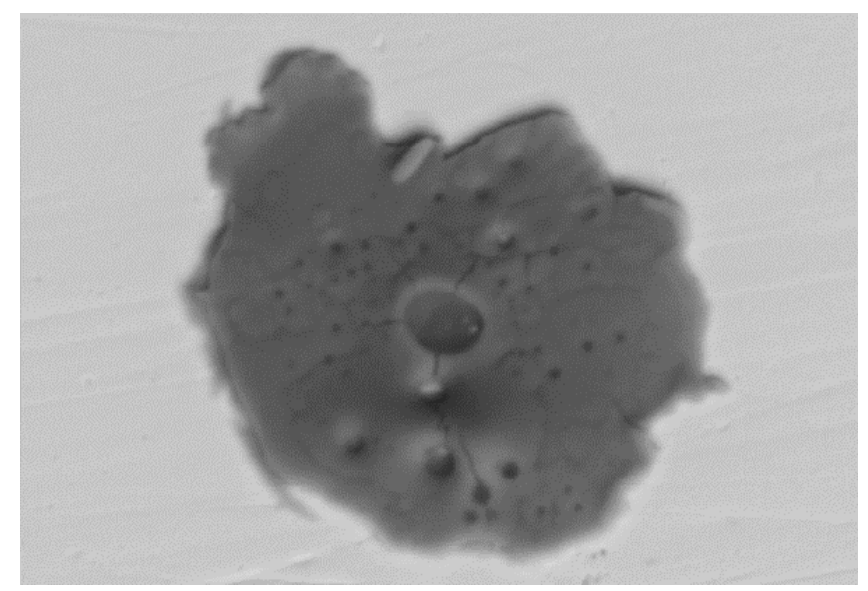

Figura 3.8 Imagen de una salpicadura sobre acero. Recubrimiento realizado en el IMTCCC. 


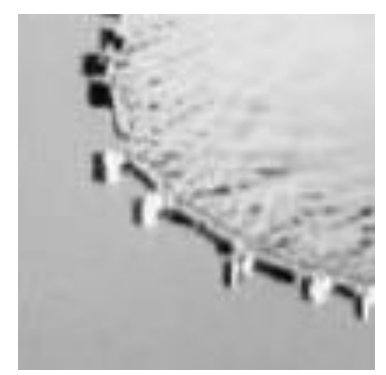

Figura 3.9 Imagen de una salpicadura de estaño sobre una placa de acero (Shakeri y Chandra, 2002).

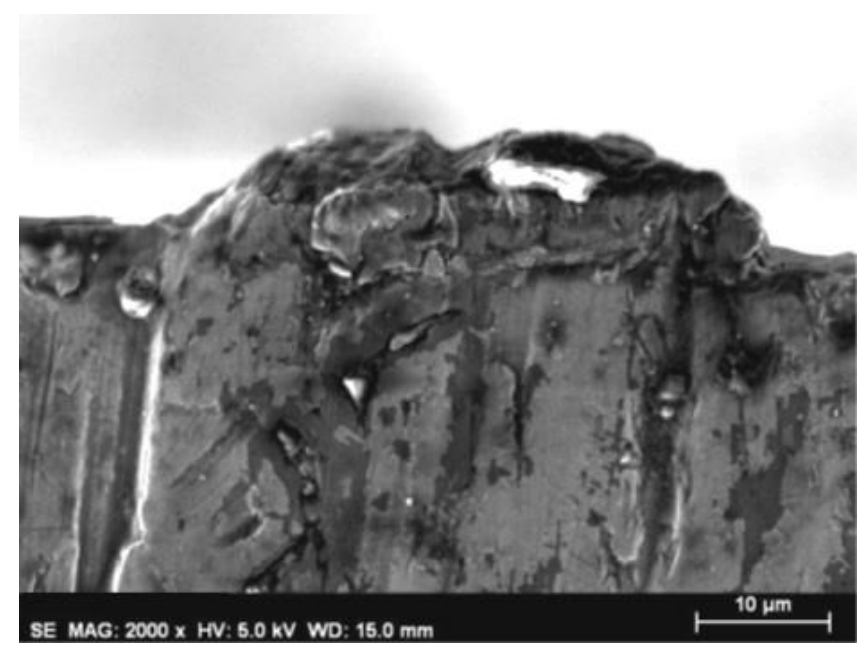

Figura 3.10 Estructura en columnas de una sección transversal de la salpicadura sobre sustrato de aluminio (Mulero, 2014).

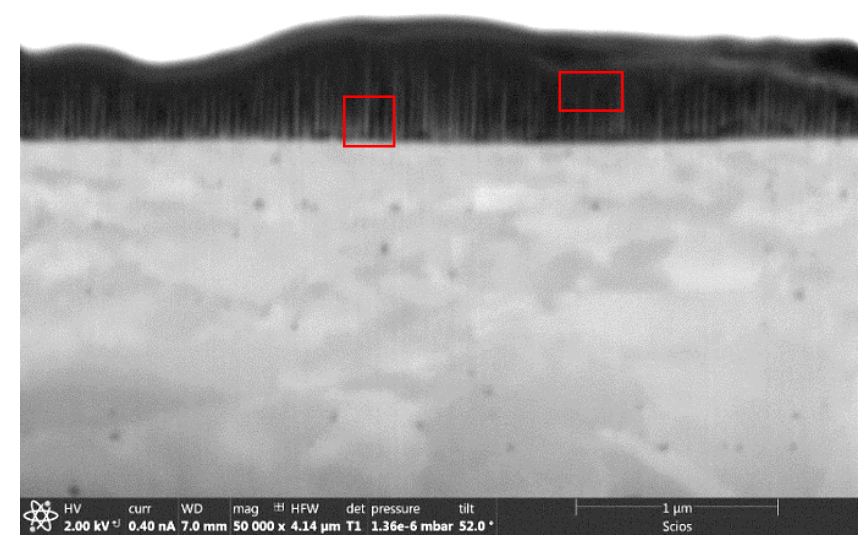

Figura 3.11 Sección de una salpicadura.

La figura 3.10 muestra una estructura con granos en forma de columna en la sección transversal de la salpicadura. Es difícil saber si la salpicadura estaba configurada de esta forma o es el resultado de la fractura ocasionada en el proceso de pulido manual. La figura 
3.11 muestra otra configuración en la que se pueden apreciar poros (zonas más oscuras). En este caso el corte, mediante haz de iones, es menos violento (Munroe, 2009). Finalmente resulta interesante comparar el tiempo necesario para realizar cada sección: 7 horas para la sección manual y 15 minutos para la sección mediante el haz de iones.

\subsection{PROCESAMIENTO DE IMAGEN}

La morfología de la salpicadura puede evaluarse mediante el análisis de varios parámetros geométricos como son circularidad, diámetro equivalente y área. Los valores de estos parámetros se obtienen a partir de la imagen digitalizada de la salpicadura adquirida por SEM. Según estos parámetros geométricos, se propone que las salpicaduras se pueden clasificar en las categorías (Mohamed et al., 2015, Kudinov et al., 1989, Oki et al., 1998, Ohmori y Li, 1993, Montavon et al., 1995, 1997, Fukumoto et al., 1995a) siguientes:

- $\quad$ salpicaduras con forma de tortita y flor,

- $\quad$ con forma de corona circular con circunferencia interior de diámetro reducido, igual a la anterior pero floreada, con circunferencia exterior de diámetro ampliado y

- $\quad$ salpicadura fragmentada.

Las salpicaduras con forma de tortita tienen un buen contacto con el sustrato, al igual que las que tienen forma de flor. Las salpicaduras con forma de burbuja, como se muestra en la figura 3.12, es debido a los gases atrapados en la partícula. Estos gases, originariamente a una alta temperatura, se enfrían y dilatan provocando, en ocasiones, la ruptura superficial de la salpicadura. El cráter dejado por el volumen de estos gases compromete la propia resistencia de la salpicadura. Por el contrario, aquellas con forma de corona circular disponen de un buen contacto con el sustrato.

La aplicación informática MatLab, elegida para el análisis objeto de este apartado, proporciona un instrumento de procesamiento de imágenes que permite calcular el diámetro de un círculo con el área de la región que representa la salpicadura. Este valor (Mulero, 2014) se calcula como

$$
\mathrm{d}_{\mathrm{e}}=\sqrt{\frac{\mathrm{A}}{\pi}}
$$




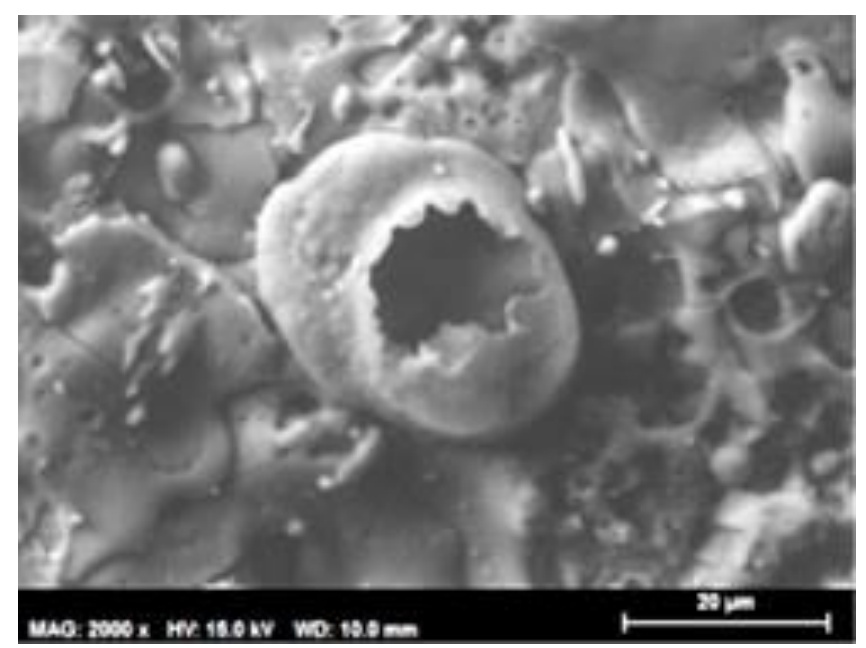

Figura 3.12 Salpicadura de alúmina con burbuja sobre sustrato de aluminio. Recubrimiento realizado en el IMTCCC (Mulero, 2014).

Antes de aplicar esta herramienta, es necesario limpiar las discontinuidades que existen alrededor de la salpicadura y que pueden dificultar el cálculo del diámetro equivalente. Para ello, se van a aplicar una serie de procesos sobre la imagen original que se han resumido en este apartado, siendo tratados con más detalle en el apartado siguiente.

A continuación, se van a enumerar dichos procesos junto con un comentario sobre su significado. Estos comienzan con una transformación de la imagen original en una binaria, donde el color de los objetos es blanco y el fondo negro. Esta operación se denomina binarización y puede realizarse mediante un proceso de umbralización. De esta forma, aquellos pixeles con valores de gris por encima de un umbral son considerados objetos y se evalúan como 1 (blanco), y aquellos pixeles que están por debajo de un nivel se consideran fondo y se les proporciona el valor 0 .

El proceso que calcula este valor umbral global de forma automática y que se utiliza para convertir una imagen de nivel gris en una imagen binaria se denomina método de Otsu de umbralización (Otsu, 1979). El método Otsu de umbralización automática busca un valor umbral que minimice la variación entre las clases de los píxeles en blanco y de los pixeles en negro.

Seguidamente, se realizan unas series de operaciones morfológicas sobre la imagen binaria, que consisten en separar (cerrar) los pequeños objetos del fondo que los envuelve. A medida que más operaciones se realicen sobre la imagen, objetos más grandes pueden ser cerrados; por lo que el número de veces que se realice depende del tamaño de los 
objetos que se quieren cerrar, o eliminar, y del tamaño del elemento estructurante utilizado en estas operaciones.

El elemento estructurante se elige de forma que preserve la naturaleza en forma de disco del objeto y por tanto tiene forma de disco con un radio que varía de 0 a 10 pixeles. Las operaciones morfológicas que usan elementos en forma de discos se ejecutan mucho más rápido cuando éste es una aproximación discreta en forma de disco. La operación de cierre morfológico es una dilatación seguida por una erosión, utilizando el mismo elemento estructurante para ambas operaciones. Estas operaciones serán comentadas en el siguiente apartado.

El resultado de los procesos anteriormente comentados sobre una imagen real SEM de una salpicadura con forma de corona circular, es el que se muestra en las figuras $3.13 \mathrm{y}$ 3.14. La figura 3.14 es la imagen resultado tras la binarización por el método Otsu y diversas operaciones de cierre sobre la imagen binaria. Como se puede comprobar se ha conseguido aislar por completo la salpicadura; eliminando pequeños objetos que la rodean, como las letras inferiores y salpicaduras secundarias, más pequeñas, que no interesan en el análisis objeto de este trabajo.

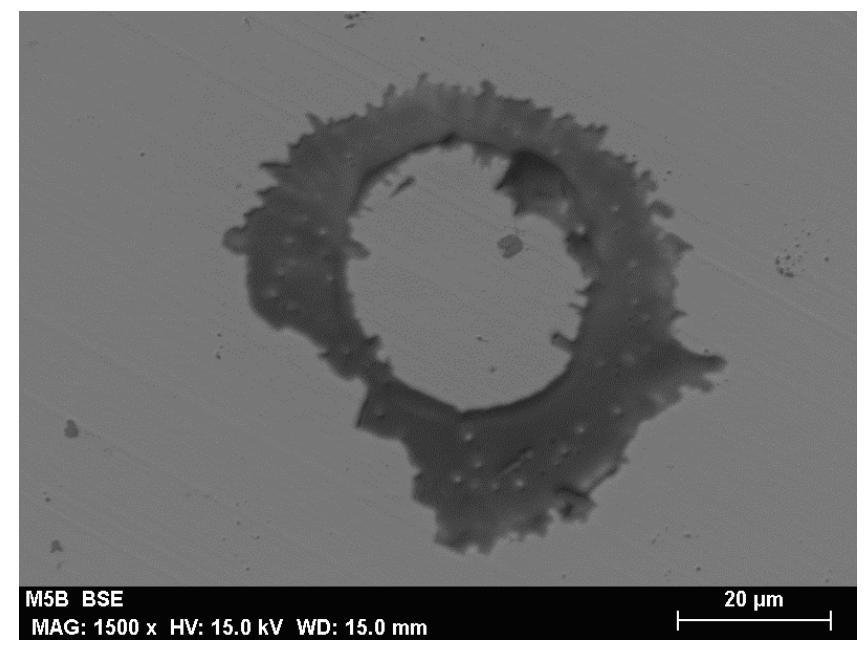

Figura 3.13 Figura original.

A partir de la figura 3.14 es posible obtener el contorno interior y exterior de toda la corona de la salpicadura, considerando como objeto el fondo de todo el agujero interior de la salpicadura. Mediante una simple etiqueta de todos los pixeles interiores vecinos exclusivamente de pixeles 0 (negro) se obtendría el objeto agujero. Así, la figura 3.15 muestra el resultado de aislar el perímetro exterior e interior de la salpicadura. Una vez 
obtenidos ambos objetos es fácil obtener diferentes parámetros geométricos como área, perímetros, ejes asociados a elipses equivalentes, etc. Entre estos parámetros los diámetros equivalentes tanto interior (agujero o corona interior) como exterior (corona exterior).

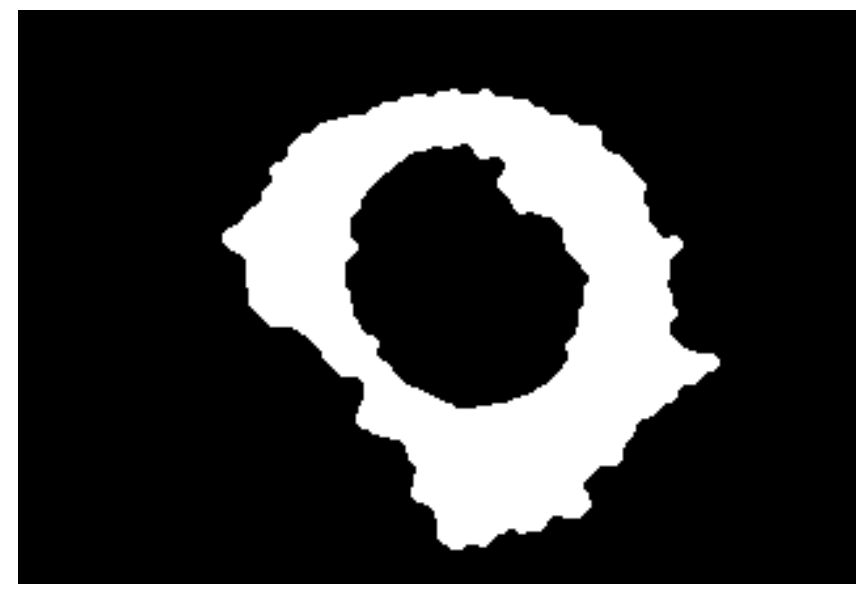

Figura 3.14 Imagen rellenada.

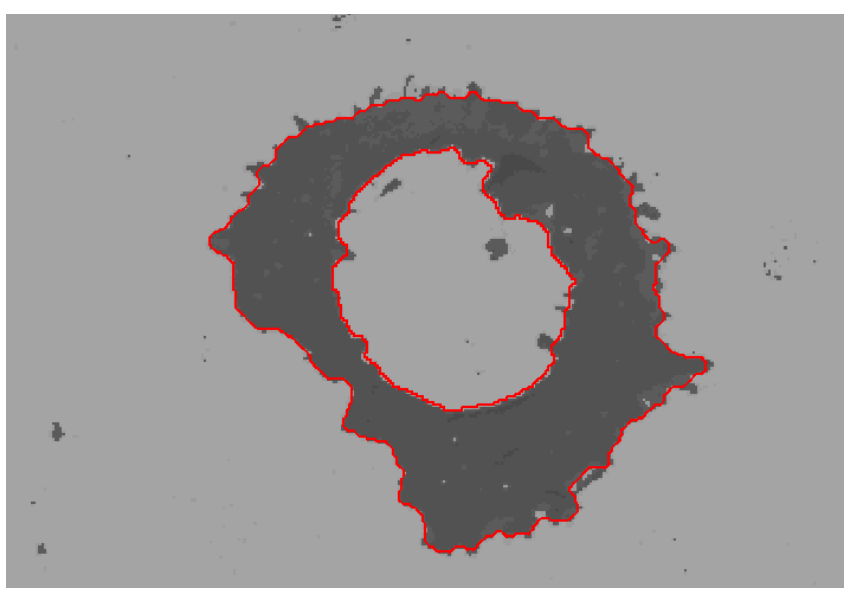

Figura 3.15 Selección de los contornos de la salpicadura.

\subsubsection{PROCESAMIENTO DE IMAGEN: ANÁLISIS DE VISTA SUPERIOR}

Nuestro objetivo en este apartado es simplificar una imagen compleja, donde los objetos heterogéneos se organizan en el fondo, en una matriz de vectores. A su vez, cada componente del vector corresponde a una propiedad morfológica de ese objeto (Mulero et al., 2015).

Para lograr nuestro propósito debemos simplificar el problema utilizando las herramientas proporcionadas por las técnicas de procesamiento de imágenes. Por ejemplo, las técnicas de mejora de contraste se emplean para mejorar el rango dinámico de los grados de gris de la imagen, por lo que los objetos importantes en la imagen se vuelven más evidentes 
que el fondo. Los métodos de selección de umbral se utilizan para obtener una imagen binaria donde hay un fondo y un primer plano. Las operaciones morfológicas se utilizan para eliminar pequeños artefactos alrededor de los objetos principales, así como suavizar los bordes del objeto principal. Las técnicas de etiquetado permiten diferenciar con una etiqueta a cada uno de los objetos que están en un fondo común (etiquetado como objeto 0) y la técnica de extracción de características se utilizan para obtener algunas características discriminatorias que pueden facilitar la caracterización de la salpicadura con una determinada etiqueta y perfectamente aislada de los demás objetos de la escena. En este caso, el procedimiento automático consta de cuatro etapas, como se muestra en la figura 3.16.

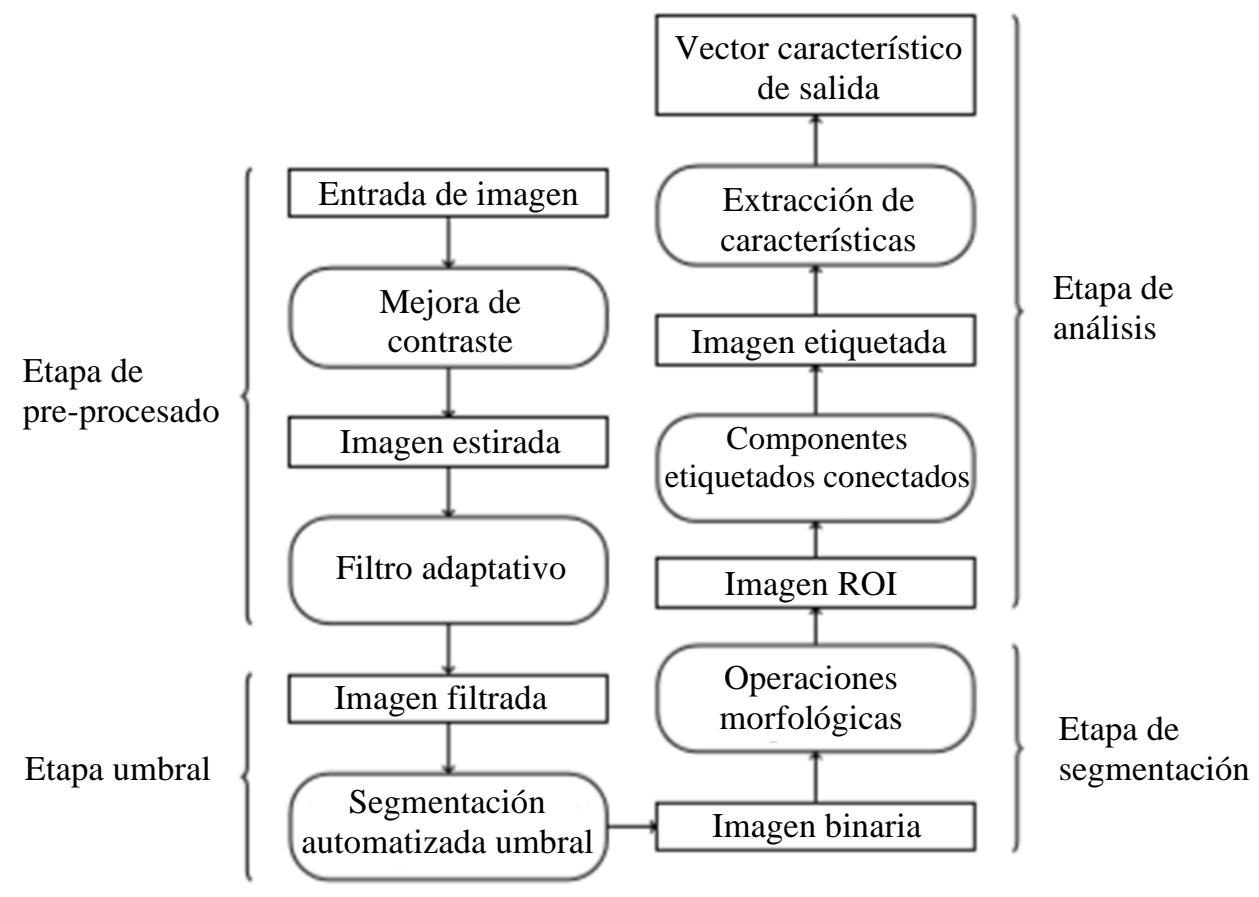

Figura 3.16 Flujo de trabajo (Mulero et al., 2015).

La primera etapa consiste en una etapa de preprocesamiento en la que se mejora el contraste de la imagen SEM. La segunda etapa realiza la segmentación, que implica el cálculo del umbral mediante el método de Otsu. La etapa tercera lleva a cabo la detección en la que la imagen binaria se procesa mediante diversas operaciones morfológicas, técnicas de etiquetado, para obtener una imagen donde se etiqueta la salpicadura. La cuarta etapa implica el análisis y caracterización de la imagen (Mulero et al., 2015). En esta, la salpicadura segmentada se caracteriza mediante técnicas basadas en el etiquetado de componentes conectados y extracción de características. 
En la primera etapa, el algoritmo acomoda el valor de intensidad de la imagen original en una nueva imagen transformada con mayor rango dinámico en su escala de grises, posteriormente los valores de los píxeles se reasignan para cubrir todo el rango disponible del histograma. En otras palabras, los valores que representan el límite del histograma entre el 1\% y el $99 \%$ del total de los píxeles se proyectan en el rango de 0 a 1 , mientras que el resto de los valores se recortan.

En la segunda etapa o la etapa binarización, una vez que la imagen se ha mejorado en contraste, se transforma del nivel de gris, codificado de 0 a 1, a binario: negro o 0 (fondo) y blanco o 1 (primer plano). Con esta operación se persigue delimitar objetos colocados en el fondo.

En esta etapa debe encontrarse un umbral global óptimo que convierta la imagen en escala de grises a una binaria, y delimite los límites de la salpicadura. En este caso, hemos utilizado el método de Otsu, presentado anteriormente, que elige un determinado umbral que minimiza la varianza entre las clases blancos (primer plano) y negros (fondo). El algoritmo asume que la imagen contiene dos clases (fondo y primer plano) y por tanto, con un histograma bimodal (píxeles de primer plano y de fondo), calcula posteriormente el umbral óptimo que separa las dos clases para que su dispersión combinada (varianza intraclase) sea mínima. Nuestro segundo objetivo se obtiene directamente porque una imagen binaria con objetos en su fondo tiene los bordes de estos objetos delimitados dado que los límites se obtienen con el cruce entre píxeles binarios (blanco y negro).

En la tercera etapa, los objetos binarios obtenidos en la etapa anterior se etiquetan utilizando una técnica basada en componentes conectados. El algoritmo implementado utiliza el procedimiento general propuesto por Haralick y Shapiro (Haralick y Shapiro, 1991). El algoritmo devuelve una matriz del mismo tamaño que la imagen de entrada que contiene etiquetas para los pixeles conectados en la imagen de entrada. De este modo, los píxeles etiquetados con 0 son el fondo, los píxeles etiquetados con 1 representan un objeto del primer plano, los píxeles etiquetados con 2 representan el segundo objeto del primer plano, y así sucesivamente. El procedimiento encuentra el objeto con área máxima porque la salpicadura es el objeto con área máxima debido a nuestro conocimiento a priori. El resto de objetos se rechazan fácilmente etiquetándolos con 0 (fondo). 
Ahora, la imagen binaria va a ser sometida a diferentes operaciones morfológicas que aplican un elemento de estructuración que no cambia el tamaño de la imagen. La dilatación agrega píxeles a los límites de los objetos de la imagen, mientras que la erosión los elimina. El número de píxeles agregados o eliminados de los objetos depende del tamaño y la forma del elemento estructurante utilizado y de la propia imagen. La regla utilizada para procesar los píxeles define una operación u otra. En una dilatación, el valor asociado al píxel de salida es el mayor valor de todos los píxeles en las inmediaciones de el de entrada. En una erosión, el valor de el de salida es el valor mínimo de todos los píxeles en la proximidad de el de entrada.

Este procedimiento nos permite cerrar los límites de los objetos y eliminar pequeños objetos de un tamaño cercano al elemento estructurante en unas pocas iteraciones.

En la cuarta etapa, y en la medida en que nuestra imagen binaria también es una imagen etiquetada, es decir, cada objeto de la escena es independiente y localizable por su etiqueta, podemos calcular diferentes propiedades geométricas de la salpicadura. Para ser más precisos, nos interesan el perímetro (exterior e interior), el cuadro delimitador y el diámetro y elipse equivalentes que se ajustan a la salpicadura. En resumen, una imagen compleja, donde los objetos heterogéneos se organizan en el fondo, se simplifica en un vector, donde el vector corresponde al objeto correspondiente a la salpicadura. Más tarde, cada componente del vector se simplifica, a su vez, a una propiedad morfológica de ese objeto. 


\section{CAPÍTULO 4}

\section{MODELOS EN RED}

La resolución de los problemas señalados en el capítulo 2, la razón de ser de esta memoria, supone solucionar las ecuaciones desarrolladas tomando en consideración, igualmente, las condiciones iniciales y de contorno particulares para cada supuesto. En las secciones sucesivas deduciremos el modelo en red concerniente a la ecuación de gobierno de una celda elemental para el proceso de solidificación de una gota, usando una discretización congruente.

El impacto isotérmico de una gota implica la solución de un problema de frontera móvil con unas condiciones de contorno especialmente difíciles de representar, por lo que será abordado mediante un procedimiento contrastado, como el método de volúmenes finitos. No obstante, se han desarrollado partes del código necesario para realizar este cálculo mediante el método de redes, como el llenado y vaciado de una celda y el cálculo de la tensión superficial. Queda pendiente la modelización de la transferencia de cantidad de movimiento en la celda que acaba de llenarse. Por esta razón la modelización del impacto isotérmico mediante el método de redes no está incluida en este trabajo.

\subsection{MODELIZACIÓN DEL IMPACTO ISOTÉRMICO DE UNA GOTA}

\subsubsection{MÉTODO DE VOLÚMENES FINITOS}

Se va a simular una gota de agua de $2 \mathrm{~mm}$ de diámetro a una velocidad de $1 \mathrm{~m} / \mathrm{s}$, para comparar los resultados con los obtenidos en la información disponible (Qiao, 1996; Pasandideh-Fard, 1998). Las propiedades del agua a $25^{\circ} \mathrm{C}$ son: densidad de $997 \mathrm{~kg} / \mathrm{m}^{3}$, viscosidad cinemática de $8,57 \cdot 10^{-7} \mathrm{~m}^{2} / \mathrm{s}$ y coeficiente de tensión superficial $0,073 \mathrm{~N} / \mathrm{m}$.

Las ecuaciones de balance, ecuaciones 2.72 a 2.73, se formulan en el software de elementos de volúmenes finitos utilizado, Fluent, mediante ecuaciones más generales (Fluent, 2006).

La ecuación de conservación de masa, o ecuación de continuidad, viene definida como

$$
\frac{\partial \rho}{\partial \mathrm{t}}+\nabla \cdot(\rho \overrightarrow{\mathrm{v}})=\mathrm{S}_{\mathrm{m}}
$$


donde $S_{\mathrm{m}}$ es la masa añadida a la fase continua a partir de la segunda fase dispersa y cualquier fuente definida por el usuario.

La ecuación de conservación de momento, en un sistema de referencia inercial, viene definida por:

$$
\frac{\partial \rho}{\partial \mathrm{t}}+\nabla \cdot(\rho \overrightarrow{\mathrm{v}})=-\nabla \rho+\nabla(\vec{\tau})+\rho \overrightarrow{\mathrm{g}}+\overrightarrow{\mathrm{F}}
$$

donde $\overline{\bar{\tau}}$ viene definido por:

$$
\overline{\bar{\tau}}=\left[\left(\nabla \overrightarrow{\mathrm{v}}+\nabla \overrightarrow{\mathrm{v}}^{\mathrm{T}}\right)-\frac{2}{3} \nabla \overrightarrow{\mathrm{v}} \mathrm{I}\right]
$$

Para geometrías axisimétricas, como la del problema a resolver, las ecuaciones de conservación de momento axial y radial vienen definidas por:

$$
\begin{aligned}
& \frac{\partial}{\partial x}\left(\rho v_{x}\right)+\frac{1}{r} \frac{\partial}{\partial x}\left(r \rho v_{x} v_{x}\right)+\frac{1}{r} \frac{\partial}{\partial r}\left(r \rho v_{r} v_{x}\right)= \\
& -\frac{\partial \rho}{\partial \mathrm{x}}+\frac{1}{\mathrm{r}} \frac{\partial}{\partial \mathrm{x}}\left[\mathrm{r} \mu\left(2 \frac{\partial \mathrm{v}_{\mathrm{x}}}{\partial \mathrm{x}}-\frac{2}{3}(\nabla \cdot \overrightarrow{\mathrm{v}})\right)\right]+\frac{1}{\mathrm{r}} \frac{\partial}{\partial \mathrm{r}}\left[\mathrm{r} \mu\left(2 \frac{\partial \mathrm{v}_{\mathrm{x}}}{\partial \mathrm{r}}+\frac{\partial \mathrm{v}_{\mathrm{r}}}{\partial \mathrm{x}}\right)\right]+\mathrm{F}_{\mathrm{x}}
\end{aligned}
$$

$\mathrm{y}$

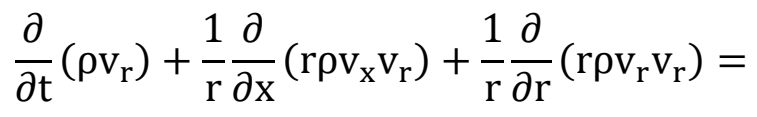

$$
\begin{aligned}
& -\frac{\partial \rho}{\partial \mathrm{r}}+\frac{1}{\mathrm{r}} \frac{\partial}{\partial \mathrm{x}}\left[\mathrm{r} \mu\left(\frac{\partial \mathrm{v}_{\mathrm{r}}}{\partial \mathrm{x}}+\frac{\partial \mathrm{v}_{\mathrm{x}}}{\partial \mathrm{r}}\right)\right]+\frac{1}{\mathrm{r}} \frac{\partial}{\partial \mathrm{r}}\left[\mathrm{r} \mu\left(2 \frac{\partial \mathrm{v}_{\mathrm{r}}}{\partial \mathrm{r}}-\frac{2}{3}(\nabla \cdot \overrightarrow{\mathrm{v}})\right)\right] \\
& -2 \mu \frac{v_{r}}{r^{2}}+\frac{2}{3} \frac{\mu}{r}(\nabla \cdot \vec{v})+\rho \frac{v_{z}^{2}}{r}+F_{r}
\end{aligned}
$$

donde

$$
(\nabla \cdot \vec{v})=\frac{\partial v_{x}}{\partial x}+\frac{\partial v_{r}}{\partial r}+\frac{v_{r}}{r}
$$

y $v_{z}$ la velocidad de remolino. 
Fluent recomienda elegir el eje de simetría sobre el eje $\mathrm{x}$, por tanto, el eje perpendicular representará la coordenada r. Las ecuaciones $4.1,4.4$ y 4.5 son equivalentes a:

$$
\begin{gathered}
\frac{1}{r} \cdot \frac{\partial\left(r \cdot u_{r}\right)}{\partial r}+\frac{\partial u_{z}}{\partial z}=0 \\
\frac{\partial u_{x}}{\partial t}-g+u_{x} \cdot \frac{\partial u_{x}}{\partial x}+u_{r} \cdot \frac{\partial u_{x}}{\partial r}-\frac{v}{r} \frac{\partial u_{x}}{\partial r}-v\left[\frac{\partial^{2} u_{x}}{\partial x^{2}}+\frac{\partial^{2} u_{x}}{\partial r^{2}}\right] \\
+u_{x} \cdot\left(\frac{\partial u_{x}}{\partial x}+\frac{\partial u_{r}}{\partial r}+\frac{u_{r}}{r}\right)-\frac{v}{3} \frac{\partial}{\partial x}\left(\frac{\partial u_{x}}{\partial x}+\frac{\partial u_{r}}{\partial r}+\frac{u_{r}}{r}\right)=0 \\
\frac{\partial u_{r}}{\partial t}+u_{x} \cdot \frac{\partial u_{r}}{\partial x}+u_{r} \cdot \frac{\partial u_{r}}{\partial r}-\frac{v}{r} \frac{\partial u_{r}}{\partial r}+v \frac{u_{r}}{r^{2}}-v\left[\frac{\partial^{2} u_{r}}{\partial x^{2}}+\frac{\partial^{2} u_{r}}{\partial r^{2}}\right] \\
+u_{r} \cdot\left(\frac{\partial u_{x}}{\partial x}+\frac{\partial u_{r}}{\partial r}+\frac{u_{r}}{r}\right)-\frac{v}{3} \frac{\partial}{\partial r}\left(\frac{\partial u_{x}}{\partial x}+\frac{\partial u_{r}}{\partial r}+\frac{u_{r}}{r}\right)+v \frac{u_{z}^{2}}{r}=0
\end{gathered}
$$

Las ecuaciones 4.8 y 4.9 se convierten en las ecuaciones de Navier-Stokes si desaparecen los dos últimos sumandos de la primera ecuación y los tres últimos sumandos de la segunda ecuación, lo cual ocurre en el interior de la gota.

Fluent utiliza un módulo de generación de geometrías denominado SpaceClaim. Con este módulo se genera el dominio a discretizar, figura 4.1 , de $10 \mathrm{~mm}$ por $3 \mathrm{~mm}$, suficiente para una gota de radio $1 \mathrm{~mm}$.

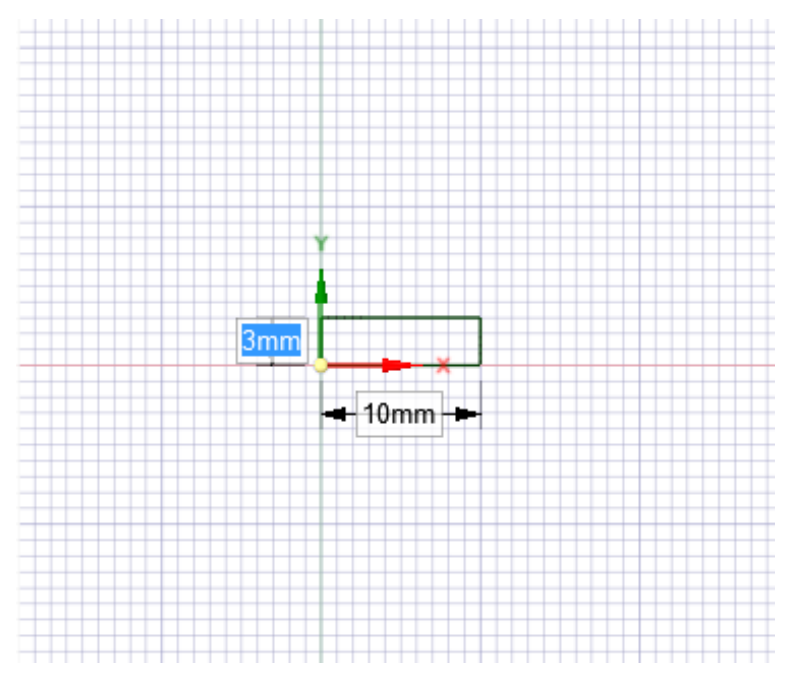

Figura 4.1. Dominio a discretizar. 
En referencia a la discretización utilizada, los elementos de volumen usados en el dominio vienen definidos por $\Delta \mathrm{x}=1.2301 \mathrm{e}-5 \mathrm{~m}$ y $\Delta \mathrm{y}=1.244 \mathrm{e}-5 \mathrm{~m}$, y son del tipo cuadrilátero.

Se utilizará un modelo axisimétrico, como ya se ha mencionado, con cálculo de doble precisión y procesamiento en serie.

La tensión superficial utiliza un modelo de fuerza, con adhesión a la pared. El coeficiente de tensión superficial es $0,073 \mathrm{~N} / \mathrm{m}$.

Se utiliza un solver basado en presión con formulación de velocidad absoluta, modo de cálculo transitorio y que incluye la gravedad. Otras opciones seleccionadas son modelo VOF, tipo nítido para el modelado de interfase y formulación implícita de fuerzas de volumen.

Los parámetros usados para el cálculo de la fracción de volumen son: formulación explícita, con corte de fracción de volumen en 1e-06 y número de Courant de 0,25. El número de Courant es un número adimensional que compara el intervalo temporal en una iteración con el tiempo característico de tránsito del fluido en una celda a través de un volumen de control. En la formulación explícita, el intervalo temporal usado en el cálculo de la fracción de volumen no es el mismo que el usado en las ecuaciones de mecánica de fluidos. El software utilizado refina el intervalo temporal automáticamente a partir del número de Courant permitido cerca de la superficie libre. El tiempo característico mencionado en la definición del número de Courant representa el tiempo requerido para el vaciado de la celda. Se considera que este tiempo es el menor de los tiempos de tránsito en la interfase. Así, el intervalo temporal se calcula a partir del tiempo característico y el máximo número de Courant permitido.

Los ajustes de discretización temporal son: 0,1 para el número global de Courant, un tiempo total de $0,01 \mathrm{~s}$, un tamaño mínimo de incremento de tiempo de 1e-08s, un tamaño máximo de incremento de tiempo de 1e-06s, un factor mínimo de cambio de intervalo temporal de 0,5, un factor máximo de cambio de intervalo temporal de 5 y un número fijo de saltos temporales de 1 .

Con la información anterior se puede aplicar el algoritmo de cálculo de incrementos temporales, que es del tipo híbrido. Este se estima a partir del incremento proporcionado por los métodos basados en velocidad, flujo y flujo promedio, explicado más adelante:

$$
\Delta \mathrm{t}_{v}=\operatorname{Cou} \frac{\Delta \mathrm{x}}{\mathrm{v}_{\mathrm{fluid}}} \quad \text { (basado en velocidad) }
$$




$$
\Delta \mathrm{t}_{\mathrm{f}}=\operatorname{Cou} \frac{\mathrm{v}_{\text {fluid }}}{\sum_{\text {cell }} \mathrm{U}_{\mathrm{f}}} \quad \text { (basado en flujo) }
$$

donde Cou es el número de Courant, vfluid es la velocidad del fluido, $\Delta x$ es el tamaño de la celda, $\mathrm{V}$ es el volumen y $\mathrm{U}_{\mathrm{f}}$ es el flujo saliente.

Para el flujo promedio el intervalo temporal se promedia a partir de los incrementos temporales basados en flujo en las celdas vecinas a la considerada.

El algoritmo de selección de valores iniciales es del tipo estándar, con referencia en la zona de la celda. Los valores iniciales son presión manométrica 101325 Pa y temperatura 300 K. Las velocidades axiales, radiales y la fracción de volumen iniciales son nulas.

La condición de contorno de la frontera horizontal superior se define como "pressure outlet" y ha sido dividida en 900 segmentos. La condición de contorno de la frontera vertical derecha se define de igual forma y ha sido dividida en 252 segmentos. En la opción de momentos se ha seleccionado $101325 \mathrm{~Pa}$ como presión de referencia, mientras que para el método de especificación de dirección de reflujo la opción elegida es normal al contorno. En la opción térmica se ha seleccionado $298 \mathrm{~K}$ para la temperatura total de reflujo.

La condición de contorno de la frontera horizontal inferior se define como "wall" y ha sido dividida en 900 segmentos. Esta condición de contorno incluye varias opciones. Dentro de la opción térmica se selecciona temperatura, y se definen una temperatura superficial de $298 \mathrm{~K}$, un espesor de pared de $2,4 \cdot 10^{-3} \mathrm{~m}$ y una resistencia de contacto de $1,8 \cdot 10^{-6} \mathrm{~m}^{2} \cdot \mathrm{K} \cdot \mathrm{W}^{-1}$. Dentro de la opción de momentos, se definen pared estacionaria para el movimiento de la pared y sin deslizamiento (no slip) para la condición de cortadura.

La condición de contorno de la frontera vertical izquierda se define como "axis" y ha sido dividida en 252 segmentos.

En condiciones de operación se selecciona un punto, que siempre será aire, cuya coordenada vertical es 0,01 m y cuya coordenada horizontal es 0,0005 m. La presión y la temperatura de operación de la fase aire en el dominio son 101325 Pa y 298 K, respectivamente.

La velocidad inicial de la gota es $-1 \mathrm{~m} \cdot \mathrm{s}^{-1}$. Su temperatura inicial es de $298 \mathrm{~K}$, idéntica a la del sustrato. 
La mayoría de generadores de malla utilizan volúmenes de celda que crecen muy rápido desde los contornos, aunque este procedimiento evita mallados muy densos, puede crear dificultades para resolver el flujo en zonas concretas que exijan un mallado más fino.

La función de adaptación de región permite refinar las celdas interiores o exteriores a una región definida dentro del dominio. En concreto se pueden refinar cuadriláteros o círculos en 2D.

El procedimiento para seleccionar un círculo consiste en indicar las coordenadas del centro y su radio. Una vez definida la región las celdas interiores son seleccionadas de forma automática.

La gota de agua antes del impacto se modela mediante un patch. La coordenada horizontal del centro del patch es 0 , la vertical $0,0018 \mathrm{~m}$ y el radio es $1 \mathrm{~mm}$.

La opción seleccionada de solver se basa en la presión (pressure-based). El resto de opciones elegidas son: absoluta para la formulación de velocidad, transitorio para el tipo de análisis y axisimétrico para el tipo de dominio. La solución debe incluir el efecto de la gravedad.

La opción de modelo seleccionado es "Multiphase-Volume of Fluid", correspondiente al método VOF. El resto de opciones elegidas son: dos para el número de fases eulerianas con esquema explícito, $10^{-6}$ para el valor límite de fracción de volumen (volume fraction cutoff) y 0,25 para el número de Courant. Además, se activa la opción de fuerza máxima implícita (implicit body force).

En la definición de los materiales, dentro del apartado fluidos, se han seleccionado aire y agua, y dentro del apartado sólidos, se ha seleccionado acero.

En la definición de las fases, se incluyen el aire como primaria y el agua como secundaria. En la definición de la fase secundaria, se incluye como interacción la tensión superficial, en concreto se seleccionan la opción "continuum surface force" y "wall adhesion".

Las zonas asociadas a las condiciones de contorno y el interior del dominio se definen como "mixture".

El método de solución elegido es del tipo acoplamiento velocidad-presión y esquema SIMPLE. Las funciones y ecuaciones dependientes de la discretización espacial son: gradiente, presión, momento, fracción de volumen y energía. Para la estimación del gradiente se selecciona el método de mínimos cuadrados basado en celda (Least Squares Cell Based), para la ecuación de 
presión el algoritmo PRESTO, para la ecuación de momento el algoritmo de segundo orden corriente arriba, para la ecuación de fracción de volumen el algoritmo CICSAM y para la ecuación de energía el algoritmo de segundo orden corriente arriba. La formulación del transitorio se realiza mediante un algoritmo implícito de primer orden.

La convergencia de la solución se acelera mediante una selección adecuada de factores de relajación correspondientes a una serie de variables: la unidad para la densidad, las fuerzas de volumen y la energía, 0,1 para el momento y 0,9 para la actualización de la fracción de líquido.

La primera etapa del cálculo está condicionada por la elección del método de inicialización, sistema de referencia y los valores iniciales para una serie de propiedades del dominio. Para el primero se elige del método estándar y para el segundo el relativo a la celda. El patch incluido en el modelo debe de ser definido de acuerdo con los datos relativos a la gota.

El procesamiento se define mediante: el método de selección del intervalo temporal, el número de éstos, el número máximo de iteraciones por intervalo y el número global de Courant. Para el primero se elige la opción variable, con un límite inferior de $10^{-6} \mathrm{~s}$ y un límite superior de $10^{-5} \mathrm{~s}$, para el segundo 3000,50 para el tercero y 0,1 para el cuarto.

\subsection{MODELOS EN RED PARA SIMULACIÓN DEL PROCESO DE SOLIDIFICACIÓN}

González- Fernández y Alhama pormenorizan las reglas generales del método de simulación por redes (MESIR), con aplicaciones en una tipología de problemas diversa (GonzálezFernández y Alhama, 2001). No obstante, se procede a detallar las etapas del diseño del modelo en red.

El modelo más sencillo de solidificación corresponde a una salpicadura en forma de cilindro. Dada su axisimetría sólo es necesario calcular una sección rectangular, figura 4.2. En esta figura se incluye una porción importante del sustrato con objeto de representar la gran inercia térmica asociada a la diferencia de espesor entre la salpicadura y este sustrato.

El modelo es aplicable a geometrías más complejas como las representadas en la figura 4.3 en la que (a) corresponde a una gota con solidificación rápida, y por tanto, el aplastamiento está poco desarrollado. La geometría resultante es similar a la de la figura 2.39. Por el contrario, en la figura 4.3 (b) podemos observar que el aplastamiento es más completo. 


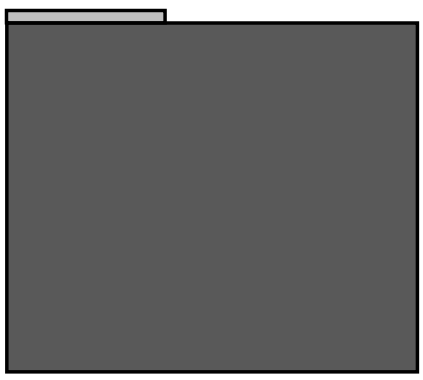

Figura 4.2 Porción de sustrato (gris oscuro) con sección de salpicadura (gris claro) (González Morales et al., 2020).

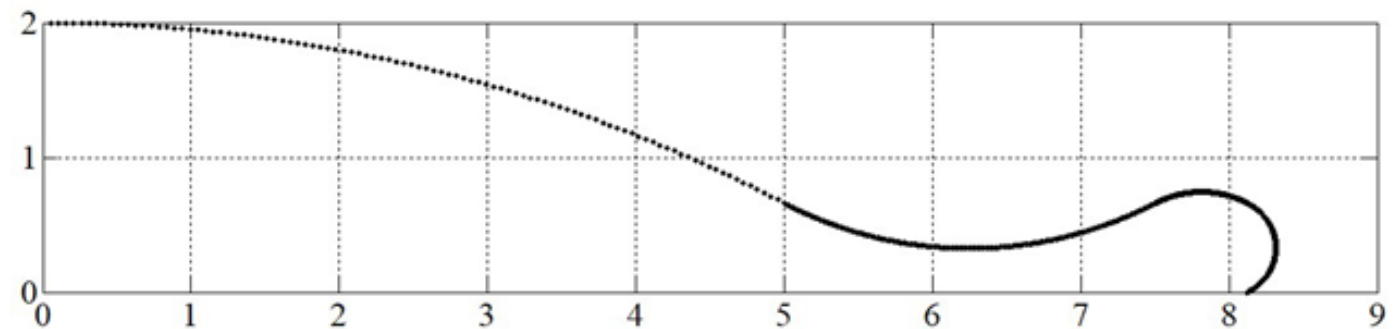

a)

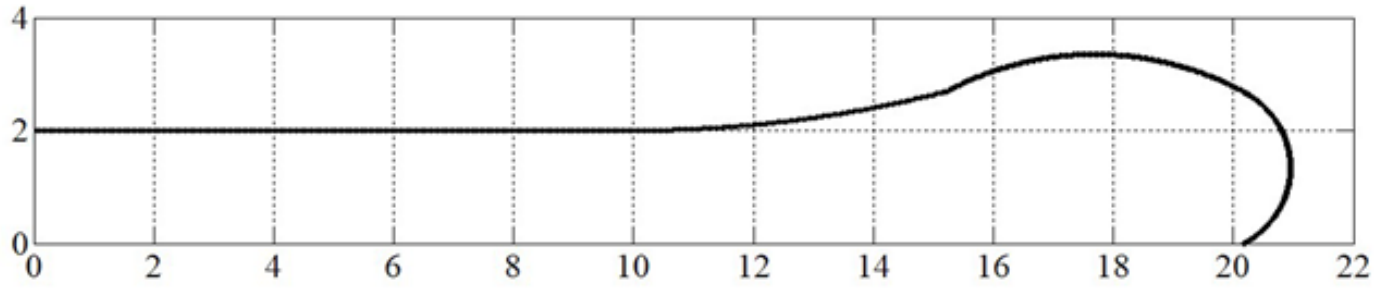

b)

Figura 4.3 a) Sección de gota con solidificación rápida, en $\mu \mathrm{m}$ y b) Sección de gota con solidificación lenta, en $\mu \mathrm{m}$ (González Morales et al., 2020).

El mallado de la salpicadura, parte superior de la figura 4.2, tiene 61x10 celdas; mientras que el mallado del sustrato tiene $183 \times 183$ celdas.

A partir de las ecuaciones de balance, ecuaciones 2.87 y 2.88 , el modelo en red completo se forma con una red básica. Estas ecuaciones representan la transmisión de calor para cada fase del material.

Para aplicar las ecuaciones es necesario considerar un elemento de volumen, figura 4.4, que tiene una simetría cilíndrica, dado que el problema es axisimétrico.

De forma análoga al análisis hecho para el impacto, se considera que la distribución de temperatura tiene dos dimensiones. Por tanto, se discretiza el material en celdas bidimensionales, dividiéndose las variables espaciales $\mathrm{r}$ y $\mathrm{z}$ en $\mathrm{n}$ segmentos. 


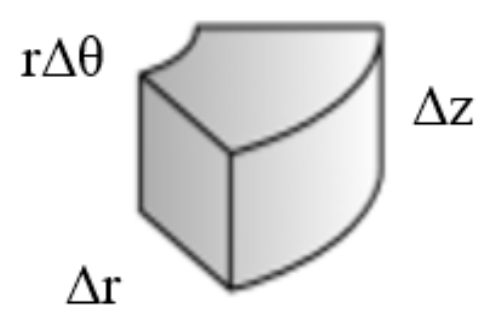

Figura 4.4. Elemento de volumen utilizado en los cálculos de solidificación (González Morales et al., 2020).

La ecuación 2.87 se puede expresar mediante una ecuación en diferencias finitas, aunque es conveniente reescribirla de una determinada forma dado que tiene muchos términos. Así, dicha ecuación puede ser expresada de la siguiente forma:

$$
\frac{\partial \mathrm{T}_{1}}{\partial \mathrm{t}}+\mathrm{D}_{\mathrm{l}} \frac{1}{\mathrm{r}} \frac{\partial \mathrm{T}_{1}}{\partial \mathrm{r}}+\mathrm{D}_{\mathrm{l}} \frac{\partial^{2} \mathrm{~T}_{1}}{\partial \mathrm{r}^{2}}+\mathrm{D}_{\mathrm{l}} \frac{\partial^{2} \mathrm{~T}_{1}}{\partial \mathrm{z}^{2}}=0
$$

Ngspice discretiza la derivada temporal de forma que automáticamente ajusta el incremento de tiempo para alcanzar la convergencia más rápido. Al igual que en la discretización espacial, las derivadas se asocian a balances sobre la celda y no sobre cada punto de la malla.

El segundo sumando, será discretizado de la siguiente manera:

$$
\frac{-\mathrm{D}_{\mathrm{l}}}{\mathrm{r} \cdot \Delta \mathrm{r}} \cdot\left(\mathrm{T}_{\mathrm{l,k}, 2}-\mathrm{T}_{\mathrm{l,k}-1,2}\right)
$$

Y el último sumando como:

$$
\frac{\mathrm{T}_{\mathrm{l,k}, 0}-\mathrm{T}_{\mathrm{liq}, \mathrm{k}, 2}}{\frac{\Delta \mathrm{r}^{2}}{2 \cdot \mathrm{D}_{\mathrm{l}}}}+\frac{\mathrm{T}_{\mathrm{l}, \mathrm{k}, 0}-\mathrm{T}_{\mathrm{l,k}-1,2}}{\frac{\Delta \mathrm{r}^{2}}{2 \cdot \mathrm{D}_{1}}}+\frac{\mathrm{T}_{\mathrm{l}, \mathrm{k}, 0}-\mathrm{T}_{\mathrm{l}, \mathrm{k}, 3}}{\Delta \mathrm{z}^{2} / 2 \cdot \mathrm{D}_{\mathrm{l}}}+\frac{\mathrm{T}_{\mathrm{l}, \mathrm{k}, 0}-\mathrm{T}_{\mathrm{l}, \mathrm{k}-\mathrm{ni}, 3}}{\Delta \mathrm{z}^{2} / 2 \cdot \mathrm{D}_{\mathrm{l}}}
$$

A continuación, se procede al diseño del modelo en red. La Figura 4.2 representa una celda interior al dominio. En este circuito, los sumandos de la ecuación 4.21 equivalen a una corriente eléctrica que se equilibra con la corriente de otro término en un nodo común.

El término de la izquierda de las ecuaciones anteriores, $\mathrm{dT}_{\mathrm{k}} / \mathrm{dt}$, es la corriente que cruza el condensador $\mathrm{C}_{\mathrm{Tk}}$. El voltaje a través de cada condensador, $\mathrm{V}_{\mathrm{CTk}}=\mathrm{C}_{\mathrm{Tk}}{ }^{-1} \cdot \int\left(\mathrm{dT} \mathrm{T}_{\mathrm{k}} / \mathrm{dt}\right) \cdot \mathrm{dt}$ es simplemente la variable $T_{k}$ cuando $C_{T k}=1 F$. Es necesario implementar en el circuito una resistencia de valor muy alto (teóricamente infinito), $\mathrm{R}_{\mathrm{Inf}}$, para mantener la continuidad eléctrica requerida por Ngspice (Ngspice, 2014). Continuando con el símil eléctrico, con el voltaje inicial del condensador se introducen las condiciones iniciales. 
El sumando segundo, corriente $\mathrm{I}_{\mathrm{Bk}}$, se implementa mediante una fuente de corriente controlada.

Los cuatro términos lineales de la ecuación 4.23, $\mathrm{I}_{\mathrm{R} 1 \mathrm{Tk}}$, $\mathrm{I}_{\mathrm{R} 2 \mathrm{Tk}}$, $\mathrm{I}_{\mathrm{R} 3 \mathrm{Tk}} \mathrm{e} \mathrm{I}_{\mathrm{R} 4 \mathrm{Tk}}$, son implementados como simples resistencias, $\mathrm{R}_{1 \mathrm{Tk}}, \mathrm{R}_{2 \mathrm{Tk}}, \mathrm{R}_{3 \mathrm{Tk}}$ e $\mathrm{R}_{4 \mathrm{Tk}}$, respectivamente, ya que la ecuación constitutiva de este componente eléctrico es $i_{R}=V_{R e s} / R$. Los valores de las resistencias son $R_{1 T k}$ $=\mathrm{R}_{3 \mathrm{Tk}}=\Delta \mathrm{z}^{2} / 2 \mathrm{D}_{1}$ y $\mathrm{R}_{4 \mathrm{Tk}}=\mathrm{R}_{2 \mathrm{Tk}}=\Delta \mathrm{r}^{2} / 2 \mathrm{D}_{\mathrm{l}}$.

De esta manera, la red básica de la temperatura $\mathrm{T}$ contiene una fuente de corriente controlada, un condensador y cuatro resistencias, Figura 4.5.

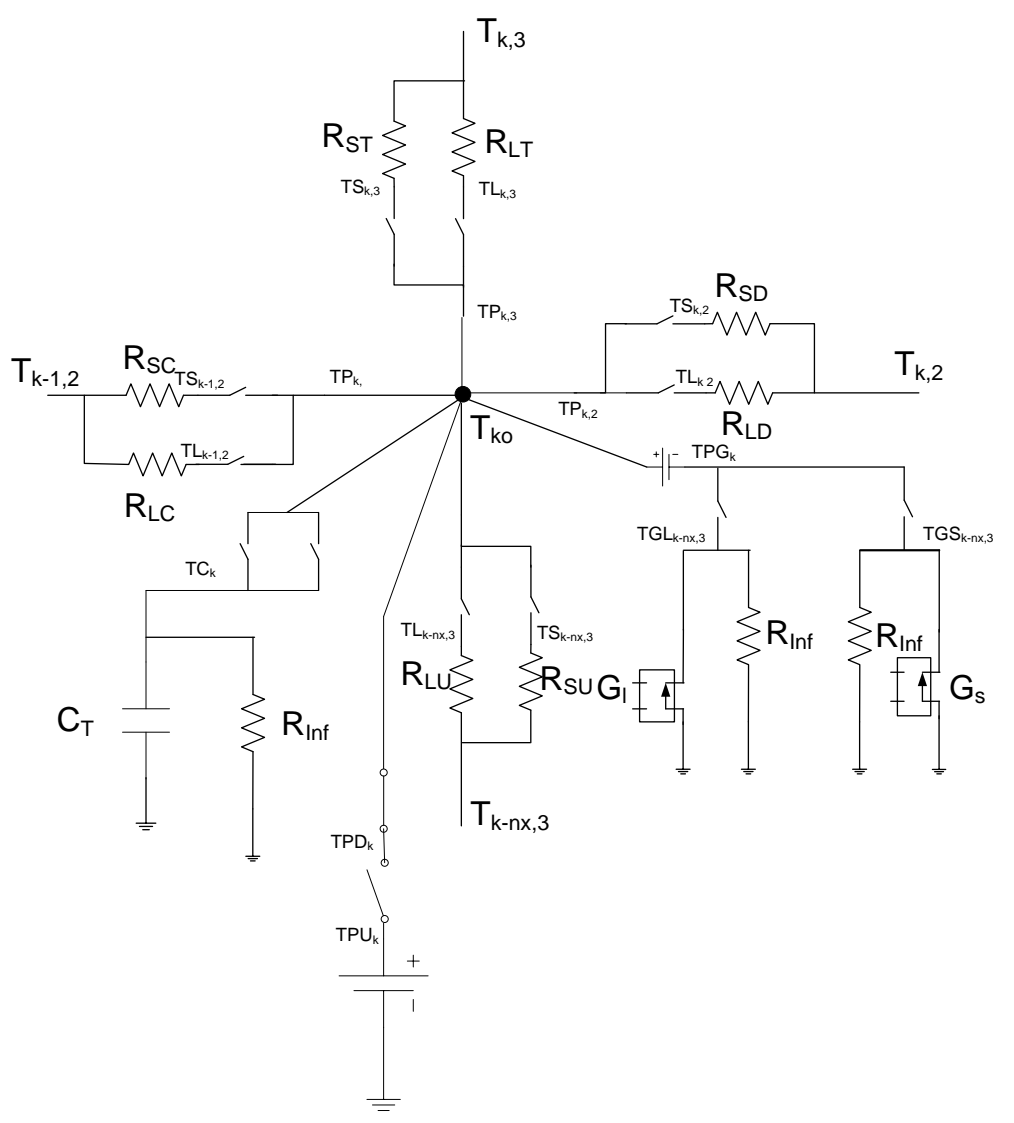

Figura 4.5 Modelo de red para temperatura, T (González Morales et al., 2020).

El circuito representado en la figura 4.5 presenta las resistencias y la fuente de corriente duplicadas, una de ellas representa el comportamiento de sólido y la otra el de líquido. Cada resistencia o fuente de la duplicación se conecta al centro de la celda con un interruptor que se cierra cuando la fase coincide con la indicada en la resistencia o fuente.

Cuando la celda está solidificando, su temperatura permanece constante. Esto se consigue mediante una pila que se conecta durante dicho momento. Para conseguir este objetivo se necesitan dos interruptores. La solidificación acaba cuando la celda ha perdido su calor latente. 
La ecuación 2.89 se puede expresar mediante una ecuación diferencial en diferencias finitas. Antes de la discretización es conveniente reescribirla dejando en un término separado la derivada de volumen solidificado. Así dicha ecuación puede ser expresada de la siguiente forma:

$$
-\frac{\mathrm{K}_{\mathrm{l}}}{\rho \mathrm{L}_{\mathrm{f}}}\left(\frac{\partial \mathrm{T}_{1}}{\partial \mathrm{r}}+\frac{\partial \mathrm{T}_{\mathrm{l}}}{\partial \mathrm{z}}\right) \mathrm{dS}=\frac{\mathrm{d} \Omega_{\text {celda }}}{\mathrm{dt}}
$$

Esta ecuación se puede representar mejor mediante un circuito equivalente si se integra respecto del tiempo. Si además se dividen ambos términos de la ecuación por el volumen de la celda,

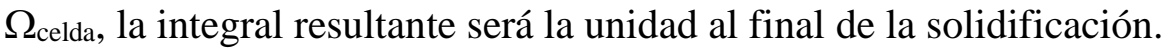

$$
-\int_{0}^{t} \frac{\mathrm{K}}{\rho \mathrm{L}}\left(\frac{\partial \mathrm{T}_{1}}{\partial \mathrm{r}}+\frac{\partial \mathrm{T}_{1}}{\partial \mathrm{z}}\right) \frac{\mathrm{dS}}{\Omega_{\text {celda }}} \mathrm{dt}=\int_{0}^{t} \frac{\mathrm{d} \Omega}{\Omega_{\text {celda }}}<1
$$

Las derivadas entre paréntesis en la ecuación 4.25 serán discretizadas mediante:

$$
-\frac{K_{1}}{\rho L \Delta z} \frac{T_{j, 0}-T_{j-n x, 0}}{\Delta z}-\frac{K_{l}}{\rho L \Delta r} \frac{T_{j, 0}-T_{j+1,0}}{\Delta r}-\frac{K_{l}}{\rho L \Delta z} \frac{T_{j, 0}-T_{j+n x, 0}}{\Delta z}-\frac{K_{l}}{\rho L \Delta r} \frac{T_{j, 0}-T_{j-1,0}}{\Delta r}
$$

El término discretizado será representado por una fuente de corriente controlada. La integración temporal se realiza mediante un condensador, que se conecta a la fuente de corriente cuando la celda alcanza la temperatura de solidificación y se desconecta cuando el voltaje alcanza el valor unidad. Así, la ecuación 4.25 es equivalente al circuito de integración representado en la figura 4.6 .

La ecuación 2.91 se puede expresar mediante una ecuación en diferencias finitas. Antes de realizar la discretización es conveniente reescribirla de forma que tenga las mismas unidades que las utilizadas en el circuito de la figura 4.5. Así dicha ecuación puede ser expresada de la siguiente forma:

$$
\frac{1}{\rho \cdot c_{p}} \frac{d Q}{d t} \frac{1}{d S}=\frac{h_{i}}{\rho \cdot c_{p}}\left(T_{\text {sup }}-T_{a m b}\right)
$$

El término a la derecha de la ecuación 4.27, transmisión convectiva, es representado mediante una fuente de corriente controlada. 


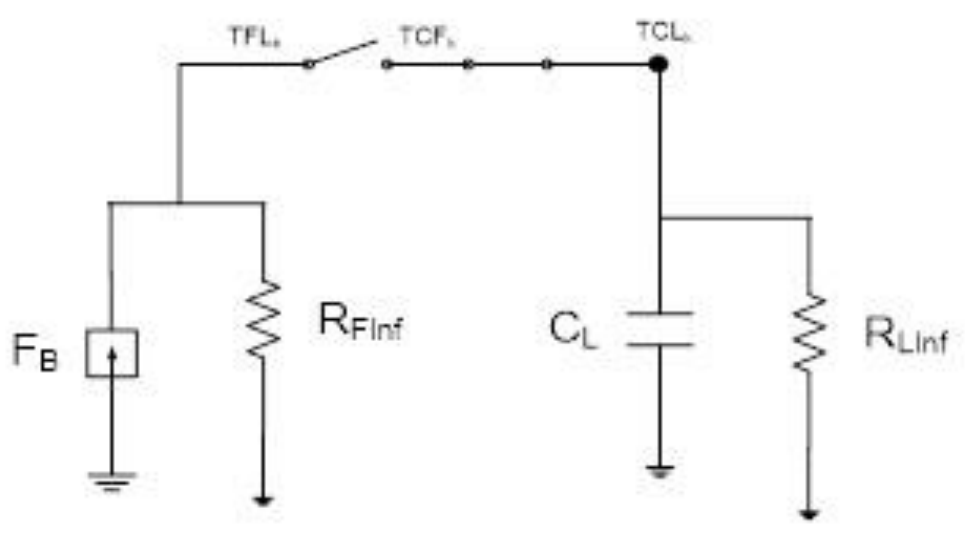

Figura 4.6 Modelo de red para el circuito de solidificación (González Morales et al., 2020).

Así, de la misma forma la radiación se puede representar como:

$$
\frac{1}{\rho \cdot c_{\mathrm{p}}} \frac{\mathrm{dQ}}{\mathrm{dt}} \frac{1}{\mathrm{dS}}=\frac{\varepsilon \sigma}{\rho \cdot c_{\mathrm{p}}}\left[\left(\mathrm{T}_{\text {pared }}\right)^{4}-\left(\mathrm{T}_{\mathrm{r}}\right)^{4}\right]
$$

Siendo el término de la derecha, la transmisión por radiación que puede ser reproducida por una fuente de corriente controlada.

El último elemento a considerar en el circuito es la representación del contacto entre la salpicadura y el sustrato. Para ello, se utilizará un modelo similar al de Sobolev, mencionado en el apartado 2.3.4. La discretización espacial de dicho modelo se representa como:

$$
\dot{\mathrm{Q}}=\frac{\mathrm{T}_{\mathrm{sal}}-\mathrm{T}_{\mathrm{s}}}{\frac{1}{\mathrm{~h}_{\mathrm{c}} \cdot \mathrm{A}}}
$$

Para implementar esta ecuación en el modelo en red resulta más práctico convertir esta resistencia de contacto en una conductividad equivalente, por lo que a partir de la ecuación de Fourier podemos escribir:

$$
\dot{\mathrm{Q}}=\mathrm{K}_{\text {gap }} \cdot \mathrm{A} \cdot \frac{\mathrm{T}_{\text {sal }}-\mathrm{T}_{\mathrm{s}}}{\Delta \mathrm{z}_{\text {gap }}}=\frac{\mathrm{T}_{\mathrm{sal}}-\mathrm{T}_{\mathrm{s}}}{\frac{1}{\mathrm{~h}_{\mathrm{c}} \cdot \mathrm{A}}}
$$

de donde $\mathrm{K}_{\mathrm{gap}}=\mathrm{h}_{\mathrm{c}} \cdot \Delta \mathrm{z}_{\mathrm{gap}}=\Delta \mathrm{zgap}_{\mathrm{gap}} / \mathrm{R}_{\mathrm{th}}$

En nuestro modelo las resistencias, en la parte inferior de la celda vienen representadas por $\mathrm{R}_{1 \mathrm{Tk}}$ $=\Delta \mathrm{z}^{2} / 2 \mathrm{D}_{\text {gap }}$, que equivale a $\mathrm{R}_{1 \mathrm{Tk}}=\Delta \mathrm{z}^{2} \cdot \rho_{\mathrm{salp}} \cdot \mathrm{c}_{\mathrm{e}, \mathrm{sal}} / 2 \mathrm{k}_{\mathrm{gap}}=\Delta \mathrm{z} \cdot \rho_{\mathrm{sal}} \cdot \mathrm{c}_{\mathrm{e}, \mathrm{sal}} \cdot \mathrm{R}_{\mathrm{th}} / 2$. 
Con objeto de verificar el modelo se van a comparar los resultados de la tesis de PasadidehFard para la solidificación de una salpicadura de estaño sobre sustrato de acero, usando los mismos valores de entrada con los obtenidos por el Método de Redes. El modelo utilizado incluye resistencias de contacto, aunque no radiación térmica. A continuación, se aplicará el modelo desarrollado a una salpicadura de alúmina sobre acero. En este caso la radiación térmica ha sido incluida dado que las temperaturas alcanzadas son mucho más altas. 


\section{ANÁLISIS DE IMPACTO DE GOTA FUNDIDA Y SU SOLIDIFICACIÓN}

Se presenta una aplicación del MESIR al proceso de solidificación recogido en el apartado 2.5. Para estos procesos se dispone de resultados obtenidos tanto aplicando software comercial o propio, como de resultados experimentales de otros autores, siendo posible verificarlos con los del método de redes.

Por otro lado, el impacto isotérmico será resuelto mediante el software comercial disponible en la UPCT. Además, las gotas de material cerámico provenientes de muestras serán catalogadas para su posterior simulación.

\subsection{SIMULACIÓN DEL IMPACTO ISOTÉRMICO DE UNA GOTA DE AGUA MEDIANTE EL MÉTODO DE VOLÚMENES FINITOS}

Como se ha mencionado en el capítulo anterior se van a exponer los resultados de la simulación mediante el método de volúmenes finitos.

Con objeto de verificar el modelo con los resultados obtenidos en la tesis de PasadidehFard se van a utilizar los mismos valores que definen su modelo, impacto de una gota de agua sobre sustrato de acero. Más concretamente, el diámetro de la gota antes del impacto es $2 \mathrm{~mm}$ y su velocidad es $1 \mathrm{~m} / \mathrm{s}$. La temperatura de la gota es de $25^{\circ} \mathrm{C}$.

Las propiedades del agua son: densidad, $997 \mathrm{~kg} / \mathrm{m}^{3}$, viscosidad cinemática, $8,57 \cdot 10^{-7} \mathrm{~m}^{2} / \mathrm{s}$ y tensión superficial, $0,073 \mathrm{~N} / \mathrm{m}$.

Las figuras 5.1 a 5.5 representan la gota en distintos intervalos.

La figura 5.6 muestra la expansión de la gota, con una duración aproximada de $3 \mathrm{~ms}$ desde el impacto, y una contracción posterior, con una duración de 1,5 ms, obtenida de la referencia mencionada anteriormente. 


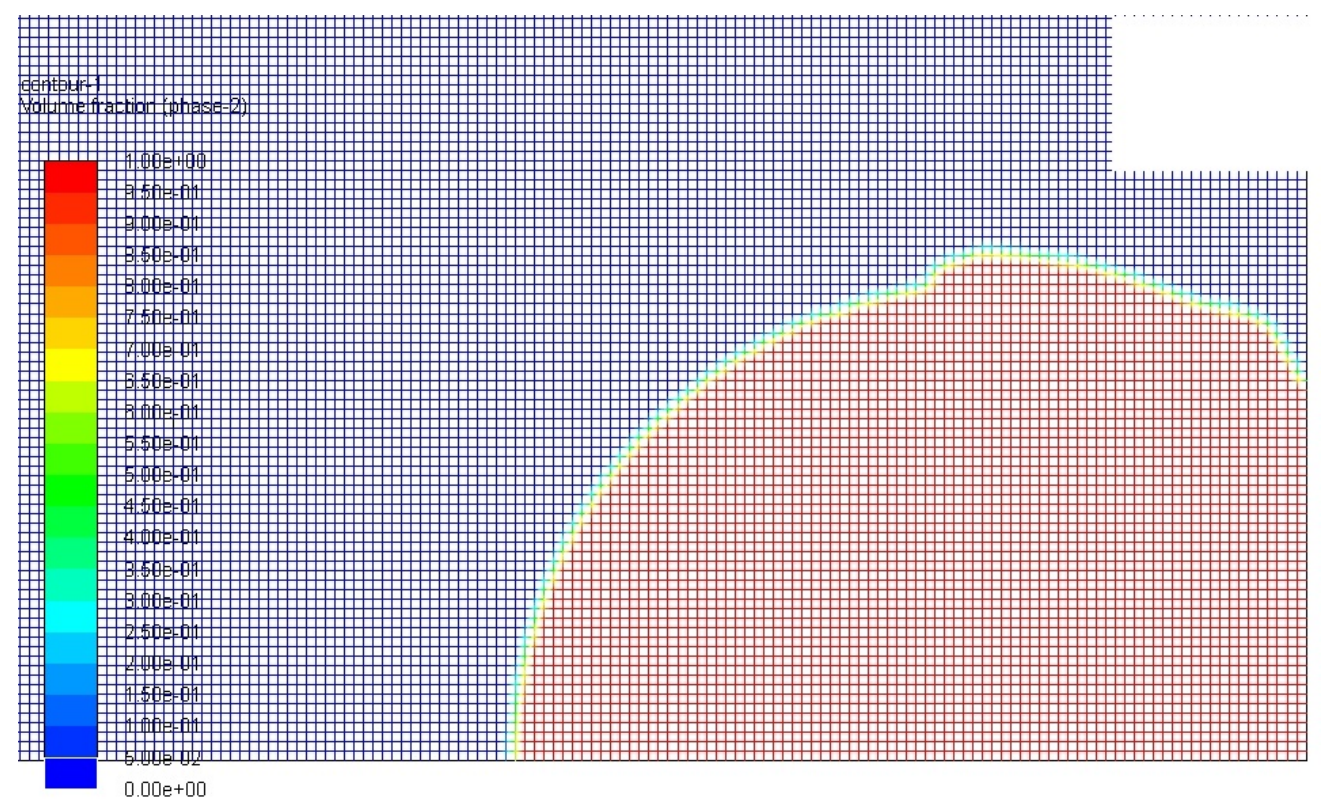
$0.001(\mathrm{~m})$

Contours of Volume fraction (phase-2) $\quad($ Time $=3.3777 \mathrm{e}-04)$

Figura 5.1 Salpicadura a $0,338 \mathrm{~ms}$.

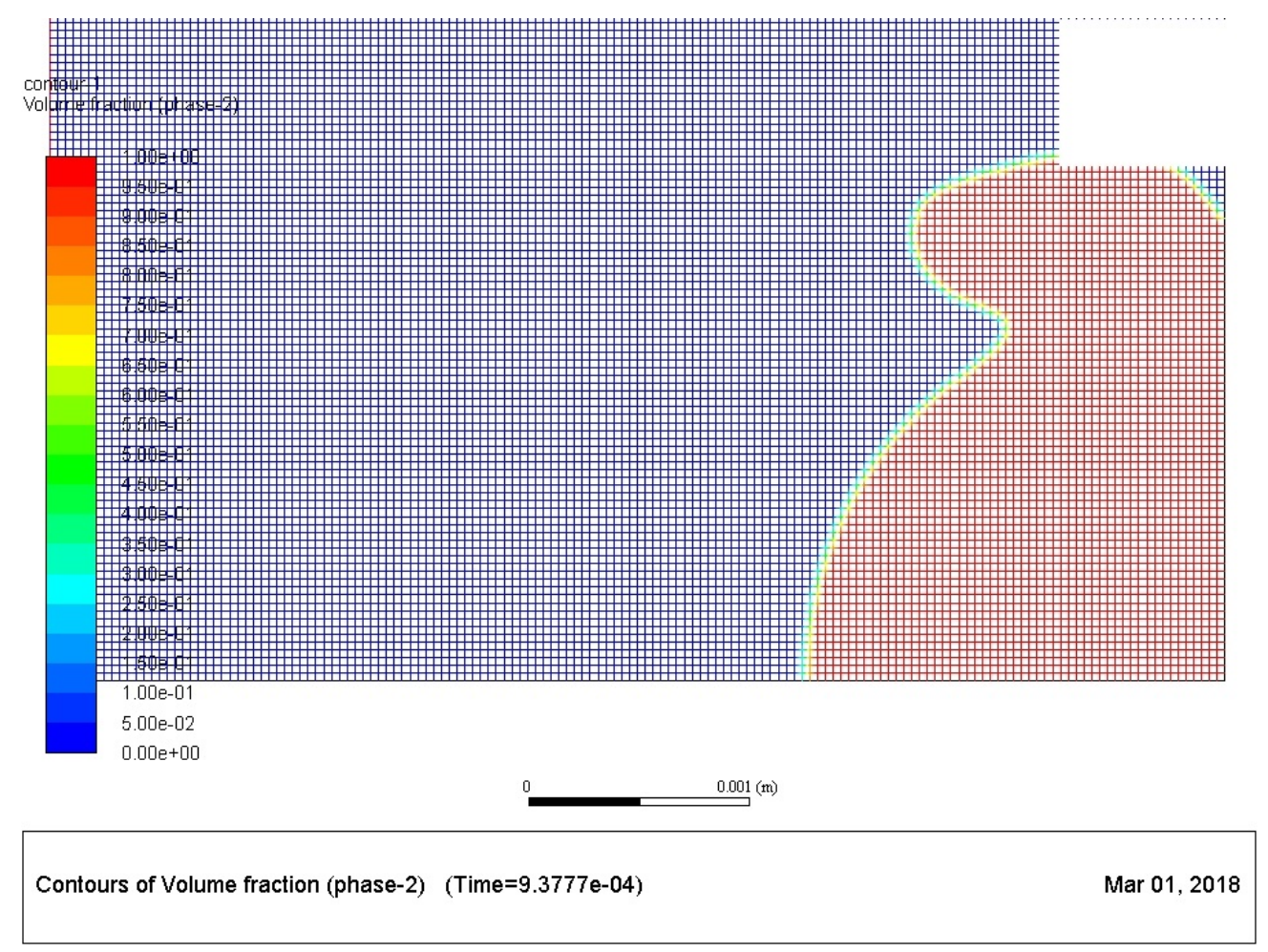

Figura 5.2 Salpicadura a $0,938 \mathrm{~ms}$. 


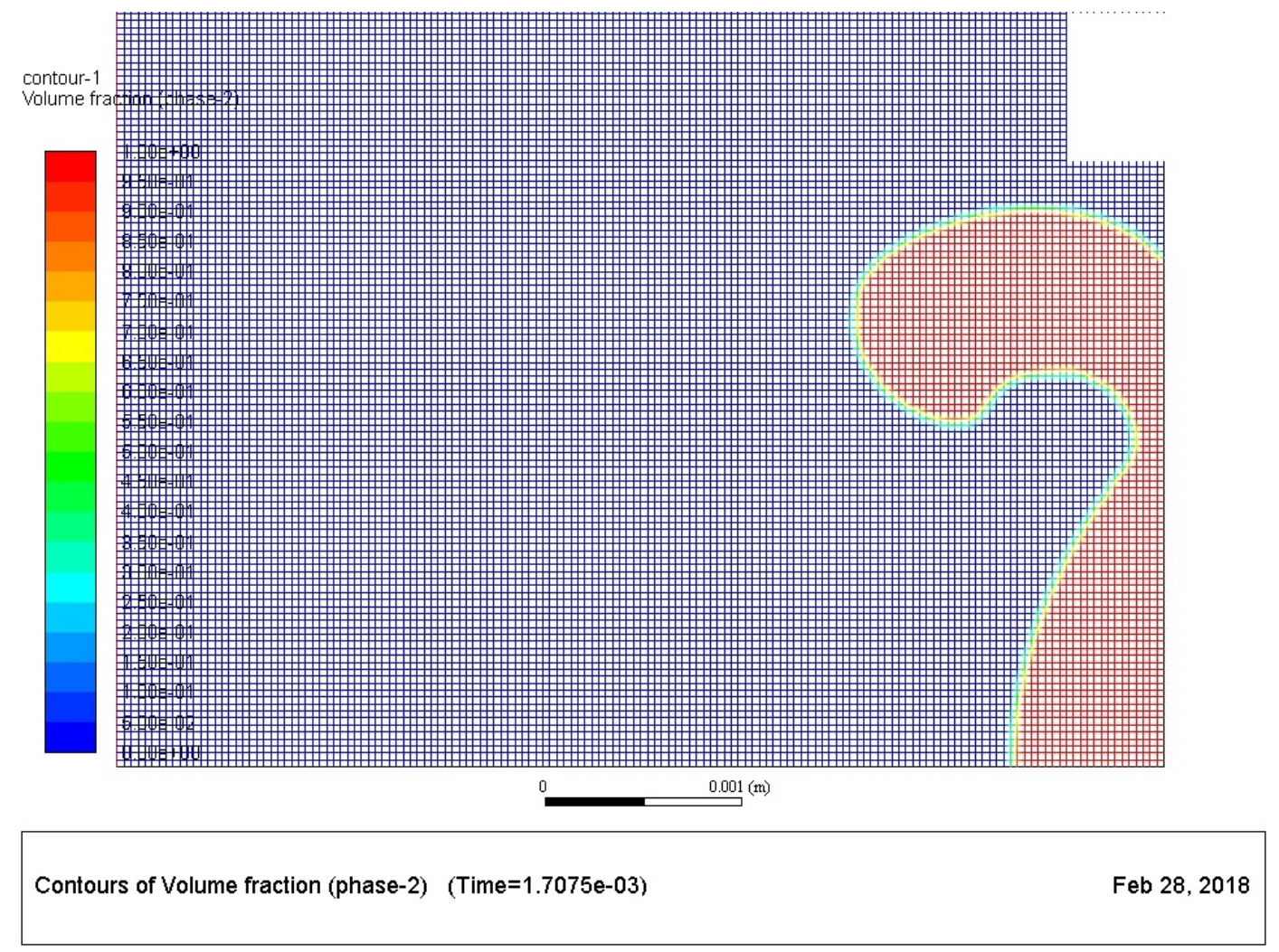

Figura 5.3 Salpicadura a 1,707 ms.

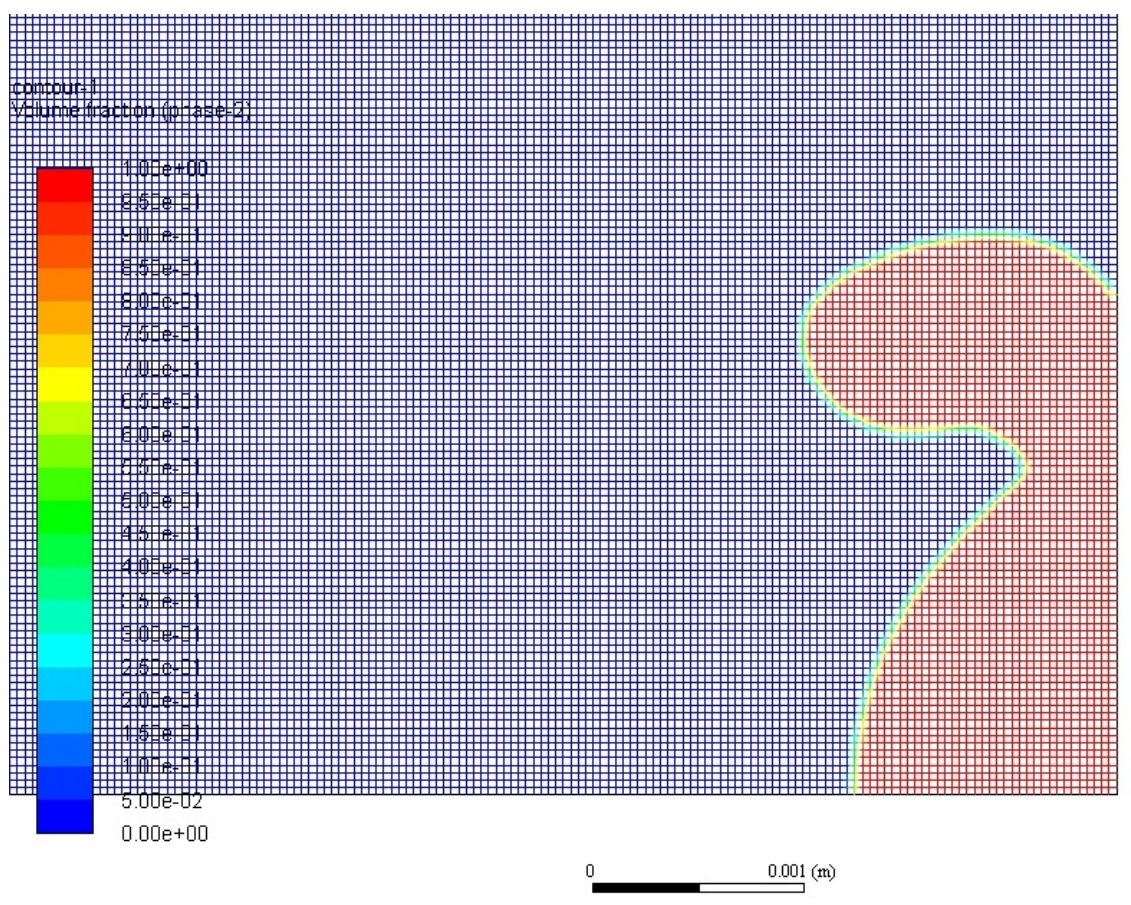

Contours of Volume fraction (phase-2) $\quad($ Time $=1.3378 \mathrm{e}-03)$

Figura 5.4 Salpicadura a 1,338 ms. 
contour- 1

Yolume fraction (phase-2)
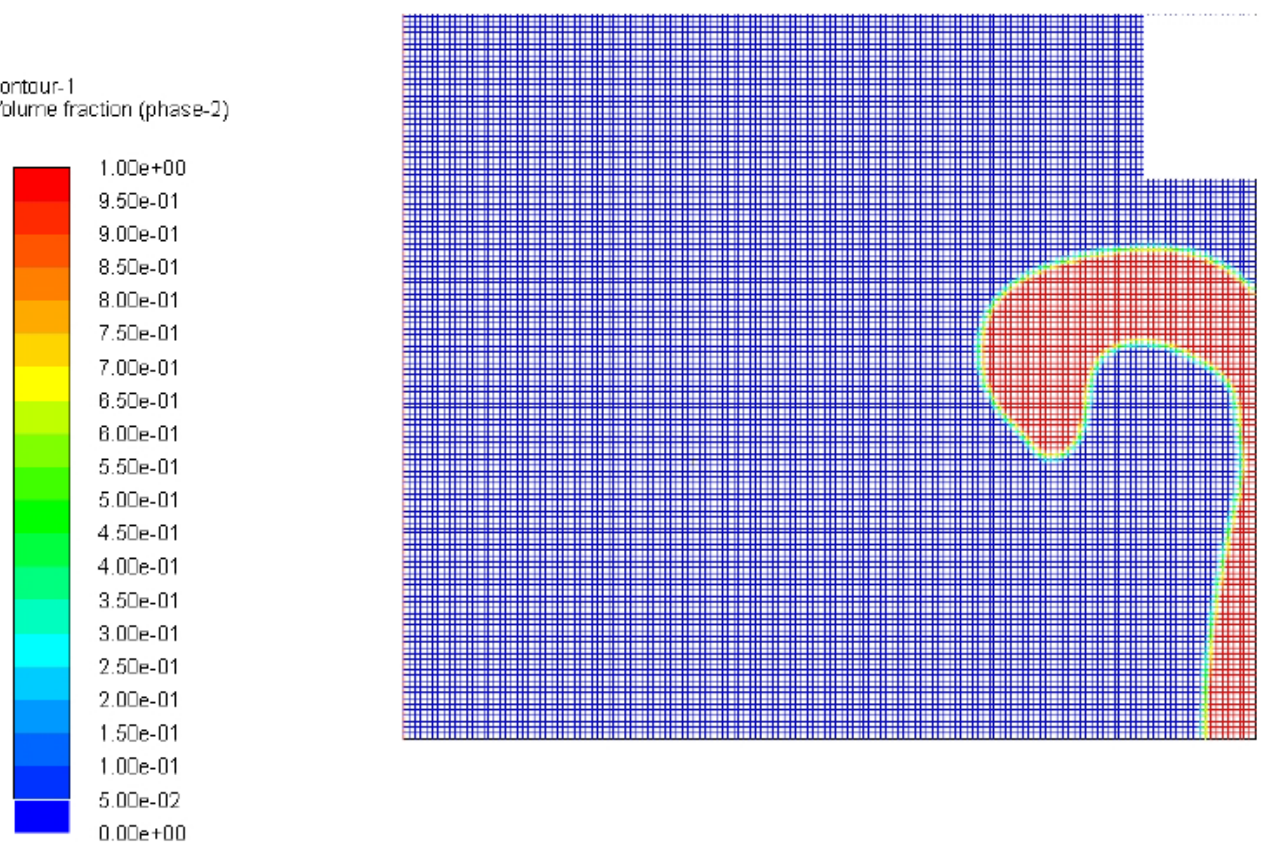

$0.002(\mathrm{n})$

$\begin{array}{lll}\text { Contours of Volume fraction (phase-2) } & \text { (Time=2.3148e-03) Feb 27. } 2018\end{array}$

ANSYS Fluent Release 18.0 (axi, dp, pbns, vof, lam, transient)

Figura 5.5 Salpicadura a 2,315 ms.
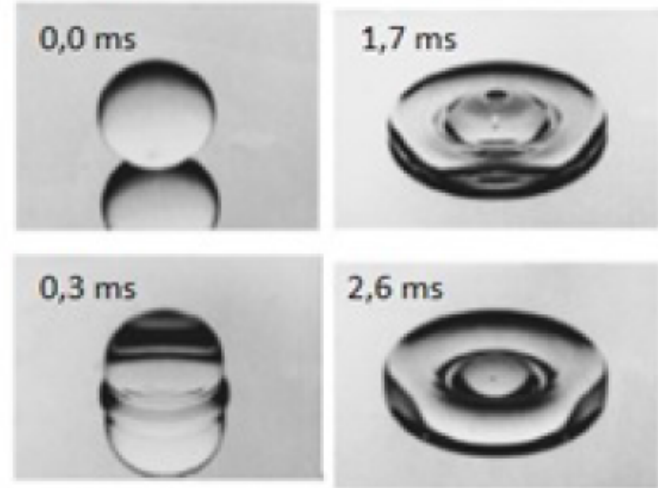

$2,6 \mathrm{~ms}$

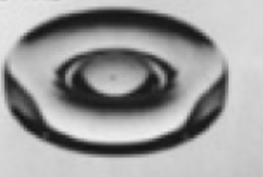

$0,9 \mathrm{~ms}$

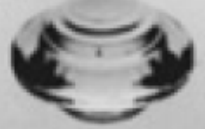

$4,0 \mathrm{~ms}$
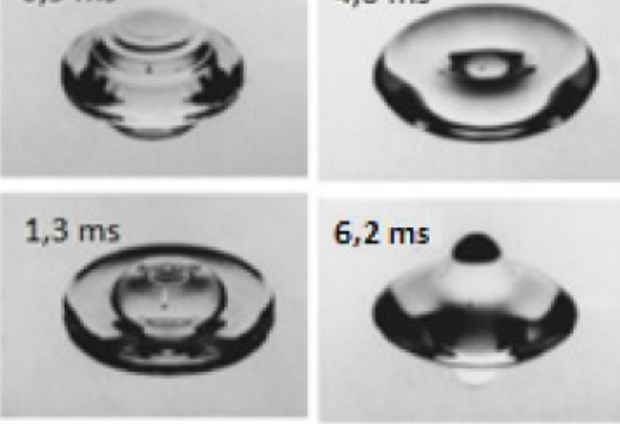

$6,2 \mathrm{~ms}$

$2 \mathrm{~mm}$

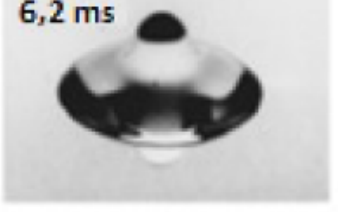

$2 \mathrm{~mm}$

Figura 5.6 Fotografía de una gota de agua de $2 \mathrm{~mm}$ de diámetro impactando sobre una superficie de acero inoxidable con una velocidad de $1 \mathrm{~m} / \mathrm{s}$ (Pasandideh-Fard et al., 1996). 


\subsection{SIMULACIÓN DEL PROCESO DE SOLIDIFICACIÓN DE UNA SALPICADURA MEDIANTE EL MÉTODO DE REDES}

\subsubsection{ANÁLISIS DE LA SOLIDIFICACIÓN Y ENFRIAMIENTO DE UNA SALPICADURA DE ESTAÑO}

Tal y como se comentó en el apartado 4.2, se va a verificar el modelo utilizando como referencia los resultados de la tesis de Pasandideh-Fard para la solidificación de una salpicadura de estaño sobre sustrato de acero, usando los mismos valores de entrada (Pasandideh-Fard, 1998). Más concretamente, el diámetro de la gota antes del impacto es $2,1 \mathrm{~mm}$ y el grado de aplanamiento es 2 . El espesor de la salpicadura, suponiendo una geometría cilíndrica y conservación de volumen, viene dado por:

$$
b_{s}=\frac{4}{3} \cdot \frac{\left(d_{p} / 2\right)^{3}}{\left(\xi \cdot d_{p} / 2\right)^{2}}
$$

La temperatura inicial de la gota es de $240{ }^{\circ} \mathrm{C}$ y la del sustrato $25^{\circ} \mathrm{C}$. El mallado de la salpicadura para el cálculo con estaño, figura 4.2, tiene $6 \times 37$ celdas; mientras que el mallado del sustrato tiene $111 \times 111$ celdas.

La comparación se va a realizar, inicialmente sin considerar radiación térmica y resistencia de contacto $R_{\text {th }}$, utilizando la temperatura en el sustrato justo debajo del centro de la salpicadura, celda 12211, como puede verse en la figura 5.7.

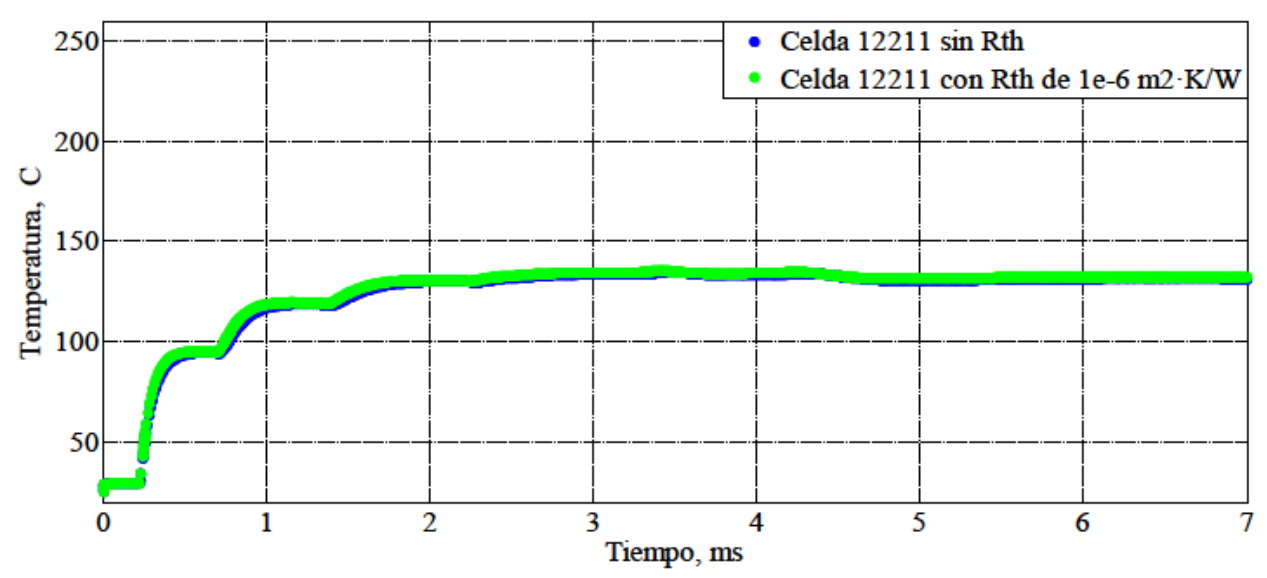

Figura 5.7 Evolución de temperaturas en la celda 12211 del sustrato sin y con $\mathrm{R}_{\text {th }} 10^{-6} \mathrm{~m}^{2} \cdot \mathrm{K} / \mathrm{W}$ (González Morales et al., 2020). 
La tabla 5.1 muestra los datos experimentales obtenidos por Pasadideh-Fard usando un termopar cuya precisión es $\pm 1{ }^{\circ} \mathrm{C}$ (Pasandideh- Fard, 1998, Pasandideh- Fard et al., 1998) y la figura 5.8 reproduce dichos resultados considerando $R_{t h}$.

Tabla 5.1 Datos experimentales para la temperatura del acero en el centro de la gota de estaño (Pasandideh-Fard, 2008)

\begin{tabular}{cc}
\hline Tiempo (ms) & Temperatura oC \\
\hline 0 & 25 \\
0,15 & 129 \\
0,33 & 143 \\
0,5 & 151 \\
0,75 & 160 \\
1 & 161 \\
1,25 & 161 \\
1,5 & 161 \\
\hline
\end{tabular}

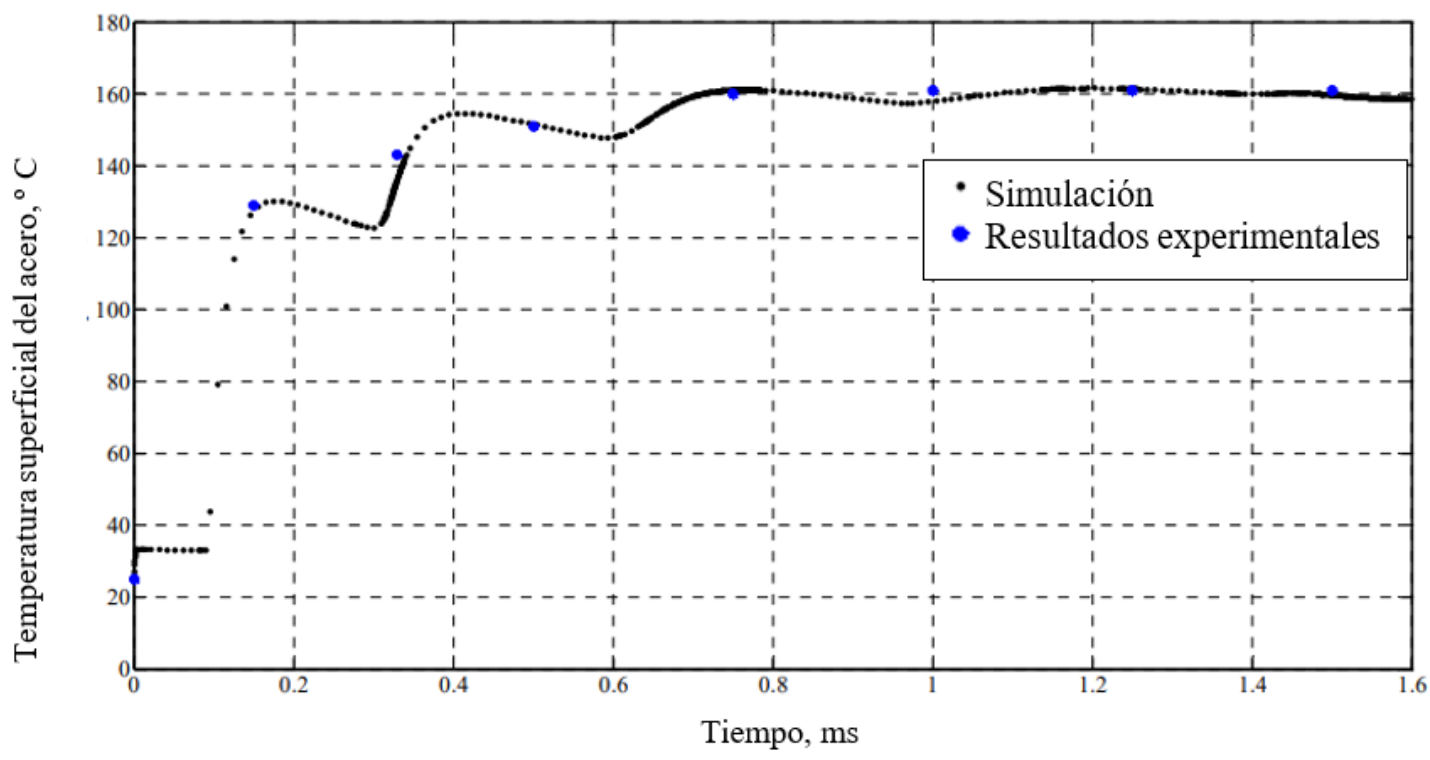

Figura 5.8 Evolución de temperaturas en el sustrato en el centro de la gota de estaño (Pasandideh-Fard, 1998) 
La temperatura obtenida mediante el Método de Redes a los $7 \mathrm{~ms}$ es inferior en $35^{\circ} \mathrm{C}$ al valor obtenido por Pasandideh-Fard. Debe mencionarse que el centro de la celda no se encuentra en la interfase si no que está a $0,0291 \mathrm{~mm}$ por debajo de la superficie del sustrato. La figura 5.9 representa la temperatura en el punto de la salpicadura que está sobre este, es decir a $0,0291 \mathrm{~mm}$ sobre la interfase, celda 12322 . Esta temperatura es inferior en $12^{\circ} \mathrm{C}$ al valor obtenido por Pasandideh-Fard. A continuación, vamos a analizar el efecto de incluir una resistencia de contacto en la interfase igual a $10^{-6} \mathrm{~m}^{2} \cdot \mathrm{K} / \mathrm{W}$. Las figuras 5.7 y 5.9 muestran también los resultados obtenidos. En este caso, la temperatura a los $7 \mathrm{~ms}$ en el estaño es inferior en $15^{\circ} \mathrm{C}$ al valor obtenido por Pasandideh-Fard.

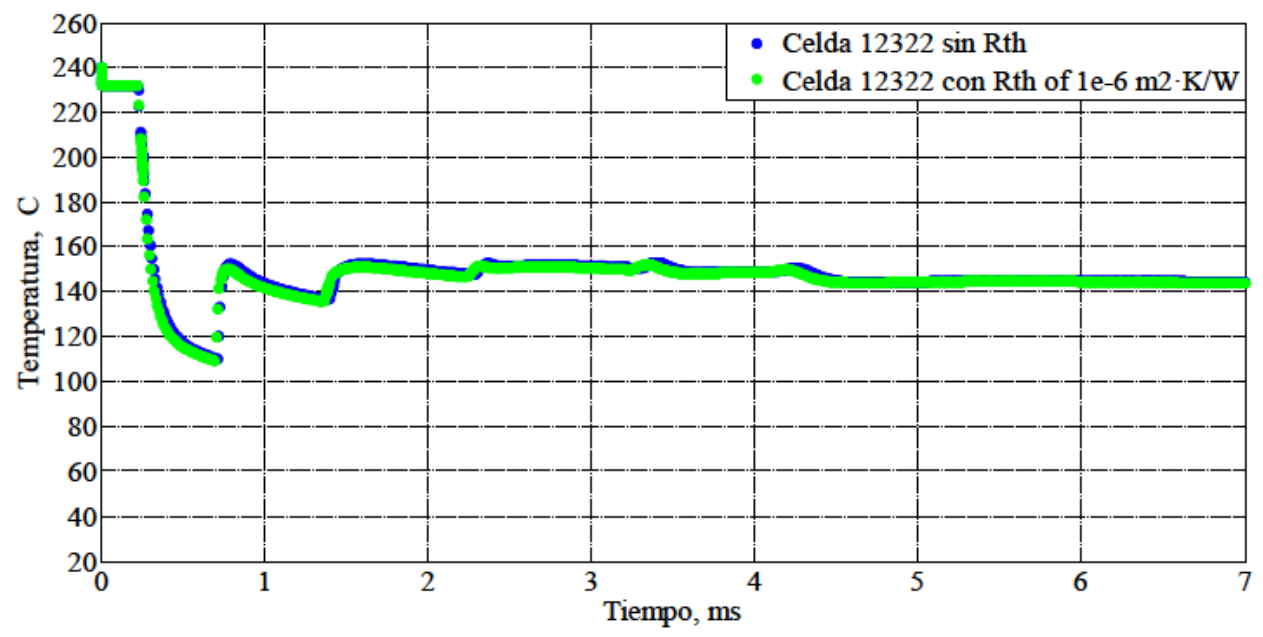

Figura 5.9 Evolución de temperaturas en la celda 12322 del estaño $\sin$ y con $R_{\text {th }} 10^{-6} \mathrm{~m}^{2} \cdot \mathrm{K} / \mathrm{W}$ (González Morales et al., 2020).

\subsubsection{ANÁLISIS DE LA SOLIDIFICACIÓN Y ENFRIAMIENTO DE UNA SALPICADURA DE ALÚMINA SIN CALENTAMIENTO DEL SUSTRATO}

A continuación, se va a mostrar la evolución de la temperatura de la alúmina fundida a $2070{ }^{\circ} \mathrm{C}$ sobre sustrato de acero a $25^{\circ} \mathrm{C}$, sin considerar la resistencia de contacto. Se va a adoptar como diámetro de la gota antes del impacto es $17,7 \mu \mathrm{m}$, valor obtenido a partir de los datos del polvo de tamaño $-20+5 \mu \mathrm{m}$, y como radio de la salpicadura $30 \mu \mathrm{m}$, valor obtenido a partir del análisis de imagen de las gotas tipo tortita. En este caso el cálculo del espesor es más simple:

$$
\mathrm{b}_{\mathrm{s}}=\frac{4}{3} \cdot \frac{\left(\mathrm{d}_{\mathrm{p}} / 2\right)^{3}}{(\mathrm{D} / 2)^{2}}
$$


El mallado de la salpicadura para el cálculo con alúmina, figura 4.2, tiene 37x10 celdas; mientras que el mallado del sustrato tiene $111 \times 111$ celdas.

Para ver el efecto de la radiación térmica sobre los resultados, se va a comparar la evolución de las temperaturas en una misma celda sin considerar radiación térmica y considerándola. Para ello elegiremos una celda en la superficie de la salpicadura, la 12655. La figura 5.10 representa evolución de temperaturas durante $0,1 \mathrm{~ms}$ en dicha celda considerando radiación y esta evolución sin radiación. A partir de esta figura podemos observar que a $30 \mu$ s la temperatura sin considerar radiación es idéntica a considerarla. El calor perdido por transmisión térmica es superior al perdido por radiación, lo cual es lógico teniendo en cuenta los valores de emisividad de los materiales utilizados, 0,24 para el acero y 0,28 para la alúmina. A pesar de este resultado, los cálculos se harán considerando radiación.

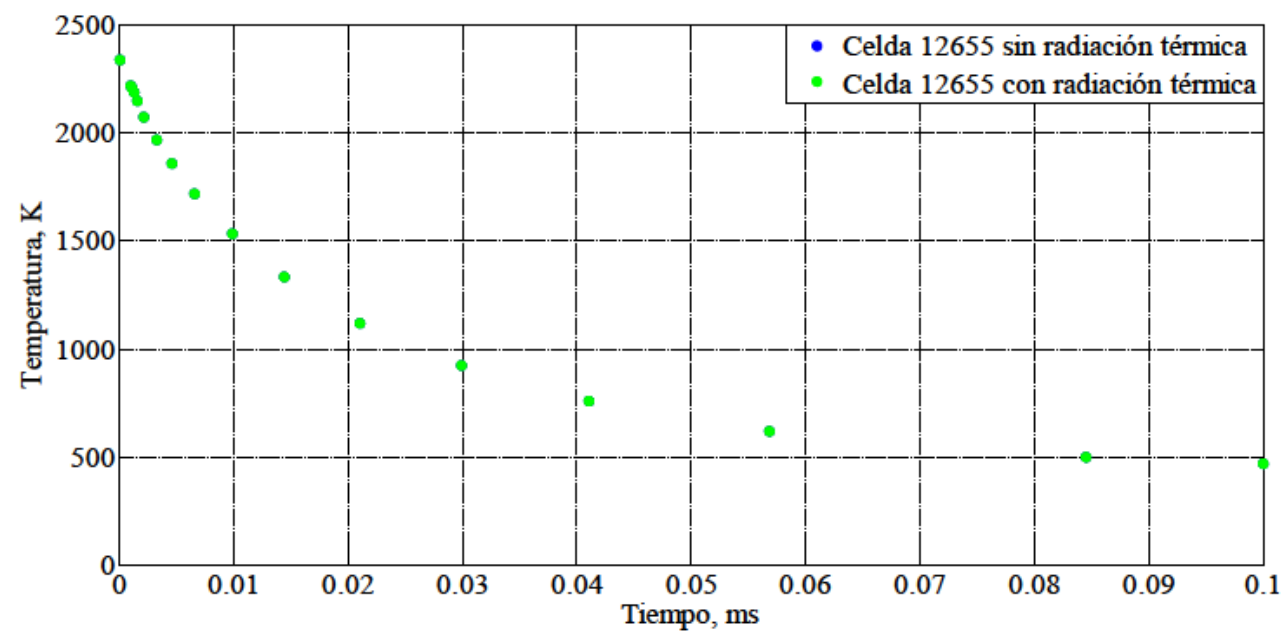

Figura 5.10 Evolución de temperaturas la celda 12655 de la salpicadura con y sin radiación térmica

(González Morales et al., 2020).

A partir de ahora sólo vamos a tener en cuenta resultados obtenidos considerando radiación térmica. La figura 5.11 muestra la distribución de temperaturas en la salpicadura a $9,84 \mu \mathrm{s}$ sin precalentamiento, mientras que la figura 5.12 muestra la distribución de temperaturas en el sustrato, igualmente las figuras 5.13 y 5.14 representan esas mismas distribuciones a $21,06 \mu \mathrm{s}$. Las distribuciones de temperatura mantienen la forma, aunque lógicamente sus valores disminuyen con el tiempo. 


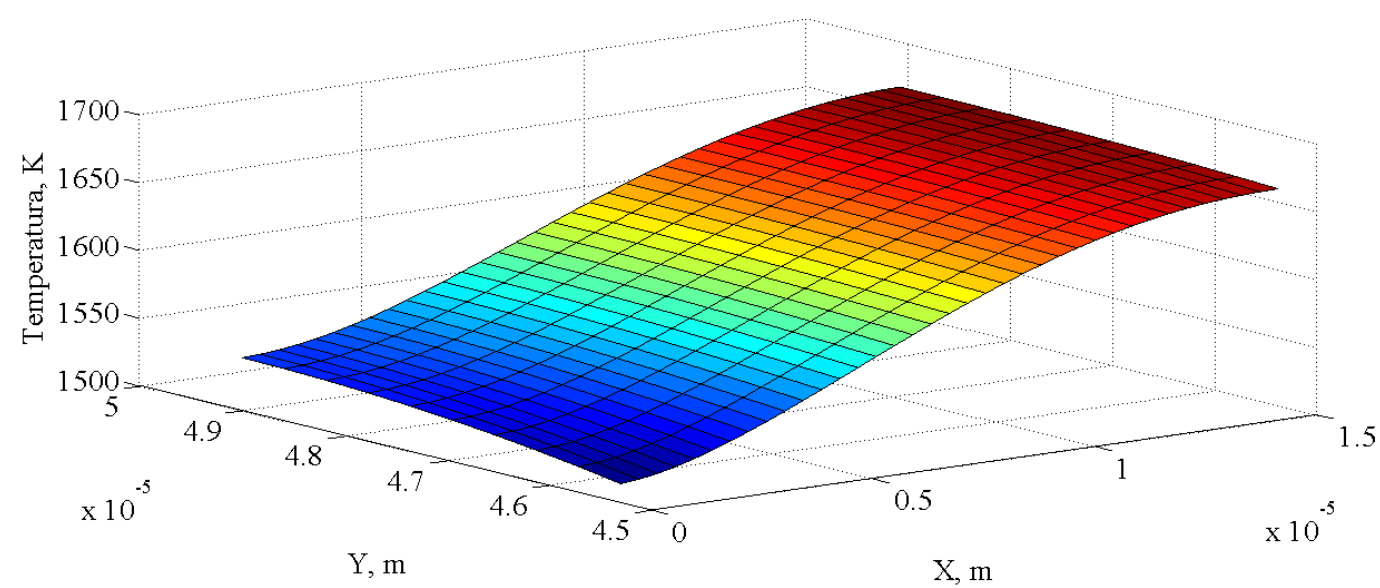

Figura 5.11 Distribución de temperaturas en la salpicadura considerando radiación térmica en 9,84 $\mu$ s.

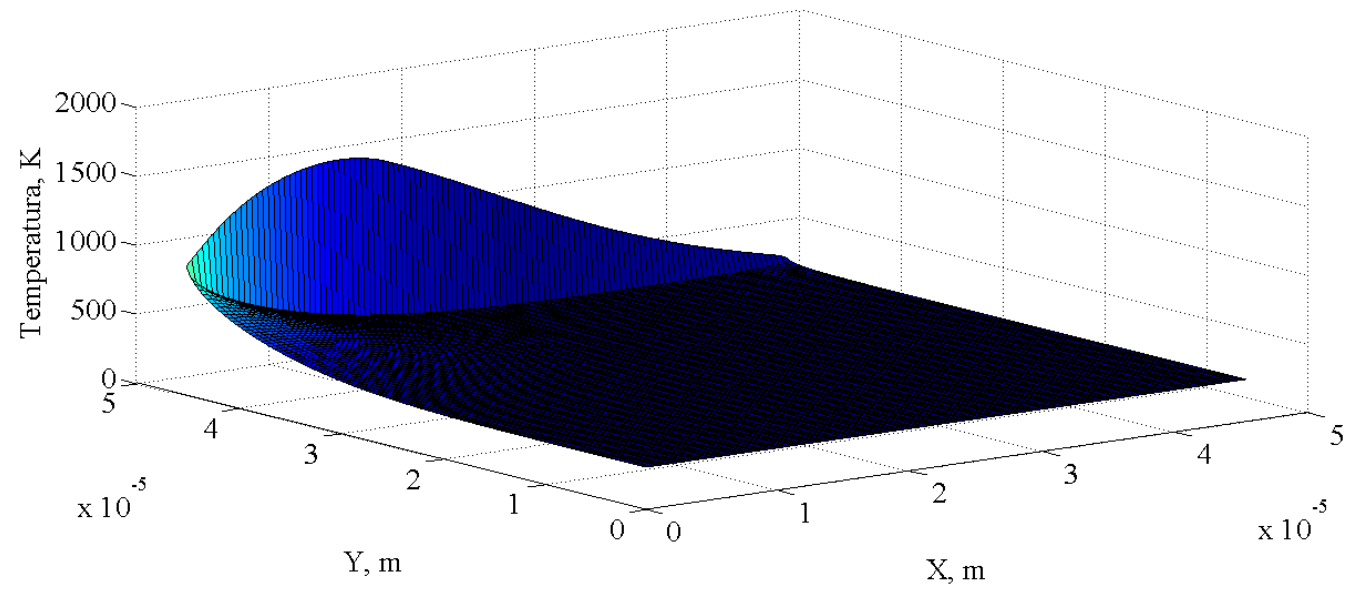

Figura 5.12 Distribución de temperaturas en el sustrato considerando radiación térmica en 9,84 $\mu \mathrm{s}$.

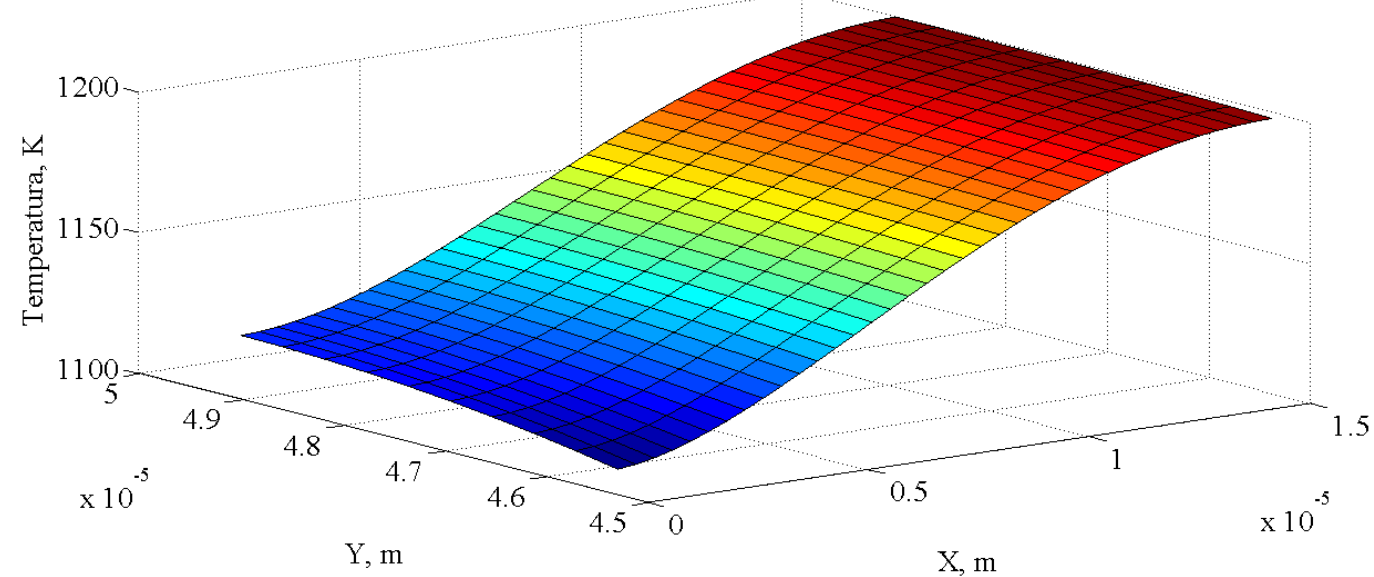

Figura 5.13 Distribución de temperaturas en la salpicadura considerando radiación térmica en 21,06 $\mu$ s.

Los nodos 12322, 12340 y 12358 pertenecen a la salpicadura y se encuentran en la zona adyacente al acero, el primero en el centro de la salpicadura, el segundo a un cuarto de 
esta y el último en su borde. La figura 5.15 muestran la evolución de las temperaturas en dichos nodos.

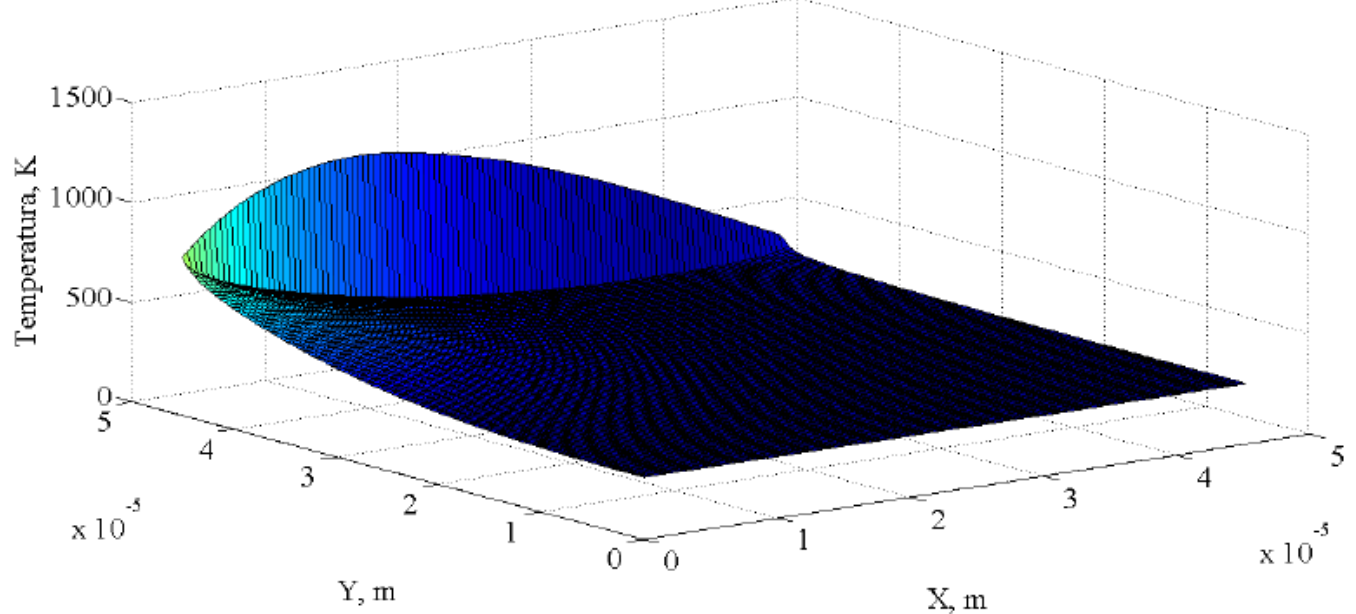

Figura 5.14 Distribución de temperaturas en el sustrato considerando radiación térmica en 21,06 $\mu$ s.

La característica más importante que podemos observar en las figuras mencionadas es la solidificación en menos de $1 \mu \mathrm{s}$. Adicionalmente, estos resultados nos indican que la celda cerca del eje de simetría es la que se enfría más rápidamente. Así, la temperatura a $10 \mu \mathrm{s}$ es $466,9 \mathrm{~K}$ en la celda 12322 , mientras que en la celda 12358 es $471,8 \mathrm{~K}$.

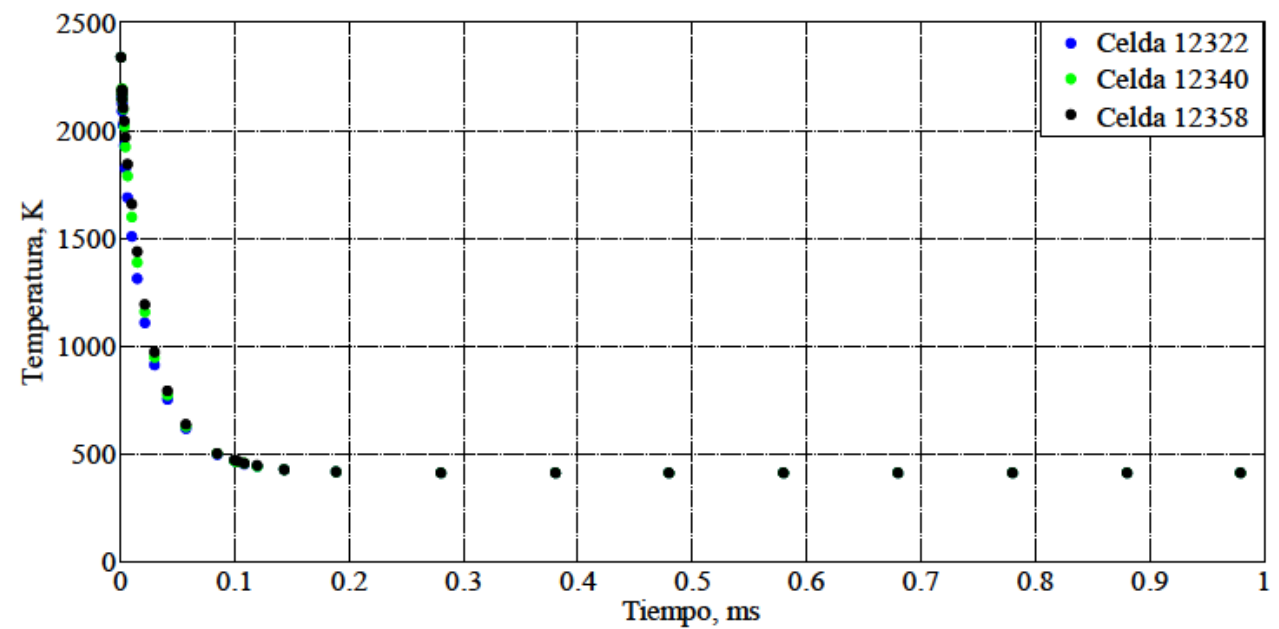

Figura 5.15 Evolución de temperatura en las celdas 12322, 12340 y 12322 de la salpicadura considerando radiación térmica en $1 \mathrm{~ms}$ (González Morales et al., 2020).

Las celdas 12655, 12673 y 12691 se encuentran en la superficie de la alúmina, la primera en el centro de la salpicadura, la segunda a un cuarto de esta y la última en su borde. La figura 5.16 muestra la evolución de la temperatura en dichas celdas. En la superfície de 
la salpicadura se repite la misma tendencia de la interfase con el sustrato, aunque con menores diferencias de temperatura.

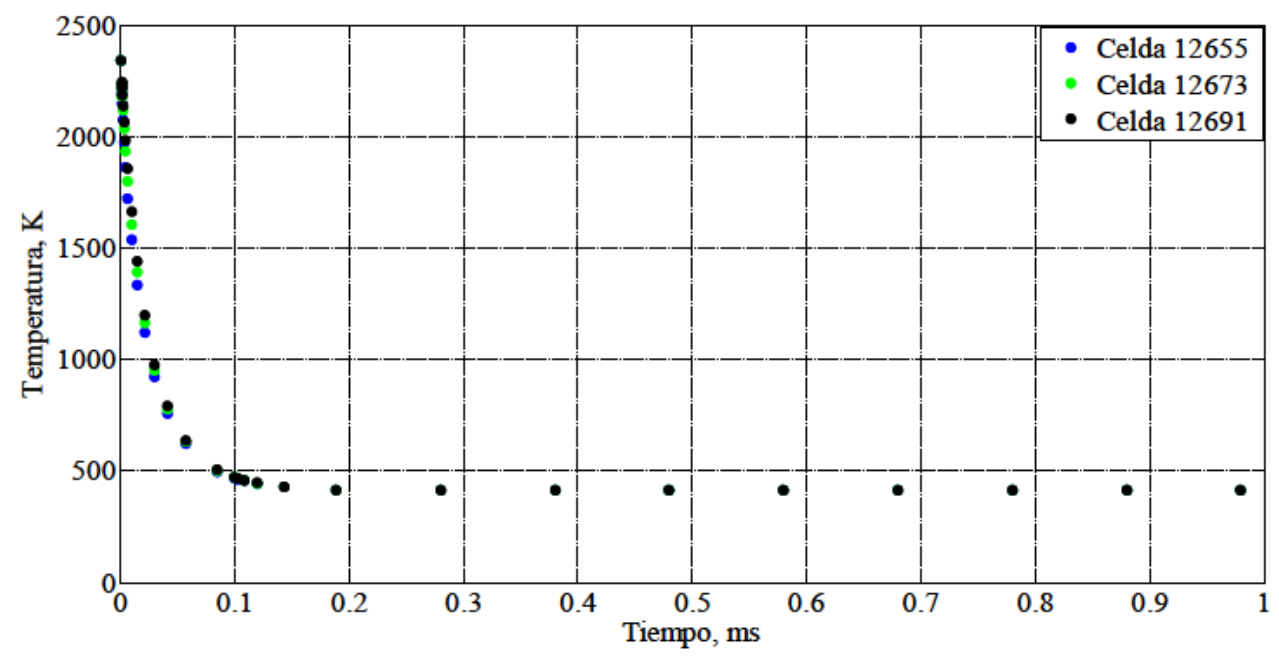

Figura 5.16 Evolución de temperatura en las celdas 12655, 12673, 12691 de la salpicadura considerando radiación térmica en $1 \mathrm{~ms}$ (González Morales et al., 2020).

Las celdas 12507,12525 y 12543 se encuentran a mitad de espesor de la salpicadura, la primera en el centro de la salpicadura, la segunda a un cuarto de esta y la última en su borde. La figura 5.17 presenta la evolución de la temperatura en dichas celdas. La tendencia de las temperaturas en dirección horizontal, observada anteriormente, se mantiene.

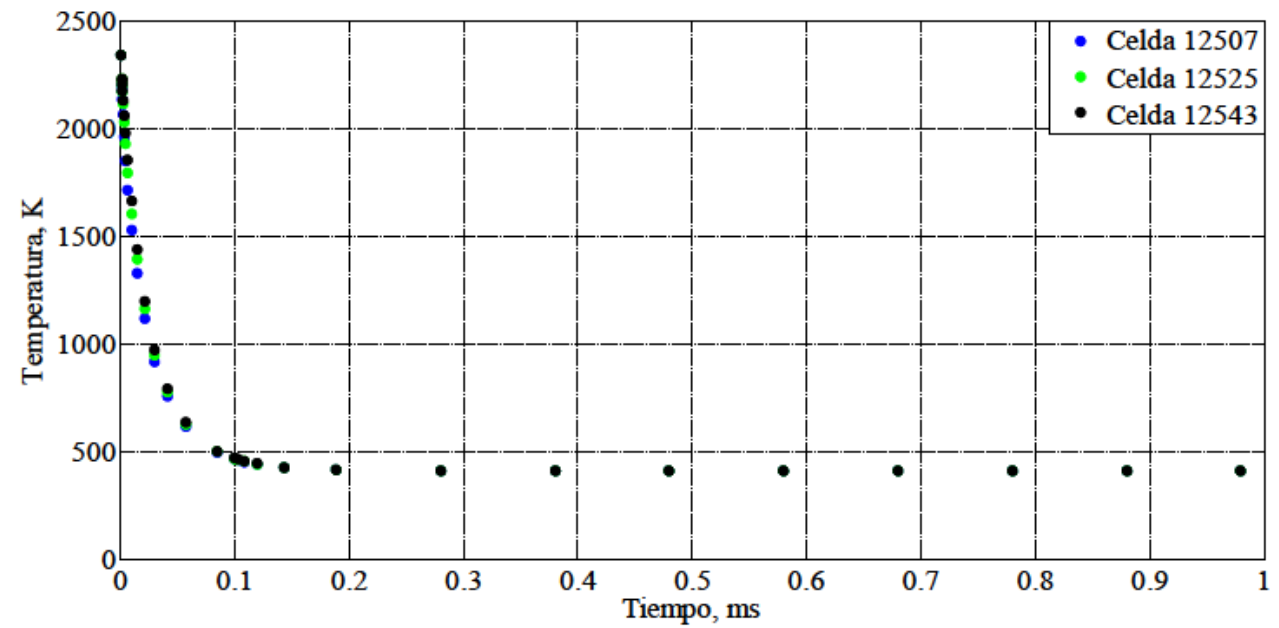

Figura 5.17 Evolución de temperatura en la celda 12507, 12525 y 12543 de la salpicadura considerando radiación térmica en $1 \mathrm{~ms}$ (González Morales et al., 2020). 
A continuación, se van a analizar los nodos 12211,12229 y 12247, pertenecientes al acero y adyacentes a la salpicadura. Su posición tiene la misma coordenada horizontal que los nodos 12322,12340 y 12358, pertenecientes a la alúmina y analizados anteriormente. Adicionalmente, se ha seleccionado el nodo 12321 que estando en la superficie del acero se encuentra en el borde del sustrato. La figura 5.18 representa el proceso de calentamiento y posterior enfriamiento de estos nodos. Es de resaltar el mayor enfriamiento del nodo que se encuentra bajo la salpicadura. Así, la celda 12211 alcanza una temperatura máxima de $956,1 \mathrm{~K}$ a 4,57 $\mu$ s, la celda $122291705 \mathrm{~K}$ a 3,23 $\mu$ s y la celda $122471561 \mathrm{~K}$ a $457 \mu$ s. Por el contrario, la celda en el borde del sustrato, 12321, no sufre alteración térmica debido a la buena conductividad térmica del acero.

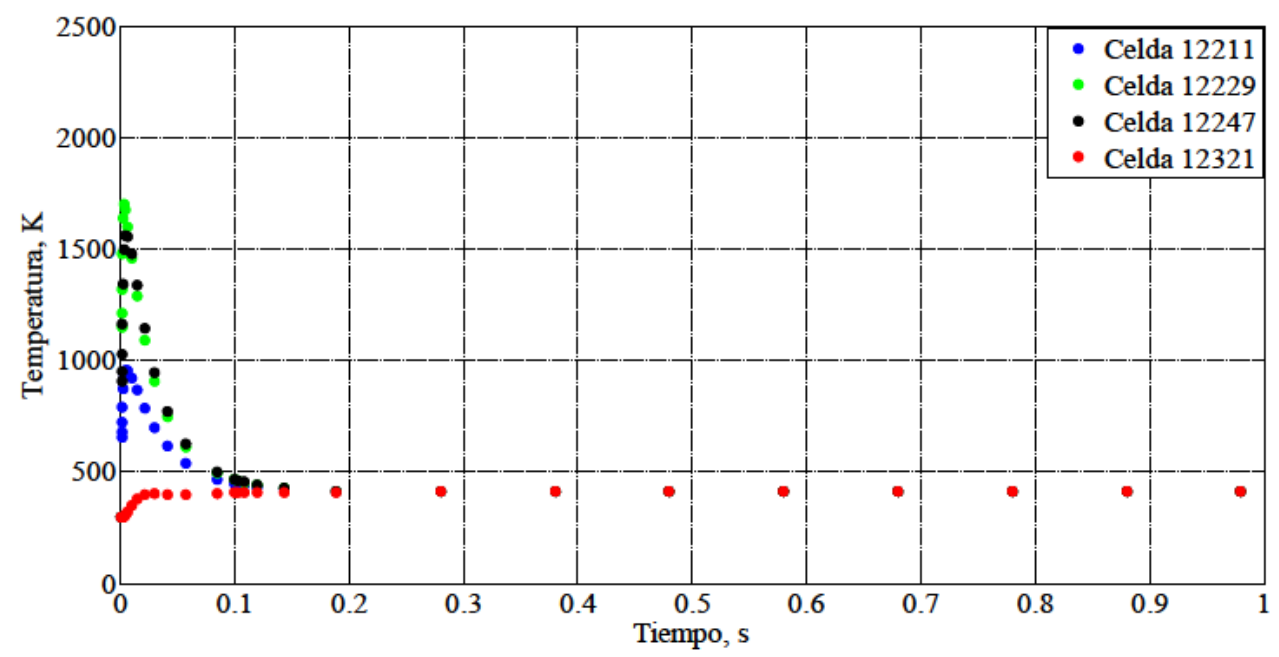

Figura 5.18 Evolución de temperaturas en las celdas 12211, 12229, 12247 y 12321 del sustrato (González Morales et al., 2020).

La figura 5.19 muestra la evolución de la temperatura en los nodos 5551 y 1 . Estos nodos se encuentran en el centro del acero, el primero a mitad de su espesor y el último en la cara opuesta a la que recibe la salpicadura. La buena conductividad térmica del acero implica que estos puntos no sufren alteración térmica.

En la figura 5.20 se presenta la velocidad de enfriamiento de las celdas 12340,12322 y 12655 de la salpicadura. La celda 12340 está situada a mitad de distancia entre el centro y el borde, y en la interfase. A partir de lo comentado en el apartado 2.3.1, los cambios de fase se producen por debajo de los $1373 \mathrm{~K}$. Según la figura 5.15, estas temperaturas sólo aparecen en esta celda entre 14,38 y $21,05 \mu \mathrm{s}$. En este intervalo vemos que las velocidades de enfriamiento superan ampliamente $\operatorname{los} 10^{5} \mathrm{~K} / \mathrm{s}$, mencionados en el mismo 
apartado, como condición para la generación de fase amorfa, por lo que cabe esperar que sólo se genere esta fase en esa zona.

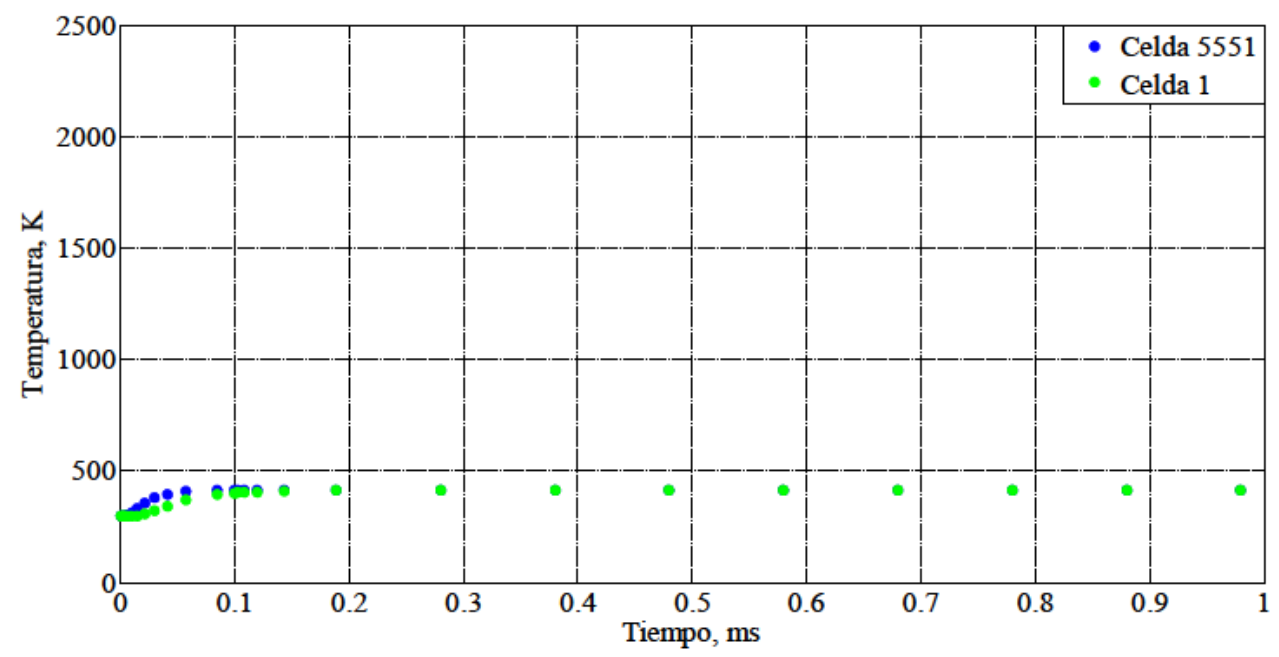

Figura 5.19 Evolución de temperaturas las celdas 5551 y 1 del sustrato (González Morales et al., 2020).

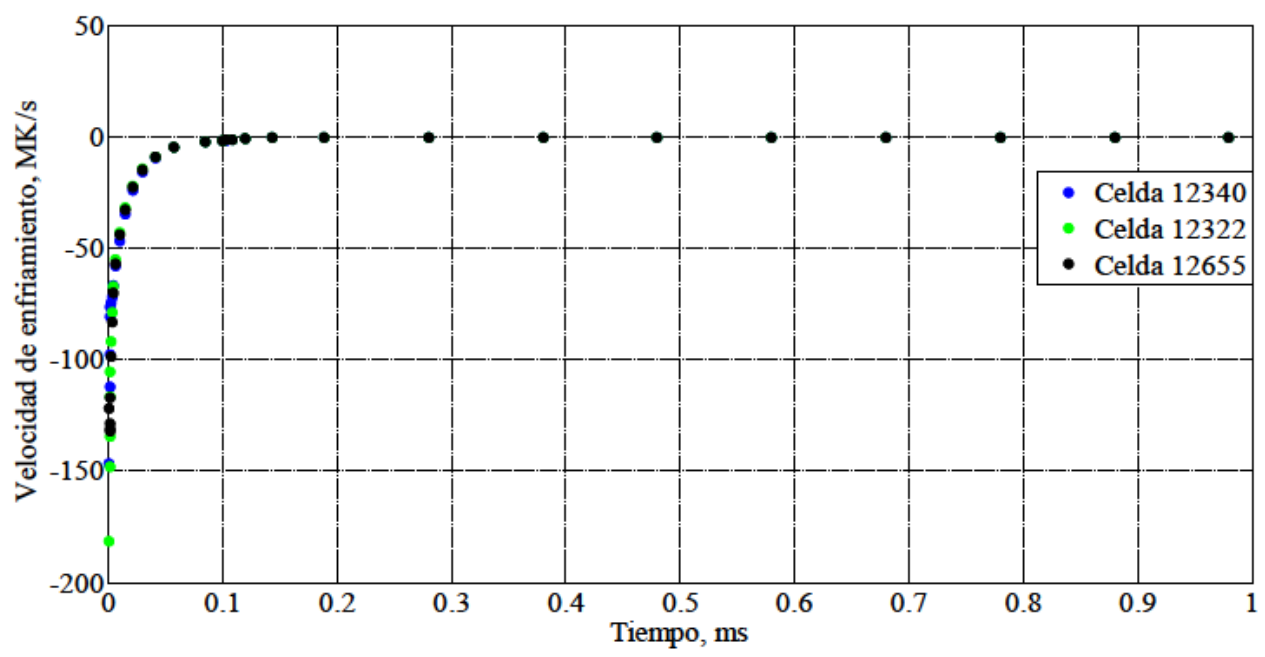

Figura 5.20 Evolución de la velocidad de enfriamiento en la celda 12340, 12322 y 12655 alúmina a $1 \mathrm{~ms}$ (González Morales et al., 2020).

La celda 12322 de la salpicadura está situada en el centro de dicha salpicadura, y en la interfase. Siguiendo el mismo proceso aplicado a la celda 12340 , la figura 5.15 nos indica que las temperaturas por debajo de $1373 \mathrm{~K}$ aparecen entre 9,84 y 14,38 $\mu$ s. Comparando estos resultados con los de la figura 5.20, podemos llegar a la conclusión de que solo se genera fase amorfa.

La celda 12655 de la salpicadura se encuentra situada en el centro de dicha salpicadura, y en la superficie. Siguiendo el mismo proceso aplicado a la celda 12340 , la figura 5.16 
nos indica que las temperaturas por debajo de $1373 \mathrm{~K}$ aparecen entre 9,84 y $14,38 \mu$ s. Comparando estos resultados con los de la figura 5.20, podemos llegar a la conclusión de que solo se genera fase amorfa.

\subsubsection{ANÁLISIS DEL EFECTO DEL CALENTAMIENTO DEL SUSTRATO}

A continuación, se representa la evolución de la temperatura en $1 \mathrm{~ms}$ considerando una temperatura inicial del sustrato de $150^{\circ} \mathrm{C}$ para las celdas 12322,12340 y 12358 , figura 5.21. Comparándolas con las análogas para una temperatura del sustrato a $25^{\circ} \mathrm{C}$, figura 5.15 , se puede observar que el enfriamiento es más lento con el sustrato más caliente. Análogamente, los resultados de la figura 5.21 nos indican que la celda cerca del eje de simetría es la que se enfría más rápidamente. Así, la temperatura a 31,95 $\mu$ s es 967,9 K en la celda 12322 , mientras que en la celda 12358 es $1020 \mathrm{~K}$.

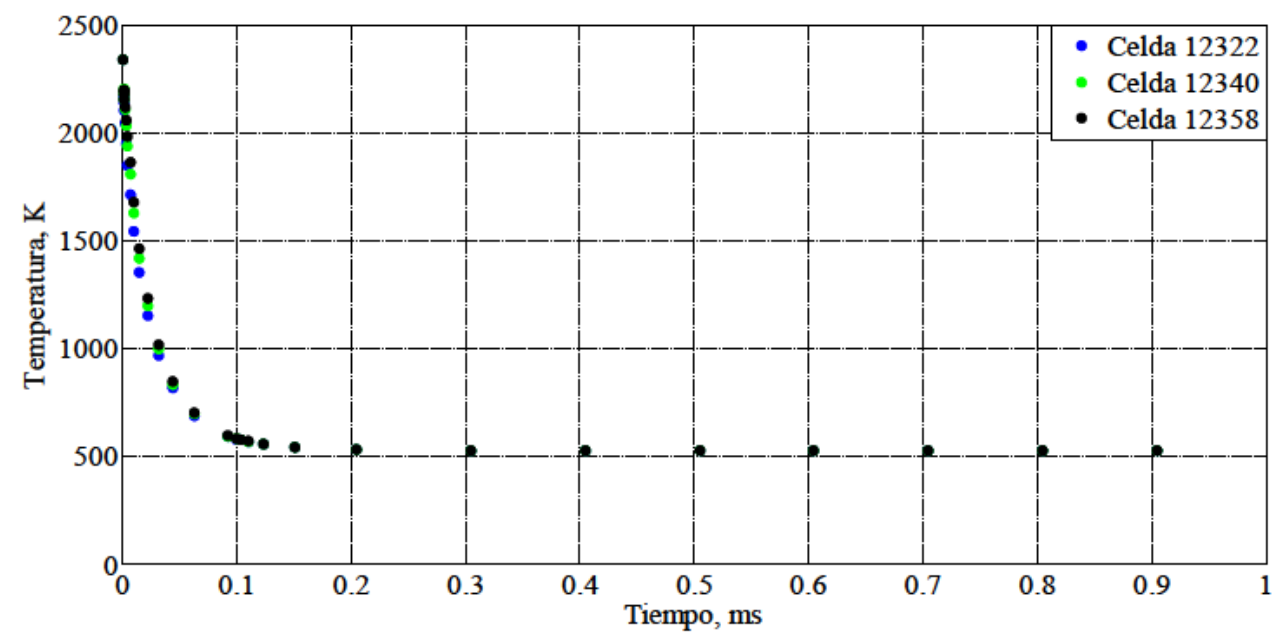

Figura 5.21 Evolución de la temperatura en la celda 12322, 12340 y 12358 de la alúmina para temperatura del sustrato $150^{\circ} \mathrm{C}$ en $1 \mathrm{~ms}$ (González Morales et al., 2020).

Se representa la evolución de la temperatura en $1 \mathrm{~ms}$ y temperatura del sustrato $150{ }^{\circ} \mathrm{C}$ para las celdas 12655,12673 y 12691, figura 5.22. Comparando dicha figura con la análoga para una temperatura del sustrato a $25^{\circ} \mathrm{C}$, figura 5.16 , se puede observar que la superficie de la salpicadura sigue la misma tendencia. 


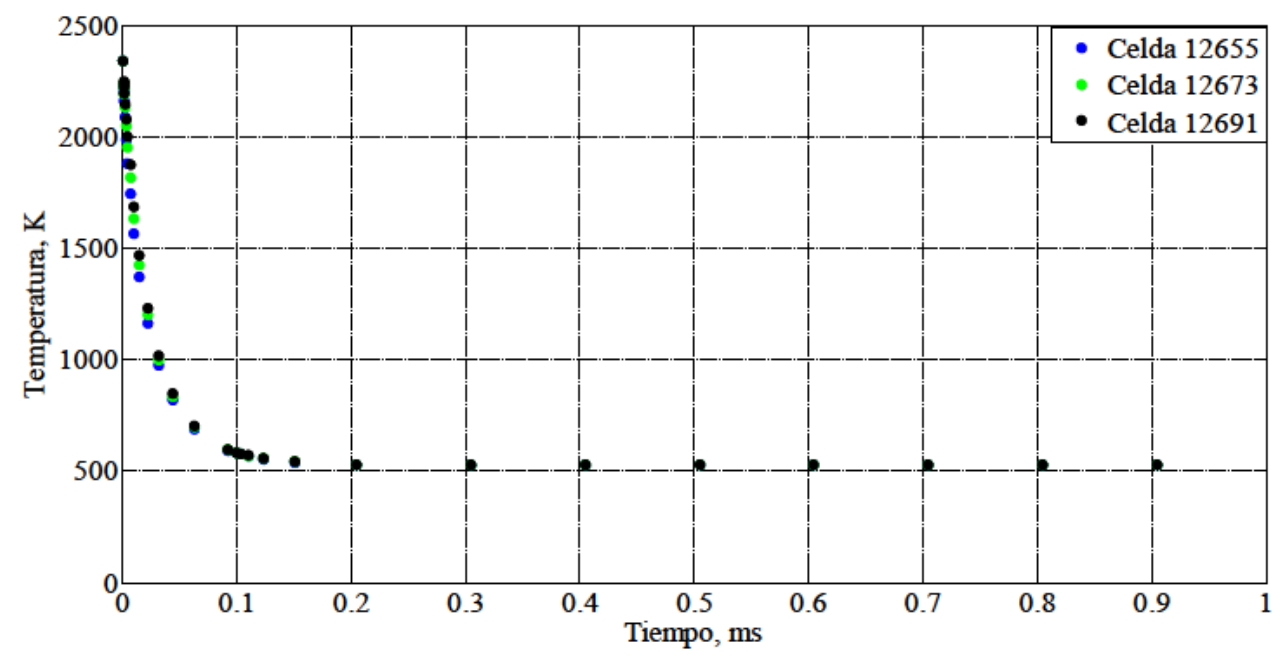

Figura 5.22 Evolución de la temperatura en la celda 12655, 12673 y 12691 de la alúmina para temperatura del sustrato $150^{\circ} \mathrm{C}$ en $1 \mathrm{~ms}$ (González Morales et al., 2020).

La figura 5.23 muestra la distribución de temperaturas en la salpicadura a $9,84 \mu$ s con precalentamiento, mientras que la figura 5.24 muestra la distribución de temperaturas en el sustrato, igualmente las figuras 5.25 y 5.26 representan esas mismas distribuciones a $21,06 \mu \mathrm{s}$. Al igual que ocurre con sus análogas sin precalentamiento, figuras 5.11 a 5.14 , las distribuciones de temperatura mantienen la forma, aunque lógicamente sus valores disminuyen con el tiempo.

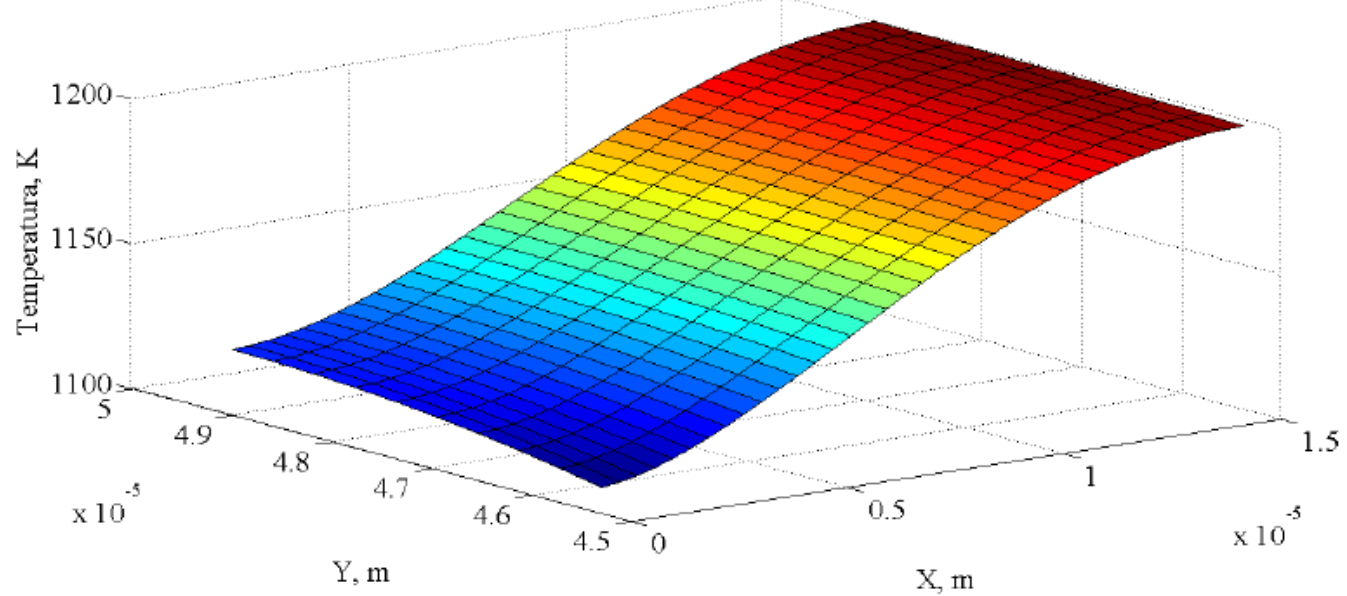

Figura 5.23 Distribución de temperaturas en la salpicadura considerando radiación térmica en 9,84 $\mu$ s y precalentamiento. 


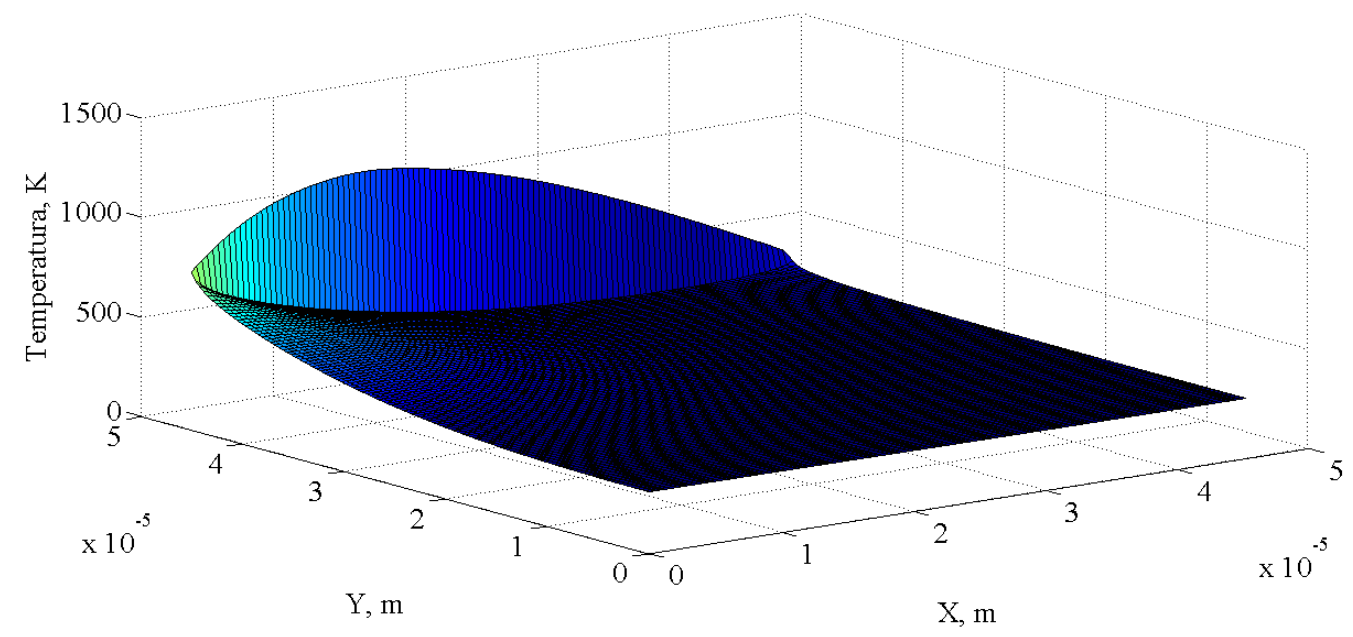

Figura 5.24 Distribución de temperaturas en el sustrato considerando radiación térmica en $9,84 \mu$ s y precalentamiento.

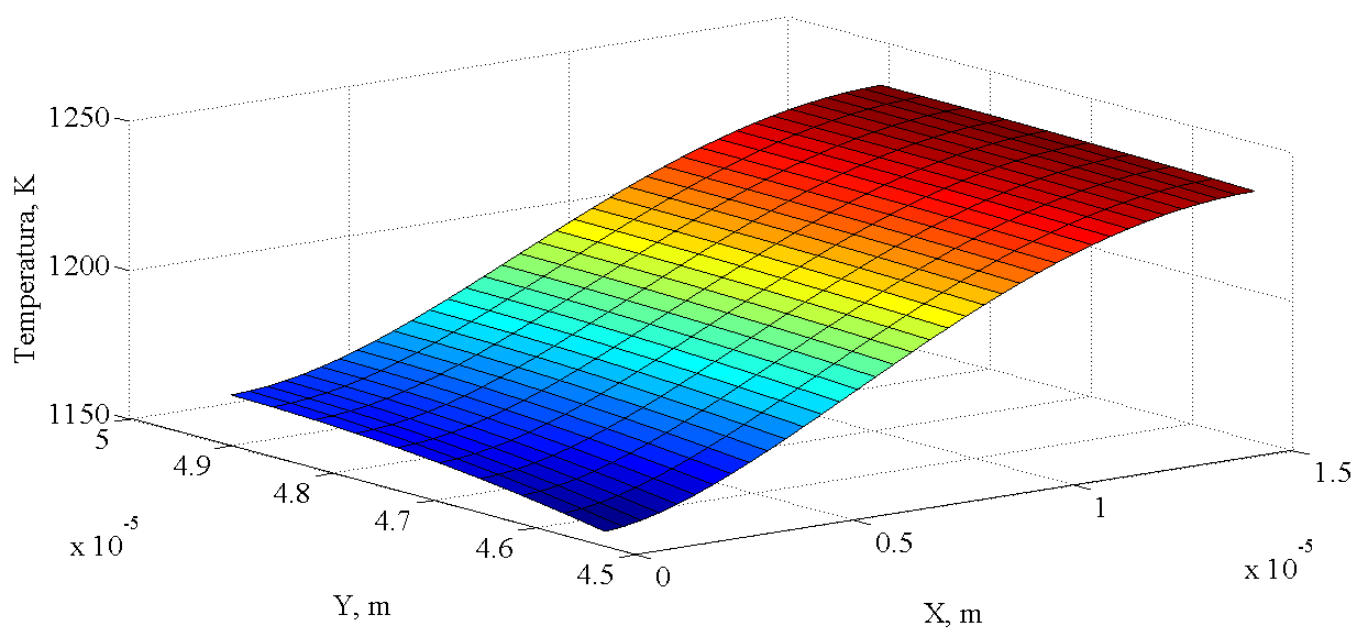

Figura 5.25 Distribución de temperaturas en la salpicadura considerando radiación térmica en 21,06 $\mu$ s y precalentamiento.

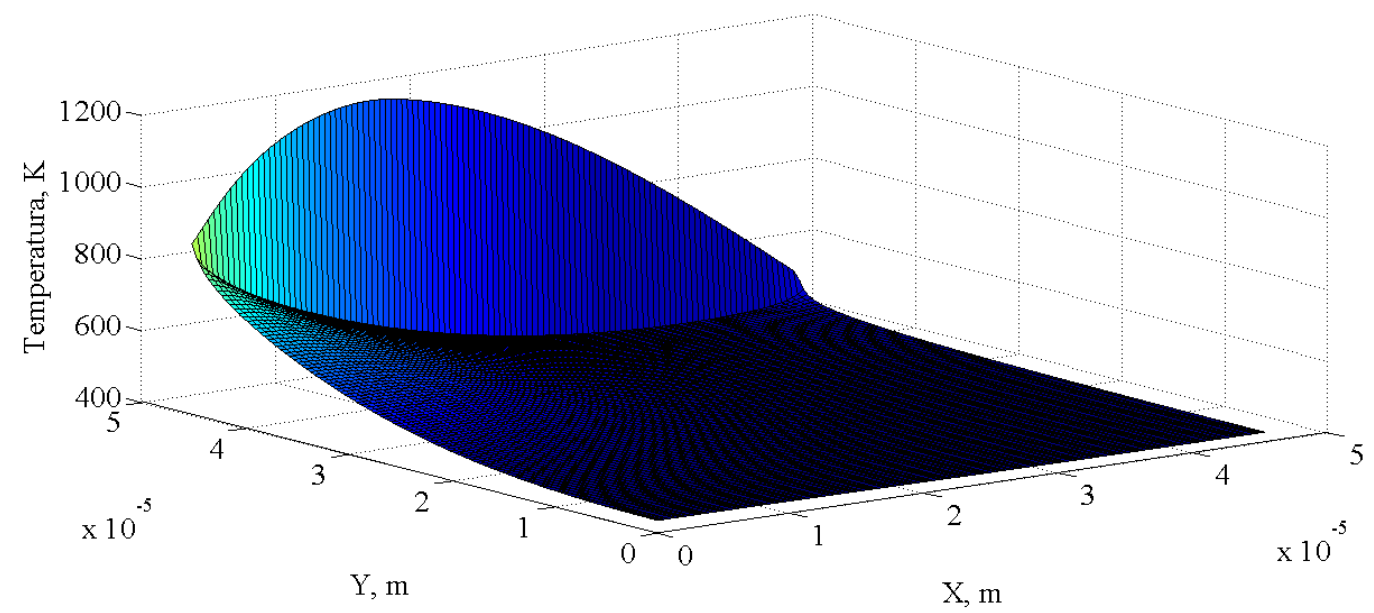

Figura 5.26 Distribución de temperaturas en el sustrato considerando radiación térmica en 21,06 $\mu \mathrm{s} \mathrm{y}$ precalentamiento. 


\subsection{PROCESAMIENTO DE IMAGEN DE SALPICADURAS SOBRE SUSTRATO}

Se estudian cinco muestras con revestimiento de APS realizado en el IMTCCC, con los parámetros indicados en la tabla 3.1, con el objeto de obtener imágenes digitales de las salpicaduras del revestimiento mediante técnicas de procesamiento de imagen para caracterizar su morfología.

El software es capaz de identificar el contorno de las salpicaduras, tanto en forma de tortita como de corona circular. La figura 5.27, muestra un ejemplo con las salpicaduras ya caracterizadas y segmentadas por el sistema, en concreto en términos de tamaño, circularidad, perímetro, excentricidad, área, solidez y diámetro equivalente.
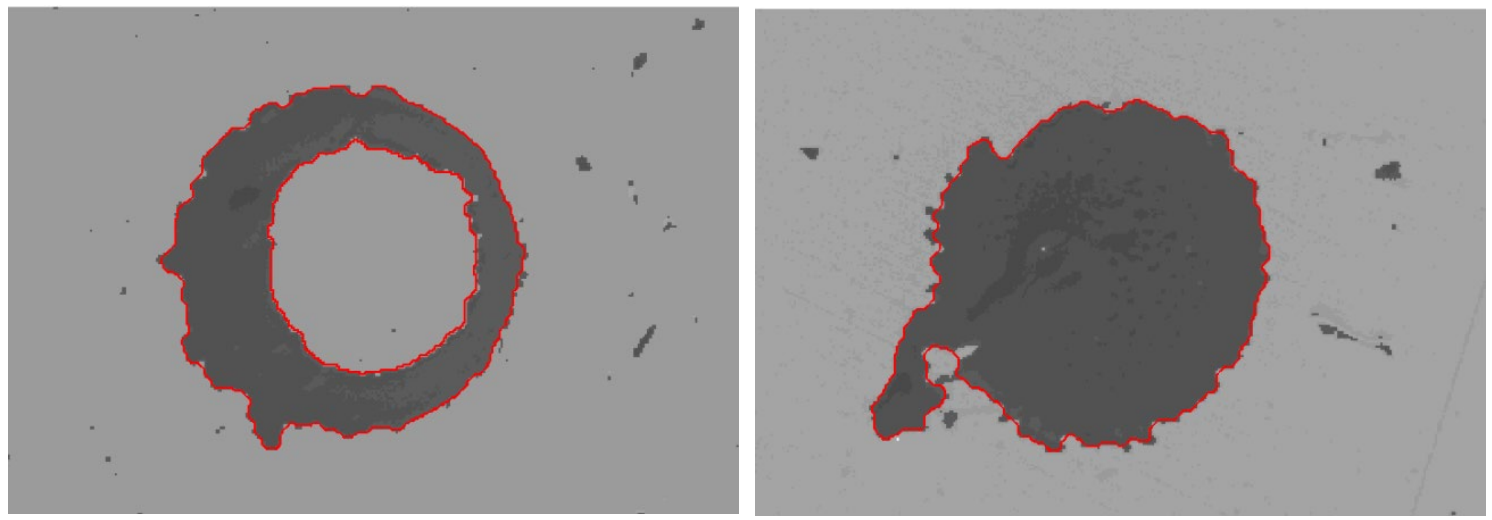

Figura 5.27 Salpicaduras segmentadas y caracterizadas en procesamiento de imagen.

\subsection{ANÁLISIS DE LA VISTA SUPERIOR DE LAS SALPICADURAS}

Aunque se analizan las salpicaduras de todas las muestras, para una correcta comprensión del proceso de análisis se profundiza en las operaciones realizadas sobre la muestra $\mathrm{S}_{1}$. En las tablas 5.2 a 5.4 se indican los datos de un total de 12 salpicaduras en forma de corona circular, siendo la tabla 5.2 las dimensiones en pixeles, la tabla 5.3 las medidas necesarias para los cambios de escala y la tabla 5.4 los valores en $\mu \mathrm{m}$.

Los diámetros equivalentes están calculados en píxeles, $d_{\mathrm{ep}}$, a partir de las imágenes suministradas por el microscopio. Igualmente se puede obtener el ancho en pixeles, $\mathrm{L}_{\mathrm{p}}$, de las imágenes obtenidas. Si se mide su ancho en mm, L', y la longitud de la barra de escala en mm, S', se puede obtener la relación entre el ancho de la figura en $\mu \mathrm{m}, \mathrm{Lr}$, y la longitud de la barra de escala en $\mu \mathrm{m}, \mathrm{S}$ : 


$$
\frac{\mathrm{Lr}}{\mathrm{L}^{\prime}}=\frac{\mathrm{S}_{\mathrm{r}}}{\mathrm{S}^{\prime}}
$$

Tabla 5.2. Dimensiones de las salpicaduras en forma de corona circular para la muestra $\mathrm{S}_{1}$.

\begin{tabular}{cccc}
\hline Designación & $\begin{array}{c}\mathbf{d}_{\mathrm{ep}} \text { exterior } \\
\text { (pixel) }\end{array}$ & $\begin{array}{c}\mathrm{d}_{\mathrm{ep}} \text { interior } \\
\text { (pixel) }\end{array}$ & $\begin{array}{c}\text { Lp } \\
\text { (pixel) }\end{array}$ \\
\hline S.1.3_10 & 38,794 & 22,568 & 84 \\
\hline S.1.2_7 & 47,620 & 29,164 & 84 \\
\hline S.1.1_9 & 36,772 & 22,680 & 84 \\
\hline S.1.4_14 & 42,054 & 24,824 & 84 \\
\hline S.1.5_11 & 41,120 & 22,568 & 84 \\
\hline S.1.6_7 & 31,895 & 19,512 & 84 \\
\hline S.1.3_12 & 37,797 & 27,315 & 84 \\
\hline S.1.2_8 & 33,833 & 21,705 & 84 \\
\hline S.1.1_7 & 57,007 & 37,526 & 136 \\
\hline S.1.3_9 & 35,396 & 22,112 & 84 \\
\hline S.1.1_11 & 44,338 & 32,332 & 84 \\
\hline S.1.3_7 & 40,022 & 29,273 & 84 \\
\hline
\end{tabular}

A partir de la ecuación 5.1 se puede obtener el valor de Lr, con el que se puede obtener el diámetro equivalente en micras, $\mathrm{de}_{\mathrm{e}}$ :

$$
\mathrm{d}_{\mathrm{e}}=\frac{\mathrm{Lr}}{\mathrm{L}_{\mathrm{p}}} \cdot \mathrm{d}_{\mathrm{ep}}
$$

La tabla 5.5 indica la misma información de las salpicaduras en forma de tortita para la muestra $\mathrm{S}_{1}$.

Las figuras 5.28 a 5.30 muestran de forma resumida la media y los rangos de valores de los diámetros equivalentes para las diferentes muestras en función de: tamaño de polvo para dos conjuntos de intensidad y caudal másico de hidrógeno, y velocidad angular del suministrador de polvo.

A partir de estos datos, se pueden obtener dos relaciones: i) la morfología de la salpicadura no parece estar relacionada con el diámetro equivalente medio para la salpicadura en forma de corona circular y de tortita, y ii) el grosor de la corona circular 
depende del diámetro equivalente externo promedio. Es decir, cuanto mayor sea el tamaño de la corona circular, mayor será el grosor.

Tabla 5.3. Ancho de la imagen calculado a partir de la escala SEM en $\mu \mathrm{m}$ para la muestra $\mathrm{S}_{1}$.

\begin{tabular}{|c|c|c|}
\hline Designación & $\begin{array}{c}\text { Escala SEM } \\
\qquad(\mu \mathrm{m})\end{array}$ & $\begin{array}{c}L_{r} \\
(\mu \mathrm{m})\end{array}$ \\
\hline S.1.3_10 & 20 & 82,500 \\
\hline S.1.2_7 & 10 & 66,000 \\
\hline S.1.1_9 & 20 & 82,500 \\
\hline S.1.4_14 & 10 & 66,000 \\
\hline S.1.5_11 & 10 & 55,000 \\
\hline S.1.6_7 & 20 & 80,000 \\
\hline S.1.3_12 & 20 & 82,500 \\
\hline S.1.2_8 & 10 & 66,000 \\
\hline S.1.1_7 & 10 & 66,000 \\
\hline S.1.3_9 & 9 & 57,951 \\
\hline S.1.1_11 & 10 & 55,000 \\
\hline S.1.3_7 & 10 & 55,000 \\
\hline
\end{tabular}

Tabla 5.4. Dimensiones de las salpicaduras en forma de corona circular para la muestra $\mathrm{S}_{1}$

\begin{tabular}{cccc}
\hline Designación & $\begin{array}{c}\mathrm{d}_{\mathrm{e}} \text { exterior } \\
(\boldsymbol{\mu \mathrm { m } )})\end{array}$ & $\begin{array}{c}\mathrm{d}_{\mathrm{e}} \text { interior } \\
(\boldsymbol{\mu \mathrm { m }})\end{array}$ & $\begin{array}{c}\text { Ancho } \\
(\mu \mathrm{m})\end{array}$ \\
\hline S.1.3_10 & 38,101 & 22,165 & 7,968 \\
\hline S.1.2_7 & 37,415 & 22,914 & 7,251 \\
\hline S.1.1_9 & 36,115 & 22,275 & 6,920 \\
\hline S.1.4_14 & 33,042 & 19,505 & 6,769 \\
\hline S.1.5_11 & 26,924 & 14,776 & 6,074 \\
\hline S.1.6_7 & 30,377 & 18,582 & 5,897 \\
\hline S.1.3_12 & 37,122 & 26,827 & 5,147 \\
\hline S.1.2_8 & 26,583 & 17,054 & 4,764 \\
\hline S.1.1_7 & 27,663 & 18,211 & 4,726 \\
\hline S.1.3_9 & 24,419 & 15,255 & 4,582 \\
\hline S.1.1_11 & 29,031 & 21,170 & 3,931 \\
\hline S.1.3_7 & 26,205 & 19,167 & 3,519 \\
\hline
\end{tabular}


Tabla 5.5. Dimensiones de las salpicaduras en forma de tortita para la muestra $\mathrm{S}_{1}$.

\begin{tabular}{|c|c|c|c|}
\hline Designación & $\begin{array}{c}d_{e} \\
(\mu \mathrm{m})\end{array}$ & Designación & $\begin{array}{c}d_{e} \\
(\mu \mathrm{m})\end{array}$ \\
\hline S.1.2_1 & 45,319 & S.1.5_6 & 29,827 \\
\hline S.1.6_1 & 38,321 & S.1.2_2 & 29,794 \\
\hline S.1.3_2 & 38,109 & S.1.1_2 & 28,541 \\
\hline S.1.3_4 & 36,771 & S.1.4_13 & 28,476 \\
\hline S.1.2_3 & 35,294 & S.1.4_4 & 27,923 \\
\hline S.1.4_2 & 35,099 & S.1.3_5 & 27,807 \\
\hline S.1.6_2 & 35,008 & S.1.4_1 & 27,724 \\
\hline S.1.6_3 & 34,260 & S.1.6_5 & 27,702 \\
\hline S.1.6_6 & 33,329 & S.1.4_3 & 27,193 \\
\hline S.1.4_9 & 33,080 & S.1.3_3 & 26,469 \\
\hline S.1.5_3 & 32,126 & S.1.4_6 & 26,156 \\
\hline S.1.2_5 & 31,551 & S.1.4_5 & 25,992 \\
\hline S.1.2_4 & 31,114 & S.1.6_4 & 25,291 \\
\hline S.1.4_11 & 30,507 & S.1.1_3 & 24,428 \\
\hline S.1.4_12 & 30,458 & S.1.4_7 & 24,422 \\
\hline S.1.5_10 & 30,222 & S.1.1_1 & 24,395 \\
\hline S.1.5_4 & 30,041 & S.1.5_2 & 22,577 \\
\hline
\end{tabular}

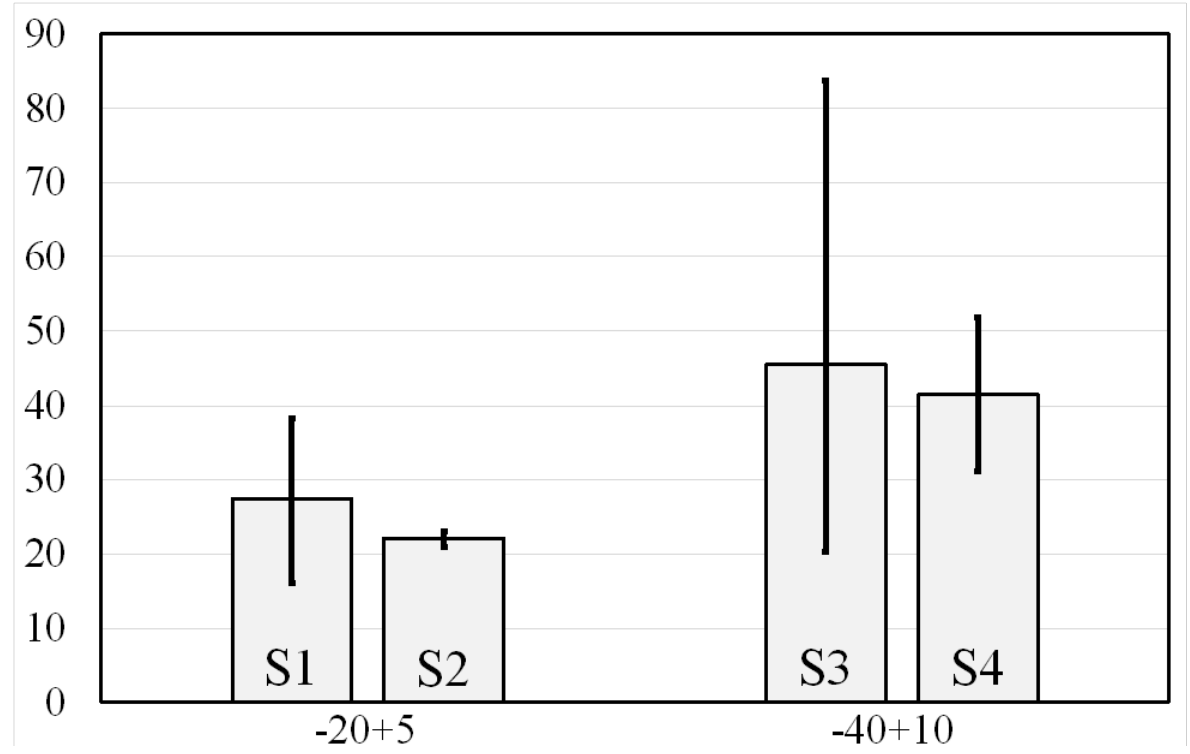

Figura 5.28 Diámetro equivalente de las salpicaduras en forma de tortita respecto a diferentes tamaños de polvo para dos conjuntos de intensidades y caudal másico de hidrógeno. 


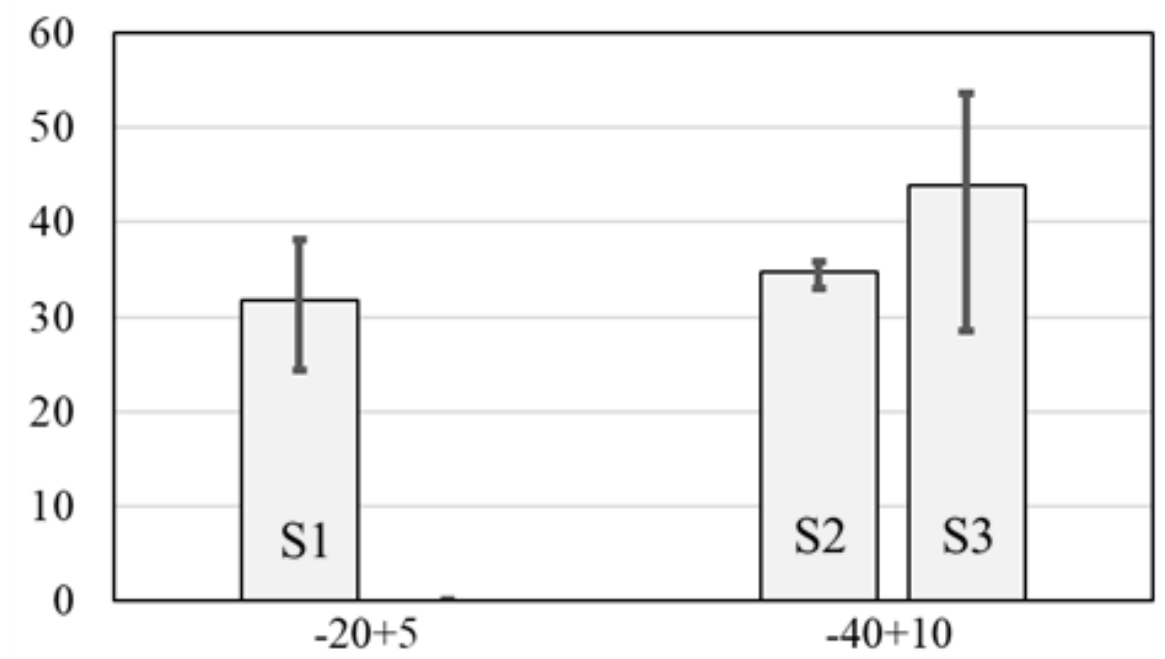

Figura 5.29 Diámetro equivalente de las salpicaduras en forma de corona circular respecto a diferentes tamaños de polvo para dos conjuntos de intensidades y caudal másico de hidrógeno.

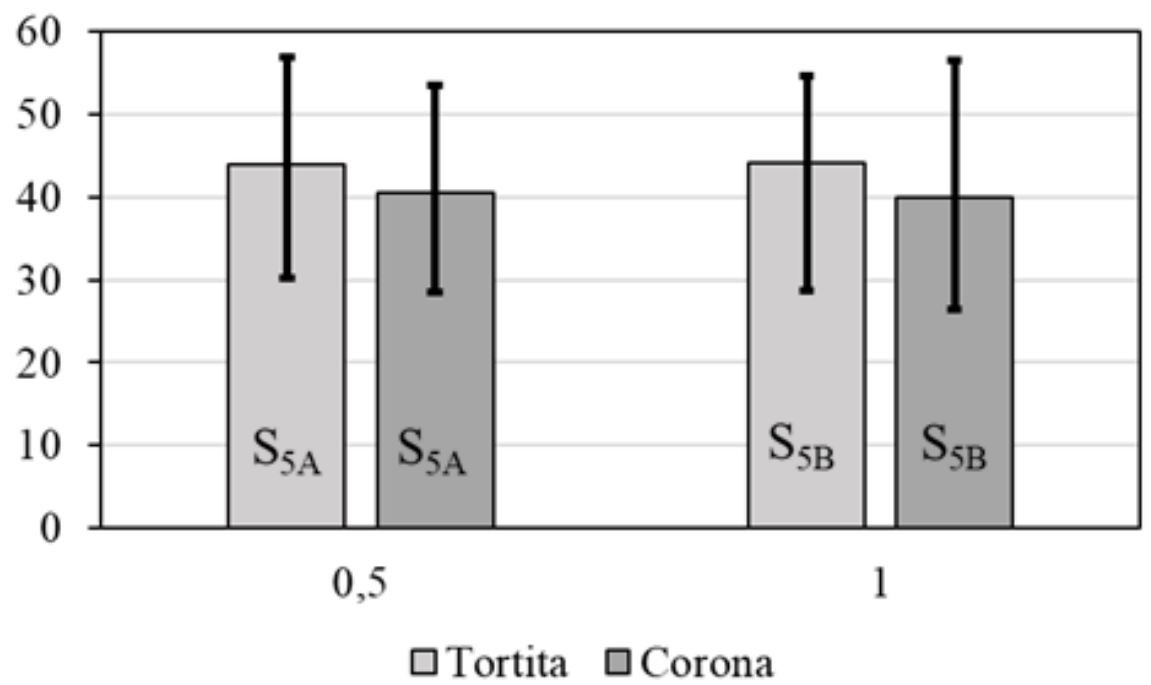

Figura 5.30 Diámetro exterior equivalente de las salpicaduras en forma de tortita y corona circular respecto a diferentes velocidades angulares del suministrador de polvo.

En la figura 5.28, referida a salpicaduras en forma de tortita, se puede observar que cuanto mayor es el tamaño del polvo, mayor es el diámetro de la salpicadura. La misma relación se encuentra entre la intensidad de la corriente y el diámetro equivalente. En la figura 5.29 , referida a salpicaduras en forma de corona, se vuelven a encontrar las mismas relaciones, aunque con una menor sensibilidad al tamaño del polvo. Si se comparan las salpicaduras en forma de tortita y las de corona circular se puede observar que los tamaños de las dos morfologías son similares.

Por último, en la figura 5.30, se observa que las revoluciones por minuto tienen influencia en el diámetro equivalente. 


\subsection{ANÁLISIS DE LA SECCIÓN DE LAS SALPICADURAS}

Se seleccionan salpicaduras en forma de tortita y de corona circular de la muestra S1 para su análisis de la sección transversal. Esta se realiza mediante SEM-FIB, figura 5.31, de modo que permite un corte selectivo de dichas salpicaduras.

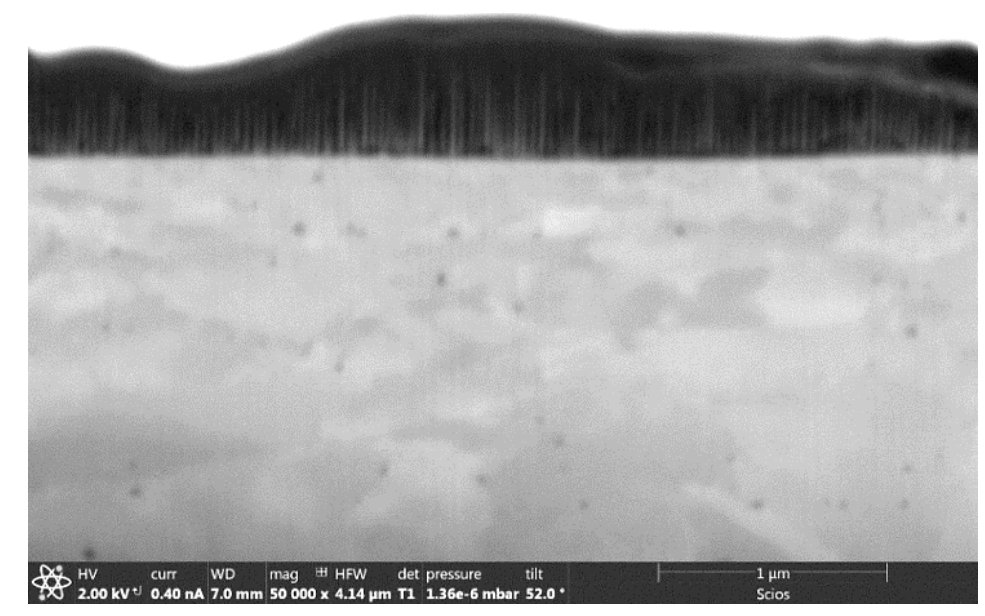

Figura 5.31 Sección transversal mediante SEM-FIB, salpicadura muestra $\mathrm{S}_{1}$.

En la figura anteriormente mencionada, se puede observar el espesor de la salpicadura de alúmina sobre el sustrato de acero donde se aprecian poros en la estructura, sin embargo, en dicha imagen se observa adicionalmente un artefacto producido por el haz de iones del FIB y por tanto hay que diferenciar dicho artefacto de los elementos microestructurales reales. Es el conocido como "cascada" o "cortina" que obstruye la visión de la microestructura de la salpicadura, éstos pueden producirse debido a elementos introducidos durante la preparación, poros o grietas (Munroe, 2009). 


\section{CONTRIBUCIONES Y CONCLUSIONES}

Como conclusión general, esta memoria ha analizado salpicaduras cerámicas desde una perspectiva global, incluyendo simulación numérica y procedimientos experimentales. Los resultados de la simulación permiten un estudio detallado considerando condiciones de estudio sin interferencias ambientales; mientras que los segundos nos permiten comparar los resultados con la realidad. Por tanto, los primeros aportan información sobre la relación entre los parámetros de operación y los resultados, y los segundos permiten mejorar la definición de las condiciones de contorno impuestas en el modelo numérico. Esto ha obligado a un doble trabajo asociado al dominio de estas técnicas, numéricas y experimentales, no habitual en este tipo de estudios, pero que han aportado una comprensión más general sobre el fenómeno, y por ello, más completa.

En referencia a la simulación numérica, el esfuerzo también ha sido doble, dado que ha sido necesario utilizar dos métodos numéricos de naturaleza distinta debido al cambio de geometría asociado a uno de los cálculos. Así, para el análisis de la primera parte del fenómeno es más eficiente el método de volúmenes finitos, que presenta una gran flexibilidad en problemas que implican mecánica de fluidos. Para la segunda parte del fenómeno, la geometría puede considerarse estacionaria, lo que permite el uso del método de simulación por redes implementado en software libre.

Las contribuciones y conclusiones particulares de esta memoria se pueden sintetizar en los siguientes puntos:

\section{En relación con la simulación del impacto de una gota}

Se ha simulado el impacto de una gota mediante software comercial de volúmenes finitos. El desarrollo del modelo ha obligado a un detallado estudio de las opciones disponibles en dicha aplicación informática, que ha implicado la implementación de diferentes opciones de cálculo, que salvo la correcta, han conducido a resultados inadecuados. Esta búsqueda es inabordable sin un profundo conocimiento del método VOF.

La versión equivalente utilizando el método de redes obligaría a tratar con una variable vectorial, la velocidad, y no una variable relacionada con la energía, como en el caso de la temperatura. Con esta variable escalar la equivalencia con el voltaje es inmediata. La 
solución propuesta aplica las ecuaciones de conservación de momento en el centro de la celda y las de conservación de volumen en los nodos periféricos de la celda. Esta propuesta permite evitar las restricciones impuestas a la fracción de volumen, que se cumplen de forma automática, agilizando el cálculo. No obstante, el cambio de geometría relacionado con la transición entre la esfera de la gota que impacta y la forma característica de la salpicadura ha supuesto un obstáculo insalvable para aplicar el método de simulación por redes, por lo que este método no ha sido aplicado.

\section{En relación con la simulación de la solidificación de una salpicadura}

Se ha desarrollado un modelo en red para la simulación de la solidificación de una salpicadura utilizando software libre. Esto permite la futura incorporación de rutinas para análisis complementarios. Dado que solo las operaciones de cálculo y representación de resultados necesarias son implementadas, el sistema es más eficiente que un software generalista.

La aplicación del modelo desarrollado aporta una gran cantidad de información, tanto espacial como temporalmente. A partir de esta, el cálculo de las velocidades de enfriamiento se puede realizar con gran precisión. Esto último ofrece la posibilidad de confirmar la formación de una fase concreta en la salpicadura asociada a unos parámetros de fabricación, determinando el rango de valores en que la fase deseada aparece, lo que permite la optimización de dichos parámetros.

Esta información tan completa permite pensar en este proceso de fabricación a un nivel de complejidad superior al imaginado hasta ahora.

El modelo puede ser mejorado de forma sencilla a partir de resultados experimentales, aunque estos sólo pueden mostrar el fenómeno de forma bastante aproximada, con una resolución espacial y temporal mucho más basta.

\section{En relación con el ensayo experimental}

Se ha desarrollado una metodología para la obtención de muestras de gotas aisladas en condiciones de operación normal de fabricación y con los materiales habitualmente empleados en aplicaciones industriales. Este procedimiento es rápido y económico, y fácilmente integrable en un proceso automatizado de optimización de revestimientos. 
El análisis de la morfología de la salpicadura utilizando las técnicas más modernas de procesamiento de imagen también se ha automatizado. Este procesamiento proporciona un valor que permite la clasificación eficiente de estas morfologías para la posterior asignación de correspondencias entre estas y los parámetros de fabricación asociados al revestimiento. En concreto, el parámetro seleccionado para la clasificación es el diámetro equivalente. Este procedimiento de clasificación ha sido ampliado a morfologías más complejas que las salpicaduras en forma de tortita. Así, las salpicaduras en forma de corona, que son también frecuentes, pueden clasificarse mediante el uso de dos diámetros: exterior e interior. Con estos diámetros equivalentes para cada colección de parámetros de fabricación podemos establecer un criterio de selección de dichos parámetros. La siguiente etapa en este proceso de fabricación es relacionar las morfologías de las gotas con los valores de adherencia y de tensiones residuales, que determinan la resistencia del revestimiento. La etapa final implica la correlación entre la adherencia de la gota individual y la del revestimiento. Evidentemente esta última etapa queda fuera de los objetivos de esta tesis, aunque sus resultados son aplicables a esta.

Las operaciones automatizadas, mencionadas en el párrafo anterior, requieren el uso de equipos sofisticados que aseguren la repetibilidad necesaria en los ensayos y una reducida interacción con el material de la muestra. Así, para el análisis de la sección de la salpicadura, el único medio experimental que nos permite verificar nuestros resultados de simulación, se han realizado muchas pruebas utilizando procedimientos tradicionales de corte y pulido en metalografía que han resultado insatisfactorios. Finalmente se ha optado por el FIB, mencionado en algunos artículos de carácter científico. Afortunadamente, dicho equipo está disponible en el Servicio de Apoyo a la Investigación perteneciente a la Universidad de Murcia. Este procedimiento, no probado antes en esta instalación, se ha implementado con éxito en el desarrollo de esta tesis, suministrando una valiosa información sobre el proceso de solidificación de la salpicadura. Por tanto, se ha verificado la capacidad de las instalaciones disponibles en la Región de Murcia para el análisis visual de la morfología y sección de una salpicadura cerámica. Esta cuestión es clave para la verificación de los programas de simulación de impacto y solidificación de gotas, tal como se ha mencionado en el apartado anterior, donde el conocimiento profundo de esta morfología es fundamental en el proceso de optimización de un revestimiento cerámico. 
Como conclusión general, cabe decir que la aplicación del método de volúmenes finitos al análisis del impacto de gotas de material cerámico, junto con la aplicación del método de simulación por redes a la solidificación han proporcionado modelos eficientes y precisos capaces de reproducir soluciones de simulaciones numéricas y resultados experimentales, con tiempos de computación adecuados sin necesidad de asumir las hipótesis simplificadoras en las ecuaciones de gobierno que aparecen en la literatura científica relacionada con el tema. Por otro lado, la elaboración de un software específico para la simulación numérica directa de los problemas, sin necesidad de entrar en el núcleo de cálculo, dota a la comunidad científica de una herramienta potente de cálculo y predicción en problemas de índole similar. 


\section{BIBLIOGRAFÍA}

Abhat, A., "Low temperature latent heat thermal energy storage: Heat storage materials", Solar Energy, 1983, doi: 10.1016/0038-092X(83)90186-X.

Acedo Fornell, M. C., "Thermally sprayed coatings on piston rings, processing and characterisation", en. Augsburg, 2005.

Ahmed, S. G. y Meshrif, S. A., “A new numerical algorithm for 2D moving boundary problems using a boundary element method", Comput. Math. with Appl., 2009, doi: 10.1016/j.camwa.2009.03.115.

Alcaraz, D., Alhama, F. y Moreno, J. A., "Influencia de la distribución de las fibras en la conductividad térnnica de materiales compuestos con matrices de aleaciones de titanio y de magnesio", Revista de Metalurgia, 2005, doi: 10.3989/revmetalm.2005.v41.iextra.1044.

Alarcón, M., Alhama, F. y González-Fernández, C.F., "Transient conduction in a fin-wall assembly with harmonic excitation", Network thermal admittance Heat Transfer Engineering, 2002, 23, pp. 31-43, doi: 10.1080/01457630252800412.

Alarcón García, M. "Transporte de calor en sistemas con aletas. Coeficientes de rendimiento y red de transferencia”. Tesis doctoral, UPCT, 2001.

Alhama, F., "Estudio de respuestas térmicas transitorias en procesos no lineales de conducción de calor mediante el método de simulación por redes", Tesis doctoral UPCT, 1998.

Alhama F., López Sánchez J.F. y González-Fernández C.F., "Heat conduction through multilayered wall with variable boundary conditions", Energy, 1997, 22, pp. 797-803.

Alhama, F. y Zueco, J., "Application of a lumped model to solids with linearly temperature-dependent thermal conductivity”, Applied Mathematical Modelling, 2007, 31, pp. 302-310, doi: 10.1016/j.apm.2005.11.015. 
Alhama, I., Alhama, F. y Soto, A., "Fatsim-A: An educational tool based on electrical analogy and the code PSpice to simulate fluid flow and solute transport processes", Computer Application in Engineering Education, 2011a, 16, pp. 72-82, doi: 10.1002/cae.20577.

Alhama, I., Soto, A. y Alhama, F., "Simulation of flow and solute coupled 2-D problems with velocity-dependent dispersion coefficient based on the network method", Hydrological Process, 2011b, doi: 10.1002/hyp.8475.

Alhama, I., Soto A. y Alhama, F., "Mathematical characterization of scenarios of fluid flow and solute transport in porous media by discriminated nondimensionalization", Int. J. Eng. Sci., 2012, 50, 1, pp. 1-9, doi: 10.1016/j.ijengsci.2011.07.004.

Alhama, I., Soto Meca, A. y Alhama, F., FAHET: Flow and Heat Transport simulator, NAR: 08/2011/419 [software], 2010a, (C) 20042009 UPCT

Alhama, I., Soto Meca, A. y Alhama, F., FATSIM-A: Fluid Flow and Solute Transport simulator, NAR: 08/2010/1110 (DL: MU-1093-2010) [software], 2010b, C) 20042009 UPCT

Alhama, F. y Del Cerro Velázquez, F., PROCCA-09: Programa de conducción de calor, NAR: 08/2005/544 [software], 2005, @ 20042009 UPCT.

Alhama, F. y Sánchez, J.F., OXIPSIS_12: Oxidation Processes Simulation Software, 2013, UPCT.

Allen, R.F., "The role of surface tension in splashing", J. Coll. Interface, 1975, 51, pp. 350-51, doi: 10.1016/0021-9797(75)90126-5.

Amada, S., Haruyama, M., Ohyagi, T., Kazuyuki y Tomoyasu, K., "Wettability effect on the flattening ratio of molten metal droplets", Surf. Coat. Technol., 2001, 138, p 211-219, doi: 10.1016/S0257-8972(00)01077-X.

Amada, S., Tomoyasu, K., y Haruyama, M., "Splat formation of molten Sn, Cu and Ni droplets", Surf. Coat. Technol., 1997, 96, p 176-183, doi: 10.1016/S02578972(97)00083-2. 
Anderson, R., Díaz A. y Ortega, A., "Observations on the Behavior of a Liquid Droplet transported by a Gas Stream Impinging on an Isothermal Surface", Procedings of the Fourth conference on Thermal Engineering; Theory and Applications January 12-14, Abu Dhabi, UAE, 2009.

Armster, S.Q., Delplanque, J.P., Rein M., y Lavernia E.J., "thermo-fluid mechanisms controlling droplet based materials processes" Int. Mater. Rev., 2002, 7(6), pp. 265-301, doi: 10.1179/174328013X13789822110946.

Ashenford, D. E. Long, F., Hagston, W.E., Lunn, B. y Matthews, A., "Experimental and theoretical studies of the low-temperature growth of chromia and alumina", Surface and Coatings Technology, 1999, 116-119, 699-704, doi: 10.1016/S0257-8972(99)00181-4.

ASM Handbook, Welding, Brazing and Soldering, vol. 6, ASM International, 1993.

American Welding Society, Thermal spraying: practice, theory and application, prepared by AWS Committee on Thermal Spray”. Miami, FL, USA: American Welding Society, 1999, pp. 2-15.

Bankoff, S. G., "Heat conduction or diffusion with change of phase", Adv. Chem. Eng., 1964, 5, 75, doi: 10.1016/S0065-2377(08)60007-1.

Baxter, D. C., "The fusion times of slabs and cylinders", J. Heat Transfer, Trans. ASME, Series $C, \mathbf{1 9 6 2}$, 84, 317-326, doi: 10.1115/1.3684380.

Bég, O.A, Zueco J. y Takhar, H.S. “Unsteady magnetohydrodynamic Hartmann Couette flow and heat transfer in a Darcian channel with Hall current, ion slip, viscous and Joule heating effects: Network numerical solutions", Commun. Nonlinear Sci. Numer. Simul., 2009, 14, 4, pp.1082-1097, doi: 10.1016/j.cnsns.2008.03.015.

Bejan, A., y Kraus, A. D. Heat Transfer Handbook. Volumen 1. John Wiley y Sons, 2003, doi: 10.1021/ja1097622. 
Benavent-Climent, A., Castro, E. y Gallego, A. "Evaluation of low-cycle fatigue damage in rc exterior beam-column subassemblages by Acoustic Emission", Constr. Build. Mater., 2010, 24, pp. 1830-1842, doi: 10.1016/j.conbuildmat.2010.04.021.

Bennett, T. y Poulikakos, D., "Heat Transfer Aspects of Splat- Quench Solidification: Modeling and Experiment", J. Mater. Sci., 1994, 29, pp. 2025-39, doi: 10.1007/BF01154677.

Bianchi, L., Denoirjean, A., Blein, F., y Fauchais, P. "Microstructural Investigation of Plasma Sprayed Ceramic Splats", Thin Solid Films, 1997a, 299, pp. 125-35, doi: 10.1016/S0040-6090(96)09307-8.

Bianchi, L., Leger, A. C., Vardelle, M., Vardelle, A., y Fauchais, P. "Splat formation and cooling of plasma-sprayed Zirconia" Thin Solid Films, 1997b, 305, pp. 35-47, doi: 10.1016/S0040-6090(97)80005-3.

Bianchi, L., Grimaud, A., Blein F., Lucchese, P., y Fauchais, P. (1995). "Comparison of plasma sprayed alumina coatings by RF and DC plasma spraying", J. Therm. Spray Technol., 1995, 4(1), pp. 59-66, doi: 10.1007/BF02648529.

Blackwell, B. F. y Hogan, R. E., “One-dimensionalablation using Landau Transformation and finite control volume procedure". J. Thermophy. Heat Transf., 1994, 8, 2, doi: $10.2514 / 3.535$.

Brossard, S., "Microstructural analiys of termal spray coatings by electron microscopy". University of New South Wales, 2010.

Cao, Y., Faghri, A., y Chang, W.S., "A numerical analysis of Stefan Problems for generalized multi-dimensional phase-change structures using the enthalpy transforming model," Int. J. Heat Mass Transfer, 1989, 32, pp. 1289-98, doi: 10.1016/00179310(89)90029-X.

Carslaw, H. S. y Jaeger, J. C., "Conduction of heat in solids", $2^{\mathrm{a}}$ ed., Clarendon Press. Oxford Univ. Press, London and New York, 1959.

Cedelle, J., Vardelle, M., Pateyron, B., y Fauchais, P., "Experimental investigation of the splashing processes at impact in plasma sprayed coating formation", Proceedings of the 
International Thermal Spray Conference, 2004, pp. 1008-1013, Osaka, Japan and DVS Düsseldorf, Germany (electronic version).

Cerrato, Y., Gutiérrez, J. y Ramos, M., “Análisis de la transmisión de calor en materiales con parámetros térmicos no lineales". Anales de Física, Serie A, 1989a, 85 1-12.

Cerrato, Y., Gutiérrez, J. y Ramos, M., "Mathematical study of the solutions of a diffusion equation with exponential diffusión coeficient: explicit self-similar solutions to some boundary value problems". J. Phys. A. Math. Gen., 1989b, 22 419-431, doi: $10.1088 / 0305-4470 / 22 / 4 / 011$.

Chan, R. K.-C. y Street, R. L., “'SUMMAC - A Numerical Model for Water Waves”, 1970.

Cho, S. H. y Sunderland, J. E., "Phase change problems with temperature-dependent thermal conductivity", Journal of Heat Transfer, 1974, 96(2), pp. 214-218. doi: $10.1115 / 1.3450167$.

Chow, T. S., "Wetting of rough surfaces". Journal of Physics: Condensed Matter, 1998, 10 (27): L445, doi:10.1088/0953-8984/10/27/001.

Chraska, T. y King, A.H., "Growth of columnar grains during zirconia-yttria splat solidification", J. Mater. Sci. Lett., 1999, 18[18] 1517-1519, doi: 10.1023/A:1006698402307.

Chraska, T. y King, A.H., "Transmission electron microscopy study of rapid solidification of plasma sprayed zirconia - Part I. First splat solidification" Thin Solid Films, 2001, 397 30-39, doi: 10.1016/S0040-6090(01)01360-8.

Christoulis, D.K., Pantelis, D.I., De Dave-Fabrègue, N., Borit, F., Guipont, V. y Jeandin, M., "Effect of substrate temperature and roughness on the solidification of copper plasma sprayed droplets". Materials Science and Engineering, 2008, A 485, 119-129, doi: 10.1016/j.msea.2007.07.059.

Chung M. y Rangel R. H., "simulation of metal droplet deposition with solidification including undercooling and contact resistance effects". Numerical Heat Transfer, Part A, 2000, vol. 37, No. 3, pp. 201-226, doi: 10.1080/104077800274262. 
Cleland, D. J., Cleland, A. C., Earle, R. L., "Prediction of freezing and thawing times for multidimensional shapes by simple formulae". Int. J. Refrig., 1987, 10, 156-164, doi: 10.1016/0140-7007(87)90006-5.

Crank, J., "Free and moving boundary problems". Oxford Univ. Press (Clarendon), Londonand New York, 1984.

Dagnall, H., "Exploring surface texture”. Taylor Hobson Limited 2003, Leicester, UK.

David, J. R., Handbook of Thermal Spray Technology, 2004, p. 123, New York, ASM International, doi: 10.1017/S1366728916000250.

De Gennes P.G., "Soft Interfaces”. Cambridge, UK: Cambridge University Press, 1994, ISBN 0521564174.

Del Cerro Velázquez, F., Gómez-Lopera, S. y Alhama, F., “A powerful and versatile educational software to simulate transient heat transfer processes in simple fins", Comput. Appl. Eng. Educ., 2008, 16, pp. 72-82, doi: 10.1002/cae.20159.

Denoirjean, A., Grimaud, A., Fauchais, P., Tristant, P., Tixier, C., y Desmaison, J., "Splat formation first step of multitechnique deposition plasma spraying and microwave plasma enhanced CVD”. Thermal Spray: Meeting in Challenges of the 21st Century (C. Coddet, ed.), 1998, vol. 2, pp. 1369-1374. ASM International, Materials Park, OH, USA.

Dhiman R., McDonald A., y Chandra S., "Predicting splat morphology in a thermal spray process". Surf. Coatings Technol., 2007, 201 (18) 7789-7801, doi: 10.1016/j.surfcoat.2007.03.010.

Dursunkaya, Z. y Nair, S., “A moving boundary problem in a finite domain”. J. Appl. Mech., 1990, 57, 50-56, doi: 10.1115/1.2888323.

Dutil, Y., Rousse D.R., Ben Salah N., Lassue S. y Zalewski L., “A review on phasechange materials: Mathematical modeling and simulations", Renewable and Sustainable Energy Reviews. 2011, doi: 10.1016/j.rser.2010.06.011.

Dykhuizen, R.C., "Review of impact and solidification of molten thermal spray droplets" J. Therm. Spray Technol., 1994, 3(4), pp. 351-61, doi: 10.1007/BF02658980. 
Escure, C., Vardelle, M., y Fauchais, P., "Visualization of particle impact in thermal spray", Thermal Spray: Surface Engineering Via Applied Research, 2000, pp. 743-52, C.C. Berndt, ed., ASM International, Materials Park, OH.

Escure, C., Vardelle, M., Vardelle, A. y Fauchais, P., "Visualization of the impact of drops on a substrate in plasma spraying deposition and splashing modes", Thermal Spray 2001, New Surface for a New Millenium, 2001, pp. 805-12, C.C. Berndt, K.A. Khor, and E.F. Lugscheider, ed., ASM International, Materials Park, OH.

Escure, C., Vardelle, M., y Fauchais, P., "Experimental and theoretical study of the impact of alumina droplet on cold and hot substrates", Plasma Chem. Plasma Process., 2003, pp. 291-309, doi: 10.1023/A:1022976914185.

Espié, G., Fauchais, P., Hannoyer, B., Labbe, J. C. y Vardelle, A., In 'Heat and mass transfer under plasma conditions during the APS on the wettability' Annals of the N.Y. Academy of Sciences, NY, USA (P. Fauchais, et al., eds.), 1999, Vol. 891, p. 143., doi: 10.1111/j.1749-6632. 1999.tb08761. x.

Eustathopoulos, N., Nicholas, M.G. y Drevet, B., "Wettability at high temperaturas". Pergamon, 1999, ISBN 0080421466.

Evans, G. W., Asaacson, E. y MacDonald, J. K. L., "Stefan-like problems", Q. Appl. Math., 1950, 8, 312-329, doi: 10.1090/qam/37451.

Eyres, N. R., Hartree, D. R., Ingham, J., Jackson, R., Sarjant, R. J. y Wagstaff, J. B., “The calculations of variable heat flow in solids". Phil. Trans. Royal. Soc., 1946, A240, 1-57, doi: 10.1098/rsta.1946.0002.

Fauchais, P., Fukumoto, M., Vardelle, A., y Vardelle, M., "Knowledge concerning splat formation: An invited review". Journal of Thermal Spray Technology, 2004, volume 13(3) September, 337-360, doi: 10.1361/10599630419670.

Fauchais, P., Leger, A.C., Vardelle, M. y Vardelle, A., "Formation of plasma-sprayed oxide coatings" Proc. of the Julian Szekely Memorial Symp. on Materials Processing, 1997, pp. 571-92, H.Y. Sohn, J.W. Evans, and D. Apelian, ed., TMS, Warrendale, PA.

Fauchais, P., Vardelle, M., Vardelle, A., Bianchi, L., y Leger, A. C., "Parameters 
controlling the generation and properties of plasma sprayed zirconia coatings", Plasma Chem. Plasma Process., 1995, 16(1), pp. 99S-125S, doi: 10.1007/BF01512630.

Fluent 6.3. User's guide. 2006. Fluent INC. Centerra Resource Park 10 Cavendish Court Lebanon, NH 03766

Frederick, D. y Greif, R., "A method for the solution of heat transfer problem with a change of phase". J. Heat transf., 1985, 107, 520-526, doi: 10.1115/1.3247455.

Fukanuma, H., "Mathematical modeling of flattening process on rough surfaces in thermal spray", Thermal Spray: Practical Solutions for Engineering Problems (C. C. Berndt, ed.), 1996, pp. 647-656, ASM International, Materials Park, OH, USA.

Fukanuma, H., Xie, R., Oo, N., Fujiwara, J. Y. y Kuroda, S., "Characterization of roughened substrate surface on bond strength of thermal spray deposits", International Thermal Spray Conference Proceedings (E. Lugscheider, ed.), 2002, pp. 312-317, DVS, Düsseldorf, Germany.

Fukumoto M., Hayashi H. y Yokoyama T., "Relationship between particle's splat pattern and coating adhesive strength of HVOF sprayed Cu-Alloy”, J. Jpn. Therm. Spray Soc., 1995a, 32-3, pp. 149-56 (in Japanese).

Fukumoto, M., Katoh, S. y Okane, I., "Splat behavior of plasma sprayed particles on flat substrate surface", Proc. of the 14th Int. Thermal Spray Conference, 1995b, vol. 1, A., pp. 353-59, Ohmori, ed., High Temp. Soc. of Japan, Osaka, Japan,

Fukumoto, M., Huang, Y. y Ohwatari, M., "Flattening mechanism in thermal sprayed particle impinging on a flat surface", Thermal Spray: Meeting the Challenge of the 21st Century, 1998, C. Coddet, ed., ASM International, Materials Park, OH, pp. 401-07.

Fukumoto, M. y Huang, Y., "Flattening mechanism in thermal sprayed Ni particles impinging on flat substrate surface”, J. Therm. Spray Technol., 1999, 8(3), pp. 427-32, doi: 10.1361/105996399770350386.

Fukumoto, M., Nishioka E., y Matsubara T., "Flattening and solidification behavior of metal droplet on flat substrate surface held at various temperatures", Surf. Coat. Technol., 1999, 120-121, pp. 131-37, doi: 10.1016/S0257-8972(99)00349-7. 
Fukumoto, M., Nishioka, E., y Matsubara, T., "Effect of interface wetting on flattening of freely fallen metal droplet onto a flat substrate surface", Thermal Spray: Surface Engineering Via Applied Research, 2000, C.C. Berndt, ed., ASM International, Materials Park, OH, pp. 797-802.

Fukumoto, M., Nishioka, E., y Nishiyama, T., "Proposal for new criterion for splashing of thermal sprayed particle onto a flat substrate", Thermal Spray 2001, New Surface for a New Millenium, 2001, C.C. Berndt, K.A. Khor, and E.F. Lugscheider, ed., ASM International, Materials Park, OH, pp. 841-48.

Fukumoto, M., Nishiyama, T., y Nishioka, E., "Effect of surface morphology of substrate on flattening behavior of freely fallen metal droplet", Proc. Int. Thermal Spray, Conf. Essen, 2002, E. Lugscheider, ed., DVS, Düsseldorf, Germany, pp. 37-41.

Fukumoto, M., Yamaguchi, T., Yamada, M., y Yasui, T., "Splash splat to disk splat transition behaviour in plasma-sprayed metallic materials", J. Therm. Spray Technol., 2007, 16(5-6), p 905-912, doi: 10.1007/s11666-007-9083-y.

Glorieux, B., Millot, F., Rifflet, J.C. y Coutures, J.P., "Density of superheated and undercooled liquid alumina by a contactless method", Int. J. Thermophys, 1999, 20[4] 1085-1094, doi: 10.1023/A:1022650703233.

Gómez Lopera, S., Alhama, F y del Cerro Velázquez, F., PRODASIM: Programa de diseño de aletas simples, NAR: 08/2005/544 [software], 2005, (C UPCT.

González-Fernández, C.F. y Alhama, F., "Heat Transfer and the Network Simulation Method". J. Horno (ed.) Transworld Research Network, Trivandrum, 2001.

González-Fernández, C.F., Alhama, F. y López-Sánchez, J.F., “Application of the network method to heat conduction processes with polynomial and potentialexponentially varying thermal properties". Numer Heat Transf A, Appl, 1998a, 33, pp.549, doi: 10.1016/s0010-4655(98)00026-5.

González-Fernández, C.F., Alhama, F., Alarcón, M. y López Sánchez, J.F., "Digital simulation of transient heat conduction with polynomial variable termal conductivity and specific heat", Computer Physics Communications, 1998b, 111, pp. 53-58, doi: 10.1016/s0010-4655(98)00026-5. 
González Morales, N., Sánchez-Pérez, J.F., Moreno Nicolás, J.A. y Killinger, A., "Modelling of Alumina Splat Solidification on Preheated Steel Substrate Using the Network Simulation Method", Mathematics, 2020, 8(9), 1568, doi:10.3390/math8091568.

Good, Robert J., "Contact angle, wetting, and adhesion: a critical review". J. Adhesion Sci. Technol, 1992, 6 (12): 1269-1302, doi:10.1163/156856192X00629.2.92.

Goodman, T. R., “Application of integral methods to transient nonlinear heat transfer". Adv. Heat Transf., 1964, 1, 71, doi: 10.1016/S0065-2717(08)70097-2.

Goodman, T. R. y Shea, J. J., “The melting of finite slabs”. ASME, J. Appl. Mech., 1960, 27, 16-24, doi: 10.1115/1.3643893.

Gougeon, P. y Moreau, C., "Simultaneous Independent Measurements of Splat Diameter and Cooling Time During Impact on A Substrate of Plasma Sprayed Molybdenum Particles", J. Therm. Spray Technol., 2001, pp. 76-82, 10(1), doi: 10.1361/105996301770349538.

Grigull, U. y Sandner, H., "Heat conduction". International Series in Heat and Mass Transfer. 1984, Springer-Verlag, Berlin.

GTV Verschleiss-Schutz GmbH, https://www.gtv-mbh.com

Gualtieri, M.L., Prudenziati, A.M. y Gualtieri, A.F., "Quantitative determination of the amorphous phase in plasma sprayed alumina coatings using the Rietveld method", Surf. Coat. Tech., 2006, 201[6] 2984-2989, doi: 10.1016/j.surfcoat.2006.06.009.

Gutman, L. N., "On the problem of heat transfer in phase-change materials for small Stefan numbers". Int. J. Heat Mass Transf., 1986, 29, 921-926, doi: 10.1016/00179310(86)90187-0.

Haddadi, A., Nardou, F., Grimaud, A., y Fauchais, P., "Generation of the first layers of a zirconia plasma sprayed coating: Correlation between splat layering and spraying parameters". Thermal Spray: Science and Technology (C.C. Berndt and S. Sampath, eds.), 1995, pp. 249-254, , ASM International, Materials Park, OH, USA. 
Haralick, R.M. y Shapiro, L. Computer and Robot Vision, Addison- Wesley Longman Publishing Co, Inc., 1991.

Harlow, F. H. y Welch, J. E., "Numerical Calculation of Time-Dependent Viscous”, Phys. Fluids, 1965, 8, 2182, doi: 10.1063/1.1761178.

Haure, T., "Multifunctional layers by PACVD and Plasma Spraying", Ph.D. Thesis, University of Limoges, France, 2003.

Haure, T., Denoirjean, A., Tristant, P., Hidalgo, H., Leniniven, C., Desmaison, J. y Fauchais, P., "Alumina duplex coating by multiprocesses: Air plasma spraying and plasma enhanced chemical vapor deposition", Thermal Spray 2001: New Surfaces for a New Millenium (C.C. Bernd, K.A., Khor \& E. Lugscheider, eds.), 2001, p. 613, ASM International, Materials Park, OH, USA.

Hirt, C. W. y Nichols, B. D., "Volume of Fluid (VOF) Method for the Dynamics of Free Boundaries," Journal of Computational Physics., 1980, doi:10.1016/00219991(81)90145-5.

Hofmeister, W. y Bayuzick, R.J., "Observation of thermal profiles during impact and solidification of Nickel droplets", Solidification, 1998, pp. 375-87, S.P. Marsh et al., ed., The Minerals, Metals and Materials Society, Warrendale, PA.

Horno, J., García Hernández, M. T., y González-Fernández, C. F., "Digital simulation of electrochemical processes by network approach”, J. Electroanal. Chem., 1993, 352, pp. 83-97, doi: 10.1016/0022-0728(93)80256-H.

Horno, J., González, Caballero, A., Hayas, A. y González-Fernández, C. F., “The effect of previous convective flux on the nonstationary diffusion through membranes", $J$. Membr. Sci., 1990, 48, pp. 67-77, doi: 10.1016/S0376-7388(00)80796-6.

Horno, J., González-Fernández, C. F. y Hayas, A., "The network method for solutions of oscillating reaction-diffusion systems", Comp. Phys. Comm., 1995, 118, pp. 310-319, doi: 10.1006/jcph.1995.1101.

Houben, J.M., "Future Development in Thermal Spraying”, 2nd National Conference on Thermal Spray, 1984, pp. 1-19, Aandrijf- en Tribotechniek. 
Huang, Y., Ohwatari, M., y Fukumoto, M., "Effect of substrate material on flattening behavior of plasma sprayed Ni particles", Proc. 6th Int. Symposium, 1996, pp. 731-36, Japan Welding Society, Osaka, Japan.

Hunter, L. W. y Kuttler, J. R., "The enthalpy method for heat conduction problems with moving boundaries". J. Heat Transf., 1989, 111, 239-242, doi: 10.1115/1.3250668.

Hunter, L. W. y Kuttler, J. R., "Enthalpy method ablation-type moving boundaries problems". J. Thermophys., 1991, 5, 240-242, doi: 10.2514/3.253.

Hwang, C.C., Lin, S. y Shen, L. F., "Effects of wall conduction and interface thermal resistance on the phase-change problem”. Int. J. Heat Mass Transf., 1994, 37, 1849-1994, doi: 10.1016/0017-9310(94)90325-5.

Imber, M. y Huang, P., "Phase change in a semiinfinite solid with temperature dependent thermal properties”. Int. J. Heat Mass Transf., 1973, 16, 1951-1954, doi: 10.1016/00179310(73)90214-7.

Inada, S. y Yang, W.J., "Solidification of Molten Metal Droplets Impinging on a Cold Surface", Exp. Heat Transfer, 1994, 7(2), pp. 93-100.

Jackson, K. A. y Hunt, J. D., "Lamellar and Rod Eutectic Growth", Transactions of the Metallurgical Society of AIME, 1966, Vol. 236, pp. 1129-1142.

Ji, M. y Bu-xuan, W., "The penetration rate of solid-liquid phase-change heat transfer interface with different kinds of boundary conditions". Int. J. Heat Mass Transf., 1995, 38, 2135-2138, doi: 10.1016/0017-9310(94)00322-M.

Jiang X.Y., Wan Y.P., Wang X.Y., Zhang H., Goswami R., Herman H., y Sampath S., "Investigation of splat/substrate contact during Molybdenum thermal spraying", Thermal Spray: Surface Engineering via Applied Research, 2000, pp. 729-36, C.C. Berndt, ed., ASM International, Materials Park, $\mathrm{OH}$.

Jiang X.Y., Wan Y., Herman H., y Sampath S., "Role of condensates and adsorbates on substrate surface on fragmentation of impinging molten droplets during thermal spray", Thin Select Films, 2001, 385(1-2), pp. 132-61, doi: 10.1016/S0040-6090(01)00769-6.

Johnson R. E., “Wettability”, Ed. Berg, John. C. New York, NY: Marcel Dekker, Inc., 
1993.

Johnson, W. E., "Development and Application of Computer Programs Related to Hypervelocity Impact”, Systems, Science and Software, 1970, report 3SR-353.

Kahranan, R., "A simplified numerical model for melting of ice with natural convection". Int. Commun. Heat Mass Transf., 1998, 25, 359-368, doi: 10.1016/S07351933(98)00023-2.

Kamnis, S. y Gu, S., "Numerical Modelling of Droplet Impingement", Journal of Physics D: Applied Physics, 2005, vol. 38, pp. 3664-3673, doi: 10.1088/0022-3727/38/19/015.

Kang, C. W. y Ng, H.W., "Splat morphology and spreading behavior due to oblique impact of droplets onto substrates in plasma spray coating process", Surf. Coat. Technol., 2006, 5462-5477, doi: 10.1016/j.surfcoat.2005.07.067.

Kershner, J. D. y Nader, C. L., "2DE: A Two-Dimensional Continuous Eulerian Hydrodynamic Code for Computing Multicomponent Reactive Hydrodynamic Problems," Los Alamos Scientific Laboratory report LA-4846, 1972.

Koichi, M. y Kozo, F., "Confluent hipergeometric solutions of heat conduction equation”, Int. J. Heat Mass Transf., 1990, 6, 209-219, doi: 10.1016/0017-9310(90)90049-Z.

Kou S., "Welding Metallurgy", John Wiley \& Sons, 2a ed. New York, 2003.

Kreith, F. y Romie, F. E., "A study of the thermal diffusion equation with boundary conditions corresponding to solidification or melting of materials initially at the fusion temperature". Proceedings of the Physical Society, 1955, Section B., 277-291, doi: 10.1088/0370-1301/68/5/302.

Krivoshapko, S. y Ivanov, V.N., "Encyclopedia of Analytical Surfaces”, Encyclopedia of Analytical Surfaces. Springer, 2015, doi: 10.1007/978-3-319-11773-7.

Kudinov, V. V., Pekshev, P. Y. y Safiullin, V. A., "Forming of the Structure o Plasma Sprayed Materials". High Temp. Dust Laden Jets, (ed.) sololenko et Fedorchenko, 1989, pp. 381-418.

Kulkarni, A.A., Goland, A., Herman, H., Allen, A.J., Ilavsky, J., Long, G.G. y De Carlo, 
F., "Advanced Microstructural Characterisation of Plasma spraying", Journal of Thermal Spray Technology, 2004, 14(2), pp. 238-250, doi: 10.1361/10599630523818.

Kumar, K. T. y Railkar, S. B., “Transfinite element methodology for non-linear/linear transient thermal modelling/analysis: progress and recent advances". Int. J. Num. Meth. Eng., 1988, 25, 475-494, doi: 10.1002/nme.1620250213.

Kumar, A., "Solidification of impinging molten metal droplet on a cold substrate". Int. J. Mech. Eng. \& Rob. Res., 2014, ISSN 2278 - 0149.

Kurz, W. y Fisher, D.J., Fundamentals of Solidification, 3rd ed., Trans Tech Publications, 1989.

Landau, H. G., "Heat conduction in a melting solid". Quart. Appl. Math., 1950, 8, 81-94, doi: $10.1090 /$ qam/33441.

Landron, C., Hennet, L., Jenkins, T.E., Greaves, G.N., Coutures, J. P., y Soper, A.K., "Liquid alumina: Detailed atomic coordination determined from neutron diffraction data using empirical potential structure refinement" Phys. Rev. Lett., 2001, 86[21] 4839-4842, doi: 10.1103/PhysRevLett.86.4839.

Lecomte, D. y Batsale, J. C., “A suitable approximate solution of Neumwnn's problem”. Int. J. Heat Mass Transf., 1991, 334, 894-897, doi: 10.1016/0017-9310(91)90136-3.

Leger, A. C., Vardelle, M., Vardelle, A., Dussoubs, B., y Fauchais, P., "Splat formation: Ceramic particles on ceramic substrate", Thermal Spray: Science and Technology (C.C. Berndt and S. Sampath, eds.), 1995, pp. 169-177ASM International, Materials Park, OH, USA.

Levi, C.G., Jayaram, V., Valencia, J.J. y Mehrabian, R., "Phase selection in electrohydrodynamic atomization of alumina", J. Mater. Res., 1988 3[5] 969-983, doi: 10.1557/JMR.1988.0969.

Levin, I. y Brandon, D. "Metastable alumina polymorphs: Crystal structures and transition sequences", J. Am. Ceram. Soc., 1998, 81[8] 1995-2012, doi: 10.1111/j.11512916.1998.tb02581.x.

Lahmar-Mebdoua, Y., Vardelle, A., Fauchais, P. y Gobin, D., "Modelling the nucleation 
process in alumina lamellae deposited on a steel substrate". International Journal of Thermal Sciences, 2010, 49, 522-528, doi: 10.1016/j.ijthermalsci.2009.09.011.

Li, C. J. "Characterisation of the microstructure and properties of plasma-sprayed ceramic coatings". $\mathrm{PhD}$ thesis, Osaka University, 1989.

Li, C. J., Li, J. L., Wang, W.-B., Ohmori, A., y Tani, K., "Effect of particle- substrate material combinations on morphology of plasma sprayed splats", Thermal Spray: Meeting the Challenges of the 21st Millenium, 1998, C. Coddet, ed., ASM International, Materials Park, OH, pp. 481-80.

Li, C. J., Li, J. L., y Wang, W.B. "The effect of substrate preheating and surface organic covering on splat formation", Thermal Spray: Meeting the Challenges of the 21st Century, 1998, C. Coddet, ed., ASM International, Materials Park, OH, pp. 473-80.

Li, C. J., Li, J. L., Wang, W.B., Fu A. J. y Ohmori A., "A mechanism of the splashing during droplet splatting", Thermal Spraying in United Spray Conference Proc. Düsseldorf, E. Lugscheider and P.A. Kammer, 1999, pp. 530-35ed., DVS, Düsseldorf Germany.

Li, C. J., Liao, H. L., Gougeon, P., Montavon, G., y Coddet, C., "Experimental Determination of the Relationship Between Flattening Degree and Reynolds Number for Spray Molten Droplets", Surf. Coat. Technol., 2005, 191, p 375-383, doi: 10.1016/j.surfcoat.2004.04.063.

Liu, H., Lavernia, E. J. y Rangel, R H., "Numerical Simulation of Substrate Impact and Freezing of Droplets in Plasma Spray Processes". Journal of Physics D: Applied Physics, 1993, Vol. 26, pp. 1900-1908, doi: 10.1088/0022-3727/26/11/010.

Liu W., Wang G.X., y Matthys E.F., “Thermal Analysis and Measurements for a Molten Metal Drop Impacting on a Substrate: Cooling, Solidification and Heat Transfer Coefficient”, Int. J. Heat Mass Transfer, 1995, 38(8), pp. 1387-95, doi: 10.1016/00179310(94)00262-T.

Loulou, T. y Delaunay, D., "The interface temperature of two suddenly contacting bodies, one of them undergoing phase change". Int. J. Heat Mass Transf., 1997, 40, 1713-1716, doi: 10.1016/S0017-9310(96)00228-1. 
Lozano, C. J. y Reemsten, R., "On a Stefan problem with an emerging free boundary". Numer. Heat Transf., 1981, 2, 239-245, doi: 10.1080/01495728108961790.

Luna Abad, J.P. Desarrollo de un programa de conducción de calor, usando analogía eléctrica, mediante el lenguaje C\# y el módulo de cálculo PSpice. Aplicaciones lineales y no lineales en diferentes geometrías. Tesis Doctoral, UPCT, 2010.

Madejski J., "Solidification of droplet on a cold surface," Int. J. Heat Mass Transfer, 1976, 19, pp. 1009-20, doi: 10.1016/0017-9310(76)90183-6.

Maître, A., Denoirjean, A., Fauchais, P. y Lefort, P. "Plasma-jet coating of preoxidized XC38 steel: influence of the nature of the oxide layer", Phys. Chem. Chem. Phys. 2002, 15(4), 3887-3893, doi: 10.1039/b202553a.

Marín, F., Moreno, Nicolás J. A. y Alhama, F., "Modelling of stick-slip behavior with different hypothesis on friction forces”. International, Journal of Engineering Science, 2012, doi: 10.1016/j.ijengsci.2012.06.002.

Marín, F. Alhama, F. Meroño, P. A. y Moreno, J. A., "Modelling of stick-slip behaviour in a Girling brake using network simulation method". Nonlinear Dynamics, 2016, volume 84, Issue 1, pp 153-162, doi: 10.1007/s11071-015-2312-x.

Marmur, A. "Wetting of Hydrophobic Rough Surfaces: To be heterogeneous or not to be", Langmuir, Marmur, 2003, 19: 8343-8348, doi:10.1021/la0344682.

MATLAB, 2007. The Mathworks, Inc. Natick, Massachusetts, United States. https://es.mathworks.com/products/matlab.html.

Mehdizadeh N.Z., Chandra S. y Mostaghimi J., "effect of substrate temperature and roughness on coating formation”, Proc. Int. Thermal Spray Conf., Essen, 2002, pp. 83037, E. Lugscheider, ed., DVS, Düsseldorf, Germany.

Mifune, N. y Harada, Y. "Mechanism of Vertical Microcracking in $\mathrm{CaOSiO}_{2}-\mathrm{CaOZrO}_{2}$ Sprayed Thermal Barrier Top Coating”, Materials Transactions, 2004, 4(5), pp. 17881793, doi: 10.2320/matertrans.45.1788.

Mills, A. F., "Heat and mass transfer". Routledge, New York, 1995, doi: $10.4324 / 9780203752173$. 
Mohamed, D., Eddine, B.N., y Nacer, D., "Effect of substrate preheating, roughness and particles size on splat morphology of termal sprayed coatings", International Journal of Computational and Experimental Science and Engineering, 2015, vol, pp 16-18.

Montavon, G., Sampath, S., Berndt, C.C., Herman, H. y Coddet, C., "Effect of vacuum plasma spray processing parameters on splats", J. Therm. Spray Technol., 1955, 4(1), pp. 67-74, doi: 10.1007/BF02648530.

Montavon, G., Sampath, S., Berndt, C.C., Herman, H. y Coddet, C., "Effects of the spray angle on splat morphology during thermal spraying”. Surface and Coatings Technology, 1997, 91, pp 107-115, doi: 10.1016/S0257-8972(96)03137-4.

Morales Guerrero, J. L., Moreno Nicolás, J. A. y Alhama, F., EPSNET_10: Elasticity problems simulation network. NAR 08/2011/418 [software], 2011. Universidad Politécnica de Cartagena.

Morales Guerrero, J. L., Moreno Nicolás, J. A. y Alhama, F., "New additional conditions for the numerical uniqueness of the Boussinesq and Timpe solutions of elasticity problems". Int. J. of Computer Mathematics, 2012a, 89, 13-14, pp. 1794-1807, doi: 10.1080/00207160.2012.667088.

Morales Guerrero, J. L., Moreno Nicolás, J. A. y Alhama, F. “Application of the network method to simulate elastostatic problems defined by potential functions. Applications to axisymmetrical hollow bodies". Int. J. of Computer mathematics, 2012b, 89, 13-14, pp. 1781-1793, doi: 10.1080/00207160.2012.667088.

Moreno Nicolás, J.A., Gómez de León Hijes, F. y Alhama, F., "Solution of temperature fields in hydrodynamics bearing by the numerical network model". Tribol. Int., 2007, 40, pp. 139- 145, doi: 10.1016/j.triboint.2006.03.008.

Mostaghimi, J., Pasandideh-Fard, M. y Chandra, S., "Dynamics of Splat Formation in Plasma Spray Coating Process". Plasma Chemistry and Plasma Processing, 2002, Volume 22, Issue 1, pp 59-84, doi: 10.1023/A:1012940515065.

Moya, A.A., "Influence of dc electric current on the electrochemical impedance of ionexchange membrane systems". Electrochim. Acta, 2011, 56, pp. 3015-3022, doi: 10.1016/j.electacta.2010.12.103. 
Muelhbauer, J. C. y Sunderland, J. E. "Heat conduction with a freezing or melting". Appl. Mech. Rev., 1965, 18, 951.

Mulero, M.A., "Analysis of APS Coating by SEM Image Processing Techniques”, 2014, UPCT. Proyecto Fin de Máster.

Mulero, M.A., Zapata, J., Vilar, R., Martínez, V., Gadow, R., "Automated image inspection system to quantify thermal spray splat morphology", Surface and Coatings Technology, 2015, doi: 10.1016/j.surfcoat.2015.07.065.

Mundo, C., Sommerfeld, M., y Tropea, C., "Droplet-Wall Collisions: Experimental Studies of the Deformation and Break-Up Process," Int. J. Multiphase Flow, 1995, 21, pp. 151-73.

Munroe, P.R., "The application of focused ion beam microscopy in the material sciences". Material characterization, 2009, 60(1): 2-13, doi: 10.1016/j.matchar.2008.11.014.

Nagel, L.W. SPICE2: A computer program to simulate semiconductor circuits. Memo. No. UCB/ERL M520. Electronic Research Laboratory, Univ. de California, Berkeley, CA 94720, 1975.

Nagel, L.W., SPICE (Simulation program with integrated circuit emphasis). Berkeley, CA, University of California, Electronics Res. Lab., ERL-M382, 1977.

Nenzi, P., y Vogt, H., Ngspice Users Manual, Version 26, 2014.

Nichols, B. D. y Hirt, C. W., "Improved Free-Surface Boundary Conditions for Numerical Incompressible Flow Calculations", Journal of Computational Physics, 1971, doi: 10.1016/0021-9991(71)90022-2.

Nichols, B.D. y Hirt, C.W. y Hotchkiss, R.S., "SOLA-VOF: A solution algorithm for transient fluid flow with multiple free boundaries". Tech. Rep., 1980, LA-8355. 39.

Nishioka, E., Matsubara, T. y Fukumoto, M., "Effect of wetting at splat/substrate interface on flattening behavior of freely fallen droplet", Int. J. Mater. Product Technol., Special Issue, SPM1, 2001, pp. 700-05.

Nogi, K., Iwamoto, N. y Ogino, K., "Wetting Mechanism of Ceramics by Liquid Metals", 
Bull. Japan Inst. Metals, 1992, 31(4), pp. 278-81.

Noh, W. F. y Woodward, P., "The SLIC (Simple Line Interface Calculation) Method," LaWrence Livermore Laboratory report UCRL-52111, 1976, doi: 10.1007/3-540-08004X_336.

Nyros, J. G. y Hsieh, C. K., "Combination of source-and-sink method and complextemperature method for the solution of Stefan problems imposed with cyclic temperature and flux conditions". J. Heat Transf., 1994, 116, 753-756, doi: 10.1115/1.2910932.

Ohmori, A. y Li, C. J., "The structure of thermally sprayed ceramic coatings and its dominant effect on the coating properties". Plasma Spraying, theory \& applications (ed.) Surayanarayanam, 1993, pp. 179-200, World Scientific Publishing CO., doi: 10.1142/9789814354479_0007.

Oki, S., Gohda, S. y Yamakawa, M., "Surface morphology of plasma sprayed ceramic coatings", Proceedings of the International Thermal Spray Conference, 1998, Vol. 1, 1998, pp. 593-597.

Oksa, M., Turunen, E., Suhonen, T., Varis, T. y Hannula, S., "Optimization and Characterisation of High Velocity Oxy-fuel Sprayed Coatings: Techniques, Materials \& Applications". Coatings, 2011, 17-52, doi: 10.3390/coatings1010017.

Oliver, D. L. R. y Sunderland, J. E., “A phase change problem with temperaturedependent thermal conductivity and specific heat". Int. J. Heat Mass Transf., 1987, 30, 2657-2661, doi: 10.1016/0017-9310(87)90147-5.

Otsu, N., "A threshold selection method from gray-level histograms", IEEE Transactions on Systems, Man, and Cybernetics, 1979, 9 (1), 62-66. doi:10.1109/TSMC.1979.4310076.

Pantelis D.I. Traité Métall. 1993, M1 240, 22.

Pasandideh-Fard, M., "Droplet Impact and Solidification in a Thermal Spray Process". Ph.D. Thesis, University of Toronto, Toronto, Canada, 1998.

Pasandideh-Fard, M., Bhola, R., Chandra, S., y Mostaghimi, J., "Deposition of Tin Droplets on a Steel Plate: Simulations and Experiments", Int. J. Heat Mass Trans., 1998, 
41, p 2929-2945, doi: 10.1016/S0017-9310(98)00023-4.

Pasandideh-Fard, M., Pershin, V., Chandra, S. y Mostaghimi J., "Splat shapes in a thermal spray coating process: simulations \& experiments". Journal of Thermal Spray Technology, 2002, 11, pp. 206-217, doi: 10.1361/105996302770348862.

Pasandideh-Fard, M., Qiao, Y. M., Chandra, S. and Mostaghimi, J., "Capillary effects during droplet impact on a solid surface", Phys. Fluids, 1996, 8 (3), doi: $10.1063 / 1.868850$.

Pawlowski, L., “'The Science and Engineering of Thermal Spray Coatings', John Wiley, New York, NY, USA, 1995.

Pawlowski, L., "The Science \& Engineering of Thermal Spray Coatings", second edition, John Wiley \& Sons, Ltd, 2008, 67-113, doi: 10.1002/9780470754085.

Pech, J., Hannoyer, B., Bianchi, L., Fauchais, P., Denoirjean, A., "Study of Oxide Layers Obtained on 304L Stainless Steel Substrate Heated by a d.c. Plasma Jet," Thermal Spray: A United Forum for Scientific and Technological Advances, 1997, pp. 775-82, C.C. Berndt, ed., ASM International, Materials Park, OH.

Pech, J., Hannoyer, B., Lagnoux, O., Denoirjean, A. y Fauchais, P. "Influence of preheating parameters on the plasma jet oxidation of a low-carbon steel", Progress in Plasma Processing of Materials, (P. Fauchais and J. Amouroux, eds.), 1999a, pp. 543554. Pub. Begell House, NY, USA.

Pech, J., Hannoyer, B., Denoirjean, A., Bianchi, L. y Fauchais, P., "Influence of substrate preheating monitoring on alumina splat formation in d.c. plasma processes", Thermal Spray: A United Forum for Scientific and Technological Advances (C.C. Berndt, ed.), 1999b, pp. 759-765, ASM International, Materials Park, OH, USA.

Pershin, V., Pasandideh-Fard, M., Mostaghimi, J. y Chandra, S., "Effect of substrate properties on the formation of plasma sprayed alumina splats", Thermal Spray: New Surfaces for a New Millenium, 2001a, pp. 813-20, C.C. Berndt, K.A. Khor, and E.F. Lugscheider, ed., ASM International, Materials Park, $\mathrm{OH}$.

Pershin, L., Lufitha, M., Chandra, S. y Mostaghimi, J., "Effect of substrate temperature 
on nickel coating adhesion", 15th Int. Symposium on Plasma Chemistry, 2001b, pp. 263337, vol. 6, A. Bouchoule, J.M. Pouvesle, A.L. Thomann, J.M. Bauchire, and E. Robert, ed. GREMI, CNRS, Univ. of Orléans, France.

Qiao Y.M., "Effect of gravity and surfactant on spray cooling of hot surfaces," Ph.D. Thesis, University of Toronto, Toronto, Canada, 1996.

Ramos, M., Aguirre-Puente, J. y Posado, R., "Nueva aproximación al estudio de los procesos de congelación mediante la definición de un calor latente efectivo". Anales de Física, serie A, 1991, 87.

Ramos, M., Cerrato, Y. y Gutiérrez, J., “An exact solution for a finite Stefan problem with temperature dependent thermal conductivity and specific heat". Int. J Refrig., 1994a, 17, 130-134, doi: 10.1016/0140-7007(94)90054-X.

Ramos, M., Sanz, P. D., Aguirre-Puente, J. y Posado, R, "Use of equivalent volumetric enthalpy veriation in non-linear phase change processes: freezing zone progression and thawing time determination". Int. J. Refirg., 1994b, 17, 364-380, doi: 10.1016/01407007(94)90072-8.

Ramos, M., Ortiz, R., Cerrato, Y. y Diez-Gil, J. L., "Non-linear model for magma solidification”. J. Phys. Earth, 1995, 43, 35-44, doi: 10.4294/jpe1952.43.35.

Rangel, R.H. y Bian, X., "The inviscid stagnation-flow solidification problem", International Journal of Heat and Mass Transfer, 1996, doi: 10.1016/00179310(95)00260-X.

Robert, C., Denoirjean, A., Vardelle, A., Wang, G. X. y Sampath, S., "Nucleation and phase selection in plasma-sprayed alumina: modelling and experiment". Thermal Spray: Meeting the Challenges of the 21st Century (C. Coddet, ed.), 1998, pp. 767-773, ASM International, Materials Park, OH, USA.

Rowlinson, J.S. y Widom, B., Molecular Theory of Capillarity. Oxford, UK: Clarendon Press, 1982. ISBN 019855642X.

Ruan, Y., Li, B. Q. y Liu, J. C., “A finite element method for steady-state conduction advention phase change problems", Finite Elem. Anal. Des., 1955, 19, 153-168. 
Rubinstein, L. I., The Stefan problem”. Am. Math. Soc. Transl. Math Monogr., 27, 1971. ISBN-13: 978-0821815779.

Runnels, S. R. y Carey, G. F., "Finite element simulation of phase change using capacitance methods". Numer. Heat Transf., Part B, 1991, 19, 13-30, doi: $10.1080 / 10407799108944954$.

Safai, S. y Herman, H., "Microstructural investigation of plasma sprayed aluminum coatings", Thin Solid Films, 1977, 45, pp. 295-307, doi: 10.1016/0040-6090(77)902632.

Sakakibara, N., Tsukuda, H., y Notomi, A., "The splat morphology of plasma sprayed particles and the relation to coating properties", Thermal Spray: Surface Engineering via Applied Research, 2000, pp. 753-58, C.C. Berndt, ed., ASM International, Materials Park, $\mathrm{OH}$.

Sampath, S. y Herman, H., "Rapid solidification and microstructure dependent during plasma spray deposition", J. Therm. Spray Technol., 1996, 5(4), pp. 445-56, doi: $10.1080 / 10407799108944954$.

Shakeri, S., y Chandra, S., "Splashing of molten tin droplets on a rough steel surface". International Journal of Heat \& Mass Transfer, 2002, 45, 4561-4575, doi: 10.1016/S0017-9310(02)00170-9.

Shamsundar, N., y Sparrow, E. M., "Analysis of multidimensional conduction phase change via the entalpy method". Journal of Heat Transfer., 1975, doi: 10.1115/1.3450375.

Sharfrin, E., "Constitutive relations in the wetting of low energy surfaces and the theory of the retraction method of preparing monolayers", The Journal of Physical Chemistry, 1960, 64 (5): 519-524, doi:10.1021/j100834a002.

Shastri, S. S., "Method of lines and entalphy merhod for solving moving boundary problems". Int. Commun. Heat Mass Transf., 1998, 25, 531-540, doi: 10.1016/s07351933(98)00040-2.

Shukla, R. K., Patel, V. y Kumar, A., "Modeling of rapid solidification with undercooling 
effect during droplet flattening on a substrate in coating formation". J Therm Spray Tech., 2018, 27:269-287, doi: 10.1007/s11666-017-0666-y.

Sobolev, V.V. y Guilemany, J.M., "Flattening of droplets and formation of splats in thermal spraying: a review of recent work- Part 1," J. Therm. Spray Technol., 1999a, 8(1), pp. 87-101, doi: 10.1361/105996399770350610.

Sobolev, V.V. y Guilemany, J.M., "flattening of droplets and formation of splats in thermal spraying: a review of recent work-Part 2," J. Therm. Spray Technol., 1999b, 8(2), pp. 301-314, doi: 10.1361/105996399770350520.

Sobolev, V.V., Guilemany, J.M. y Martin, A.J., "Influence of surface roughness on the flattening of powder particles during thermal spraying”. J. Therm. Spray Techn., 1996, 5(2), 207-214, doi:10.1007/BF02646434.

Solomon, A. D., "Melt time and heat flux for a simple PCM body". Sol. Energy, 1979, 22, 251-257, doi: 10.1016/0038-092X(79)90140-3.

Soto, A., "Simulación numérica de procesos de intrusión salina en acuíferos mediante el método de simulación por redes”. Tesis doctoral, UPCT, 2007.

Soto Meca, A., Alhama, F. y González-Fernández, C.F., “An efficient model for solving density driven groundwater flow problems based on the network simulation method", $J$. Hidrology, 2007, 339, pp. 39-53, doi: 10.1016/j.jhydrol.2007.03.003.

Stefan, J., "Ueber die theorie der eisbildung, insbesondere ueber die eisbildung im polarmeere". Ann. Phys. Chem., 1981, 42, 269, doi: 10.1002/andp.18912780206.

Stow, C.D. y Hadfield, M.G., “An experimental investigation of fluid flow resulting from the impact of a water drop with an underlying dry surface" Proc. R. Soc. London, 1981, A373, pp. 419-41.

Stringer, J., Wilcox, B.A.y Jaffee, R.I., "The high-temperature oxidation of nickel $20 \mathrm{wt} \%$ chromium alloys containing dispersed oxide phases", Oxidation of metals, 1972, doi: 10.1007/BF00614617.

Suganuma, K., "Interface binding energy and strength of metal/ceramic joint", Bull. Japan Inst. Metals, 1990, pp. 882-87, 29(11). 
Sun, D. W., Xu, J., Zang, H., Wan, Y. P., Prasad, V. y Wang, G. X. "Effect of contact resistance and substrate melting on thermal spray coating". Thermal Spray: Surface Engineering via Applied Research (C.C. Berndt, ed.), 2000, pp. 195-201, ASM International, Materials Park, OH, USA.

Tanaka, Y. y Fukumoto, M., "Investigation of Dominating Factors on Flattening Behavior of Plasma Sprayed Ceramic Particles”, Surf. Coat. Technol., 1999, 120-121, pp. 124-30.

Tanaka, Y. y Fukumoto, M., "Influence of solidification and wetting on flattening behavior of plasma sprayed ceramic particles," Int. J. Mater. Product Technol., Special Issue, SPM1, 2001, pp. 518-23.

Tao, L. N., "The exact solutions of some Stefan problems with prescribed heat flux". ASME, J. Appl. Mech., 1981, 48, 732-736, doi: 10.1115/1.3157724.

Tao, L. N. "Heat conduction problem with temperature dependent materials properties". Int. J. Heat Mass Transf., 1989, 32, 487-491, doi: 10.1016/0017-9310(89)90136-1.

ThermoFisher Scientific. Electron microscopic solutions, 2019, https://www.fei.com.

Trapaga, G., Matthys, E. F., Valencia J. J. y Szekely, J., "Fluid Flow, Heat Transfer and Solidification of Molten Metal Droplets Impinging on Substrates: Comparison of Numerical and Experimental Results", Metallurgical Transactions B, 1992, vol. 23, pp. 701-718, doi: 10.1007/BF02656450.

Universidad de Murcia. Instalaciones y equipos. https://www.um.es.

UPCT. Microscopia electrónica de barrido. https://www.upct.es/sait/es.

Valette, S., Denoirjean, A., Lefort, P., y Fauchais, P., "Influence of dc plasma preheating on oxide layers formed by furnace heating on low carbon steel substrates and resulting adhesion/cohesion of alumina coatings", J. High Temp. Mater. Process., 2003, 7(2), 195, doi: 10.1615/HighTempMatProc.v7.i2.100.

Valette, S., Denoirjean, A., Soulestin, B., Trolliard, G., Hannoyer, B., Lefort, P. y Fauchais, P., "Alumina coatings on preoxidized low carbon steel. Interfacial phenomena between alumina and iron oxide layer", Proceedings of the International Thermal Spray 
Conference, 2004, Osaka, DVS Du“ sseldorf, Germany (electronic version).

Valette, S., Influence of the Preoxidation of a Steel Substrate on the Adhesion of an Alumina Coating d.c. Plasma Sprayed, Ph.D. Thesis, University of Limoges, 2004.

Vardelle, A., Themelis, N.J., Vardelle, M., y Fauchais, P., "Transport and Chemical Rate Phenomena in Plasma Sprays", J. High Temp. Mater. Proc., 1997, 1(3), pp. 295-314, doi: 10.1615/HighTempMatProc.v1i3.20.

Vardelle, A., Moreau, C., y Fauchais, P. "Deposit Formation Dynamics," MRS Bull., 2000, July, pp. 32-37.

Vardelle, A., Vardelle, M., Fauchais, P. y Gobin, D. "Monitoring Particle Impact on a Substrate During Plasma Spray Process", NATO Ser. E Appl. Sci., 1995, 282, p 95-121.

Venkateshan, S. P. y Kothari, N. S., "Approximate solutiion of one-dimensional heat diffusion problems via hybrid profiles". Heat Fluid Flow, 1987, 8, 243-247, doi: 10.1016/0142-727X(87)90035-X.

Venkateshan, S. P. y Solaiappan, O., "A general integral method for one dimensional ablation". Waerme- \& Stoffuebertrag., 1990, 25, 141-14.

Versteeg, H K y Malalasekera, W., "An Introduction to Computational Fluid Dynamics". Pearson Education Limited. Second edition, 2007.

Villa, M., Dosta, S., Fernández, J. y Guilemany, J.M., "La proyección fría (CGs): Una alternativa a las tecnologías convencionales de deposición”. Revista de Metalurgia, 2012, 48 (3), 175-191.

Wang, G. X. y Matthys, E. F., "Experimental Investigation of Interfacial Thermal Conductance for Molten Metal Solidification on a Substrate". Journal of Heat Transfer, 1996, vol. 118, pp. 157-163, doi: 10.1115/1.2824029.

Wang, G. X., Prasad, V., Sampath, S., y Hermann, H., "Modeling of rapid solidification during splat quenching solidification". The Minerals, Metals \& Materials Society/AIME, 1998a, pp. 485-496.

Wang, S. P., Wang, G. X. y Matthys, E. F., "Melting and resolidification of a substrate in 
contact with a molten metal: Operational maps", Int. J. Heat Mass Transfer, 1998b, 41, 1177, doi: 10.1016/S0017-9310(97)00222-6.

Wang, X. Y., Zhang, H., Zheng, L. L. y Sampath S., “An integrated model for interaction between melt flow and nonequilibrium solidification in thermal spraying”. International Journal of Heat and Mass Transfer, 2002, vol. 45, no. 11, pp. 2289-2301, doi: 10.1016/S0017-9310(01)00328-3.

Wang W., Lambert R. A., y Rangel R. H., "Parametric study of multi-splat solidification/remelting including contact resistance effects". International Journal of Heat and Mass Transfer, 2008, 51, 4811-4819, doi: 10.1016/j.ijheatmasstransfer.2008.02.015.

Wenzelburger, M., Escribano, M. y Gadow, R. "Modeling of thermally sprayed coatings on light metal substrates: layer growth and residual stress formation", Surface and Coatings Technology, 2004, 180 -181, pp. 429-435, doi: 10.1016/j.surfcoat.2003.10.125.

Whyman, G., Bormashenko, E. y Stein, T., "The rigorous derivation of Young, CassieBaxter and Wenzel equations and the analysis of the contact angle hysteresis phenomenon", Chemical Physics Letters, 2008, 450, 355-359, doi: 10.1016/j.cplett.2007.11.033.

$\mathrm{Xu}$, Q., Lavernia, E.J., "Influence of nucleation and growth phenomena on microstructural evolution during dropletbased deposition”, Acta Mater. 2001, 49, 38493861, doi: 10.1016/S1359-6454(01)00253-1.

Yang, K., Liu, M., Zhou, K. y Deng, C., "Recent Developments in the Research of Splat Formation Process in Thermal Spraying”. Journal of Materials, 2013, 14 pages, doi: $10.1155 / 2013 / 260758$.

Young, T., "An Essay on the Cohesion of Fluids". Philosophical Transactions of the Royal Society, 1805, 95: 65-87, doi:10.1098/rstl.1805.0005.

Zanchetta, A., Lefort, P. y Gabbay, E., "Thermal expansion and adhesion of ceramic to metal sealings: Case of porcelain-kovar junctions". Journal of the European Ceramic Society, 1995, 15. 233-238doi: 10.1016/0955-2219(95)93944-X. 
Zhang, Y., Chen, Z. y Wang, Q., “Analytical solution of melting in a subcooled semiinfinite solid with boundary conditions of the second kind". J. Ther. Sci., 1993a, 2, 111115, doi: 10.1007/BF02718266.

Zhang, Y. W., Jin, Y. Y., Chen, Z. Q., Dong, Z. F. y Ebadian, M. A., “An analytical solution to melting in a finite slab with a boundary condition of the second kind". J. Heat Transf., 1993b, 115, 463-467, doi: 10.1115/1.2910700.

Zhang, H., Wang, X.Y., Zheng, L.L. y Sampath, S., "Numerical simulation of nucleation, solidification, and microstructure formation in thermal spraying". International Journal of Heat and Mass Transfer, 2004, 47, 2191-2203, doi: 10.1016/j.ijheatmasstransfer.2003.11.030.

Zhao, Z., Poulikakos, D. y Fukai, J., "Heat Transfer and Fluid Dynamics During the Collision of a Liquid Droplet on a Substrate-I, Modeling”. International Journal of Heat and Mass Transfer, 1996a, vol. 39, pp. 2771-2789, doi: 10.1016/0017-9310(95)00305-3.

Zhao, Z., Poulikakos, D. y Fukai J., "Heat Transfer and Fluid Dynamics During the Collision of a Liquid Droplet on a Substrate-II, Experiments". International Journal of Heat and Mass Transfer, 1996b, vol. 39, pp. 2791-2802, doi: 10.1016/00179310(95)00306-1.

Zhong, J., Chow, L. C. y Chang, W. S. "Finite element eigenvalue method for solving phase change problems". J Thermophys., 1991, 5, 589-598, doi: 10.2514/3.304.

Zhu R., Cui S. y Wang X., “Theoretical foundation of Zisman's empirical equation for wetting of liquids on solid surfaces", European Journal of Physics, 2010, 31 (2): 251, doi: 10.1088/0143-0807/31/2/001.

Zimmer, A., "The effect of cooling rate in thermally sprayed alumina". Journal of Ceramic Processing Research. 2010, Vol. 11, No 2, 221-224.

Zubair, S. M., y Chaudry, M. A., "Exact solutions of solid-liquid phase-change heat transfer when subjected to convective boundary condition". Waerme- \& Stoffübertrag., 1994, 30, 77-81.

Zueco J., Alhama F. y González-Fernández C.F., "Inverse problem of estimating time- 
dependent heat transfer coefficient with the network simulation method". Commun. Numer. Meth. Engng., 2005, 21, pp. 39-48.

Zueco, J., Alhama F. y González-Fernández, C.F., "Inverse determination of heat generation sources on two dimensional homogeneous solids. Application to orthotropic médium”. Int. Comms. Heat Mass Transfer, 2006, 32, pp. 49-55. 